\title{
Growth, characterization and performance of bulk and nanoengineered molybdenum oxides for electrochemical energy storage and conversion
}

\author{
C.V. Ramana ${ }^{1,2, *}$, A. Mauger ${ }^{2}$, C.M. Julien ${ }^{2 \#}$ \\ ${ }^{I}$ Center for Advanced Materials Research (CMR), University of Texas at El Paso, El Paso, \\ 500 W University Ave, El Paso, Texas 79968, USA
}

2Department of Mechanical Engineering, University of Texas at El Paso, 500 W University Ave, El Paso, Texas 79968, USA

${ }^{3}$ Institut des Minéralogie, de Physique des Matériaux et de Cosmologie (IMPMC), Sorbonne Université, CNRS-UMR 7590, 4 place Jussieu, 75752 Paris, France

*Corresponding author: rvchintalapalle@utep.edu (C.V.R.)

\#Corresponidng author: christian.julien@sorbonne-universite.fr (C.M.J)

Keywords: Molybdenum oxides; Nanostructures; Cathodes; Anodes; Lithium-ion batteries; Sodium-ion batteries; Intercalation; Conversion 


\section{Abstract}

Molybdenum oxides $\left(\mathrm{MoO}_{\mathrm{y}}\right)$ exhibit quite interesting structural, chemical, electrical, optical and electrochemical properties, which are often dependent on the synthetic procedures and fabrication conditions. While these oxides show promise in a diverse applications ranging from electronics to energy storage and micromechanics, engineering the phase and microstructure is the key to achieving the desired properties and performance, especially in electrochemical energy storage and conversion technologies. In the course of development of lithium batteries delivering high-power and high-energy density for powering electric vehicles, here in this paper, we examine the performances of Mo-oxides, which are candidates as electrodes materials primarily for lithium-ion batteries (LIBs), while some aspects considered in sodium-ion batteries (SIBs) or electrochemical supercapacitors (ECs). Due to the wide range of oxidation states (from +6 to +2 ) they are promising as both positive (cathode) and negative (anode) electrodes of electrochemical cells. Based on their specific structural, chemical, electrical, and optical properties, which are dependent on the growth conditions and the fabrication technique, this review highlights the progress in improving and understanding the electrochemical performance of $\mathrm{MoO}_{\mathrm{y}}$ compounds. Various materials $(2.0 \leq y \leq 3.0)$ including anhydrous, hydrates, nanorods, nanobelts, composites and thin films of $\mathrm{MoO}_{\mathrm{y}}$ are considered. Due to their higher oxidation states, $\mathrm{MoO}_{\mathrm{y}}$ have been shown to undergo reversible topotactic lithium intercalation reactions; however, electrochemical features appear strongly dependent on the crystal quality and structural arrangement in the host lattice. Several structural characteristics such as in-situ and ex-situ X-ray diffraction (XRD) patterns, Raman spectra are also presented. The approaches used for performance improvement are summarized, and the causes of first-cycle irreversible capacity loss are discussed in detail. Several sub-stoichiometric $\mathrm{MoO}_{\mathrm{y}}$ positive electrodes exhibit excellent cycle life (up to 300 cycles) with high initial coulombic efficiency (80-90\%) and large reversible capacity (>300 $\mathrm{mAh} \mathrm{g}^{-1}$ ). Molybdenum oxides also categorized as one of the conversion-type transition-metal oxides and applied as negative electrodes for LIBs and SIBs with a specific capacity approaching $1000 \mathrm{mAh} \mathrm{g}^{-1}$. In addition to the discussion of the key aspects of crystal growth, characterization, and structureproperty relationships, the future prospects to design Mo-oxide materials to enhance the structural stability and electrochemical performance are presented. 


\section{Introduction}

Nowadays, a great deal of efforts directed towards the green and sustainable energy development in view of the concerns about climate change and global warming. The major contribution comes from human activities for the energy conversion, especially the fossil fuel combustion for electricity, heat and transportation. The fossil fuels consumption for energy production and transporation presumably result in the emission of green-house gases and subsequently causes the global warming effects. Converting global energy consumption through electrification of alternative forms of transportation requires the use of efficient power sources, with an emphasis on hybrid electric (HEVs), plug-in hybrid electric (PHEVs) and fully electric vehicles (EVs) [1]. Other current applications concern batteries used to solve the intermittence problems of the electricity produced by wind or photovoltaic plants, more and more developed as renewable energy sources, and considered as the only solution to give access of electricity to the sub-Saharan countries in Africa, for example. Moreover, economics and environmental incentives, as well as advances in electricity production via renewable intermittent sources are reshaping the traditional distribution network (smart grid environment, vehicle-to-grid (V2G) infrastructure) [2]. High energy density lithium ion batteries (LIBs) and sodium ion batteries (SIBs) are suitable storage systems for such applications.

The concept of LIB (often called a 'rocking-chair battery') was first formulated by Armand in the late 1970s [3]. In a LIB, the lithium ion moved reversibly between the positive and the negative electrode as intercalation materials of different potentials. This important principle was experimentally established by Lazzari and Scrosati over 60 cycles and implemented with a lithiated $\mathrm{WO}_{2}$ anode and a $\mathrm{TiS}_{2}$ cathode, which operate in the potential range 0.8-2.1 volts [4]. In 1991, Sony Corporation announced the first commercialization of a LIB, which consisted of lithium cobaltate $\mathrm{LiCoO}_{2}$ (LCO) as positive electrode and carbon (graphite) as negative electrode in between of which a separator soaked with an organic electrolyte (ionic conductor) [5]. Depending on the choice of the electrodes, the volumetric energy density of LIBs is in the range of $200-350 \mathrm{Wh} \mathrm{L}^{-1}$ and on average the gravimetric density is $150 \mathrm{Wh} \mathrm{kg}^{-1}$. However, two critical issues need to be addressed: performance and safety [6]; also, significant improvements of LIBs must be achieved for vehicular applications in both energy density and rate capability. For an analysis of the LIBs deficiencies and possible remedies, see the report by Blomgren [7]. Briefly, the main deficiencies are: (i) low capacity density of the carbonaceous anode, (ii) formation of a resistive solid-electrolyte interphase (SEI), (iii) low specific capacity of the cathode and (iv) limiting cycle life due to the cathode-electrolyte interphase (CEI). Thus, the replacement with new anode and/or cathode materials is needed that could provide high 
coulombic efficiency (CE), good power capability, low irreversible capacity, and low cost with little or no loss of capacity density or cell voltage. Due to its disadvantages of high price, cobalt toxicity and a rather small capacity $\left(\approx 140 \mathrm{mAh} \mathrm{g}^{-1}\right)$ LCO cannot be used as power supply for EVs. The energy density $E$ must satisfy the relation $E=Q V$, which imposes high operating cell voltage $(V)$ and large stored capacity $(Q)$ delivered to loads. According to the Faraday law $\left(Q=n F / M_{\mathrm{w}}\right)$, the capacity is determined by the number of transferred electrons $(n)$ and the molar weight of the active electrode material $\left(M_{\mathrm{w}}\right)$. Since, for safety and energetic reasons discussed elsewhere [8], the most feasible methods involve an increase of the capacity and working voltage of the cathode and to avoid the use of graphite as an anode.

Among the transition-metal oxides (TMOs) of diverse compositions and morphological architectures, the various compounds with two- and tri-dimensional structures have been intensively investigated as cathode and anode materials. Molybdenum (Mo) oxides are among those TMOs. Micro- and nano-structured molybdenum oxides $\left(\mathrm{MoO}_{\mathrm{y}}\right)$ with $2.0 \leq y \leq 3.0$ have shown to be attractive materials in early applications [8]. For example, in 1980s, taking advantages of the superior electrochromic response of $\mathrm{MoO}_{3}$ to the other materials, General Motors introduced a rear-view electrochromic mirror in Cadillac cars based on $\mathrm{MoO}_{3}[9,10]$. $\mathrm{MoO}_{3}$ is not only a candidate material for energy storage, batteries and supercapacitors [11-14], but also have potential applications in the fields of display devices [15], gas sensors [16-19], electrochromics [20-22], lubricants [23], field-emission-devices [24], organic solar cells [25], organic-light-emitting-diode (OLED) devices [26]. $\mathrm{MoO}_{3}$ also serves as a precursor for preparing a wide variety of nanomaterials indetended for specific electronic and optoelectronic applications [27-29]. Moreover, $\mathrm{MoO}_{\mathrm{y}}$ are important compounds in selective oxidation catalysis [30-32]. $\mathrm{MoO}_{\mathrm{y}}$ materials are used industrially as catalysts for partial oxidation of hydrocarbons to carbon acids, selective catalytic reduction of $\mathrm{NO}_{\mathrm{y}}$, production of acrylonitrile, fabrication of acrylic acid and for olefin metathesis reactions [33].

In addition to diverse crystallography and structural features, Mo-oxides posesses interesting electronic structure. With respect to electronic structure, the Mo-oxide phases can be arranged into five groups:

(i) The strictly stoichiometric anhydrous $\mathrm{MoO}_{3}$ polymorphs ( $\alpha$-, $\beta$ - and $\varepsilon$-phases), which are nearly insulators (with an unfilled $4 \mathrm{~d}$ band).

(ii) The nearly-stoichiometric $\alpha-\mathrm{MoO}_{3-\delta}$ (with $\delta<0.03$ ), which retains the orthorhombic symmetry of $\alpha-\mathrm{MoO}_{3}$. This set of materials are unintentionally $n$-type semiconductors at ambient conditions, partly due to intrinsic point defects related to oxygen vacancies $\left(V_{\mathrm{O}}\right)$ and molybdenum interstitials $\left(\mathrm{Mo}_{i}\right)$ [34]. 
(iii) The defective $\mathrm{MoO}_{3-\delta}$ (with $0.03<\delta<0.11$ ).

(iv) $\mathrm{Mo}_{\mathrm{n}} \mathrm{O}_{3 \mathrm{n}-1}$ suboxides (Magnéli phases, $n=4-9$ ), which collapse into $\mathrm{ReO}_{3}$-type structures with crystallographic shear planes due to the destabilization of the $\mathrm{MoO}_{3}$ structure by the loss of oxygen [35-40].

(v) The hydrated $\mathrm{MoO}_{3} \cdot n \mathrm{H}_{2} \mathrm{O}$ phases [41].

This review is focused on key issues and trends in research on the material science aspects of a variety of Mo-oxides $\left(\mathrm{MoO}_{3}, \mathrm{MoO}_{\mathrm{y}}, \mathrm{Mon}_{\mathrm{n}} \mathrm{O}_{3 \mathrm{n}-1}, \mathrm{MoO}_{3} \cdot \mathrm{nH}_{2} \mathrm{O}, \mathrm{MoO}_{2}\right)$ used in many advanced systems for energy storage and conversion with a special emphasis toward the compounds that are candidates as positive or negative electrodes in rechargeable lithium and sodium batteries. One of the most interesting properties of $\mathrm{MoO}_{\mathrm{y}}$ compounds is their intercalation ability, which is possible only if the bonding between the layers or tunnels of the host materials is weak. This technique has been applied to develop nanohybrids and widely used in electrochemical devices and displays because the layered structure facilitates the formation of $\mathrm{Mo}(\mathrm{VI}) / \mathrm{Mo}(\mathrm{V})$ couple [42]. With the realized property enhancements originating from the incorporation of conducting polymers into layered inorganic hosts, interest in $\mathrm{MoO}_{3}$ nanocomposites have attracted great interest. Various combinations of electronic and/or ionic conductive polymers and $\mathrm{MoO}_{3}$ have been explored, requiring a wide variety of synthetic methods to effect inclusion of the polymer in the interlamellar gap of the host material [43]. Thus, based on this brief overview, it is very clear that the fundamental understanding of the crystal growth, chemical bonding, structural quality, morphology, surface chemistry, electronic properties of Mo-oxides is critical to tune the synthetic conditions and procedures so as to obtain materials with enhanced electrochemical perfromance. Furthermore, a deeper understanding of the Mo-oxides from a fundamental scientific perspective will enable even design materials with unexpected properties and phenomena, which might be useful for integration into other future applications. Therefore, the synthesis, structural and electrochemical properties of Mo-oxides are thoroughly examined.

This paper is organized as follows. Section 2 is devoted to the properties of anhydrous $\mathrm{MoO}_{3}$ phases including nanomaterials and $\mathrm{MoO}_{3}$ used as cathode and anode materials in rechargeable batteries. In Section 3, we expose the properties of $\mathrm{MoO}_{3} \cdot n \mathrm{H}_{2} \mathrm{O}$ hydrates and their derivative products. The non-stoichiometric $\mathrm{MoO}_{\mathrm{y}}$ and oxygen deficient molybdenum oxides $\mathrm{Mo}_{\mathrm{n}} \mathrm{O}_{3 \mathrm{n}-1}$ are evaluated in Section 4. Finally, Section 5 is devoted to the electrochemical features of $\mathrm{MoO}_{2}$ used as anode in lithium and sodium batteries. In the very section (conclusions), for completeness, a very short panel devoted to discuss the limit of performance of Mo oxides. 


\section{Anhydrous molybdenum trioxides}

Anhydrous molybdenum trioxides have six polytypic forms. At ambient conditions the thermodynamically stable phase is orthorhombic $\left(\alpha-\mathrm{MoO}_{3}\right)$, while hexagonal $\left(h-\mathrm{MoO}_{3}\right)$ and monoclinic $\left(\beta-\mathrm{MoO}_{3}, \beta\right.$ '- $\mathrm{MoO}_{3}, \varepsilon-\mathrm{MoO}_{3}\left(\mathrm{MoO}_{3}-\mathrm{II}\right)$ and $\mathrm{MoO}_{3}$-III) are metastable phases [44]. The crystallographic parameters of anhydrous $\mathrm{MoO}_{3}$ polymorphs are listed in Table 1.

Table 1. Crystallographic parameters of the anhydrous molybdenum trioxides.

\begin{tabular}{|c|c|c|c|c|c|}
\hline \multirow{2}{*}{ Compound } & \multirow{2}{*}{ Space group } & \multicolumn{3}{|c|}{ Cell parameters $(\AA)$} & \multirow{2}{*}{ Réf } \\
\hline & & $a / \alpha$ & $b / \beta$ & $c / \gamma$ & \\
\hline$\alpha-\mathrm{MoO}_{3}$ & Pbnm & 3.962 & 13.850 & 3.696 & {$[45]$} \\
\hline$\beta-\mathrm{MoO}_{3}$ & $P 2_{1} / n$ & 7.118 & $5.366 / 91.99^{\circ}$ & 5.568 & [46] \\
\hline$\beta^{\prime}-\mathrm{MoO}_{3}$ & $P 2{ }_{1} / n$ & 7.424 & $7.478 / 90.09^{\circ}$ & 7.689 & {$[47]$} \\
\hline $\mathrm{h}-\mathrm{MoO}_{3}$ & $P 6_{3} / m$ & 10.57 & - & 3.72 & [48] \\
\hline$\varepsilon-\mathrm{MoO}_{3}$ & $P 2_{1} / m$ & 3.954 & $3.687 / 103.75^{\circ}$ & 7.095 & [49] \\
\hline
\end{tabular}

\subsection{Orthorhombic $\alpha-\mathrm{MoO}_{3}$}

Molybdenum trioxide exists as mineral molybdite (molar mass $143.94 \mathrm{~g} \mathrm{~mol}^{-1}$, density 4.70 $\mathrm{g} \mathrm{cm}^{-3}$, melting point $802{ }^{\circ} \mathrm{C}$ ).

\subsubsection{Brief history}

It was Carl Wilhem Scheele who, in 1778, identified molybdenum by separation from lead and isolated the oxide $\mathrm{MoO}_{3}$ and the molybdenite, $\mathrm{MoS}_{2}$. In 1861, Adolf Nordenskiold synthesized a $\mathrm{MoO}_{3}$ crystal by sublimation of ammonium molybdate and determined the crystal axial ratio as $a: b: c=0.3872: 1: 0.4792$. In 1931, it was Haakon Bräkken and Nora Wooster, who reported the crystal structure of $\mathrm{MoO}_{3}$; the works carried out independently obtained fairly similar results [50,51]; a new axial ratio of 0.282:1:0.265 was determined by X-ray measurements. In 1940s, the Uppsala's group, by means of X-ray methods, revised the crystallographic structure of all forms of molybdenum oxides [52]. In 1950, Oskar Glemser published a series of papers on Mo oxides investigated by X-ray powder technique and electrical resistivity measurements [53]; they also formulated a series of molybdenum oxide hydroxides [54]. Since 1956, $\mathrm{MoO}_{3}$ has been the subject of numerous studies as a host structure for the intercalation of various atoms or molecules, which lead in particular to molybdenum 
bronzes $\mathrm{H}_{\mathrm{x}} \mathrm{MoO}_{3}$ [55]. Since then, a large number of works were devoted to the study of insertion in aqueous environments and in $\mathrm{H}_{2} \mathrm{SO}_{4}$ [56]. In the 1960s, Morehouse Glicksman [57] investigated the discharge characteristics of $\mathrm{MoO}_{3}$ in strongly alkaline aqueous electrolyte. In the 1970s, several attempts made to use $\mathrm{MoO}_{3}$ as a battery electrode [58-60]. The electrochemical behavior of $\mathrm{MoO}_{3}$ as positive electrode material in organic solvent lithium batteries was investigated for the first time by Campanella and Pistoia [58,59], who recognized the poor solubility of $\mathrm{MoO}_{3}$ in aprotic solvent and reported the open circuit voltages (OCV) of the $\mathrm{Li}(\mathrm{s}) \mid \mathrm{Li}^{+}$(nonaqueous solvent $\mid \mathrm{MoO}_{3}$ (s) of $\sim 2.8 \mathrm{~V}$. Further, during the early years of lithium battery research, $\mathrm{MoO}_{3}$ was actively investigated as lithium insertion compound [42,61-65]. In 1974, the growing interest in lithium anode batteries has led to studies on the properties of $\mathrm{MoO}_{3}$ in an aprotic medium [66,67]. The lithiated phase of $\mathrm{MoO}_{3}$ was synthesized both by reaction of n-butyllithium and electrochemically. The maximum $x$ value in $\mathrm{Li}_{x} \mathrm{MoO}_{3}$ obtained by chemical lithiation is 1.55 [62]. Besenhard and Schöllhorn [61] investigated the charge and discharge process of $\mathrm{Li} / / \mathrm{MoO}_{3}$ cells using different aprotic electrolytes and have shown the process to be a reversible "topotactic" redox reaction to form the ternary phase $\mathrm{Li}_{\mathrm{x}} \mathrm{MoO}_{3}$, which exhibits an increase of the interlayer spacing of $\sim 1 \AA$. The term "topotactic" refers to solid-state reactions, which are characterized by the fact that defined lattice matrix elements specific to the original solid phase remain unaltered in the course of the reaction with respect to their structural architecture [68]. The Hagenmuller's group reported that the high-temperature lithium molybdenum bronzes monoclinic $\mathrm{Li}_{\mathrm{x}} \mathrm{MoO}_{3}\left(0.31 \leq x \leq 0.39\right.$ at $\left.560{ }^{\circ} \mathrm{C}\right)$ and $\mathrm{Li}_{\mathrm{x}} \mathrm{Mo}_{6} \mathrm{O}_{17}(x=0.9$ display structures different than that of $\alpha-\mathrm{MoO}_{3}$ itself [69].

\subsubsection{Structure}

Of the anhydrous $\mathrm{MoO}_{3}$ polymorphs, the orthorhombic $\alpha-\mathrm{MoO}_{3}$ phase is the stable form at room temperature and possesses a 2D layered structure [70]. The $\alpha$-phase $\mathrm{MoO}_{3}$ can be represented as the double layers of linked distorted $\mathrm{MoO}_{6}$ octahedra parallel to (010) planes (Fig. 1). In each double layer $\mathrm{MoO}_{6}$ octahedra form edge sharing zigzag rows along the (001) direction and corner haring rows along the (100) direction. Successive layers are held together by weak interlayer forces with an easy cleavage along the (010) planes (Fig. 1a). The octahedral coordination of Mo with $\mathrm{O}$ characterizes the geometrical structure of $\mathrm{MoO}_{3}$ with $\mathrm{Mo}$ surrounded by four close neighbor $\mathrm{O}$ atoms at distances of 1.95, 1.95, 1.73, and $1.67 \AA$ and two $\mathrm{O}$ atoms at significantly longer distances of 2.25 and $2.33 \AA$. These values indicate that the $\mathrm{MoO}_{6}$ octahedra are distorted and three different types of oxygen neighbors are present in the coordination sphere of Mo. They are termed as terminal (non-bridging) $\mathrm{O}(1)$, bridging $\mathrm{O}(2)$, 
and chain oxygens $\mathrm{O}(3)$ (see Fig. 1c). The terminal oxygen $\mathrm{O}(1)$ is doubly bound to a single Mo at a short bond length of $1.67 \AA$. $\mathrm{O}(2)$ is two-fold coordinated and the Mo-O bonds with bond lengths of 1.79 and $2.25 \AA$ characterize the bridging oxygen located asymmetrically between two Mo centers. The symmetric bridging oxygen $\mathrm{O}(3)$ is bound to three Mo atoms, with two equivalent Mo-O bonds (1.94 $⿱$ ) and a longer Mo-O bond (2.33 $\mathrm{A}$ ) [35]. The large work function of $\mathrm{MoO}_{3}$ of $6.6 \mathrm{eV}$ is due to its closed shell character and the dipole layer created by planes of terminal $\mathrm{O}(1)$ oxygen sites which lower the electrostatic potential of the inner Mo$\mathrm{O}$ units. These $\mathrm{O}(1)$ sites arise from the high stoichiometry of $\mathrm{MoO}_{3}$. The oxygen vacancy is most stable at the 2-fold $\mathrm{O}(2)$ site. It is a shallow donor and has a small formation energy in the $\mathrm{O}$ poor limit so that $\mathrm{MoO}_{3}$ easily becomes a degenerate semiconductor [71,72]. Figure 1d displays the XRD pattern of the layered $\alpha-\mathrm{MoO}_{3}$ showing fingerprints at $2 \theta=12.7^{\circ}, 23.3^{\circ}$, $25.6^{\circ}, 27.2^{\circ}$, and $38.9^{\circ}$, which correspond to the (020), (110), (040), (0.21) and (060) planes (JCPDS card no. 05-0508, S.G.), and crystallizes in the unique orthorhombic crystal structure (space group Pbnm) with lattice unit-cell constants $a=3.962 \AA, b=13.858 \AA$ and $c=3.697 \AA$. Unit cell parameters of $\alpha-\mathrm{MoO}_{3}$ investigated through 80 years are given in Table 2. [45,52,73].

Table 2. Unit cell parameters of $\alpha-\mathrm{MoO}_{3}$ (Pbnm S.G.) through 80 years.

\begin{tabular}{lccccc}
\hline Authors (year) & $a(\AA)$ & $b(\AA)$ & $c(\AA)$ & $V(\AA)^{3}$ & Ref. \\
\hline Bräkken (1931) & 3.962 & 13.855 & 3.701 & 203.1 & {$[73]$} \\
Wooster (1931) & 3.93 & 13.97 & 3.67 & 201 & {$[74]$} \\
Magnéli (1950) & 3.966 & 13.85 & 3.696 & 203.0 & {$[52]$} \\
Kilborg (1963) & 3.9628 & 13.855 & 3.6964 & 202.9 & {$[45]$} \\
Sitepu (2005) & $3.9621(7)$ & $13.855(1)$ & $3.6986(4)$ & 203.0 & {$[75]$} \\
\hline
\end{tabular}

(a)

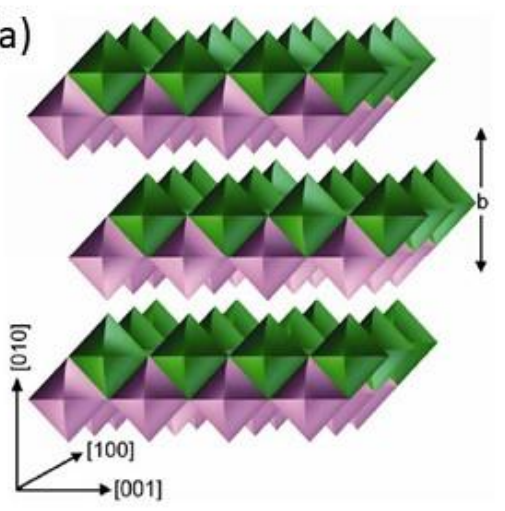

(b)

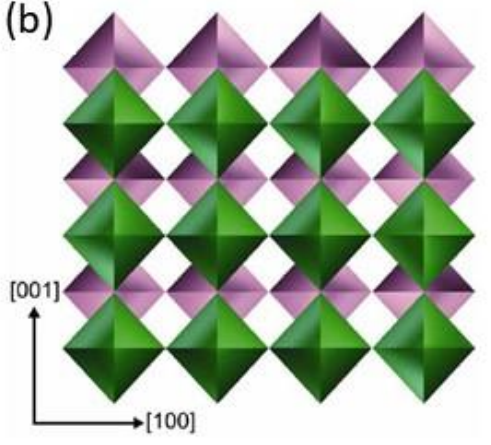

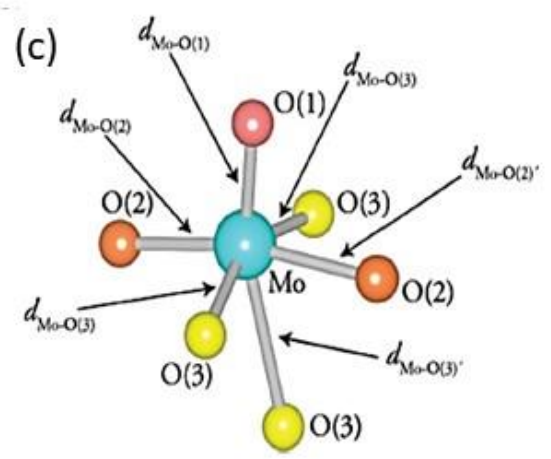



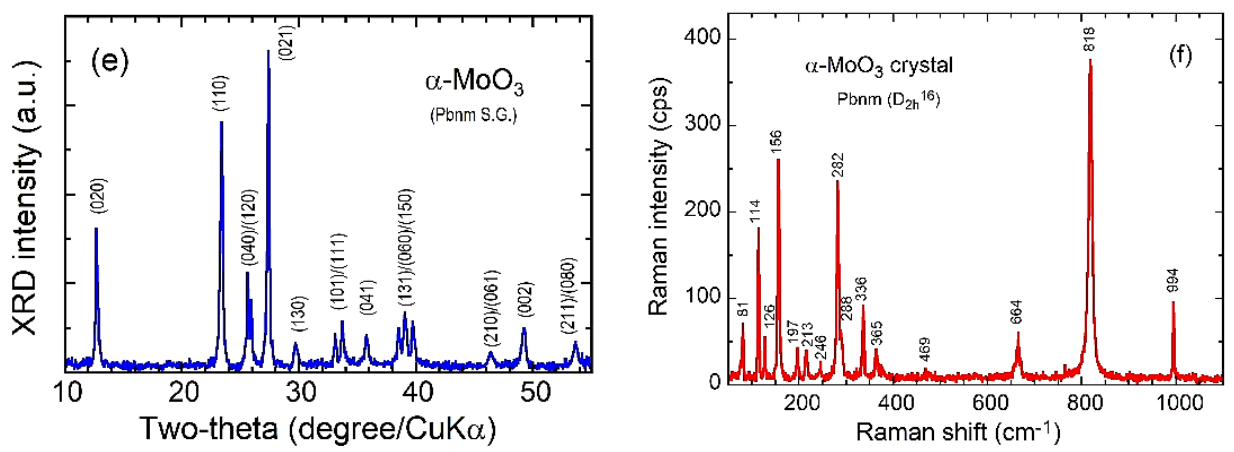

Fig. 1. Structural model for $\mathrm{MoO}_{3} \alpha$-phase (a) The unit cell includes four formula units located on double-layer slabs along the (010) direction. (b) The (010) projection of an individual double-layer. (c) The three different types of oxygen neighbors present in the coordination sphere of molybdenum. The Mo-O framework consists of $\mathrm{MoO}_{6}$ octahedra sharing edges $(\mathrm{O} 2-$ $\mathrm{O} 2$ '). (d) XRD pattern of orthorhombic $\alpha-\mathrm{MoO}_{3}$ (white crystal). (e) Raman spectrum recorded with the excitation laser line $\lambda=532 \mathrm{~nm}$.

The local structure was investigated using Raman scattering (RS) and Fourier transform infrared (FTIR) spectroscopy, which are effective tools to study the structure of crystalline, disordered and amorphous substances. The vibrational spectrum of a molecule, as observed in Raman studies, is the direct manifestation of forces arising from mutual interactions of electrons and nuclei and the RS spectrum can be analysed in terms of internal and external mode. Thus, from the observed mode frequencies, we can glean information about the force constants which hopefully can then be correlated with electronic structure and bonding theories. Several reports have been devoted to the study of vibrational features of $\mathrm{MoO}_{\mathrm{y}}$ materials [41,76-80]. Figure $\mathbf{1 f}$ shows the RS spectrum of crystalline $\alpha-\mathrm{MoO}_{3}$. The observed bands are assigned according to the single crystal model of Py and Masche [76]. The Raman spectrum of $\alpha-\mathrm{MoO}_{3}$ single crystal has characteristic bands at $996 \mathrm{~cm}^{-1}\left(A_{g}, v_{a s} \mathrm{M}=\mathrm{O}\right.$ stretch), $823 \mathrm{~cm}^{-1}$ ( $A_{g}, v_{s} \mathrm{M}=\mathrm{O}$ stretch), 667 $\mathrm{cm}^{-1}\left(B_{2 g}, B_{3 g}, v_{\text {as }} \mathrm{O}-\mathrm{M}-\mathrm{O}\right.$ stretch), $473 \mathrm{~cm}^{-1}$ ( $A_{g}, v_{a s} \mathrm{O}-\mathrm{M}-\mathrm{O}$ stretch and bend), $380 \mathrm{~cm}^{-1}\left(B_{1 g}\right.$, $\delta \mathrm{O}-\mathrm{M}-\mathrm{O}$ scissor), $376\left(B_{1 g}\right), 366 \mathrm{~cm}^{-1}\left(A_{l g}, \delta \mathrm{O}-\mathrm{M}-\mathrm{O}\right.$ scissor), $334 \mathrm{~cm}^{-1}\left(A_{g}, B_{1 g}, \delta \mathrm{O}-\mathrm{M}-\mathrm{O}\right.$ bend), $293 \mathrm{~cm}^{-1}$ ( $B_{3 g}, \delta \mathrm{O}=\mathrm{M}=\mathrm{O}$ wagging), $285 \mathrm{~cm}^{-1}$ ( $B_{2 g}, \delta \mathrm{O}=\mathrm{M}=\mathrm{O}$ wagging), $247 \mathrm{~cm}^{-1}$ (B $B_{3 g}$, $\tau \mathrm{O}=\mathrm{Mo}=\mathrm{O}$ twist $), 216 \mathrm{~cm}^{-1}\left(A_{g}\right.$, rotational rigid $\mathrm{MoO}_{4}$ chain mode, $\left.R_{c}\right), 197 \mathrm{~cm}^{-1}\left(B_{2 g}, \tau\right.$ $\mathrm{O}=\mathrm{Mo}=\mathrm{O}$ twist $), 159 \mathrm{~cm}^{-1}\left(A_{g} / B_{1 g}\right.$, translational rigid $\mathrm{MoO}_{4}$ chain mode, $\left.T_{b}\right), 129 \mathrm{~cm}^{-1}\left(B_{3 g}\right.$, translational rigid $\mathrm{MoO}_{4}$ chain mode, $\left.T_{c}\right), 116 \mathrm{~cm}^{-1}\left(B_{2 g}\right.$, translational rigid $\mathrm{MoO}_{4}$ chain mode, $\left.T_{c}\right), 100 \mathrm{~cm}^{-1}\left(B_{2 g}\right.$, translational rigid $\mathrm{MoO}_{4}$ chain mode, $\left.T_{a}\right)$ and $89 \mathrm{~cm}^{-1}\left(A_{g}\right.$, translational rigid $\mathrm{MoO}_{4}$ chain mode, $T_{a}$ ). The Raman bands at 995 and $823 \mathrm{~cm}^{-1}$ are the fingerprints of the symmetrical stretching vibration of the terminal $\mathrm{Mo}=\mathrm{O}$ bonds along the $a$ - and $b$-axes (Table 
3). The bridging oxygens (longer bond distances) along the $c$-axis are the weakly bound oxygens as shown by Mestl et al. [81]. Due to the stoichiometry deviation within the $\mathrm{MoO}_{\mathrm{y}}$ samples variations of the Raman bands of localized vibrations, e.g., the 666,823 or $995 \mathrm{~cm}^{-1}$ bands are expected as a displacement of the Mo atom toward the terminal oxygen in the $b$ direction occurs upon the loss of the bridging oxygen, thus weakening the bond to the terminal $\mathrm{O}$ atom along the $a$-axis.

Table 3. Raman vibration modes of nanostructured $\alpha-\mathrm{MoO}_{3}$. Reproduced with permission from [82]. Copyright 2012 Elsevier.

\begin{tabular}{|c|c|c|c|c|c|c|c|}
\hline \multirow[t]{2}{*}{ Modes } & \multirow[t]{2}{*}{ Assignment } & \multicolumn{6}{|c|}{ Raman shift $\left(\mathrm{cm}^{-1}\right)$} \\
\hline & & {$[82]$} & {$[44]$} & [78] & [83] & [84] & [41] \\
\hline$\overline{A_{g}}$ & $\mathrm{~T}_{\mathrm{a}}$ Translation of rigid $\mathrm{MoO}_{4}$ chain $\left(\mathrm{T}_{\mathrm{a}}\right)$ & 82 & - & 89 & 82 & 82 & 83 \\
\hline $\mathrm{B}_{2 \mathrm{~g}}$ & $\mathrm{~T}_{\mathrm{a}}$ Translation of rigid $\mathrm{MoO}_{4}$ chain $\left(\mathrm{T}_{\mathrm{a}}\right)$ & 98 & - & 100 & - & 98 & 98 \\
\hline $\mathrm{B}_{2 \mathrm{~g}}$ & $\mathrm{~T}_{\mathrm{c}}$ Translation of rigid $\mathrm{MoO}_{4}$ chain $\left(\mathrm{T}_{\mathrm{c}}\right)$ & 116 & 116 & 116 & 115 & 114 & 116 \\
\hline $\mathrm{B}_{3 \mathrm{~g}}$ & $\mathrm{~T}_{\mathrm{c}}$ Translation of rigid $\mathrm{MoO}_{4}$ chain $\left(\mathrm{T}_{\mathrm{c}}\right)$ & 127 & 130 & 129 & 129 & 128 & 128 \\
\hline $\mathrm{A}_{\mathrm{g}} / \mathrm{B}_{1 \mathrm{~g}}$ & $\delta\left(\mathrm{O}_{2} \mathrm{Mo}_{2}\right)_{n}$ & 159 & 157 & 159 & 158 & 157 & 156 \\
\hline $\mathrm{B}_{2 \mathrm{~g}}$ & $\delta \mathrm{O}_{2} \_\mathrm{Mo} \_\mathrm{O}_{2}$ scissoring & 196 & 198 & 197 & 198 & 197 & 198 \\
\hline $\mathrm{Ag}_{\mathrm{g}}$ & $\delta \mathrm{O}_{2} \_\mathrm{Mo}-\mathrm{O}_{2}$ scissoring & 218 & 217 & 216 & 216 & 216 & 218 \\
\hline $\mathrm{B}_{3 \mathrm{~g}}$ & $\delta \mathrm{O}_{2} \_\mathrm{Mo}-\mathrm{O}_{2}$ scissoring & 245 & 246 & 247 & 246 & 244 & 246 \\
\hline $\mathrm{B}_{2 \mathrm{~g}}$ & $\delta \mathrm{O}_{1}=\mathrm{Mo}=\mathrm{O}_{1}$ wagging & 283 & 284 & 285 & 284 & 282 & 286 \\
\hline $\mathrm{B}_{3 \mathrm{~g}}$ & $\delta \mathrm{O}_{1}=\mathrm{Mo}=\mathrm{O}_{1}$ wagging & 292 & 291 & 293 & - & - & 291 \\
\hline $\mathrm{Ag}_{\mathrm{g}} / \mathrm{B}_{1 \mathrm{~g}}$ & $\delta \mathrm{O}_{3} \_\mathrm{Mo} \_-\mathrm{O}_{3}$ bending & 338 & 338 & 334 & 336 & 336 & 338 \\
\hline$A_{g}$ & $\delta \mathrm{O}_{2}=\mathrm{Mo}=\mathrm{O}_{2}$ scissoring & 365 & 365 & 366 & 365 & 365 & 366 \\
\hline $\mathrm{B}_{1 \mathrm{~g}}$ & $\delta \mathrm{O}_{2}=\mathrm{Mo}=\mathrm{O}_{2}$ scissoring & 379 & 378 & 376 & 379 & 377 & 380 \\
\hline$A_{g}$ & $v_{\mathrm{as}} \mathrm{Mo} \_\mathrm{O}_{2} \_$Mo bending & 471 & 471 & 473 & - & 469 & 472 \\
\hline $\mathrm{B}_{2 \mathrm{~g}} / \mathrm{B}_{3 \mathrm{~g}}$ & $v_{\text {as }} \mathrm{Mo} \_\mathrm{O}_{2}-$ Mo stretching & 664 & 667 & 667 & 666 & 666 & 666 \\
\hline $\mathrm{A}_{\mathrm{g}}$ & $v_{\mathrm{s}} \mathrm{Mo} \_\mathrm{O}_{3} \_$Mo stretching & 816 & 817 & 823 & 819 & 818 & 820 \\
\hline$A_{g}$ & $v_{\mathrm{as}} \mathrm{Mo}=\mathrm{O}_{1}$ stretching & 992 & 996 & 996 & 996 & 994 & 996 \\
\hline
\end{tabular}

\subsubsection{Synthesis}

A variety of synthesis routes have been developed for the preparation of $\mathrm{MoO}_{\mathrm{y}}$ materials to control their structure and morphology. They include solid state reaction [85], wet-chemical synthesis [86], sol-gel route [20], precipitation [87], thermal oxidation [88], thermal evaporation [83], flame synthesis process [89], hot-plate method [90], mechanochemical technique [91], electrodeposition [92], electrospinning technique [93,94], solvothermal method [95], spray pyrolysis [96-98], spin coating [99], and template synthesis [100]. Synthesis techniques are briefly reviewed in this section; for a complete view see Ref. [101]. Most of crystallized $\mathrm{MoO}_{\mathrm{y}}$ were easily fabricated by heat treatment of either molybdic acid powders $\left(\mathrm{H}_{4} \mathrm{MoO}_{4}\right)$ or synthetic hydrated molybdenum trioxide $\left(\mathrm{MoO}_{3} \cdot \mathrm{nH}_{2} \mathrm{O}\right)[102,103]$. 
Different hydrothermal techniques were utilized to grow $\alpha-\mathrm{MoO}_{3}$ crystals (see Table 4) [104-107]. Various raw materials are commonly used including Mo metal powders, acid molybdic $\left(\mathrm{H}_{4} \mathrm{MoO}_{4}\right)$, ammonium molybdate $\left(\left(\mathrm{NH}_{4}\right)_{2} \mathrm{MoO}_{4}\right)$, ammonium molybdate tetrahydrate $\left(\left(\mathrm{NH}_{4}\right)_{6} \mathrm{Mo}_{7} \mathrm{O}_{24} \cdot 4 \mathrm{H}_{2} \mathrm{O}\right)$, and sodium molybdate $\left(\mathrm{Na}_{2} \mathrm{MoO}_{4}\right)$. Zhou et al. [108] fabricated flexible single crystalline nanobelts with widths of $200-500 \mathrm{~nm}$, lengths of 5-10 $\mu \mathrm{m}$, and thicknesses of $\sim 50 \mathrm{~nm}$ via hydrothermal treatment at $180{ }^{\circ} \mathrm{C}$ for $24 \mathrm{~h}$ of a peroxomolybdic acid solution prepared by reaction of $\mathrm{H}_{2} \mathrm{O}_{2}$ with Mo metal powders. Li et al. [93] prepared $\mathrm{MoO}_{3}$ nanofibers (diameter of $200 \mathrm{~nm}$ ) by a combination method of sol-gel process and electrospinning technique using $\left(\mathrm{NH}_{4}\right)_{6} \mathrm{Mo}_{7} \mathrm{O}_{24} \cdot 4 \mathrm{H}_{2} \mathrm{O}$ with the molar ratio of 1/1.28 dissolved in dilute nitric acid and then mixed with a water-ethanol (v/v 1:4) solution containing citric acid as a chelating agent for the metal ions. Subba-Reddy et al. [106] constructed nanobelts (1$5 \mu \mathrm{m}$ in length and $100-600 \mathrm{~nm}$ in diameter) by hydrothermal method using $\mathrm{MoO}_{3} \cdot n \mathrm{H}_{2} \mathrm{O}$ sols prepared by ion exchange of ammonium heptamolybdate tetrahydrate through a proton exchange resin. After ion exchange, a clear light-blue $\mathrm{MoO}_{3}$ sol $(\mathrm{pH} \approx 2.0)$ was obtained and modified with poly(ethylene glycol) (PEG). Nanocrystalline $\mathrm{MoO}_{3}$ was synthesized by a solgel method using ammonium molybdate tetrahydrate citric acid (CA) as chelating agent with the metal/CA ratio of 1:1 under neutral $\mathrm{pH}$ [109]. Pure $\mathrm{MoO}_{3}$ was obtained by calcination of dried precursor at $500{ }^{\circ} \mathrm{C}$ for $5 \mathrm{~h}$ in air, while $\mathrm{Mon}_{\mathrm{n}} \mathrm{O}_{3 \mathrm{n}-1} / \mathrm{C}$ composite was formed under argon atmosphere (Fig. 2).

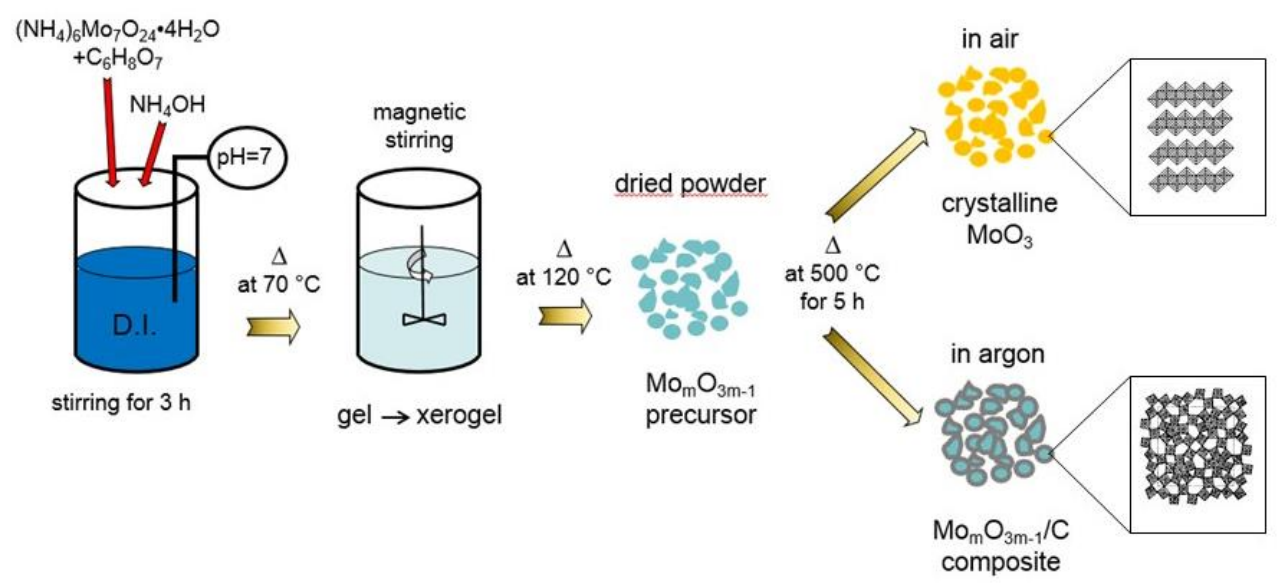

Fig. 2. Overall synthesis process of the crystalline $\mathrm{MoO}_{3}$ and $\mathrm{Mom}_{3 \mathrm{~m}-1} / \mathrm{C}$ composite. Copyright Hashem et al. [109]. Copyright 2020 Hashem et al. Under Creative Commons Attribution (CC BY) license. 
Table 4. Synthesis of $\alpha-\mathrm{MoO}_{3}$ through different hydrothermal routes.

\begin{tabular}{|c|c|c|c|}
\hline Raw material & Additive & Conditions & Ref. \\
\hline commercial $\mathrm{MoO}_{3}$ bulk & $\mathrm{CTAB}^{\mathrm{a})}$ & $180^{\circ} \mathrm{C} / 4$ days & [110] \\
\hline Mo metal powders & $\mathrm{H}_{2} \mathrm{C}_{2} \mathrm{O}_{4} \cdot 2 \mathrm{H}_{2} \mathrm{O}$ & $180^{\circ} \mathrm{C} / 5$ days & [111] \\
\hline $\mathrm{Na}_{2} \mathrm{MoO}_{4}$ & $0.2 \mathrm{mmol} \mathrm{HCl}$ & $160^{\circ} \mathrm{C} / 20 \mathrm{~h}$ & [112] \\
\hline$\left(\mathrm{NH}_{4}\right)_{6} \mathrm{Mo}_{7} \mathrm{O}_{24} \cdot 4 \mathrm{H}_{2} \mathrm{O}$ & $\mathrm{HNO}_{3}(\mathrm{pH}=4.5-9-6)$ & $140-220{ }^{\circ} \mathrm{C} / 5-62 \mathrm{~h}$ & [105] \\
\hline$\left(\mathrm{Mo}(\mathrm{NO})\left(\mathrm{NH}_{2} \mathrm{O}\right)\right)^{2+}$ & $\mathrm{HNO}_{3}$ & $220^{\circ} \mathrm{C} / 7-24 \mathrm{~h}$ & [113] \\
\hline Mo metal powders & $\mathrm{H}_{2} \mathrm{O}_{2}$ & $180^{\circ} \mathrm{C} / 24 \mathrm{~h}$ & [108] \\
\hline $\mathrm{Na}_{2} \mathrm{MoO}_{4}$ & $4 \mathrm{mmol} \mathrm{L}^{-1} \mathrm{HClO}_{4}$ & $140^{\circ} \mathrm{C} / 24 \mathrm{~h}$ & [114] \\
\hline $\mathrm{Na}_{2} \mathrm{MoO}_{4} \cdot 2 \mathrm{H}_{2} \mathrm{O}$ & 3-diaminopropane & $120^{\circ} \mathrm{C} / 48 \mathrm{~h}$ & [115] \\
\hline $\mathrm{Na}_{2} \mathrm{MoO}_{4} \cdot 2 \mathrm{H}_{2} \mathrm{O}$ & $\mathrm{NaCl}+\mathrm{GO}$ & $180^{\circ} \mathrm{C} / 24 \mathrm{~h}$ & [116] \\
\hline $\mathrm{H}_{2} \mathrm{MoO}_{4}$ & $\mathrm{HNO}_{3} / \mathrm{H}_{2} \mathrm{O}_{2}(1: 5 \mathrm{v} / \mathrm{v})$ & $120-180^{\circ} \mathrm{C} / 6 \mathrm{~h}$ & [117] \\
\hline $\mathrm{MoO}_{2}$ powders & $\mathrm{H}_{2} \mathrm{O}_{2}$ & $180^{\circ} \mathrm{C} / 10 \mathrm{~h}$ & [118] \\
\hline $\mathrm{MoO}_{3} \cdot n \mathrm{H}_{2} \mathrm{O}$ sols & poly(ethylene glycol) & $180^{\circ} \mathrm{C} / 4$ days & [106] \\
\hline
\end{tabular}

The procedure developed by Jiao et al. [119] consists in the wet-chemical synthesis using an ammonium molybdate tetrahydrate solution adjusted at $\mathrm{pH}=3.5$ with diluted glacial acetic acid with subsequent sintering at $600{ }^{\circ} \mathrm{C}$ for $24 \mathrm{~h}$. The conversion of isopolymolybdate anions $\mathrm{Mo}_{7} \mathrm{O}_{24}^{6-}$ to neutral $\mathrm{Mo}_{7} \mathrm{O}_{21}$ (or $\alpha-\mathrm{MoO}_{3}$ ) occurs by combining excess oxygen in $\mathrm{Mo}_{7} \mathrm{O}_{24}^{6-}$ with protons from the acidic medium:

$$
\mathrm{Mo}_{7} \mathrm{O}_{24}^{6-}+6 \mathrm{H}^{+} \rightarrow 7 \mathrm{MoO}_{3}+3 \mathrm{H}_{2} \mathrm{O} \text {. }
$$

Chiang et al. [120] investigated the precipitation route using the mixture of an ammonium molybdate tetrahydrate solution with ethylene glycol (dark blue solution), which precipitates after centrifugation and heating at $80{ }^{\circ} \mathrm{C}$ for $24 \mathrm{~h}$ (white powder). In a typical solid-state reaction, $\alpha-\mathrm{MoO}_{3}$ crystals obtained from the decomposition of $\mathrm{H}_{4} \mathrm{MoO}_{4}$ raw powders loaded into porcelain crucibles and positioned in a multi-zone tube furnace with a $300 \mathrm{~cm}^{3} \mathrm{~min}^{-1}$ argon flow. After 2-h purge, the furnace temperature is ramped from room temperature to the desired heat-treatment temperature over a 1-h period. This thermal treatment maintained at $750{ }^{\circ} \mathrm{C}$ for $2 \mathrm{~h}$ provides well-crystallized specimens [121]. Figure 3 shows the SEM images of samples produced by heat treatment of molybdic acid at temperature $400 \leq T_{\mathrm{a}} \leq 800^{\circ} \mathrm{C}$. Hydrates contain $\mathrm{MoO}_{5}\left(\mathrm{H}_{2} \mathrm{O}\right)$ octahedral units, while they are intercalated by water molecules in $\mathrm{MoO}_{3} \cdot 2 \mathrm{H}_{2} \mathrm{O}$. During the topotactic dehydration process, the intercalated water is lost first, then neighbouring sheets condense giving the double sheets of the anhydrous $\mathrm{MoO}_{3}$ phase as the final water is lost (see sketch of Fig. 4a). TG and DTA curves of the oxide-hydrate of molybdenum $\mathrm{MoO}_{3} \cdot 2 \mathrm{H}_{2} \mathrm{O}$ shown in Fig. 4b exhibit four endothermic peaks at annealing temperature $\left(T_{\mathrm{a}}\right)$ of 120,198 , 246 , and $325^{\circ} \mathrm{C}$ corresponding to the various steps for water removal via the formation of the intermediate $\alpha-\mathrm{MoO}_{3} \cdot \mathrm{H}_{2} \mathrm{O}$. Figure $4 \mathrm{c}$ presents the XRD patterns of oxide-hydrates heat-treated 
in the temperature range $75-800{ }^{\circ} \mathrm{C}$. The phase $\alpha-\mathrm{MoO}_{3}$ appears after a thermal treatment of the molybdic acid above $750{ }^{\circ} \mathrm{C}$ in air. FTIR spectra of $\mathrm{MoO}_{3} \cdot n \mathrm{H}_{2} \mathrm{O}(n<1)$ shows the spectral features of the layered $\alpha-\mathrm{MoO}_{3} \cdot \mathrm{H}_{2} \mathrm{O}$ phase for $T_{\mathrm{a}} \approx 280{ }^{\circ} \mathrm{C}$. Note the disappearance of the $\mathrm{OH}$ stretching mode $\left(3400 \mathrm{~cm}^{-1}\right)$ for $T_{\mathrm{a}}>250{ }^{\circ} \mathrm{C}$ (Fig. 4d). The low-temperature synthesis of $\mathrm{MoO}_{3}$ nanobelts (15 nm thick) was based on the preparation of $\mathrm{MoO}_{3} \cdot \mathrm{H}_{2} \mathrm{O}$ solution (i.e., colorless solution obtained by dissolution of $20 \mathrm{mmol} \mathrm{Na} \mathrm{MoO}_{4}$ in distilled water added with $4 \mathrm{~mol}$ $\mathrm{L}^{-1}$ perchloric acid and subsequent treatment of a hydrothermal reaction [114].
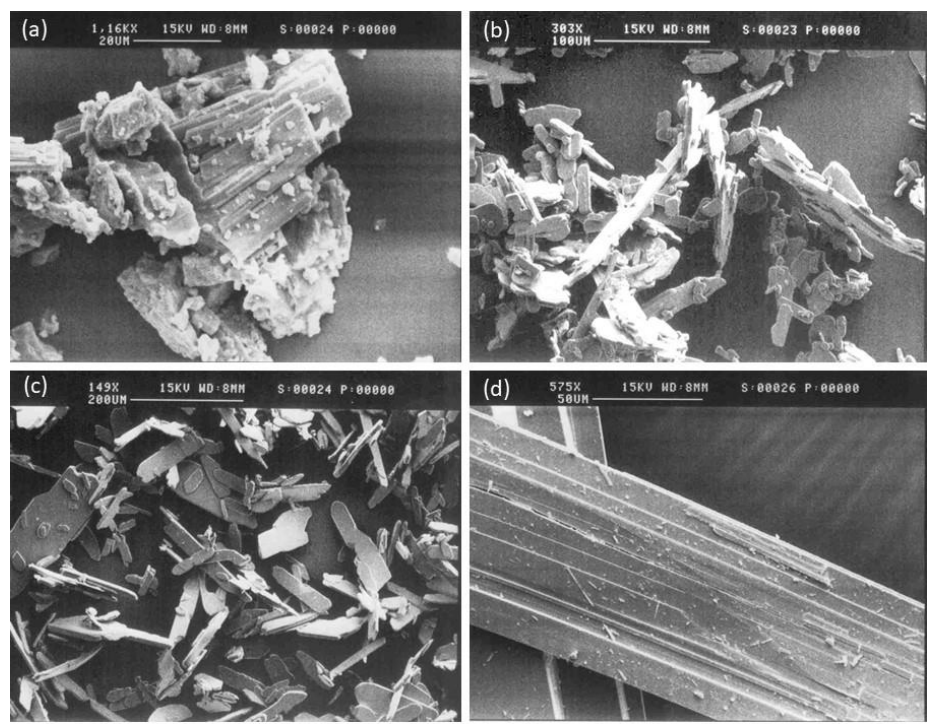

Fig. 3. SEM images of samples produced by heat treatment of $\mathrm{MoO}_{3} \cdot 2 \mathrm{H}_{2} \mathrm{O}$ hydrate at (a) 400, (b) 600 , (c) 750 and (d) $800{ }^{\circ} \mathrm{C}$. The latter sample is the well crystallized $\alpha-\mathrm{MoO}_{3}$ phase, which displays the typical elongated shape the layered structure (edge of the platelet). 


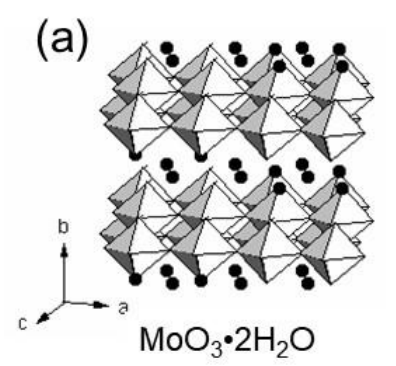

(b)

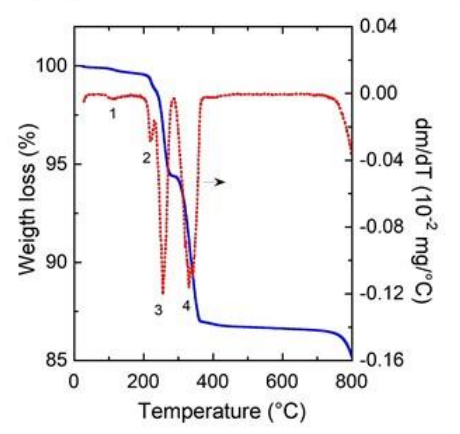

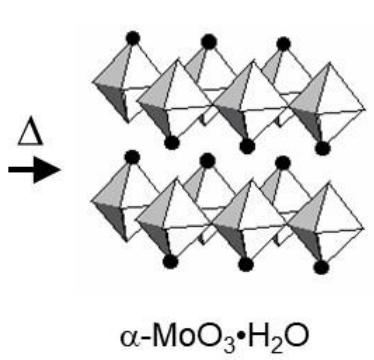

(c)

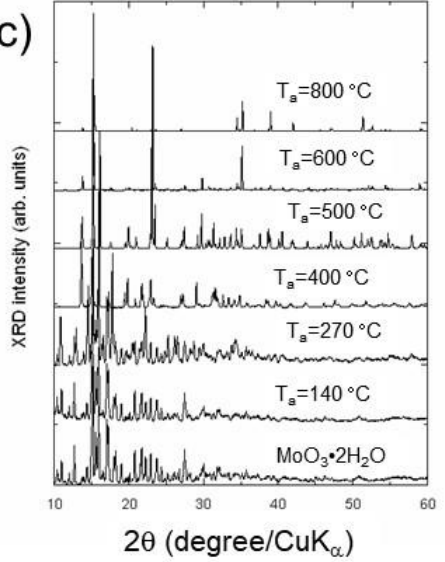

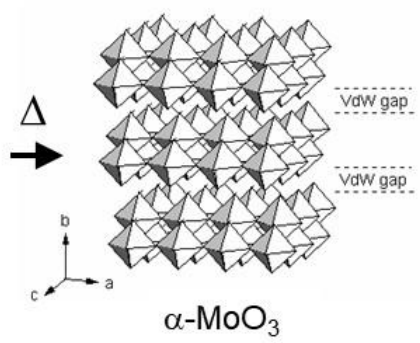

(d)

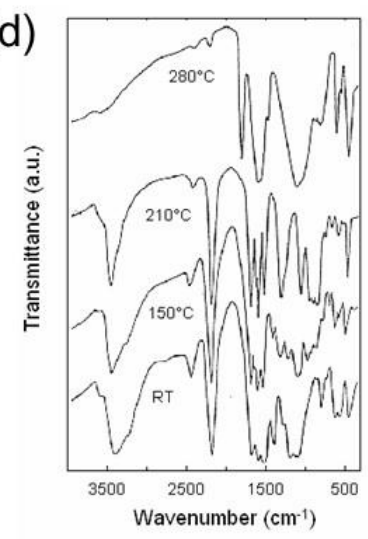

Fig. 4. (a) Sketch of the structural evolution upon heat-treatment of the hydrated $\mathrm{MoO}_{3} \cdot 2 \mathrm{H}_{2} \mathrm{O}$ precursor to form $\alpha-\mathrm{MoO}_{3}$ via the intermediate $\alpha-\mathrm{MoO}_{3} \cdot \mathrm{H}_{2} \mathrm{O}$ phase. (b) TG and DTA curves for oxide-hydrate of molybdenum. The DTA curve exhibits four endothermic peaks at 120, 198, 246, and $325{ }^{\circ} \mathrm{C}$ corresponding to the various steps for water removal. (c) X-ray diffraction patterns of oxide-hydrates of molybdenum heat-treated at various temperature in the range 75$600{ }^{\circ} \mathrm{C}$. The phase $\alpha-\mathrm{MoO}_{3}$ appears after a thermal treatment of the molybdic acid above 750 ${ }^{\circ} \mathrm{C}$ in air. (d) FTIR spectra of dehydrated $\mathrm{MoO}_{3} \cdot n \mathrm{H}_{2} \mathrm{O}(n<1)$. Spectral responses are more complex than that of crystalline $\mathrm{MoO}_{3}$, but they can be discussed in terms of internal and external modes as usual for oxide lattices.

\subsection{4. $\mathrm{MoO}_{3}$ nanostructures}

One major reason for the use of nanosized particles of materials for energy storage comes from their poor transport properties that imply poor rate performance of the electrochemical devices. This is the case for $\mathrm{MoO}_{3}$ used as electrodes in batteries and supercapacitors. As the electronic conductivity of $\mathrm{MoO}_{3}$ is $\approx 10^{-8} \mathrm{~S} \cdot \mathrm{cm}^{-1}$ at room temperature, it requires some sophisticated technology such as the use of slurry containing a huge quantity of carbon (carbon "Super P", acetylene black, amorphous carbon, etc.) or deposition at the surface of the grains for enhanced charge carrier transport [122-126]. Achieving high-rate capability depends ultimately on the geometry of the active objects building the positive and negative electrodes. 
As the performance of an electrode is governed by the transport of both electrons and ions, the ionic and electronic conductivity of the materials must be considered. For a diffusion process, the characteristic time $\tau$ for ionic species $i$ (in practice $\mathrm{Li}^{+}$or $\mathrm{Na}^{+}$ions in the present case) to reach the surface of any active particle of dimension $L$ is given by the second Fick's law that applies the chemical diffusion coefficient with $D_{L i}^{*}$ of moving ions [127]. In the case when the chemical reaction proceeds by a single-phase process, i.e., within a solid solution, $\tau$ is given by $\tau=L^{2} / 4 \pi D_{L i}^{*}$. Moreover, decreasing the size of $\mathrm{MoO}_{3}$ particles is an efficient strategy to mitigate the volume variation of the electrode during $\mathrm{Li}$ ions intercalation and deintercalation process. Nanosized $\mathrm{MoO}_{3}$ particles with different morphologies (Fig. 5) include nanoparticles [128], nanobelts [108,129,130], nanowires [131-34], nanofibers [113,135], nanotubes [136138], nanoflakes [90] and nanoribbons [18]. Designing of porous structure and carbon coating are another most popular strategy to improve the electrochemical performances of $\mathrm{MoO}_{3}$ $[139,140]$.

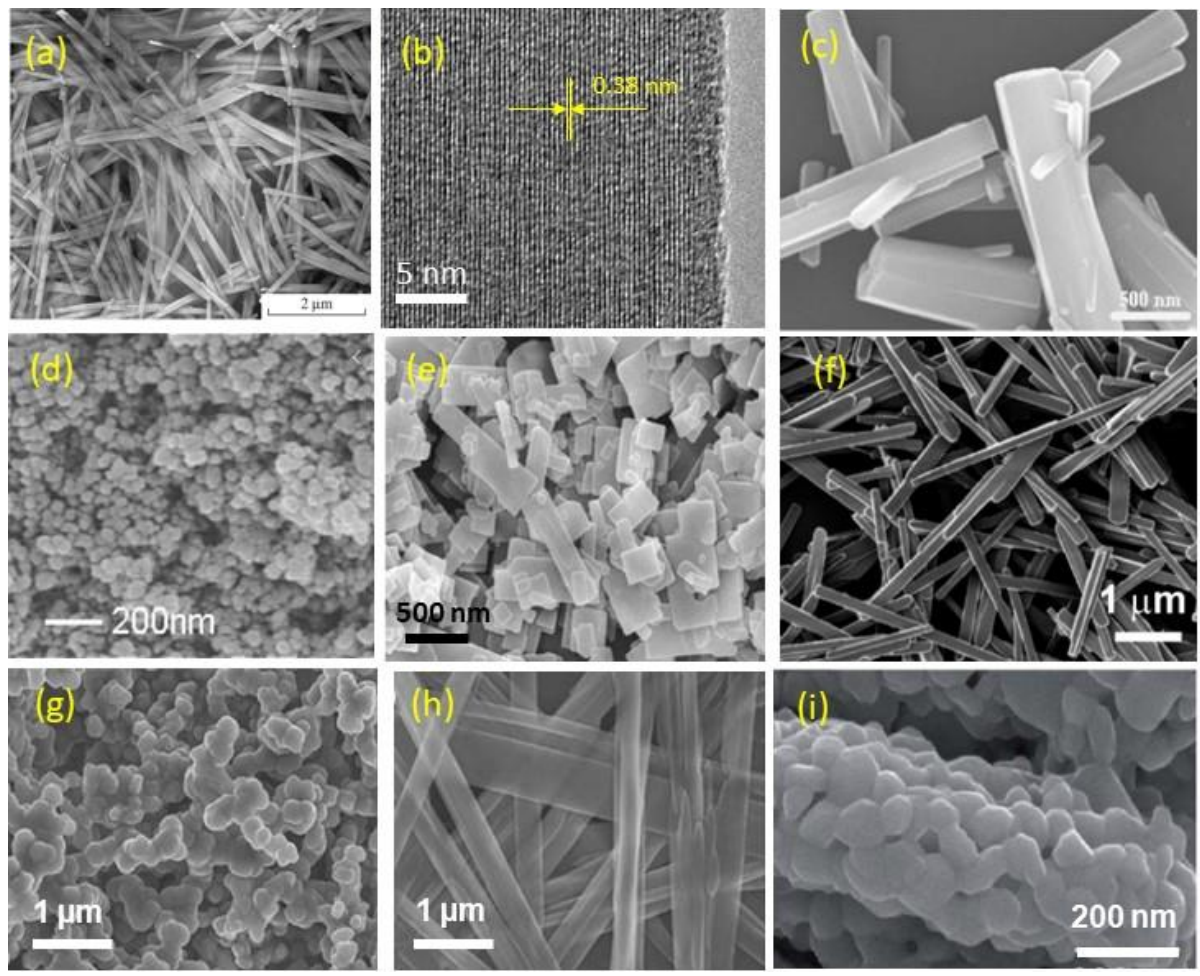

Fig. 5. SEM images of nanostructured a-MoO 3 . (a) nanofibers, (b) HRTEM image showing the lattice fringe of $0.38 \mathrm{~nm}$ which corresponds to the $d_{110}$ spacing, (c) nanoplatelets, (d) nanospheres, (e) nanoflakes, (f) nanorods, (g) nanosheets, (h) nanoribbons, (i) nanotubes. 
Due to their chromogenic, catalytic properties and ability to host foreign ions, $\mathrm{MoO}_{3}$ thin films have been applied in electrochromic display devices (see [141] and Refs. therein), optical memory devices [142], gas sensors [17], and lithium microbatteries [143-146]. Currently, there are several approaches available for preparing $\mathrm{MoO}_{3}$ films with either an amorphous or a polycrystalline structure using physical vapor deposition (PVD) and metal organic chemical vapor deposition (MOCVD) [147] are also used to fabricate $\mathrm{MoO}_{3}$ in thin film forms. The different techniques include thermal evaporation [148], magnetron sputtering [144,149], chemical vapor deposition [150,151], electrodeposition [152], flash evaporation [153,154], pulsed-laser deposition (PLD) [155-157], electron-beam deposition [158,159], ion-beam deposition [17], sol-gel spin-coating [160,161], and spray pyrolysis [162,163]. Among these methods, magnetron sputtering and pulsed-laser deposition have received considerable attention for industrial purpose because the low temperatures process [164]. $\mathrm{MoO}_{3}$ films were produced under varying conditions of growth temperature, $T_{\mathrm{s}}$, and oxygen pressure $p\left(\mathrm{O}_{2}\right)$. Analyses indicate that the microstructure of $\mathrm{MoO}_{\mathrm{y}}$ thin films is sensitive to growth conditions. For example, RHEED patterns of sputter-deposited Mo oxide films grown at $445{ }^{\circ} \mathrm{C}$ with various $p\left(\mathrm{O}_{2}\right)$ show that a secondary component phase, i.e., $\mathrm{Mo}_{8} \mathrm{O}_{23}$, is evidenced for films grown at lower $p\left(\mathrm{O}_{2}\right)$. Well-textured $\mathrm{MoO}_{3}$ film without secondary phases is obtained for $p\left(\mathrm{O}_{2}\right)=62.3 \%$ [165]. FTIR spectra of $\mathrm{PLD} \mathrm{MoO}_{3}$ films grown at different $T_{\mathrm{s}}$ show that the broad infrared absorption band in the region of $500-1000 \mathrm{~cm}^{-1}$ starts to be resolved into strong absorption peaks at around 570,625, 700, 840, and $985 \mathrm{~cm}^{-1}$ at $T_{\mathrm{s}}>200{ }^{\circ} \mathrm{C}$ [157], indicating the pure $\alpha-\mathrm{MoO}_{3}$ phase. In addition, the splitting of IR active mode at $900-1010 \mathrm{~cm}^{-1}$ is evidenced for well-crystallized film. X-ray photoelectron spectroscopy (XPS) is also a sensitive tool to evaluated the local environment: (i) the XPS Mo 3d core level spectra evidence the reduction of $\mathrm{Mo}^{6+}$ ions to $\mathrm{Mo}^{5+}$ ions in non-stoichiometric film and (ii) the broadening of the Mo 3d core level peaks is assigned to the distortion of the oxide matrix [166].

To fabricate nanoscopic $\mathrm{MoO}_{3}$, methods like template-directed reaction of molybdic acid and the subsequent leaching process [167], and templating against carbon nanotubes have been attempted [168]. Polycrystalline $\mathrm{MoO}_{3}$ thin films have been prepared by oxidation at high temperature of molybdenum compound layers deposited by chemical vapour deposition (CVD) from molybdenum hexacarbonyl $\mathrm{Mo}(\mathrm{CO})_{6}$ [169].

The main parameter for a thin film microbattery is the delivered gravimetric capacity. Rather than being expressed as the conventional unit of $\mathrm{mAh} \cdot \mathrm{g}^{-1}$, due to the uncertainty in the film density, technologists prefer the stored charge, $Q$ expressed in $\mu \mathrm{Ah}$ or in coulomb, per film surface area and the film thickness, i.e., $\mu \mathrm{Ah} \cdot \mathrm{cm}^{-2} \mu \mathrm{m}^{-1}$ or $\mathrm{mC} \cdot \mathrm{cm}^{-2} \mu \mathrm{m}^{-1}$. The relation 
between the gravimetric capacity, $Q_{\mathrm{m}}$, of the material and the volumetric capacity of a film, $Q_{\mathrm{f}}$, is given by:

$$
Q_{\mathrm{f}}=0.36 d Q_{\mathrm{m}},
$$

where $Q_{\mathrm{f}}$ is expressed in $\mathrm{mC} \cdot \mathrm{cm}^{-2} \mu \mathrm{m}^{-1}, Q_{\mathrm{m}}$ in $\mathrm{mAh} \cdot \mathrm{g}^{-1}$, and $d$ is the density of the material in $\mathrm{g} \cdot \mathrm{cm}^{-3}$. Considering the accommodation of $1.5 \mathrm{Li}$ per mole of $\mathrm{MoO}_{3}$, yielding a gravimetric capacity of $280 \mathrm{mAh} \cdot \mathrm{g}^{-1}$, the capacity of a dense film can reach the value of $\approx 130$ $\mu \mathrm{Ah} \cdot \mathrm{cm}^{-2} \cdot \mu \mathrm{m}^{-1}$. For certain applications, high-quality films grown by PLD are required. Currently, $\mathrm{PLD} \mathrm{MoO}_{3}$ thin films are grown using a $\mathrm{KrF}$ excimer laser $(\lambda=248 \mathrm{~nm})$ with a fluence of $2 \mathrm{~J} \mathrm{~cm}^{-2}$ (energy of $300 \mathrm{~mJ}$ per pulse) and deposited on various substrates heated in the range of $25 \leq T_{\mathrm{s}} \leq 500{ }^{\circ} \mathrm{C}$ under an atmosphere of $\mathrm{O}_{2}$ flow maintained at a pressure of $0.1 \leq$ $p\left(\mathrm{O}_{2}\right) \leq 20 \mathrm{~Pa}$. In the prior report, Julien et al. showed that the structure analyzed by optical spectroscopy strongly depends on $T_{\mathrm{s}}$. For $T_{\mathrm{s}}<150{ }^{\circ} \mathrm{C}$, an amorphous phase is formed, the $\beta-\mathrm{MoO}_{3}$ monoclinic phase grows at $T_{\mathrm{s}} \approx 200{ }^{\circ} \mathrm{C}$, and the layered $\alpha-\mathrm{MoO}_{3}$ orthorhombic phase appears at $T_{\mathrm{s}}=300{ }^{\circ} \mathrm{C}$ [170-172]. Al-Kuhaili et al. reported the growth of polycrystalline $\mathrm{MoO}_{3}$ films on unheated substrates using both $\mathrm{XeF}$ and $\mathrm{KrF}$ excimer lasers. By tuning the annealing temperature in the range of 300 to $500{ }^{\circ} \mathrm{C}$, both the grain size and surface roughness increased. Films formed using the $\mathrm{XeF}$ laser $(\lambda=351 \mathrm{~nm})$ and annealed at $400{ }^{\circ} \mathrm{C}$ have the best stoichiometry of $\mathrm{MoO}_{2.95}$ [155]. Analyzing the growth mechanism, Ramana and Julien concluded that the thermochemical reaction during ablation strongly influences the structural characteristics of PLD $\mathrm{MoO}_{3}$ films. Above $T_{\mathrm{s}}=400{ }^{\circ} \mathrm{C}$, the formation of compositional defects induces structural disorder, i.e., $\alpha-\beta-\mathrm{MoO}_{3-\delta}$ phase mixture $[165,173]$.

The applicability of $\mathrm{MoO}_{3}$ films as cathode component in $\mathrm{Li} / / \mathrm{MoO}_{3}$ microbatteries was demonstrated by the best electrochemical features. Early works have been reviewed by Julien et al. [174,175]. Assuming fully dense $\mathrm{MoO}_{3}$ films, a theoretical specific capacity $\sim 130 \mu \mathrm{Ah}$ $\mathrm{cm}^{-2} \mu \mathrm{m}^{-1}$ is expected compared with $69 \mu \mathrm{Ah} \mathrm{cm}^{-2} \mu \mathrm{m}^{-1}$ for $\mathrm{LiCoO}_{2}$. In 1989, Ohtsuka and Yamaki [176] prepared a Li/solid-state electrolyte/ $\mathrm{MoO}_{3-\delta}$ microbattery by thin film technology, in which the $\mathrm{MoO}_{3-\delta}$ cathode film thickness was $1.0 \mu \mathrm{m}$. The $\mathrm{Li}_{2} \mathrm{O}-\mathrm{V}_{2} \mathrm{O}_{5}-\mathrm{SiO}_{2}$ thin film electrolyte exhibits a conductivity of $1 \times 10^{-4} \mathrm{~S} \mathrm{~cm}^{-1}$ at $25^{\circ} \mathrm{C}$. The $\mathrm{Li} / / \mathrm{MoO}_{3-\delta}$ cell was cycled over 240 times with a capacity of $60 \mu \mathrm{Ah} \mathrm{cm}^{-2}$. In 1994, Julien et al. investigated the influence of the conditions of preparation of $\mathrm{MoO}_{3}$ thin on their ability to intercalate $\mathrm{Li}^{+}$ions have been evaluated [177]. Microbatteries fabricated with cathode films formed at moderate temperature $\left(T_{\mathrm{s}} \leq 250{ }^{\circ} \mathrm{C}\right)$ exhibit a monotonous discharge profile but show a strong dependence of the average voltage $v s$. deposition temperature. For $T_{\mathrm{s}}=250{ }^{\circ} \mathrm{C}$, the average potential is 2.9 $\mathrm{V}$ and the Li uptake is close to $3 \mathrm{Li} / \mathrm{Mo}$. The variation of the cell voltage is generally attributed 
to (i) the presence of large crystallites surrounded by amorphous grain boundaries, (ii) the presence of a mixed $\alpha$ - $\beta$-phase which may tune the standard potential, and/or (iii) high concentration of oxygen defects in the host structure involving a lower Fermi level in $\mathrm{MoO}_{3}$ film. An in-depth study of polycrystalline thin films for cathode applications was reported [178]. It was found that the kinetically accessible discharge range was $0 \leq x \leq 1.5$ in $\mathrm{Li}_{x} \mathrm{MoO}_{3}$ and that the operating potential for the disordered phases was higher than that of the crystal. The OCVs ranged from $3.2-2.5 \mathrm{~V}$ and the cells were discharged to $1.5 \mathrm{~V} \mathrm{vs.} \mathrm{Li}^{+} / \mathrm{Li}$. The chemical diffusion coefficient $D_{L i}^{*}$ of the crystalline film ranged from $10^{-11}-10^{-12} \mathrm{~cm}^{2} \mathrm{~s}^{-1}$ for disordered polycrystalline films with a thermodynamic factor that was approximately two orders of magnitude higher than in $\mathrm{MoO}_{3}$ crystals. Electrochemical properties of $\mathrm{MoO}_{3}$ film grown by thermal and flash evaporation have been investigated in cell of $100 \mu \mathrm{Ah}$ capacity [179]. Thermodynamic data show that microbatteries fabricated with films formed at moderate temperature exhibit a monotonous discharge voltage indicating that the $\mathrm{Li}_{\mathrm{x}} \mathrm{MoO}_{3}$ material remains in the single phase even for large degree of intercalation, $x$. The lithium diffusivity increases with the temperature $T_{\mathrm{s}}$ of preparation of the film and reaches the value of $10^{-11} \mathrm{~cm}^{2}$ $\mathrm{s}^{-1}$ in $\mathrm{Li}_{x} \mathrm{MoO}_{3}$ for $T_{\mathrm{s}}=250{ }^{\circ} \mathrm{C}$. $\mathrm{MoO}_{\mathrm{y}}$ films have been deposited on Ni substrate by rf-sputtering using different flow rate of $\mathrm{O}_{2} / \mathrm{Ar}$ mixture $(1.5 \leq \Phi \leq 8.0 \mathrm{sccm})$ as sputter gas [180]. Their electrochemical properties appear to be dependent of the oxygen flow rates and the nature of the substrate. At a flow rate of $8.0 \mathrm{sccm}$, the $\mathrm{Li} / / \mathrm{MoO}_{\mathrm{y}}$ microcell delivers a discharge capacity of $450 \mu \mathrm{Ah} \mathrm{cm}^{-2}$ at $5 \mu \mathrm{A} \mathrm{cm}^{-2}$ current density. $\widetilde{D}_{L i}$ increases at least by two orders of magnitude in films grown at high oxygen partial pressure. A value $D_{L i}^{*}=2 \times 10^{-12} \mathrm{~cm}^{2} \mathrm{~s}^{-1}$ is obtained for $\Phi$ $=8 \mathrm{sccm}$. In 2000, Ferreira et al. [181] prepared $\mathrm{MoO}_{\mathrm{y}}$ thin films deposited by r.f. reactive sputtering of metallic Mo target in an $\mathrm{Ar} / \mathrm{O}_{2}$ atmosphere. The films with different compositions and crystal structures were obtained by varying the oxygen flow $0.5 \leq \Phi \leq 4.0$. Combined XRD and XPS analyses show that, with the increase of $\Phi$, the microstructures were obtained as: amorphous $\rightarrow\left(\mathrm{MoO}_{2.8}+\alpha-\mathrm{MoO}_{3}\right) \rightarrow \beta-\mathrm{MoO}_{3} \rightarrow\left(\mathrm{MoO}_{2.8}+\beta-\mathrm{MoO}_{3}\right)$. The film formed with the $\beta-\mathrm{MoO}_{3}$ phase exhibits the best lithium insertion and electrochromism properties.

In 2001, Ohtsuka and Sakurai [144] fabricated an all-solid-state lithium microbattery with thicker cathode layer $(4.66 \mu \mathrm{m})$ to increase the cell capacity per unit area. The thin film battery architecture deposited on stainless-steel substrate is composed of a thick $\mathrm{MoO}_{3-\delta}$ cathode film, $\mathrm{Li}$ film anode and $\mathrm{Li}_{2} \mathrm{O}-\mathrm{V}_{2} \mathrm{O}_{5}-\mathrm{SiO}_{2}$ thin film electrolyte. The cathode films $\left(0.49 \mathrm{~cm}^{2}\right.$ area $)$ with composition $\mathrm{Mo}_{9} \mathrm{O}_{26}$ were grown at $100{ }^{\circ} \mathrm{C}$ by magnetron sputtering at rf-power of $200 \mathrm{~W}$ using a sintering-powdered $\mathrm{MoO}_{3}$ target in $\mathrm{Ar}$ at pressure of $\mathrm{Pa}$. The discharge curves are $\mathrm{S}$ shaped with an average potential of $2.3 \mathrm{~V}$. At discharge current density of $10 \mathrm{~mA} \mathrm{~cm}$, the 
battery has discharge capacity of $290 \mathrm{mAh} \mathrm{cm}^{-2}\left(56.4 \mu \mathrm{Ah} \mathrm{cm}^{-2} \mu \mathrm{m}^{-1}\right)$ at the $40^{\text {th }}$ cycle. Assuming a film of composition $\mathrm{Mo}_{9} \mathrm{O}_{26}$ (determined by XRD) with density $4.7 \mathrm{~g} \mathrm{~cm}^{-3}$, the first discharge capacity is equivalent to $182 \mathrm{mAh} \mathrm{g}^{-1}$.

In 2006, Ramana et al. reported a specific discharge capacity of $90 \mu \mathrm{Ah} \mathrm{cm}^{-2} \mu \mathrm{m}^{-1}$ for a PLD $\alpha-\mathrm{MoO}_{3}$ film deposited at $T_{\mathrm{s}}=400{ }^{\circ} \mathrm{C}$, while only $53 \mu \mathrm{Ah} \cdot \mathrm{cm}^{-2} \mu \mathrm{m}^{-1}$ was delivered for $T_{\mathrm{s}}=200^{\circ} \mathrm{C}$ [157]. The superiority of $\mathrm{MoO}_{3}$ cathode material that can be extend the upper limit of rechargeable lithium microbatteries was demonstrated in experiments on lithium thin-film cells fabricated on glass slides [182]. Each cell included a layer of $\mathrm{Ti}$ (for adhesion to the glass slide), a patterned layer of Pt that served as a cathode current collector, a cathode layer of $\mathrm{MoO}_{3}$, a solid electrolyte layer of $\mathrm{Li}_{3.3} \mathrm{PO}_{3.8} \mathrm{~N}_{0.22}(\mathrm{LiPON})$, and an anode layer of $\mathrm{Li}$. All the layers were deposited by magnetron sputtering except for the Li layer, which was deposited by thermal evaporation. After 5500 cycles of charge/discharge at a current density of $0.7 \mathrm{~mA} \mathrm{~cm}^{-2}$ the cell operating at temperature $150{ }^{\circ} \mathrm{C}$ delivered specific capacity of $140 \mu \mathrm{Ah} \mathrm{cm}^{-2} \mu \mathrm{m}^{-1}$, while the cell containing $\mathrm{LiCoO}_{2}$ failed. $\mathrm{MoO}_{3}$ thin films were prepared by sol-gel process from molybdenum acetylacetonate sol [183]. The films were formed onto silica substrates by spincoating with subsequent heat treatment at $508{ }^{\circ} \mathrm{C}$ for $2 \mathrm{~h}$. SEM images show grains shaping from oval to rod are distributed on the substrates in random orientation. It seems that the size and morphology of micrograins in $\mathrm{MoO}_{3}$ films depend on the heat treatment temperature, ambient and type of substrates. Comini et al. [184] have obtained needle-like nanoparticles by rf-sputtering technique and continuous planar films with sol-gel method on alumina substrates. $\mathrm{Yu}$ and coworkers reported that a porous $\mathrm{MoO}_{3}$ film prepared by a hydrothermal route and subsequent calcinations in air, delivers a high capacity of $750 \mathrm{mAh} \mathrm{g}^{-1}$ at $1 \mathrm{C}$ rate, and exhibits long cycle life of 120 cycles with $80 \%$ capacity retention as the anode of LIB [140].

Recently, Moitzheim et al. [185] reviewed the progress toward solid-state 3D thin-film Liion microbatteries and discussed the status of the individual components: thin-film cathodes, anodes, and thin-film solid electrolyte. Julien et al. investigated the electrochemical performance of molybdenum-suboxide thin films as anode layers in planar lithium microbatteries [72]. Puppala et al. investigated the microstructure and morphology of PLD $\mathrm{MoO}_{3-\mathrm{x}}$ thin films' growth for catalytic applications using a femtosecond laser (f-PLD) and a nanosecond excimer-laser (n-PLD). Substantially textured films with a partially crystalline phase prior to annealing were obtained by the f-PDL laser, while the n-PLD-grown $\mathrm{MoO}_{3-\mathrm{x}}$ films were predominantly amorphous with a smooth surface [186]. Sunu et al. claimed that asdeposited PLD films $\left(T_{\mathrm{s}}=400{ }^{\circ} \mathrm{C}, \Phi=4-5 \mathrm{~J} \cdot \mathrm{cm}^{-2}\right.$, repetition rate of 15 to $20 \mathrm{~Hz}$, and $p\left(\mathrm{O}_{2}\right)=$ $500 \mathrm{~Pa})$ are suboxide-like, i.e., mixture of $\eta--\mathrm{Mo}_{4} \mathrm{O}_{11}$ and $\chi-\mathrm{Mo}_{4} \mathrm{O}_{11}$, which transformed to 
$\mathrm{MoO}_{3}$ after annealing at $500{ }^{\circ} \mathrm{C}$ in air for $5 \mathrm{~h}$ [18]. Several works reported the PLD growth of films $\left(\mathrm{MoO}_{3}\right)_{1-\mathrm{x}}\left(\mathrm{V}_{2} \mathrm{O}_{5}\right)_{\mathrm{x}}$ with $0.0 \leq x \leq 0.3$ prepared at room temperature under an oxygen pressure of 13.3 $\mathrm{Pa}$. The effect of the $\mathrm{V}_{2} \mathrm{O}_{5}$ content on the coloring switching properties for thermochromic, gasochromic, photochromic, and electrochromic applications was investigated $[187,188]$. Contrary to pure $\mathrm{MoO}_{3}$, the electrochromism of $\mathrm{MoO}_{3}-\mathrm{V}_{2} \mathrm{O}_{5}$ films showed that the Mo oxidation state (+6) did not change considerably upon $\mathrm{Li}^{+}$insertion, while $\mathrm{V}^{5+}$ was reduced considerably to $\mathrm{V}^{4+}$ [187]. A similar improvement of the gas-sensing properties, i.e., the shortest response time and highest transmittance change, was observed for $\mathrm{V}_{2} \mathrm{O}_{5}$-doped $\mathrm{MoO}_{3}$ films under an $\mathrm{H}_{2}$ atmosphere [188]. Figure 6 presents the structural and electrochemical properties of $\mathrm{MoO}_{3}$ thin films deposited on Si wafer using PLD technique. The average grain size was estimated to be $50 \mathrm{~nm}$. The $\alpha-\mathrm{MoO}_{3}$ thin films deposited at $T_{\mathrm{s}}=400{ }^{\circ} \mathrm{C}(500 \mathrm{~nm}$ thick $)$ delivers a volumetric capacity of $90 \mu \mathrm{Ah} \mathrm{cm}^{-2} \mu \mathrm{m}^{-1}$.
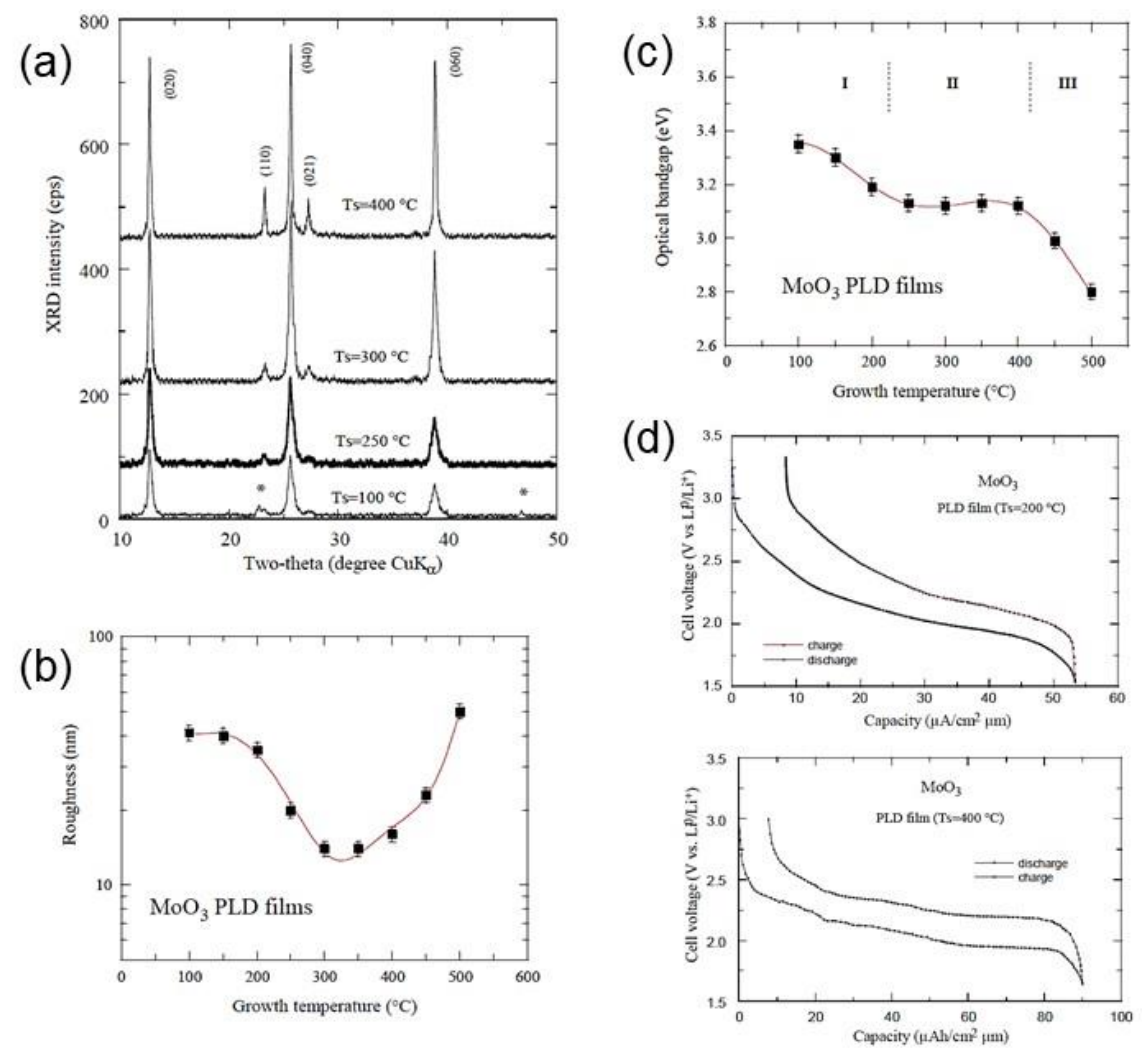

Fig. 6. Structural and electrochemical properties of $\alpha-\mathrm{MoO}_{3}$ thin films deposited on $\mathrm{Si}$ wafer using PLD technique. (a) XRD patterns for different deposition temperature. Asterisks show the peaks due to the $\beta-\mathrm{MoO}_{3}$ phase for film deposited at $T_{\mathrm{s}}=100{ }^{\circ} \mathrm{C}$. (b) Dependence of the growth temperature on the surface roughness determined by atomic force microscopy; (c) Influence of the growth temperature on the optical band gap. (d) The discharge-charge profiles 
of $\mathrm{Li} / / \mathrm{MoO}_{3}$ microcells cycled at a current density $10 \mu \mathrm{A} \mathrm{cm} \mathrm{cm}^{-2}$. A volumetric capacity of 90 $\mu \mathrm{Ah} \mathrm{cm} \mathrm{cm}^{-1}$ is obtained for film deposited at $T_{\mathrm{s}}=400{ }^{\circ} \mathrm{C}$.

\subsubsection{Electronic properties}

The chemistry of molybdenum is dominated by the consequences of the considerable extension of its $d$-orbitals and the position of the $d$-electrons redox potential relative to the anion valence band edge. Even prepared at elevated temperatures under atmospheric oxygen pressure, molybdenum trioxide always contains some oxygen defects $\left(\mathrm{MoO}_{3-\delta}\right)$. Deb estimated the oxygen vacancy concentration to be $3 \times 10^{-19} \mathrm{~mol}^{-1}$, resulting in a formal stoichiometry of $(3-\delta)=2.999$ [189]. $\mathrm{MoO}_{3}$ is an n-type semiconductor with indirect bandgap that has reported between 2.9 and $3.3 \mathrm{eV} . \alpha-\mathrm{MoO}_{3}$ is found to be indirect insulator with the conduction band minimums (CBM) located at $\Gamma$ point and the valence band maximum (VBM) at $R$ point [190]. The introduction of oxygen vacancies in $\mathrm{MoO}_{3}$ gives rise to electrical conductivity. The valence band is generated by oxygen $2 \mathrm{p}_{\pi}$ orbitals, while the conduction band is formed by overlapping metal $4 \mathrm{~d}$ and $5 \mathrm{~s}$ bands. Structural characterization of oxygen defects in $\mathrm{MoO}_{3-\delta}$ by Raman spectroscopy and X-ray diffraction has been reported by Dieterle et al. [78].

\subsubsection{Intercalation properties of $\mathrm{MoO}_{3}$}

The layered crystalline $\alpha-\mathrm{MoO}_{3}$ is an attractive material for charge storage because of its ability to intercalate ions in a wide range of composition [108,191,192]. Both faradaic and nonfaradaic mechanisms can store charge. The latter is the dominant factor in electric double-layer capacitors, in which charge is stored electrostatically from the reversible adsorption of ions onto high-surface-area materials. The other option is to store charge in a faradaic process, which again can take place on a surface, as in pseudocapacitors [193,194], or in the bulk of the material, as in conventional batteries [195]. Due to their reversibility, fairly attractive energy densities, conductivities, and Li diffusion coefficients, and a good availability, $\mathrm{MoO}_{\mathrm{y}}$ materials are probably the most promising candidates for anodes in non-aqueous batteries among all second and third row transition metal oxides. A scheme of the modification of the structure of the layered lattice of $\alpha-\mathrm{MoO}_{3}$ phase due to the intercalation of foreign ions $\left(\mathrm{Li}^{+}, \mathrm{Na}^{+}, \mathrm{K}^{+}\right.$, etc) or molecules (polypyrrole) is shown in Fig. 7. 

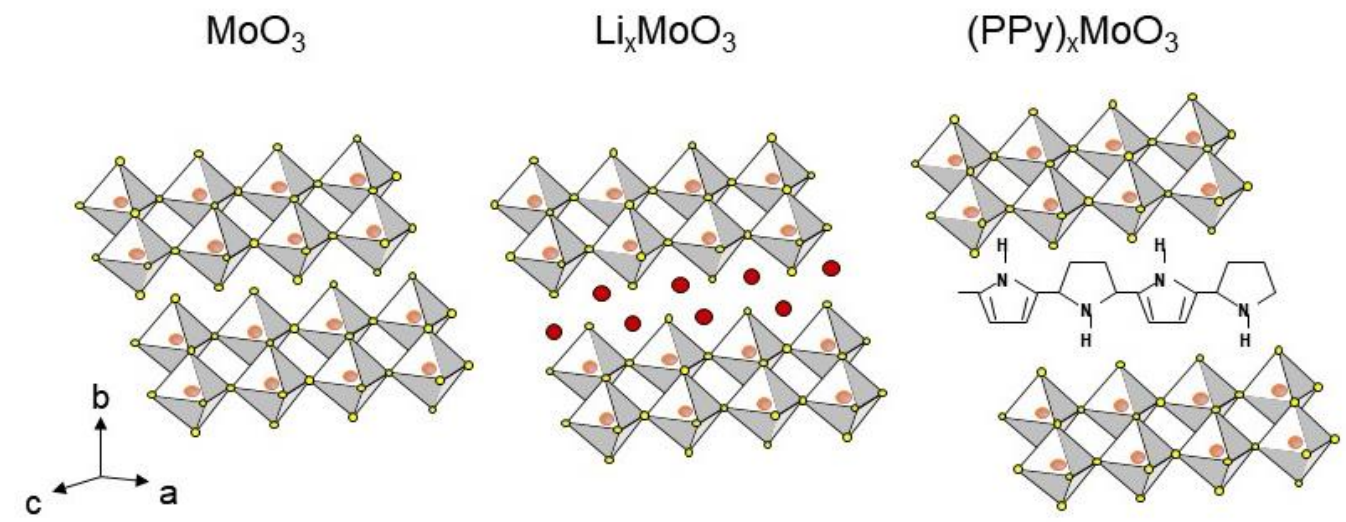

Fig. 7. Scheme of the modification of the structure of the layered lattice of $\alpha-\mathrm{MoO}_{3}$ phase due to the intercalation of foreign atoms or molecules.

\subsubsection{Chemical lithiation}

Orthorhombic $\alpha-\mathrm{MoO}_{3}$ powders synthesized by thermal decomposition of molybdic acid containing ammonium ions, $\left(\mathrm{H}_{2} \mathrm{O}\right)_{\mathrm{y}}\left(\mathrm{NH}_{4}\right)_{\mathrm{z}} \mathrm{MoO}_{3}$, in air at $600{ }^{\circ} \mathrm{C}$ for $6 \mathrm{~h}$ were lithiated by Hashem et al. [196]. $\mathrm{Li}_{x} \mathrm{MoO}_{3}$ were prepared by reaction of various amounts of water-free lithium iodide (the molar ratios of $\mathrm{Li} / \mathrm{Mo} 0.1 \leq x \leq 1.0$ in organic solution; dispersions of LiI and $\mathrm{MoO}_{3}$ powders were stirred for $24 \mathrm{~h}$ in dry n-hexane; the n-hexane was renewed two times during this period to remove the liberated iodine. The filtered powder was washed with excess of $\mathrm{n}$-hexane until the filtrate was clear from iodine. The filtered powder was heated at $250{ }^{\circ} \mathrm{C}$ under vacuum for $8 \mathrm{~h}$. The major amount of iodine evolved during this reaction step due to the reaction of LiI with $\mathrm{MoO}_{3}$ and the subsequent liberation of $\mathrm{I}_{2}$. Structural studies show that a two-phase reaction occurs during chemical lithium insertion into $\alpha-\mathrm{MoO}_{3}$. The XRD peaks related to the orthorhombic $\mathrm{MoO}_{3}$ phase disappeared gradually until the formation of completely lithiated phase at $x>0.25$ in $\mathrm{Li}_{x} \mathrm{MoO}_{3}$, for which a new peak assigned to $(010)$ refection appeared at about $2 \theta=11.4^{\circ}$. Mai et al. [197,198] reported the electroactivity of $\alpha-\mathrm{MoO}_{3}$ nanobelts after lithiation that show superior performance to non-lithiated $\alpha-\mathrm{MoO}_{3}$ nanobelts. The lithiated phase (light-blue color) was obtained by reaction of $\mathrm{MoO}_{3}$ with $\mathrm{LiCl}$ in aqueous solution for 2 days followed by a hydrothermal process at $180{ }^{\circ} \mathrm{C}$ for $24 \mathrm{~h}$. For the non-lithiated $\mathrm{MoO}_{3}$, the discharge capacity decreased from 301 to $180 \mathrm{mAh} \mathrm{g}^{-1}$ after 15 cycles, corresponding to a capacity retention of $60 \%$, whereas the discharge capacity of lithiated $\mathrm{MoO}_{3}$ decreased from 240 to $220 \mathrm{mAh} \mathrm{g}^{-1}$ after15 cycles, corresponding to a capacity retention of $92 \%$, showing the stability and drastic improvement in the charge-storage capacity of the lithiated $\mathrm{MoO}_{3}$ nanobelts. Villevieille et al. conducted similar studies on $\mathrm{MoO}_{3}$ nanobelts 
synthetized by hydrothermal route and chemically lithiated using a $\mathrm{LiCl}$ solution. The obtained nominal $\mathrm{LiMoO}_{3}$, shows enhanced electrochemical performance (>150 $\mathrm{mAh} \mathrm{g}^{-1}$ for a loading of $4 \mathrm{mg} \mathrm{cm}^{-2}$ at $3 \mathrm{C}$ rate) and can be considered as a novel cathode with high specific charge (Figs. 8a-b) [199]. High resolution in situ XRD analysis reveals almost no damage to the nanobelt electrode after 50 cycles (Fig. 8c).

(a)

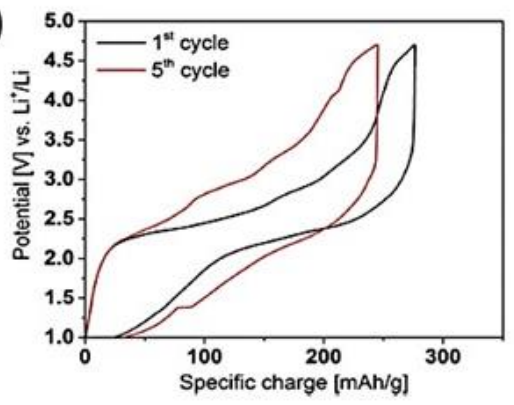

(b)

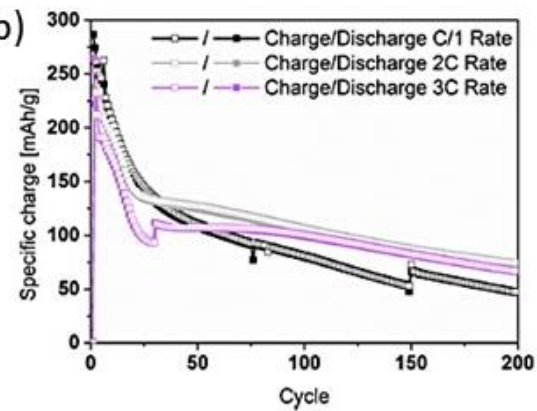

(c)

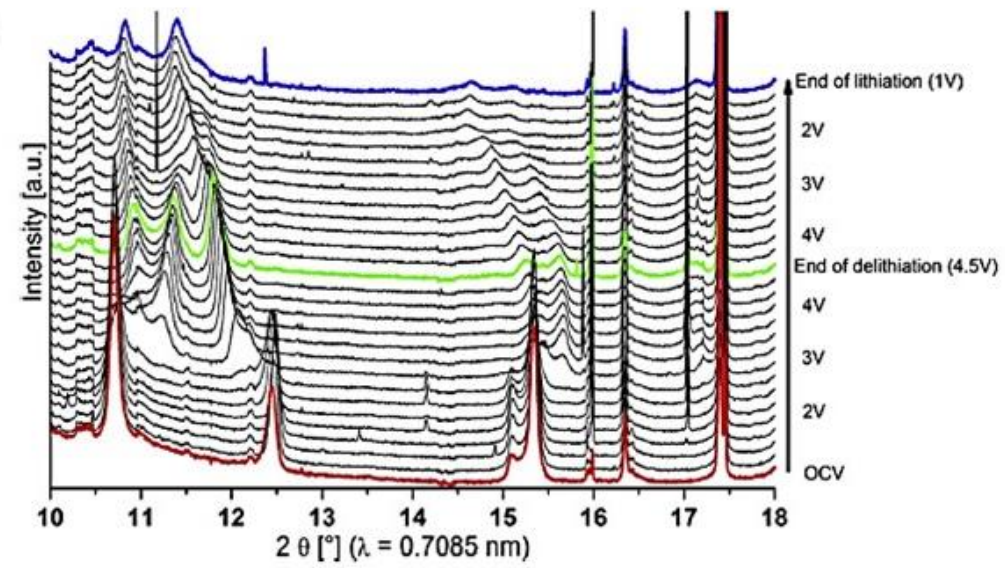

Fig. 8. (a) Galvanostatic curves of $\mathrm{LiMoO}_{3}$ nanobelts prepared using $1 \mathrm{~mol}$ of $\mathrm{LiCl}$ per $\mathrm{MoO}_{3}$ cycled at $\mathrm{C} / 10$ rate. (b) Cyclability at different $\mathrm{C}$ rate. (c) In situ XRD synchrotron pattern collected during the first cycle. In red the starting material before cycling, in green the end of the delithiation process, in blue the end of the lithiation process. Due to the small shift the changes in lattice parameter are less than 1\%. Reproduced with permission from [199]. Copyright 2015 Elsevier.

\subsubsection{Electrochemical lithiation}

In principle, many works have demonstrated the suitability of $\mathrm{Li}^{+}$ions to intercalate/deintercalate the interlayer spacing (van der Waals gap) of the $\alpha-\mathrm{MoO}_{3}$ host structure by redox reaction with the accommodation up to $1.5 \mathrm{Li}$ atom per Mo [11,64,135,196,200-203]. In the cut-off potential 3.5-1.5 V vs. $\mathrm{Li}^{+} / \mathrm{Li}$, the overall reversible intercalation/deintercalation reaction is: 


$$
x \mathrm{Li}^{+}+x \mathrm{e}^{-}+\left[\mathrm{Mo}^{\mathrm{VI}}\right] \mathrm{O}_{3} \leftrightarrow \mathrm{Li}_{\mathrm{x}}{ }^{+}\left[\mathrm{Mo}^{(6-\mathrm{x})+}\right] \mathrm{O}_{3},
$$

assuming the reduction the transition-metal cations from $\mathrm{Mo}(\mathrm{VI})$ to $\mathrm{Mo}(\mathrm{V})$ and $\mathrm{Mo}(\mathrm{IV})$ oxidation states. Note that the $\mathrm{Li}^{+}$coupled electron transfer produces intense blue coloration $\left(\mathrm{Li}_{\mathrm{x}}{ }^{+}\left[\mathrm{Mo}^{(6-\mathrm{x})+}\right] \mathrm{O}_{3}\right)$ via strong light absorption of the pristine transparent $\left[\mathrm{Mo}^{\mathrm{VI}}\right] \mathrm{O}_{3}$. Figure 9a shows the cyclic voltammograms of the electrode made of crystalline $\alpha-\mathrm{MoO}_{3}$ powders in the first five cycles at a sweep rate of $0.05 \mathrm{mV} \mathrm{s}^{-1}$. In the first cycle, two sets of cathodic and anodic peaks appear at around the potential of $2.30,2.73 \mathrm{~V}$ and $2.33,2.48 \mathrm{~V}$, which can be assigned to the insertion/extraction of $\mathrm{Li}^{+}$ions between the $\mathrm{MoO}_{6}$ octahedral interlayers and intralayers, respectively [11]. However, the set of peaks at $(2.33,2.75 \mathrm{~V})$ completely disappeared in the second and subsequent cycles, indicating irreversible capacity losses due to the unrecoverable phase transformation. The first galvanostatic discharge charge profiles of a $\mathrm{Li} / / \alpha-\mathrm{MoO}_{3}$ cell and those of subsequent cycles are shown in Figs. 9b-c. During the first cycle at C/10 current rate, the host can accommodate almost 1.6 Li/Mo, which corresponds to a specific capacity $265 \mathrm{mAh}$ $\mathrm{g}^{-1}$. A capacity retention of $152 \mathrm{mAh} \mathrm{g}^{-1}$ is remained after 100 cycles. The discharge capacities of anhydrous $\mathrm{MoO}_{3}$ reported by several workers are in the range from 1.3 to $1.6 \mathrm{Li} / \mathrm{Mo}$ in the potential range above $1.2 \mathrm{~V}$ vs. $\mathrm{Li}^{+} / \mathrm{Li}[113,196,204]$. The capacity of $\mathrm{MoO}_{3}$ observed here is approximately in good agreement with the theoretical gravimetric capacity of $280 \mathrm{mAh} \mathrm{g}^{-1}$. The disappearance of the irreversible peak (at ca. $2.75 \mathrm{~V}$ ) in the CV and the absence of voltage plateau at ca. $2.78 \mathrm{~V}$ in the galvanostatic discharge curve is related to a structural modulation that occurs upon insertion/extraction of $\mathrm{Li}^{+}$ions between the $\mathrm{MoO}_{6}$ octahedral interlayers and intralayers, respectively, and it is responsible for a capacity loss of ca. $20 \mathrm{mAh} \mathrm{g}^{-1}$. This suggests that part of the $\mathrm{Li}^{+}$ions, first introduced during the reduction reaction (discharge), later remain in the lattice. Such an effect has also been observed in $\mathrm{V}_{2} \mathrm{O}_{5}$ [205] The mechanism of Li-ions intercalation into the $\alpha-\mathrm{MoO}_{3}$ has been described as the formation of three phases separated by bi-phase domains that are responsible for voltage plateaus in the first discharge curve $[11,196,206]$. It is believed that the $\mathrm{Li}_{0.25} \mathrm{MoO}_{3}$ phase formed at $2.75 \mathrm{~V} \mathrm{vs} . \mathrm{Li}^{+} / \mathrm{Li}$ is at the origin of the irreversible capacity at the end of the first charge. Thus, for subsequent cycles of discharge-charge, the cathode material shuttles from $\mathrm{Li}_{0.25} \mathrm{MoO}_{3}$ to $\mathrm{Li}_{1.5} \mathrm{MoO}_{3}$ without the appearance of the first plateau. Based on these results, an idealized scheme of the $\mathrm{Li}$ intercalation process into the $\mathrm{MoO}_{3}$ framework is shown in Fig. 10 [135]. 

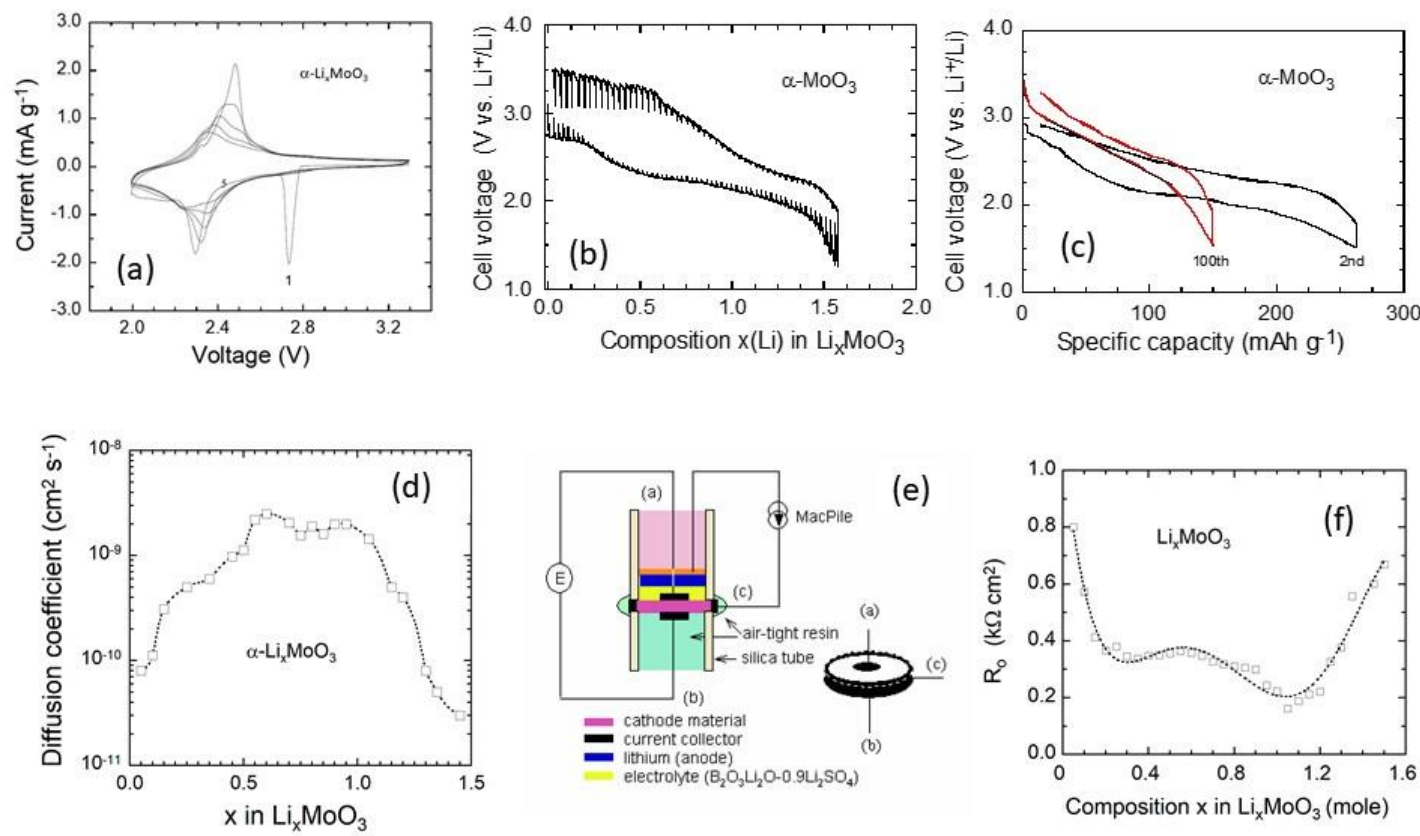

Fig. 9. Electrochemical intercalation of $\mathrm{Li}$ ions in crystalline $\alpha-\mathrm{MoO}_{3}$. (a) Five first cyclic voltammograms of $\mathrm{Li} / / \alpha-\mathrm{MoO}_{3}$ cell cycled at a sweep rate of $0.05 \mathrm{mV} \mathrm{s}^{-1}$ and cut-off potential 2.0-3.3 V vs. $\mathrm{Li}^{+} / \mathrm{Li}$. (b) First galvanostatic discharge-charge profile recorded at $\mathrm{C} / 10$ rate. (c) Electrochemical patterns at the $2^{\text {nd }}$ and $100^{\text {th }}$ cycle. (a) Variation of the chemical diffusion coefficient of $\mathrm{Li}^{+}$ions in the $\alpha-\mathrm{MoO}_{3}$ host network with the degree $x(\mathrm{Li})$ of intercalation. (e) Experimental setup of in situ measurements of the electrical resistance of the $\alpha-\mathrm{MoO}_{3}$ electrode upon Li extraction (charge). (f) Composition dependence of the electrode resistance. $\mathrm{MoO}_{3}$ can be considered such as a good self-limiting over-charge material.

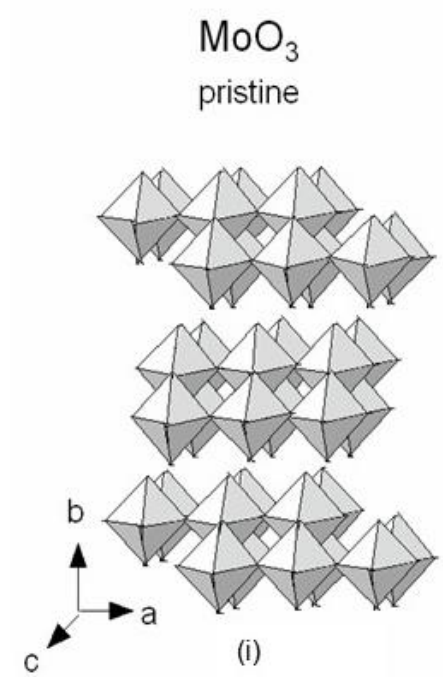

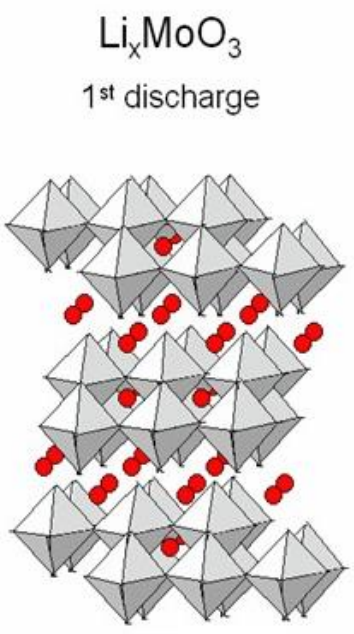

(ii)

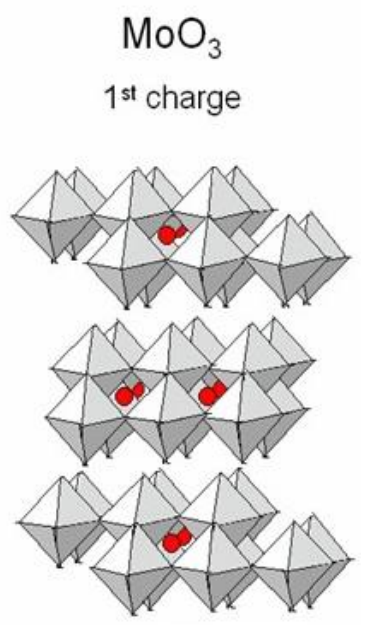

(iii)

Fig. 10. Idealized scheme of the intercalation process in $\mathrm{MoO}_{3}$ framework. At the end of the discharge, the chemical composition is $\mathrm{Li}_{1.5} \mathrm{MoO}_{3}$, while at the end of the charge, it is $\mathrm{Li}_{0.25} \mathrm{MoO}_{3}$. Reproduced with permission from [135]. Copyright 2012 Elsevier. 
The chemical diffusion coefficient, $D_{L i}^{*}$, of $\mathrm{Li}^{+}$ions in the $\alpha-\mathrm{MoO}_{3}$ host lattice depends on the composition $x$ and the morphology of the material. Figure $9 d$ shows the compositional dependence of $D_{L i}^{*}$ determined using the current step method (plot of $\Delta E$ vs $t^{-1 / 2}$ ) given by the relation [207]:

$$
D_{L i}^{*}=\widetilde{D} \frac{R T}{x F} \frac{\Delta x}{\Delta E},
$$

where $\widetilde{D}$ is the self-diffusion coefficient, $R$ and $F$ are the usual constant and $T$ is the absolute temperature. Dickens reported a chemical diffusion coefficient of $3 \times 10^{-9} \mathrm{~cm}^{2} \mathrm{~s}^{-1}$ (self-diffusion of $3 \times 10^{-10} \mathrm{~cm}^{2} \mathrm{~s}^{-1}$ ) for $\mathrm{Li}_{0.3} \mathrm{MoO}_{3}$ [200] A maximum value of ca. $10^{-10} \mathrm{~cm}^{2} \mathrm{~s}^{-1}$ has been reported for $x \approx 0.6$. Li mobility was shown to slightly decrease upon subsequent discharge-charge cycles due to irreversible structural and morphological changes of the host matrix [64]. However, when the cell was recharged, reoxidation of Mo produces a resistive compound, which induces a large polarization of the cell at the end of the charge as shown in Fig. 9a. This effect could be beneficial for application, thus, $\mathrm{MoO}_{3}$ can be considered such as a good self-limiting overcharge material. Upon lithiation of $\mathrm{Li}_{x} \mathrm{MoO}_{3}$, the electronic conductivity increases from $10^{-4} \mathrm{~S}$ $\mathrm{cm}^{-1}$ for $x=0$ to ca. $10^{-1} \mathrm{~S} \mathrm{~cm}^{-1}$ for $0.3 \leq x \leq 0.9$ [64]. In situ measurements of the electrical resistance of the electrode has been reported by Yebka et al. [204]. The results shown in Fig. 9f are in good agreement with the variation of the overpotential at the end of charge. The structural changes occurring in the positive electrode materials during Li electrointercalation were followed by in situ XRD measurements (Fig. 11a) and Raman spectroscopy (Fig. 11b) [204]. Figure 11a presents the XRD diagrams of $\mathrm{Li}_{\mathrm{x}} \mathrm{MoO}_{3}$ during the discharge process $(0.0 \leq$ $x \leq 1.5$ ). These patterns indicate the formation of a two-phase system in the range $0.0 \leq x \leq 0.25$ followed by a single phase $\mathrm{Li}_{x} \mathrm{MoO}_{3}$ for which the framework structure is almost unchanged during discharge reaction up to $1.5 \mathrm{Li} / \mathrm{Mo}$. However, one can observe the vanishing of Bragg peak at ca. $2 \theta=52^{\circ}$ for $x>0.5 \mathrm{Li} / \mathrm{Mo}$. This indicates a continuous structure reorganization corresponding to complete reversibility of the insertion/de-insertion process for the $\mathrm{Li}_{\mathrm{x}} \mathrm{MoO}_{3}$ material in the potential range 3.5-1.2 V. The orthorhombic lattice parameters of $\mathrm{Li}_{0.5} \mathrm{MoO}_{3}$ chemically intercalated by n-butyllithium have been reported by Dickens and Reynolds [200] as $a=3.64 \AA, b=16.7 \AA, c=3.77 \AA$, which result in a slight contraction along the $a$ - and $c$ direction and an expansion of the $b$-axis of $20 \%$ due to the filling of the interlayer spacing. Such a structural evolution has been reported by Tsumura et al. [11] as shown in Fig. 11c. The initial formation of the lithiated phase results in expansion of the interlayer spacing from 0.69 to 1.175 $\mathrm{nm}$. 
The evolution of the local structure of $\alpha-\mathrm{MoO}_{3}$ cathode materials during the first discharge has been studied by Raman spectroscopy. The electrode was washed with DMC solution to remove $\mathrm{LiPF}_{6}$ salt and left in a glove box for $12 \mathrm{~h}$ to reach equilibrium. Figure $11 \mathrm{~b}$ shows the Raman spectra of $\alpha-\mathrm{Li}_{x} \mathrm{MoO}_{3}$ nanofibers as a function of the concentration of $\mathrm{Li}^{+}-$ ions inserted in the range $0 \leq x \leq 1$. At the first discharge, the Raman spectrum of $\mathrm{MoO}_{3}$ nanofibers shows significant changes. As a general trend, we notice that all the main spectral features observed in $\mathrm{MoO}_{3}$ are present in the spectrum of $\mathrm{Li}_{x} \mathrm{MoO}_{3}$ and the broadening of the bands indicate that the $\mathrm{Li}_{x} \mathrm{MoO}_{3}$ phase is less ordered than the $\alpha-\mathrm{MoO}_{3}$ lattice. On comparing the Raman features of $\mathrm{Li}_{\mathrm{x}} \mathrm{MoO}_{3}$ and $\mathrm{MoO}_{3}$, the following considerations can be established: (i) the intensity of the translational modes at low frequency, i.e., 83 and $113 \mathrm{~cm}^{-1}$, is progressively quenched, (ii) some bands are enhanced, i.e., the $\delta\left(\mathrm{O}_{2}-\mathrm{Mo}-\mathrm{O}_{2}\right)$ scissoring $B_{3 g}$ and $B_{l g}$ modes at 244 and $377 \mathrm{~cm}^{-1}$, respectively, while some others vanish, i.e., the intense $\delta\left(\mathrm{O}_{1}-\mathrm{Mo}_{-}-\mathrm{O}_{1}\right)$ wagging $B_{2 g}$ mode at $282 \mathrm{~cm}^{-1}$ and the $\delta\left(\mathrm{O}_{2}-\mathrm{Mo}_{-} \mathrm{O}_{2}\right)$ scissoring $A_{g}$ mode at $364 \mathrm{~cm}^{-1}$, (iii) the single line, corresponding to the $\mathrm{Mo}=\mathrm{O}$ stretching mode (molybdyl mode) along the $c$-axis broaden and shifted up to $998 \mathrm{~cm}^{-1}$ with respect to $994 \mathrm{~cm}^{-1}$, typically observed for the $\alpha$-phase, and (iv) new spectral features are detected in the spectrum of $\mathrm{Li}_{x} \mathrm{MoO}_{3}$ (bands at 440, 758, 967 and $1013 \mathrm{~cm}^{-1}$ ). At least two factors can account for the distinction between the spectra of these materials. First, the non-equivalent character of the transition metals in the lattice of $\mathrm{Li}_{\mathrm{x}} \mathrm{MoO}_{3}$, meaning three kinds of molybdenum oxidation states from $\mathrm{Mo}^{6+}$ to $\mathrm{Mo}^{4+}$, which implies the modification in the local environment of $\mathrm{MoO}_{6}$ octahedra. Second, the Li atom oscillations may couple with some modes of the $\mathrm{MoO}_{3}$ lattice. These results are consistent with the reported data in the literature, which describe that the lithium insertion process consists in rather moderate local distortions allowing the accommodation of $1.5 \mathrm{Li} / \mathrm{mol}$ of oxide without breaking of the orthorhombic symmetry [11]. The structural modifications in $\mathrm{Li}_{x} \mathrm{MoO}_{3}$ can be also evidenced by the variation of the peak intensities of stretching modes; a decrease of the peak intensity ratio $I_{994} / I_{818}$ with the increase of Li content is shown in Fig. 11d. 

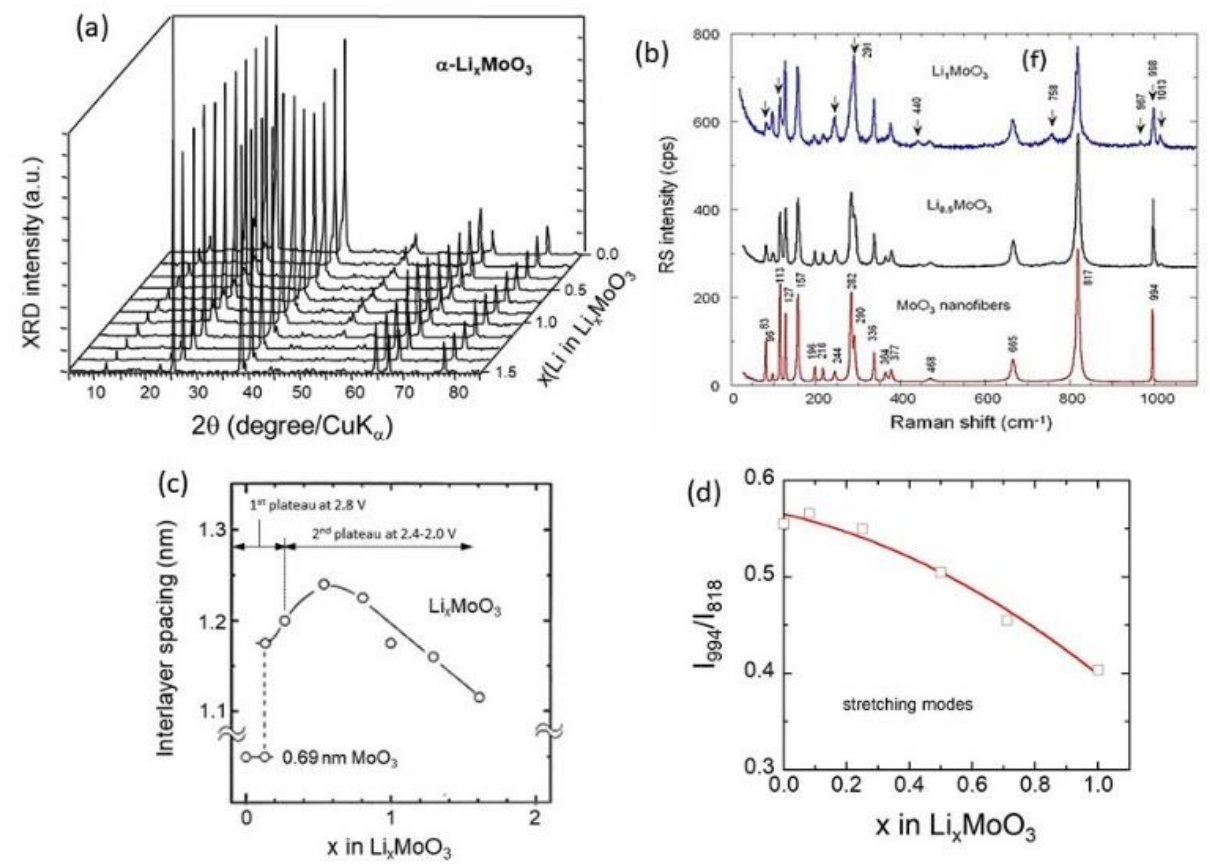

Fig. 11. (a) In-situ XRD patterns taken during the electrochemical lithium intercalation of $\alpha$ $\mathrm{MoO}_{3}$ crystal. Around $2 \theta=55^{\circ}$ the diffraction line vanishes with the increase of $\mathrm{Li}$ concentration in the lattice. (b) Raman spectra of pristine and $\mathrm{Li}_{x} \mathrm{MoO}_{3}(x=0.5$ and 1.0). New vibrational modes are marked by asterisks. (c) Change of interlayer spacing between Mo-O octahedron layers of $\mathrm{Li}_{\mathrm{x}} \mathrm{MoO}_{3}$ with lithium composition. Reproduced with permission from [11]. Copyright 1997 Elsevier. (d) Evolution of the Raman peak intensity ratio $I_{994} / I_{818}$ with $x(\mathrm{Li})$.

The mechanism of a phase transition in electrochemical lithium insertion into $\alpha-\mathrm{MoO}_{3}$ was also investigated by transmission electron microscopy (TEM), X-ray diffraction (XRD) and Xray photoelectron spectroscopy (XPS) [206,208]. The combined XPS, RBS, and NRA analysis of $\mathrm{MoO}_{3}$ thin films electrochemically treated at selected potentials between 1.7 and $3.2 \mathrm{~V}$ vs. $\mathrm{Li}^{+} / \mathrm{Li}$ allowed the dosing of intercalated lithium and the determination of the composition of the lithiated phases. $\mathrm{Li}_{0.50} \mathrm{MoO}_{3}, \mathrm{Li}_{1.20} \mathrm{MoO}_{3}$, and $\mathrm{Li}_{0.21} \mathrm{MoO}_{3}$ were obtained after intercalation at 2.58 and $1.73 \mathrm{~V}$ and deintercalation at $3.2 \mathrm{~V}$, respectively, showing that $\sim 1.2 \mathrm{~mol}$ of Li can be initially intercalated in the potential range $1.7-3.2 \mathrm{~V}$ (capacity of $223 \mathrm{mAh} \mathrm{g}^{-1}$ ), and $\sim 0.2$ mol of $\mathrm{Li}$ per mol of $\mathrm{MoO}_{3}$ is trapped in the oxide matrix after the initial stages of intercalation. The $\mathrm{Li} 1 \mathrm{~s}$ core level (at $E_{\mathrm{B}}=55.80 \mathrm{eV}$ ) is most intense at $1.73 \mathrm{~V}$ and does not vanish at $3.2 \mathrm{~V}$. Changes of the electronic structure after intercalation result from the occupation of the Mo $4 \mathrm{~d}$ states (at $E_{\mathrm{B}}=1.0 \mathrm{eV}$ ) originally empty in the pristine oxide [166]. 
Recently, Guo et al. [209] investigated the electrochemical insertion of proton in $\alpha-\mathrm{MoO}_{3}$ in acidic electrolyte (i.e., the $4.4 \mathrm{~mol} \mathrm{~L}^{-1} \mathrm{H}_{2} \mathrm{SO}_{4}$ commonly used in lead-acid batteries). Figure 12 presents the electrochemical patterns and operando structure changes of initial proton deintercalation in molybdenum bronzes $\mathrm{H}_{x} \mathrm{MoO}_{3}(0 \leq x \leq 1.68)$. Zhang et al. [210] reported how selective $\mathrm{H}_{3} \mathrm{O}^{+}$intercalation in a neutral $\mathrm{ZnCl}_{2}$ electrolyte can be achieved for water-proton co-intercalated $\alpha-\mathrm{MoO}_{3} \cdot \mathrm{H}_{2} \mathrm{O}$ molecules located between $\mathrm{MoO}_{3}$ interlayers block $\mathrm{Zn}^{2+}$ intercalation pathways while allowing smooth $\mathrm{H}_{3} \mathrm{O}^{+}$intercalation/diffusion through a Grotthuss proton-conduction mechanism. Thus, the water-proton insertion provides enhanced specific capacity of $356 \mathrm{mAh} \mathrm{g}^{-1}$, a rate capability of $77.5 \%$ at $4 \mathrm{~A} \mathrm{~g}^{-1}$ and a cycling stability of $83 \%$ over 1000 cycles.
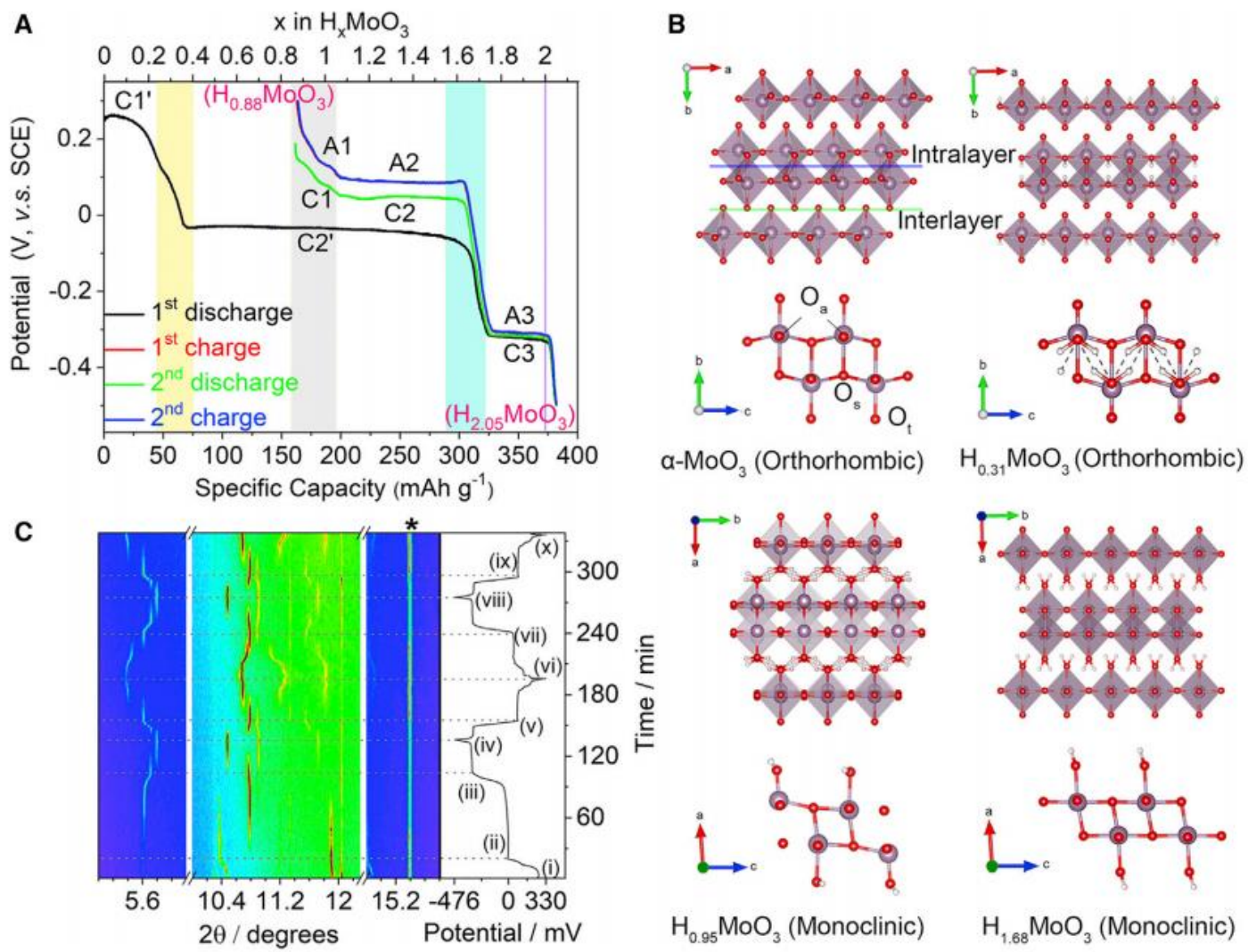

Figure 12. Electrochemistry and operando structure changes of initial proton intercalation (A) The initial galvanostatic charge-discharge profiles of $\mathrm{MoO}_{3}$ at $1 \mathrm{~A} \mathrm{~g}^{-1}$. Typical redox processes are labeled as C (cathodic)/A (anodic) $n$, where $n$ is the redox index. Note the initial cathodic processes are unique and labeled as $\mathrm{C} 1$ '/C2'. (B) Structure diagrams of $\alpha-\mathrm{MoO}_{3}$ and the hydrogen molybdenum bronzes (HMBs) with different hydrogen amounts. The purple, red, and white spheres refer to $\mathrm{Mo}, \mathrm{O}$, and $\mathrm{H}$ atoms, respectively. Note that these structures were defined by different authors; therefore, the coordinates are different. (C) The contour plot of operando 
diffraction data of cell (in $4.4 \mathrm{~mol} \mathrm{~L}^{-1} \mathrm{H}_{2} \mathrm{SO}_{4}$ electrolyte, galvanostatically tested at $1 \mathrm{C}$ ), correlated with the electrode potential as a function of time. Copyright Guo et al. [209]. Open access article under the CC BY-NC-ND license.

Several approaches have been conducted to improve the electrochemical performance of $\mathrm{MoO}_{3}$ electrodes (i.e., capacity retention, long life cycling) including nanocrystallization [130,211-213] core-shell composite [214], carbon-based hybrid [215-217], carbon encapsulation [218], MWCNT-based hybrid [219-221], incorporation into graphene network [222-224], $\mathrm{MoO}_{2}$ intergrowth [225,226], dual-ion intercalation [210,227], and coating [228230]. Nanobelts of $\alpha-\mathrm{MoO}_{3}$ have been modified to $\mathrm{H}_{x} \mathrm{Mo}(\mathrm{O}, \mathrm{N})_{3}$ through a moderate ammonolysis method, i.e., reaction at $200-300{ }^{\circ} \mathrm{C}$ with gaseous $\mathrm{NH}_{3}$, which diffuses inbetween the $\mathrm{MoO}_{3}$ layers and reacts with terminal oxygen sites. As a consequence, hydrogen is bonded to terminal oxygen, and the unit cell volume significantly shrinks mostly along the $b$-axis. The modified $\mathrm{H}_{\mathrm{x}} \mathrm{Mo}(\mathrm{O}, \mathrm{N})_{3}$ electrode exhibits a specific capacity of $\sim 250 \mathrm{mAh} \mathrm{g}^{-1}$ and shows no capacity fading over 300 cycles in the potential window 1.5-3.5 V [227].

\subsection{8. $\mathrm{MoO}_{3}$ anodes for $\mathrm{LIBS}$}

Molybdenum trioxide, which can be also categorized as one of the conversion type transition metal oxides, has additional advantageous features of low cost and environmental benignity as well as even higher capacity. However, $\mathrm{MoO}_{3}$ suffers from serious capacity fading caused by large volume changes and poor rate capability due to low conductivity. Recently, these drawbacks have been mitigated by different strategies, i.e., reduction of particle size to nanoscale and fabrication of composites.

\subsubsection{1. $\mathrm{MoO}_{3}$ nanoparticles}

The $\mathrm{MoO}_{3}$ nanoparticles have been demonstrated as high-capacity Li-ion battery anodes for next-generation electric vehicles [231-235]. Specifically, the $\mathrm{MoO}_{3}$ anodes have been shown to have approximately three times the Li-ion capacity of commercially employed graphite anodes in thick electrodes suitable for vehicular applications [128,193, 232,236-240]. Researches about $\mathrm{MoO}_{3}$ as an anode in the potential range down to $0 \mathrm{~V}$ (vs. $\mathrm{Li}^{+} / \mathrm{Li}$ ) have shown that $\mathrm{MoO}_{3}$ can theoretically accommodate $6 \mathrm{Li} / \mathrm{Mo}$ providing a specific capacity of $1117 \mathrm{mAh}$ $\mathrm{g}^{-1}$. The overall first lithiation reaction for $\mathrm{MoO}_{3}$ is described by two reactions: the lithium insertion (addition) at potential $>1.5 \mathrm{~V}$ up to $x \approx 1.2$ (Eq. 5) and the conversion (transformation) reaction at potential $<0.5 \mathrm{~V}$ up to $x \approx 6.0$ (Eq. 6 ) as follows: 


$$
\begin{aligned}
& \mathrm{MoO}_{3}+x \mathrm{Li}^{+}+x \mathrm{e}^{-} \rightarrow \mathrm{Li}_{x} \mathrm{MoO}_{3}, \\
& \mathrm{Li}_{x} \mathrm{MoO}_{3}+(6-x) \mathrm{Li}^{+}+(6-x) \mathrm{e}^{-} \rightarrow \mathrm{Mo}+3 \mathrm{Li}_{2} \mathrm{O} .
\end{aligned}
$$

Note that the amorphization of the material does not alter the overall electrochemical performance of the anode. The conversion reaction yields nanodispersed particles of Mo metal in the $\mathrm{Li}_{2} \mathrm{O}$ matrix [241]. Figure 13 shows the typical first discharge-charge curve of $\mathrm{MoO}_{3}$ nanofibers as anode materials in lithium battery. Nanofibers were synthesized by hydrothermal method from $\mathrm{MoO}_{3} \cdot 1.4 \mathrm{H}_{2} \mathrm{O}$ sols prepared by ion exchange of ammonium heptamolybdate tetrahydrate $\left(\mathrm{NH}_{4}\right)_{6} \mathrm{Mo}_{7} \mathrm{O}_{24} \cdot 4 \mathrm{H}_{2} \mathrm{O}$.

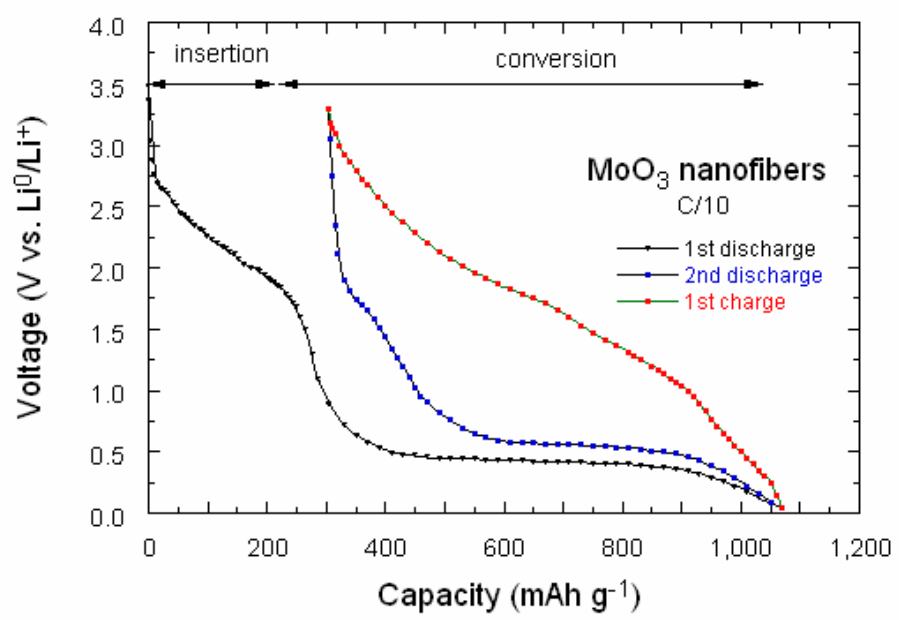

Fig. 13. The typical first discharge-charge curve of $\mathrm{MoO}_{3}$ nanofibers as anode materials in lithium battery. The overall first lithiation reaction for $\mathrm{MoO}_{3}$ is described by two reactions: the lithium insertion (addition) at potential $>1.5 \mathrm{~V}$ up to $x \approx 1.2$ and the conversion (transformation) reaction at potential $<0.5 \mathrm{~V}$ up to $x \approx 6.0$.

Xia et al. [208] investigated the lithiation mechanism in $\alpha-\mathrm{MoO}_{3}$ nanobelts using in situ TEM experiments. Results reveal that $\alpha-\mathrm{MoO}_{3}$ undergoes a two-stage delithiation process. Mo nanograins were first transformed into crystalline $\mathrm{Li}_{1.66} \mathrm{Mo}_{0.66} \mathrm{O}_{2}$ along with the disappearance of $\mathrm{Li}_{2} \mathrm{O}$ and size shrink, followed by the conversion to amorphous $\mathrm{Li}_{2} \mathrm{MoO}_{3}$. The electrochemical reactions of $\alpha-\mathrm{MoO}_{3}$ during lithiation and delithiation processes can be expressed as:

$$
\begin{aligned}
& \mathrm{MoO}_{3}+6 \mathrm{Li}^{+}+6 \mathrm{e}^{-} \rightarrow \mathrm{Mo}+3 \mathrm{Li}_{2} \mathrm{O}, \\
& \mathrm{Mo}+3 \mathrm{Li}_{2} \mathrm{O} \rightarrow 1.5 \mathrm{Li}_{1.66} \mathrm{Mo}_{0.66} \mathrm{O}_{2}+3.5 \mathrm{Li}^{+}+3.5 \mathrm{e}^{-}, \\
& 1.5 \mathrm{Li}_{1.66} \mathrm{Mo}_{0.66} \mathrm{O}_{2} \rightarrow \mathrm{Li}_{2} \mathrm{MoO}_{3}+0.5 \mathrm{Li}^{+}+0.5 \mathrm{e}^{-},
\end{aligned}
$$

where Eq. (7) represents the first lithiation and Eqs. (8) and (9) account for the two-stage phase of the subsequent delithiation/lithiation reactions (Fig.14) [208]. This shows that the total 
amount of extracted $\mathrm{Li}$ is about 4 [132,236]. The theoretical lithium storage capacity of $\mathrm{Li}_{2} \mathrm{MoO}_{3}$ is calculated to be about $734 \mathrm{mAh} \mathrm{g}^{-1}$ according to its weight and the ability of accommodating lithium ions, which is much lower than $\mathrm{MoO}_{3}$ of $1117 \mathrm{mAh} \mathrm{g}^{-1}$.
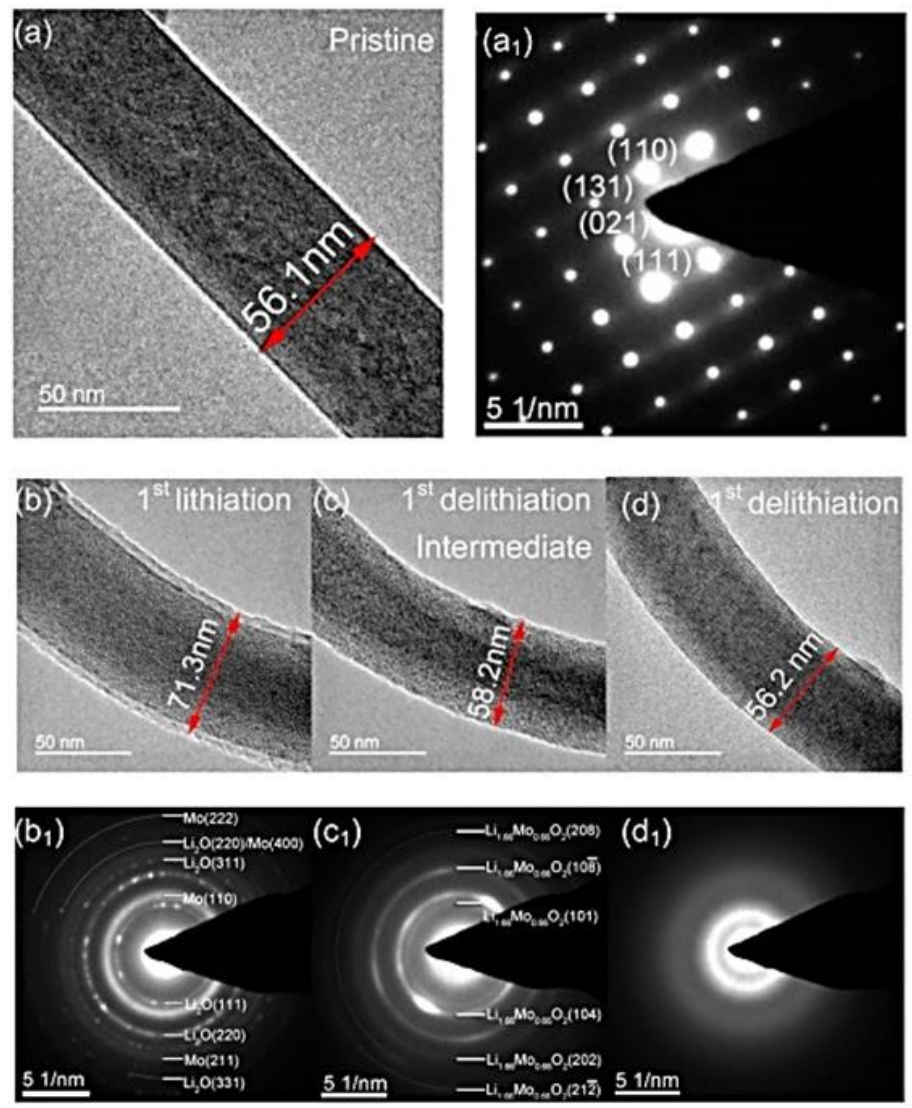

Fig. 14. HRTEM images and electron diffraction patterns (EDP) showing the microstructure evolution of $\mathrm{MoO}_{3}$ nanobelt in lithiation and delithiation processes. (a) pristine $\mathrm{MoO}_{3}$ nanobelt with a size of $56.1 \mathrm{~nm}$. (b) The first lithiation. (c) Intermediate stage of the first delithiation. (d) Delithiated $\mathrm{MoO}_{3}$ nanobelt. EDPs recorded from the nanobelt anode reveal the phase conversion during conversion. Reproduced with permission from [208]. Copyright 2016 American Chemical Society.

Ultralong $\alpha-\mathrm{MoO}_{3}$ nanobelts (length of $200-300 \mu \mathrm{m}$ and uniform width of $\sim 0.6-1.5 \mu \mathrm{m}$ ) were hydrothermally synthesized using a molybdenum organic salt precursor. The electrodes fabricated with sodium carboxymethyl cellulose (Na-CMC) binder deliver the specific capacity of over $730 \mathrm{mAh} \mathrm{g}^{-1}$ for over 200 cycles at a $0.2 \mathrm{C}$ rate. Even cycled at high rates of $1-2 \mathrm{C}$, high capacities of around 430-650 $\mathrm{mAh} \mathrm{g}^{-1}$ can be still retained [129]. Sasidharan et al. [242] synthesized $\alpha-\mathrm{MoO}_{3}$ hollow nanospheres (HNSs; outer diameter of $42 \mathrm{~nm}$; hollow cavity of 23 $\mathrm{nm}$ ) have been using a soft template of polymeric micelles with core-shell-corona architecture. The $\mathrm{MoO}_{3} \mathrm{HNSs}$ electrode delivers a discharge capacity of $263 \mathrm{mAh} \mathrm{g}^{-1}$ for the first cycle at a 
rate of $0.3 \mathrm{C}$ and maintains structural integrity even after subjecting to a high current density $2000 \mathrm{~mA} \mathrm{~g}^{-1}$ (10C rate) The capacity retention is 2.2 times higher than that of dense $\mathrm{MoO}_{3}$ particles. Ette et al. [243] prepared self-assembled lamellar $\alpha-\mathrm{MoO}_{3}$ nanoflakes $(20-30 \mathrm{~nm})$ using facile polymer (polyvinyl pyrrolidone) assisted solvothermal method. After 50 cycles, a capacity value of $1027 \mathrm{mAh} \mathrm{g}^{-1}$ can be extracted at $0.2 \mathrm{C}$ rate while at $2 \mathrm{C}$ rate it shows capacity of $700 \mathrm{mAh} \mathrm{g}^{-1}$. Riley and coworkers prepared $\alpha-\mathrm{MoO}_{3}$ nanoparticles using a hot-wire chemical vapor deposition and reported that $\mathrm{MoO}_{3}$ negative electrodes fashioned into thick electrodes containing $70 \% \mathrm{MoO}_{3}$ nanoparticles $(10-40 \mathrm{~nm}$ in diameter), active material, $20 \%$ poly (vinylidenefluoride) (PVDF), binder, and 10\% acetylene black (AB), conductive additive, can deliver a discharge capacity of $\sim 1000 \mathrm{mAh} \mathrm{g}^{-1}$ at a reduced rate to $\mathrm{C} / 10$ [237]. Later, these workers showed that coating of the electrode with $\sim 8 \AA$ of $\mathrm{Al}_{2} \mathrm{O}_{3}$ by atomic layer deposition (ALD) achieves better rate capability [244]. It was suggested that the ALD coating enabled better adhesion of the high-volume expansion $\mathrm{MoO}_{3}(\geq 100 \%)$ to the current collector. In a subsequent work, $\mathrm{MoO}_{3}$ nanoparticles prepared by hot wire chemical vapor deposition (HWCVD) have been demonstrated as high-capacity Li-ion battery anodes for next-generation electric vehicles. The $\mathrm{MoO}_{3}$ nanoparticles coated with $\sim 8 \AA$ thick $\mathrm{Al}_{2} \mathrm{O}_{3}$ layer deliver a specific capacity of $\sim 600 \mathrm{mAh} \mathrm{g}^{-1}$ at $5 \mathrm{C}$ rate [239]. The ALD-coated $\mathrm{MoO}_{3}$ composite electrode $(\sim 15$ $\mu \mathrm{m}$ thick) prepared with an $\mathrm{Al}_{3} \mathrm{O}_{3}$ coating of $\sim 8 \AA$ thick delivers a capacity of $\sim 600 \mathrm{mAh} \mathrm{g}^{-1}$ at $5 \mathrm{C}$ rate. Zhao and coworkers [245] synthesized $\mathrm{MoO}_{3}$ hollow microspheres via a template-free solvothermal route and subsequent heat treatment in air. The $\mathrm{MoO}_{3}$ hollow microspheres have a high specific surface area of $48.2 \mathrm{~m}^{2} \mathrm{~g}^{-1}$, and with such a feature, when tested as a Li-storage anode material, they show a higher discharge capacity of $1377 \mathrm{mAh} \mathrm{g}^{-1}$ in the first discharge and a high reversible capacity of $780 \mathrm{mAh} \mathrm{g}^{-1}$ after 100 cycles at a rate of $1 \mathrm{C}$ (Fig. 15). Varghese et al. [246] investigated the performance of full-cell $\mathrm{Li}$-ion batteries based on $\mathrm{MoO}_{3}$ nanobelts synthesized by hydrothermal process as cathode and prelithiated $\mathrm{MoO}_{3}$ as anode. At $1 \mathrm{~A} \mathrm{~g}^{-1}$ current density, the $\mathrm{Li}_{\mathrm{x}} \mathrm{MoO}_{3}$ anode delivers a capacity of $700 \mathrm{mAh} \mathrm{g}^{-1}$ and at $2.5 \mathrm{~A} \mathrm{~g}^{-1}$ current density a capacity of $400 \mathrm{mAh} \mathrm{g}{ }^{-1}$ is achieved. The $\mathrm{MoO}_{3} / / \mathrm{Li}_{\mathrm{x}} \mathrm{MoO}_{3}$ full-cell delivers initial energy densities of $156 \mathrm{Wh} \mathrm{kg}^{-1}$ and shows a CE of $99 \%$ over 100 cycles. 

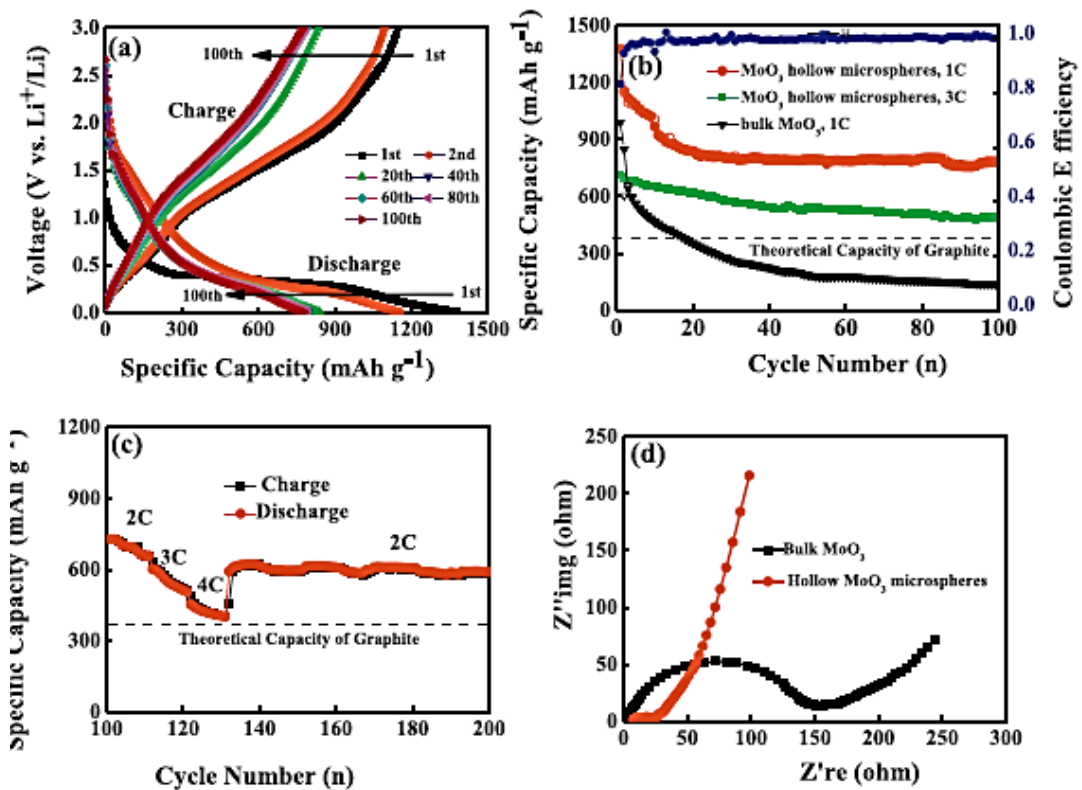

Fig. 15. (a) Discharge/charge voltage profile between 0.01 and $3 \mathrm{~V}$ at a rate of $1 \mathrm{C}$ of $\mathrm{MoO}_{3}$ hollow microspheres; (b) cycling performance of $\mathrm{MoO}_{3}$ hollow microspheres and bulk $\mathrm{MoO}_{3}$; (c) cycling performance for the different rates $(1-4 \mathrm{C})$ of $\mathrm{MoO}_{3}$ hollow microspheres; (d) electrochemical impedance spectroscopy of the $\mathrm{MoO}_{3}$ hollow microspheres. Reproduced with permission from [245]. Copyright 2013 Elsevier.

The promising characteristics of both poly( $p$-phenylene) (PPP) and $\mathrm{Na}_{0.25} \mathrm{MoO}_{3}$ as anode materials in Li-ion cells, along with substantial amounts of polymer surface impurities resulting from the hydrothermal method, have led us to develop a new technique for the inclusion of PPP in $\mathrm{MoO}_{3}$ [247]. Thus, the electrochemical reactivity of $\mathrm{MoO}_{3}$ utilizing a conversion reaction has been widely investigated [129,236]. Reversible lithium-ion insertion in $\mathrm{MoO}_{3}$ nanoparticles deposited by electrophoresis on stainless steel substrate have been reported by Lee et al. [128]. A stable capacity of $630 \mathrm{mAh} \mathrm{g}^{-1}$ was obtained for 150 cycles between 0.005 and $3.5 \mathrm{~V}$. In contrast micron-sized particles of $\mathrm{MoO}_{3}$ showed significant capacity fade after only several cycles. These thin films employed neither conductive additive nor binder as in traditional electrodes. Despite stable cycling at a rate of $\mathrm{C} / 2$, the reversible capacity was only $60 \%$ of the theoretical maximum of $\mathrm{MoO}_{3}, 1117 \mathrm{mAh} \mathrm{g}^{-1}$. Table 5 summarizes the electrochemical performance of $\mathrm{MoO}_{3}$ nanoparticles as anode materials for LIBs prepared by various methods.

Table 5. Electrochemical performance of $\mathrm{MoO}_{3}$ nanoparticles as anode materials for LIBs prepared by various methods. Relevant cycle number is given in brackets. 


\begin{tabular}{llccc}
\hline Material a) & Synthesis & $\begin{array}{c}\text { Specific } \\
\text { capacity } \\
\left(\mathrm{mAh} \mathrm{g}^{-1}\right)\end{array}$ & $\begin{array}{c}\text { Current rate } \\
\left(\mathrm{mA} \mathrm{g}^{-1}\right)\end{array}$ & Ref. \\
\hline HMPs & Solvothermal & 780 & $1 \mathrm{C}(100)$ & {$[245]$} \\
NBs (52 nm thick) & Precipitation & 300 & $1000(100)$ & {$[246]$} \\
$\mathrm{NPs}(10-40 \mathrm{~nm}$ thick $)$ & Hot-wire CVD & 940 & $\mathrm{C} / 10(40)$ & {$[237]$} \\
$\mathrm{NBs}(0.6-1.5 \mu \mathrm{m}$ width $)$ & Hydrothermal & 730 & $0.2 \mathrm{C}(200)$ & {$[129]$} \\
$\mathrm{NBs}(\sim 200 \mathrm{~nm}$ width) & Hydrothermal & 387 & $2000(80)$ & {$[248]$} \\
$\mathrm{MoO}_{3}$ microspheres & Spray-pyrolysis & 345 & $2000(300)$ & {$[249]$} \\
$\mathrm{NFs}$ & Ultrasonication & 795 & $550(100)$ & {$[250]$} \\
$\mathrm{NSs}(20-30$ in diameter $)$ & Hot-wire CVD & 630 & $150(150)$ & {$[251]$}
\end{tabular}

a) HMPs: hollow microspheres; NBs: nanobelts; NPs: nanoparticles; NFs: nanofibers; NSs: nanospheroids.

\subsubsection{2. $\mathrm{MoO}_{3}$ nanocomposites}

The $\mathrm{MoO}_{3}$ nanocomposites act as high capacity anode materials for lithium-ion batteries and exhibits good cyclic behavior. A variety of appealing strategies including carbon-based nanocomposites have been utilized to minimize the volume expansion/contraction and particle aggregation associated with the Li-insertion and extraction processes [232, 252,253]. $\mathrm{MoO}_{3}-$ based nanocomposites include: $\mathrm{MoO}_{3} @$ carbon [232,252], $\mathrm{MoO}_{3} @$ graphene [254-257], $\mathrm{MoO}_{3} @ \mathrm{rGO}[223,258-260], \mathrm{MoO}_{3} @$ metal [261,262], and $\mathrm{MoO}_{3} @$ metal oxides [238,263,264].

Tao and coworkers [252] synthesized a $\mathrm{MoO}_{3}$-carbon nanocomposite from a mixture of $\mathrm{MoO}_{3}$ nanoparticles $(2-180 \mathrm{~nm})$ and graphite by a controlled ball milling procedure. The initial capacity of the $\mathrm{MoO}_{3}$ /graphite (1:1 by weight) composite exceeds the theoretical capacity of $745 \mathrm{mAh} \mathrm{g}^{-1}$, and the stable capacity of $700 \mathrm{mAh} \mathrm{g}^{-1}$ (94\% of the theoretical capacity) still retains after 120 cycles. The electrode performance is linked with the unique nanoarchitecture of the composite and is compared with the performance of $\mathrm{MoO}_{3}$-based anode materials reported in the literature previously (nanoparticles, ball milled powders, and carbon-coated nanobelts). The high value of capacity and good cyclic stability of $\mathrm{MoO}_{3}$-carbon nanocomposite are attractive in respect to those of the reported $\mathrm{MoO}_{3}$ electrodes [254]. Hussan et al. [232] synthesized $\mathrm{MoO}_{3}$ nanobelts, diameter of $150 \mathrm{~nm}$ and a length of 5-8 $\mu \mathrm{m}$, by a simple hydrothermal route followed by carbon coating. The $\mathrm{C}-\mathrm{MoO}_{3}$ nanobelts exhibit excellent cycling stability after being cycled at a current rate of $\mathrm{C} / 10$, maintaining their capacity at 1064 $\mathrm{mAh} \mathrm{g}^{-1}$ after 50 cycles. Highly uniform $\mathrm{MoO}_{3}$ nanoparticles were prepared using hot-wire chemical vapor deposition (HWCVD) for use as active negative electrodes in high-energy LIBs [183]. An optimized reversible high capacity of $\sim 1050 \mathrm{mAh} \mathrm{g}^{-1}$ was obtained for an electrode fabricated from active material, acetylene black and PVDF (70:10:20) with a $250{ }^{\circ} \mathrm{C}$ pre-heat treatment. 
Xue et al. [238] have synthesized $\alpha-\mathrm{MoO}_{3}$ nanobelts and $\mathrm{SnO}_{2} / \alpha-\mathrm{MoO}_{3}$ core-shell nanobelts, which show extraordinarily high reversible capacity as LIB anodes. The initial coulombic efficiency (ICE) of $\alpha-\mathrm{MoO}_{3}$ nanobelts and $\mathrm{SnO}_{2} / \alpha-\mathrm{MoO}_{3}$ core-shell nanobelts is $70.8 \%$ and $69.7 \%$, respectively. The low ICE is probably attributed to the formation of solid electrolyte interphase (SEI) layer. In the following cycles, both $\alpha-\mathrm{MoO}_{3}$ nanobelts and $\mathrm{SnO}_{2} / \alpha-$ $\mathrm{MoO}_{3}$ core-shell nanobelts show high coulombic efficiency (>96.0\%). The reversible capacity of $\mathrm{SnO}_{2} / \alpha-\mathrm{MoO}_{3}$ core-shell nanobelts is $\sim 2200 \mathrm{mAh} \mathrm{g}^{-1}$, much higher than that of pure $\alpha-\mathrm{MoO}_{3}$ nanobelts $\left(\sim 1400 \mathrm{mAh} \mathrm{g}^{-1}\right)$. For pure $\alpha-\mathrm{MoO}_{3}$ nanobelts, during the first lithiation process, three peaks can be observed at 2.25, 0.4 and $0.07 \mathrm{~V}$. The peak at $2.25 \mathrm{~V}$, only observed in the first discharge process, is probably ascribed to the formation of SEI layer. The other two peaks can be attributed to the lithiation process. In the subsequent lithiation processes, all the peaks (at $0.07,0.3,0.53,1.29$ and $1.48 \mathrm{~V}$ ) are reversible, which can be attributed to the lithiation with different site energies and phase-transition process of $\alpha-\mathrm{MoO}_{3}$ nanobelts. For $\mathrm{SnO}_{2} / \alpha-\mathrm{MoO}_{3}$ core-shell nanobelts, during the first lithiation process, the irreversible peak, also observed at $2.25 \mathrm{~V}$, can be ascribed to the formation of SEI layer. In the following lithiation processes, a new and reversible peak at $\sim 0.7 \mathrm{~V}$ is observed, corresponding to the formation of $\mathrm{Li}_{22} \mathrm{Sn}_{5}$ alloys [238]. $\mathrm{MoO}_{3}$ nanoplates were used as anode material for aqueous supercapacitors with higher energy density and relatively higher power density in comparison with traditional activated carbon [240]. $\mathrm{MoO}_{3}$ nanowires were synthesized using a biomolecule-assisted hydrothermal approach and were demonstrated to be an excellent pseudocapacitor material. A specific capacitance $30 \mathrm{~F} \mathrm{~g}^{-1}$ was reported [193]. The nanocomposite $\mathrm{MoO}_{3} / \mathrm{C}$ was synthesized by a facile one-pot citric-nitrate method, where the carbon (from glucose - ratio $\mathrm{MoO}_{3}: \mathrm{C}=10: 3$ in weight corresponding to $23 \mathrm{wt} \%$ carbon) was introduced in situ, and therefore uniformly dispersed in $\mathrm{MoO}_{3}$ host, forming a homogeneous core-shell structure (thin carbon layer of 10$15 \mathrm{~nm}$ ). The $\mathrm{MoO}_{3} / \mathrm{C}$ anode exhibits superior electrochemical performance, a specific capacity of about $500 \mathrm{mAh} \mathrm{g}^{-1}$ in the voltage range of $0.01-3.0 \mathrm{~V} \mathrm{vs.} \mathrm{Li}^{+} / \mathrm{Li}$ can be maintained after 100 cycles [126]. Wang et al. [234] fabricated synergistic $\mathrm{TiO}_{2}-\mathrm{MoO}_{3}$ core-shell nanowire array anode for high energy and high power lithium-ion batteries via a combination of hydrothermal and electrodeposition process. The $\mathrm{TiO}_{2}-\mathrm{MoO}_{3}(1: 1$ mass ratio) hybrid exhibit a first specific capacity of $670 \mathrm{mAh} \mathrm{g}^{-1}$, retention of $\sim 400 \mathrm{mAh} \mathrm{g}^{-1}$ at $250 \mathrm{~mA} \mathrm{~g}^{-1}$ current rate after 200 cycles and good rate capability (up to $2 \mathrm{~A} \mathrm{~g}^{-1}$ ). The areal capacity is also as high as $3.98 \mathrm{mAh} \mathrm{cm}^{-2}$.

Martinez-Garcia et al. [265] presented the electrochemical performance of a low lithiation potential of $0.2 \mathrm{~V}$ vs. $\mathrm{Li}^{+} / \mathrm{Li}$ for pristine $\mathrm{MoO}_{3}$ nanoplatelets and $\mathrm{Si}$-decorated $\left(0.3\right.$ wt.\%). $\mathrm{MoO}_{3}$ ( $\mathrm{Si} @ \mathrm{MoO}_{3}$ ). The products of lithiation were identified as $\mathrm{Li}_{2} \mathrm{MoO}_{4}$ and $\mathrm{Li}_{1.333} \mathrm{Mo}_{0.666} \mathrm{O}_{2}$, 
respectively. The initial cyclic voltammogram of $\mathrm{Si} @ \mathrm{MoO}_{3}$ carried out in the $3.0-0.005 \mathrm{~V}$ potential range exhibits three cathodic peaks at 2.6, 2.18 and $0.02 \mathrm{~V}$ during (reduction process). Upon oxidation to $3.0 \mathrm{~V}$, the anodic peaks are observed at $0.75,1.23,1.5$, and $2.72 \mathrm{~V}$. At subsequent cycle, the features over $2.0 \mathrm{~V}$ disappear and a new cathodic peak starts evolving at a potential of $1.45 \mathrm{~V}$ after the second polarization. Si-decorated $\mathrm{MoO}_{3}$ nanoplatelets exhibit enhanced capacity of $1037 \mathrm{mAh} \mathrm{g}^{-1}$ with exceptional cyclability when charged/discharged at high current densities of $10 \mathrm{~A} \mathrm{~g}^{-1}$. Mesoporous orthorhombic $\mathrm{MoO}_{3}$ nanowire bundles with diameters $10-30 \mathrm{~nm}$ and lengths of up to $2 \mu \mathrm{m}$ were prepared by topotactic chemical transformation from triclinic $\alpha-\mathrm{MoO}_{3} \cdot \mathrm{H}_{2} \mathrm{O}$ nanorods under vacuum condition at $260{ }^{\circ} \mathrm{C}$ The electrochemical measurements indicate that the high reversible capacities of $955 \mathrm{mAh} \mathrm{g}^{-1}$ can be retained over 150 cycles at $200 \mathrm{~mA} \mathrm{~g}^{-1}$ [266]. Single-crystalline $\alpha-\mathrm{MoO}_{3}$ nanobelts with uniform width of $\sim 200 \mathrm{~nm}$ and length at the micrometer level are first synthesized by a simple water-based hydrothermal route [248]. The $\alpha-\mathrm{MoO}_{3}$ film electrode exhibits a reversible specific capacity of $\sim 1000 \mathrm{mAh} \mathrm{g}^{-1}$ at $50 \mathrm{~mA} \mathrm{~g}^{-1}$ and a stable capacity retention of $387-443 \mathrm{mAh} \mathrm{g}^{-1}$ at $2000 \mathrm{~mA} \mathrm{~g}^{-1}$.

Graphene oxide-encapsulated $\alpha-\mathrm{MoO}_{3}$ nanoribbons $\left(\mathrm{GO} / \mathrm{MoO}_{3}\right)$ composite was prepared by a self-assembly process. The great potential of this unique hybrid architecture as anode for Li-ion battery is revealed by a high specific capacity (up to $823 \mathrm{mAh} \mathrm{g}^{-1}$ after 70 cycles at 200 $\mathrm{mA} \mathrm{g}^{-1}$ ), an excellent cycling performance (with more than $754 \mathrm{mAh} \mathrm{g}^{-1}$ after 200 cycles at 1 $\mathrm{A} \mathrm{g}^{-1}$ ) and a greatly-enhanced high-rate capability (displaying a high discharge capacity of 710 mAh g ${ }^{-1}$ after 30 cycles at $3 \mathrm{~A} \mathrm{~g}^{-1}$ ) [267]. Ni et al. [268] fabricated the $\mathrm{MoO}_{3-x} / \mathrm{CNTS}$ composite via hydrothermal synthesis and controlled reduction in $\mathrm{Ar} / \mathrm{H}_{2}$ atmosphere, which consists of 63 $\mathrm{mol} \% \mathrm{MoO}_{3}$ and $37 \mathrm{~mol} \% \mathrm{MoO}_{2}$. When evaluated as an anode in the $0.05-3.0 \mathrm{~V}$ voltage range, the $\mathrm{MoO}_{3} / \mathrm{CNTs}$ hybrid retains a capacity of $421 \mathrm{mAh} \mathrm{g}^{-1}$ after 100 cycles at $200 \mathrm{~mA} \mathrm{~g}^{-1}$, and deliver 293 and $202 \mathrm{mAh} \mathrm{g}^{-1}$ at current densities of 2 and $4 \mathrm{~A} \mathrm{~g}^{-1}$, respectively. $\mathrm{MoO}_{3} @ \mathrm{C}$ nanofibers were synthesized by electrospinning the Mo precursor with polyvinyl pyrrolidone (PVP), followed by annealing. The as-prepared $\mathrm{MoO}_{3} @ \mathrm{C}$ nanofibers deliver a discharge capacity of $623 \mathrm{mAh} \mathrm{g}^{-1}$ after 100 cycles at $500 \mathrm{~mA} \mathrm{~g}^{-1}$, and $502 \mathrm{mAh} \mathrm{g}^{-1}$ even at $1000 \mathrm{~mA}$ $\mathrm{g}^{-1}$ [124]. Ding et al. [122] adopted a facile two-step method in which pristine bulk $\mathrm{MoO}_{3}$ is first converted into $\mathrm{MoO}_{3}$ nanorods $\left(\mathrm{MoO}_{3} \mathrm{NRs}\right)$ through mechanical grinding, to buffer the continuous volume changes, and then coated with amorphous carbon (a-C) through simple stirring and heating. Electrochemical tests reveal that the a-C/MoO${ }_{3} \mathrm{NRs}$ exhibits outstanding specific capacity of $856 \mathrm{mAh} \mathrm{g}^{-1}$ after 110 cycles at a current density of $0.1 \mathrm{C}$ and cycle life of $485 \mathrm{mAh} \mathrm{g}^{-1}$ after 300 cycles at $0.5 \mathrm{C}$ and $373 \mathrm{mAh} \mathrm{g}^{-1}$ after 400 cycles at $0.75 \mathrm{C}$. Yang et al. 
[269] aimed to expanded the interlayer spacing and enhanced the electrical conductivity of $\alpha-\mathrm{MoO}_{3}$ by introducing glucose in the layered framework. It is found that glucose functioned as a cage to hold the pulverized $\mathrm{MoO}_{3-\mathrm{x}}$ pieces, while the subsequent conversion reaction of between $\mathrm{Li}_{2} \mathrm{O}$, Mo and $\mathrm{Li}_{x} \mathrm{MoO}_{3}$ occurred in confined space, which maintained electrodes structural integrity. $\mathrm{MoO}_{3-\mathrm{x}} @ \mathrm{G}$ exhibits superior specific capacity of $607 \mathrm{mAh} \mathrm{g}^{-1}$ after 200 cycles at $1 \mathrm{~A} \mathrm{~g} \mathrm{~g}^{-1}$ and a coulombic efficiency kept stable near $100 \%$. The exceptional performance of $\mathrm{MoO}_{3-\mathrm{x}} @ \mathrm{G}$ is attributed to the capacitive contribution and high reversible reaction. Cao et al. [270] hybridized nanostructured $\mathrm{MoO}_{3}$ particles with foam-like carbon nanoflakes $(\mathrm{CNFs})$ via the pyrolysis of molybdenum 2-ethtlhexanoate $\left(\mathrm{C}_{48} \mathrm{H}_{90} \mathrm{MoO}_{12}\right)$ at a low temperature of $300{ }^{\circ} \mathrm{C}$ under ambient atmosphere. Electrochemical tests of the $\mathrm{MoO}_{3} / \mathrm{CNFs}$ composite as anode material for LIBs show a high discharge capacity of $791 \mathrm{mAh} \mathrm{g}^{-1}$ after 100 cycles at $500 \mathrm{~mA} \mathrm{~g}^{-1}$ and even $\sim 600 \mathrm{mAh} \mathrm{g}^{-1}$ at a high rate of $2000 \mathrm{~mA} \mathrm{~g}^{-1}$ (Fig. 16).
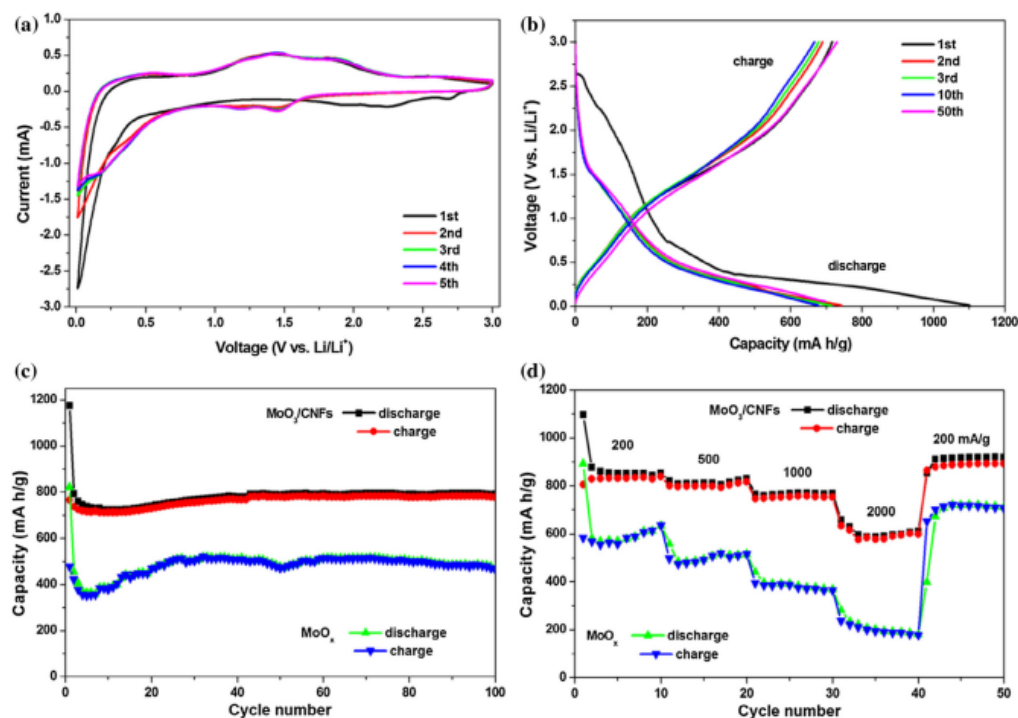

Fig. 16. (a) $\mathrm{CV}$ curves and (b) discharge-charge profiles of the $\mathrm{MoO}_{3} / \mathrm{CNFs}$. (c) Cycle performance at $500 \mathrm{~mA} \mathrm{~g}^{-1}$ and (d) rate performance at current densities ranging from 200 to $2000 \mathrm{~mA} \mathrm{~g}^{-1}$ for the $\mathrm{MoO}_{3} / \mathrm{CNFs}$ and $\mathrm{MoO}_{\mathrm{y}}$ electrodes. Reproduced with permission from [270]. Copyright 2018 Elsevier.

Ultrathin $\mathrm{N}$-doped carbon layer encapsulated $\mathrm{MoO}_{3}$ nanosheets have been synthesized by a simultaneous pyrolysis-reduction process of dodecylamine-intercalated $\mathrm{MoO}_{3}$ composites at $600{ }^{\circ} \mathrm{C}$ under a nitrogen atmosphere. The as-fabricated nanosheets can reach high initial charge and discharge capacities of 1610 and $1359 \mathrm{mAh} \mathrm{g}^{-1}$, respectively, and show remarkable cycle stability with a specific capacity of $1250 \mathrm{mAh} \mathrm{g}^{-1}$ after 60 cycles at $0.3 \mathrm{C}$ rate. High specific 
discharge capacities are maintained at fast $\mathrm{C}$ rates, e.g., 1370, 1010, 940, 610, 490 and $370 \mathrm{mAh}$ $\mathrm{g}^{-1}$ at $0.3 \mathrm{C}, 1 \mathrm{C}, 2 \mathrm{C}, 4 \mathrm{C}, 10 \mathrm{C}$, and 20C, respectively [218]. A nanocomposite $\alpha$ $\mathrm{MoO}_{3} / \mathrm{MWCNT}$ was synthesized via a surfactant-assisted solvothermal process followed by low-temperature calcination [271]. When the discharge/charge current density is increased from 0.1 to $2 \mathrm{~A} \mathrm{~g} \mathrm{~g}^{-1}$, the reversible charge capacity is only decreased from 1138 to $941 \mathrm{mAh} \mathrm{g}^{-1}$, giving a capacity retention of $82.7 \%$. After 300 cycles at a current of $0.5 \mathrm{~A} \mathrm{~g}^{-1}$, a high discharge capacity of $1350 \mathrm{mAh} \mathrm{g}^{-1}$ is maintained. Martinez-Garcia et al. [265] presented the electrochemical performance of a low lithiation potential of $0.2 \mathrm{~V} \mathrm{vs.} \mathrm{Li}^{+} / \mathrm{Li}$ for pristine $\mathrm{MoO}_{3}$ nanoplatelets and $\mathrm{Si}$-decorated $\left(0.3\right.$ wt.\%). $\mathrm{MoO}_{3}\left(\mathrm{Si} @ \mathrm{MoO}_{3}\right)$. The products of lithiation were identified as $\mathrm{Li}_{2} \mathrm{MoO}_{4}$ and $\mathrm{Li}_{1.333} \mathrm{Mo}_{0.666} \mathrm{O}_{2}$, respectively. The initial cyclic voltammogram of $\mathrm{Si} @ \mathrm{MoO}_{3}$ carried out in the $3.0-0.005 \mathrm{~V}$ potential range exhibits three cathodic peaks at 2.6, 2.18 and $0.02 \mathrm{~V}$ during (reduction process). Upon oxidation to $3.0 \mathrm{~V}$, the anodic peaks are observed at $0.75,1.23,1.5$, and $2.72 \mathrm{~V}$. At subsequent cycle, the features over $2.0 \mathrm{~V}$ disappear and a new cathodic peak starts evolving at a potential of $1.45 \mathrm{~V}$ after the second polarization. Si-decorated $\mathrm{MoO}_{3}$ nanoplatelets exhibit enhanced capacity of $1037 \mathrm{mAh} \mathrm{g}^{-1}$ with exceptional cyclability when charged/discharged at high current densities of $10 \mathrm{~A} \mathrm{~g}^{-1}$. Mesoporous orthorhombic $\mathrm{MoO}_{3}$ nanowire bundles with diameters 10-30 nm and lengths of up to $2 \mu \mathrm{m}$ were prepared by topotactic chemical transformation from triclinic $\alpha-\mathrm{MoO}_{3} \cdot \mathrm{H}_{2} \mathrm{O}$ nanorods under vacuum condition at $260{ }^{\circ} \mathrm{C}$ The electrochemical measurements indicate that the high reversible capacities of $955 \mathrm{mAh} \mathrm{g}^{-1}$ can be retained over 150 cycles at $200 \mathrm{~mA} \mathrm{~g}^{-1}$ [266]. Singlecrystalline $\alpha-\mathrm{MoO}_{3}$ nanobelts with uniform width of $\sim 200 \mathrm{~nm}$ and length at the micrometer level are first synthesized by a simple water-based hydrothermal route [248]. The $\alpha-\mathrm{MoO}_{3}$ film electrode exhibits a reversible specific capacity of $\sim 1000 \mathrm{mAh} \mathrm{g}^{-1}$ at $50 \mathrm{~mA} \mathrm{~g}^{-1}$ and a stable capacity retention of $387-443 \mathrm{mAh} \mathrm{g}^{-1}$ at $2000 \mathrm{~mA} \mathrm{~g}^{-1}$. A porous $\mathrm{MoO}_{3}$ film was prepared by electrodeposition on Ni foam substrates and exhibits a capacity of $650 \mathrm{mAh} \mathrm{g}^{-1}$ at a current density of $3 \mathrm{~A} \mathrm{~g} \mathrm{~g}^{-1}$ as anodes for LIBs [139]. $\mathrm{A} \mathrm{MoO}_{3} / \mathrm{C}$ nanocomposite synthesized using the electrospinning method with $42 \%$ carbon takes the morphology of nanofibers, with the diameter of 50-200 nm. The $\mathrm{MoO}_{3} / \mathrm{C}$ anode cycled in a 3.0-0.01 V potential window at current density of $40 \mathrm{~mA} \mathrm{~g}^{-1}$ retains a discharge capacity of $710 \mathrm{mAh} \mathrm{g}^{-1}$ after 100 cycles. When the load current density is increased to $800 \mathrm{mAg}^{-1}$, the composite delivers a discharge capacity of 300 $\mathrm{mAh} \mathrm{g}^{-1}$ after 100 cycles [125]. Sun et al. [272] reported on the synthesis of single wall carbon nanotubes (SWNTs)-bridged $\mathrm{MoO}_{3}$ nanosheets as anode material for LIBs. The $\mathrm{MoO}_{3} / \mathrm{SWNTs}$ composite as fabricated via a liquid phase exfoliation of layered $\mathrm{MoO}_{3}$ crystallites producing multilayer $\mathrm{MoO}_{3}$ nanosheets dispersed in isopropanol and mixed with solution processed 
SWNTs in the same solvent. The $\mathrm{MoO}_{3} / \mathrm{SWNT}$ s hybrid leads to a specific capacity of $865 \mathrm{mAh}$ $\mathrm{g}^{-1}$ at $100 \mathrm{~mA} \mathrm{~g}^{-1}$ after 100 cycles, with a coulombic efficiency approaching $100 \%$ and a capacity fading of $0.02 \%$ per cycle. The $\mathrm{MoO}_{3} @ \mathrm{CoMoO}_{4}$ hybrid was fabricated by a facile one-step hydrothermal method [273]. Galvanostatic charge-discharge tests show that the hybrid anode delivers a capacity of $586 \mathrm{mAh} \mathrm{g}^{-1}$ at the high current density of $1 \mathrm{Ag}^{-1}$ and an enhanced cyclic capacity of $887 \mathrm{mAh} \mathrm{g}^{-1}$ after 140 cycles at the current density of $200 \mathrm{~mA} \mathrm{~g}^{-1}$. Reduced graphene oxide wrapped hollow $\mathrm{MoO}_{3}$ nanorods $\left(\mathrm{MoO}_{3} @ \mathrm{rGO}\right)$ were fabricated by freeze drying method [274]. The $\mathrm{MoO}_{3} @$ rGO composite delivers a high reversible capacity of 842 $\mathrm{mAh} \mathrm{g}{ }^{-1}$ at $0.1 \mathrm{~A} \mathrm{~g}^{-1}$ rate, excellent cycling stability of $778 \mathrm{mAh} \mathrm{g}^{-1}$ at $0.1 \mathrm{~A} \mathrm{~g}^{-1}$ after 200 cycles and excellent rate capability (455 $\mathrm{mAh} \mathrm{g}^{-1}$ at $\left.2 \mathrm{~A} \mathrm{~g}^{-1}\right)$.

Recently, a novel composite of $\alpha-\mathrm{MoO}_{3}$ nanobelts and single-walled carbon nanohorns (SWCNHs) has been synthesized by a microwave hydrothermal method. Tested as a anode material for LIBs, the $\alpha-\mathrm{MoO}_{3} / \mathrm{SWCNH}$ composite displays a specific capacity of $654 \mathrm{mAh} \mathrm{g}^{-1}$ at $1 \mathrm{C}$ rate, excellent rate capability (275 $\mathrm{mAh} \mathrm{g}^{-1}$ at $5 \mathrm{C}$ ), and outstanding cycle life (capacity retention of $>99 \%$ after 3000 cycles at 1C) without any cracking of the electrode [275]. Feng et al. [276] produced $\mathrm{SnO}_{2} / \mathrm{MoO}_{3}$ nanoparticles encapsulated in plate-like graphite via simple hydrothermal synthesis and dry ball milling. The $\mathrm{SnO}_{2}-\mathrm{MoO}_{3}-\mathrm{C}$ displays high ICE of $70 \%$, high reversible specific capacity of $1338 \mathrm{mAhg}^{-1}$ at $0.2 \mathrm{~A} \mathrm{~g}^{-1}$ current rate after 300 cycles $(715$ $\mathrm{mAhg}^{-1}$ at $5 \mathrm{~A} \mathrm{~g}^{-1}$. Long-term cyclic tests show a capacity of $571 \mathrm{mAhg}^{-1}$ at $2 \mathrm{~A} \mathrm{~g}^{-1}$ after 1000 cycles. Zhao et al. [277] designed a core-sheath structured $\mathrm{MoO}_{3} @ \mathrm{MoS}_{2}$ composite via in situ growth of few-layered $\mathrm{MoS}_{2}$ nanoflakes on the surface of the biotemplated $\mathrm{MoO}_{3}$. The electrochemical tests show that the composite possesses a high specific capacity of $1545 \mathrm{mAh}$ $\mathrm{g}^{-1}$ at $100 \mathrm{~mA} \mathrm{~g}^{-1}$ and coulombic efficiency (above 98\%) after 150 cycles. Teng et al. [278] developed a hierarchically nanostructured composite of $\mathrm{MoO}_{3}-\mathrm{NiO} /$ graphene. Ultrafine $\mathrm{MoO}_{3}$ nanosheets and $\mathrm{NiO}$ nanoparticles were homogeneously anchored on the graphene layers. Tested as anode material for LIB, this ternary composite exhibits specific capacities of 1164 $\mathrm{mAh} \mathrm{g}^{-1}$ at $100 \mathrm{~mA} \mathrm{~g}^{-1}$ after 50 cycles and $946.9 \mathrm{mAh} \mathrm{g}^{-1}$ at $1000 \mathrm{~mA} \mathrm{~g}^{-1}$ after 180 cycles. A fibrous CNTs $/ \mathrm{MoO}_{3}$ composite, in which CNTs anchored with $\mathrm{MoO}_{3}$ nanoplates was synthesized by electrospinning process of the $\mathrm{MoO}_{2}$ (acac) $)_{2}$ PAN-CNTS complex in solution and subsequent annealing. The anode composite has high specific capacities of $972 \mathrm{mAh} \mathrm{g}^{-1}$ after 100 cycles at $1 \mathrm{~A} \mathrm{~g}^{-1}$ and $905 \mathrm{mAh} \mathrm{g}^{-1}$ after 800 long-term cycles at $2 \mathrm{~A} \mathrm{~g}^{-1}$. Rate capability tests show discharge capacities of 599 and $374 \mathrm{mAh} \mathrm{g}^{-1}$ at 5 and $10 \mathrm{mAh} \mathrm{g}^{-1}$ rate, respectively [279]. The ternary composite $\mathrm{MoO}_{3} / \mathrm{V}_{2} \mathrm{O}_{5} / \mathrm{C}$ having the morphology of nanofibers with the diameter of 200 500 nm was synthesized by electrospinning combined with heat treatment. 
Electrochemical tests of the composite containing $\sim 40 \%$ carbon retains a specific capacity of $737 \mathrm{mAh} \mathrm{g}^{-1}$ after 200 cycles at $0.2 \mathrm{~A} \mathrm{~g}^{-1}$ current density, and its coulomb efficiency is $93 \%$ [280]. Table 6 summarizes the electrochemical performance of $\mathrm{MoO}_{3}$ nanocomposites as anode materials for LIBs prepared by various methods.

Table 6. Electrochemical performance of $\mathrm{MoO}_{3}$ nanocomposites as anode materials for LIBs prepared by various methods. Relevant cycle number is given in brackets.

\begin{tabular}{|c|c|c|c|c|}
\hline Material $^{\text {a) }}$ & Synthesis & $\begin{array}{l}\text { Specific } \\
\text { capacity } \\
\left(\mathrm{mAh} \mathrm{g}^{-1}\right)\end{array}$ & $\begin{array}{c}\text { Current rate } \\
\left(\mathrm{mA} \mathrm{g}^{-1}\right)\end{array}$ & Ref. \\
\hline $\mathrm{MoO}_{3} \mathrm{NBs} / \mathrm{CNTs}$ & Hydrothermal & 166 & $5 C(500)$ & {$[281]$} \\
\hline $\mathrm{MoO}_{3} @ \mathrm{GNS}$ & Electrostatic & 833 & $200(70)$ & {$[267]$} \\
\hline $\mathrm{MoO}_{3} / \mathrm{C} \mathrm{NBs}$ & Hydrothermal & 1000 & $100(50)$ & {$[215$} \\
\hline $\mathrm{MoO}_{3-8 / \mathrm{CNTs}}$ & Hydrothermal & 421 & $200(100)$ & {$[268$} \\
\hline $\mathrm{C} / \mathrm{MoO}_{3} \mathrm{NBs}$ & Hydrothermal & 1064 & $110(50)$ & {$[232]$} \\
\hline $\mathrm{MoO}_{3} @ \mathrm{C} \mathrm{NFs}$ & Electrospinning & 623 & $500(100)$ & {$[124]$} \\
\hline $\mathrm{MoO}_{3} \mathrm{NPs} / \mathrm{C}$ & Ball milling & 700 & $150(120)$ & {$[252]$} \\
\hline $\mathrm{aC}^{-\mathrm{MoO}_{3}} \mathrm{NRs}$ & Mechanical grinding & 485 & $0.5 \mathrm{C}(385)$ & {$[122]$} \\
\hline $\mathrm{MoO}_{3-\delta} /$ graphene & Vacuum drying & 607 & $1000(200)$ & {$[269]$} \\
\hline $\mathrm{MoO}_{3} / \mathrm{CNFs}$ & Pyrolysis & 791 & $500(100)$ & {$[270]$} \\
\hline $\mathrm{MoO}_{3} / \mathrm{N}$-doped $\mathrm{C}$ & Pyrolysis-reduction & 1250 & $0.3 \mathrm{C}(60)$ & {$[218]$} \\
\hline $\mathrm{MoO}_{3} / \mathrm{MWCNT}$ & Solvothermal & 1350 & $500(300)$ & {$[271]$} \\
\hline $\mathrm{MoO}_{3} / \mathrm{C}$ layer $(10-15 \mathrm{~nm})$ & Hydrosol-gel & 500 & $100(100)$ & {$[126]$} \\
\hline $\mathrm{MoO}_{3} / \mathrm{C}$ microspheres & Spray-pyrolysis & 808 & $1000(100)$ & {$[282]$} \\
\hline $\mathrm{SnO}_{2} / \alpha-\mathrm{MoO}_{3} \mathrm{NBs}$ & Ultrasonication & 1895 & $\mathrm{C} / 10(50)$ & {$[238$} \\
\hline $\mathrm{MoO}_{3} / \mathrm{C}$ & Electrospinning & 300 & $800(100)$ & {$[125]$} \\
\hline $\mathrm{MoO}_{3} / 29 \% \mathrm{C}$ microballs & Spray-pyrolysis & 733 & $2000(300)$ & {$[249]$} \\
\hline $\mathrm{MoO}_{3} /$ graphene & In situ hydrothermal & 869 & $50(80)$ & {$[253]$} \\
\hline $\mathrm{MoO}_{3} /$ graphene & Spray-pyrolysis & 1296 & $2000(100)$ & {$[283]$} \\
\hline $\mathrm{MoO}_{3} / \mathrm{SWCNHs}$ & Microwave hydrothermal & 654 & $1000(3000)$ & {$[275$} \\
\hline $\mathrm{MoO}_{3} /$ graphene (1:1 in wt.) & Sonication & 574 & $500(100)$ & {$[284]$} \\
\hline $\mathrm{MoO}_{3} / \mathrm{rGO}$ & Freeze drying & 778 & $100(200)$ & {$[274]$} \\
\hline $\mathrm{SnO}_{2} / \mathrm{MoO}_{3} / \mathrm{C}$ & Hydrothermal & 1338 & $200(300)$ & {$[276]$} \\
\hline
\end{tabular}

a) CNFs: carbon nanofibers; SWCNHs: single-walled carbon nanohorns.

Xia et al. [215] designed a polyporous $\mathrm{MoO}_{3} / \mathrm{C}$ nanobelt anode material by a hydrothermal route with $\left(\mathrm{NH}_{4}\right)_{6} \mathrm{Mo}_{7} \mathrm{O}_{24} \cdot 4 \mathrm{H}_{2} \mathrm{O}$ and activated carbon. The carbon component (8 wt.\%) present in the composite serves as a physical barrier preventing the aggregation of the $\mathrm{MoO}_{3}$ nanoparticles, and offers good electronic conductivity for electrode reaction. The $\mathrm{MoO}_{3} /$ carbon nanobelts exhibit a high specific capacity of $1000 \mathrm{mAh} \mathrm{g}^{-1}$ after 50 cycles at a current density of $0.1 \mathrm{~A} \mathrm{~g}^{-1}$ and retain a discharge capacity of $675 \mathrm{mAh} \mathrm{g}^{-1}$ at a current density of $5 \mathrm{~A} \mathrm{~g}^{-1}$ and long-term cycle stability to 550 cycles. In situ XRD examination on $\mathrm{MoO}_{3} / \mathrm{C}$ electrode is 
performed to understand the reaction mechanism of lithium with $\mathrm{MoO}_{3}$ in initial process (Fig. 17).

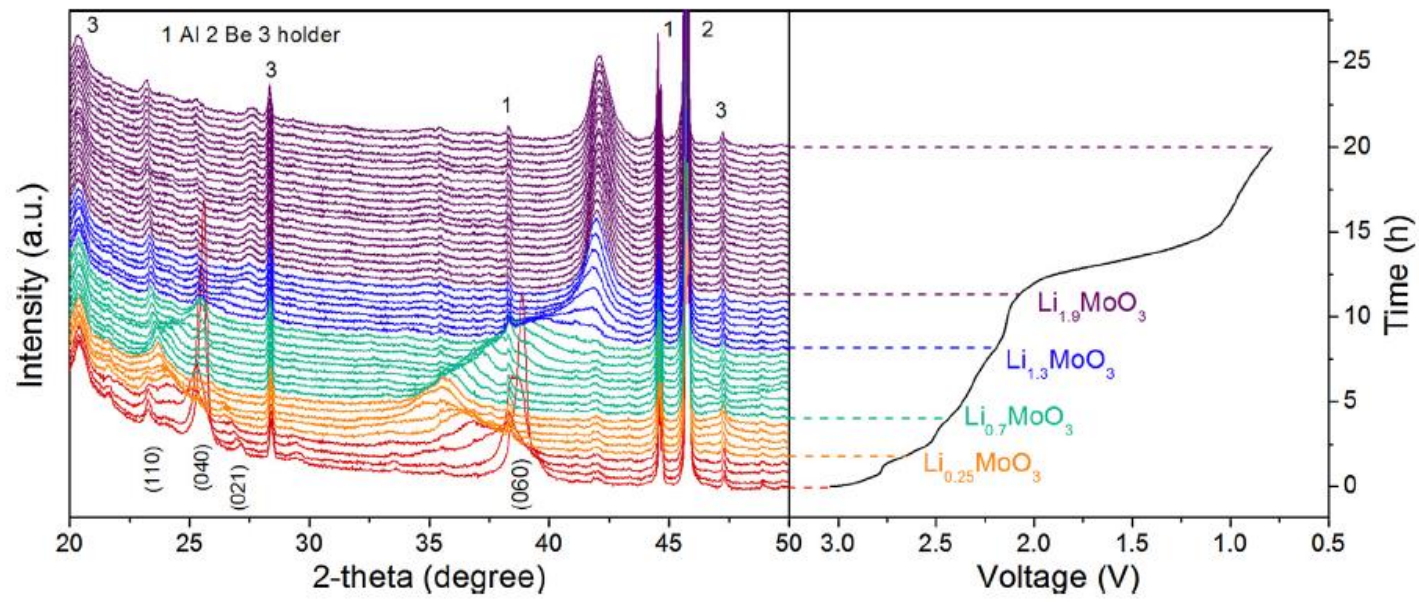

Fig. 17. In situ XRD results recorded during the first discharge of the $\mathrm{MoO}_{3} / \mathrm{C}$ cell. During the initial lithiation process, the intensities of (040) and (060) peaks strongly decrease, indicating a phase transition from pristine $\mathrm{MoO}_{3}$ to a lithium-inserted phase. The nanobelts anode delivers a specific capacity of $1014 \mathrm{mAh} \mathrm{g}^{-1}$ at $100 \mathrm{~mA} \mathrm{~g}^{-1}$ rate after 50 cycles in cut-off $0.01-3.0 \mathrm{~V}$. Reproduced with permission from [215]. Copyright 2015 Elsevier.

\subsubsection{Anodes for SIBs}

$\mathrm{MoO}_{3}$ is considered as an appealing choice of anode for sodium-ion batteries (SIBs) because of its high theoretical capacity of $1117 \mathrm{mAh} \mathrm{g}^{-1}$ (i.e., considering the charge transfer of $\left.6 \mathrm{e}^{-} / \mathrm{Mo}\right)$. However, the poor cycling stability and capacity fade results from the large volume change upon $\mathrm{Na}^{+}$storage. Hence, several investigations offer new possibilities to bypass multiple material challenges facing current sodium electrodes.

The first experimental evidence of the electrochemical insertion of sodium in the orthorhombic $\mathrm{MoO}_{3}$ lattice has been reported in 1995 by Spahr et al. [202]. Specific capacity of up to $240 \mathrm{mAh} \mathrm{g}^{-1}$ (at $0.15 \mathrm{~mA} \mathrm{~cm}^{-2}$ current density) was obtained using $0.5 \mathrm{~mol} \mathrm{~L}^{-1} \mathrm{NaClO}_{4}$ solution in propylene carbonate (PC) as electrolyte. In the first cycle (Fig. 18a), a very sharp reduction peak found in the cyclic voltammogram at a potential of about $2.4 \mathrm{~V}$ vs. $\mathrm{Na}^{+} / \mathrm{Na}$ indicates the formation of a sodium bronze, $\mathrm{Na}_{x} \mathrm{MoO}_{3}$. It is further reduced to $\mathrm{Na}_{x+y} \mathrm{MoO}_{3}$. Subsequently, $y$ moles of sodium are cycled rather reversibly. The galvanostatic dischargecharge curves (Fig. 18b) suggest the formation of the molybdenum bronze of sodium, $\mathrm{Na}_{\mathrm{x}} \mathrm{MoO}_{3}$ [285] with $0<x<0.4$ at a voltage plateau of $2.5 \mathrm{~V}$ followed by a second plateau at about 1.8 V. A maximum $\mathrm{Na}$ uptake of $\sim 1.5$ mole is obtained at a potential limit of $1 \mathrm{~V}$ vs. $\mathrm{Na}^{+} / \mathrm{Na}$. In 
2013, Hariharan reported the sodium storage in commercial $\alpha-\mathrm{MoO}_{3}$ powder (anode loading $\sim 1.5 \mathrm{mg} \mathrm{cm}^{-2}$ ) using 2016-coin-type cell with $1 \mathrm{~mol} \mathrm{~L}^{-1} \mathrm{NaClO}_{4}$ dissolved in ethylene carbonate (EC) and propylene carbonate (PC) as electrolyte (Figs. 18c-e) [233]. The sodiation and desodiation capacities of 771 and $410 \mathrm{mAh} \mathrm{g}^{-1}$ were delivered in the voltage window 0.04-3.0 $\mathrm{V}$ with average voltage profiles lying below 1.0 V. During sodiation (Fig. 18c), the voltage dropped from OCV (2.6 V) to reach a small plateau (i) at ca. $2.3 \mathrm{~V}$. resulting the formation of sodium bronze $\mathrm{Na}_{x} \mathrm{MoO}_{3}$. Beyond the first $\mathrm{Na}^{+}$insertion plateau, the voltage profile in the region 1.8-1.2 $\mathrm{V}$ corresponds to additional insertion of $\mathrm{Na}$ in $\mathrm{MoO}_{3}$ leading to the $\mathrm{Na}_{\mathrm{x}+\mathrm{y}} \mathrm{MoO}_{3}$, followed by a long sloping tail. $\mathrm{MoO}_{3}$ anode also shows favorable rate performance and long cycle life of $117 \mathrm{mAh} \mathrm{g}^{-1}$ over 500 cycles at $0.2 \mathrm{C}\left(0.223 \mathrm{~A} \mathrm{~g}^{-1}\right)$. The real-time sodiation/desodiaton behaviors of $\alpha-\mathrm{MoO}_{3}$ during electrochemical cycling was observed by Xia et al. [286] investigating the in situ TEM and the electron diffraction patterns of $\alpha-\mathrm{MoO}_{3}$ nanobelts. The EELS measurements show that upon the first sodiation, $\alpha-\mathrm{MoO}_{3}$ initially forms an amorphous $\mathrm{Na}_{x} \mathrm{MoO}_{3}$ phase and is subsequently sodiated into intermediate phase of crystalline $\mathrm{NaMoO}_{2}$, finally resulting in the crystallized Mo nanograins embedded within the $\mathrm{Na}_{2} \mathrm{O}$ matrix. During the first desodiation process, Mo nanograins are firstly re-oxidized into intermediate phase $\mathrm{NaMoO}_{2}$ that is further transformed into amorphous $\mathrm{Na}_{2} \mathrm{MoO}_{3}$, resulting in an irreversible phase transformation. The overall electrochemical reactions can be expressed by the relations:

$$
\begin{aligned}
& \mathrm{MoO}_{3}+6 \mathrm{Na}^{+}+6 \mathrm{e}^{-} \rightarrow \mathrm{Mo}+3 \mathrm{Na}_{2} \mathrm{O}, \\
& \mathrm{Mo}+3 \mathrm{Na}_{2} \mathrm{O} \leftrightarrow \mathrm{Na}_{2} \mathrm{MoO}_{3}+4 \mathrm{Na}^{+}+4 \mathrm{e}^{-},
\end{aligned}
$$

where Eq. (10) states for the first sodiation and Eq. (11) for the subsequent desodiation/sodiation. 

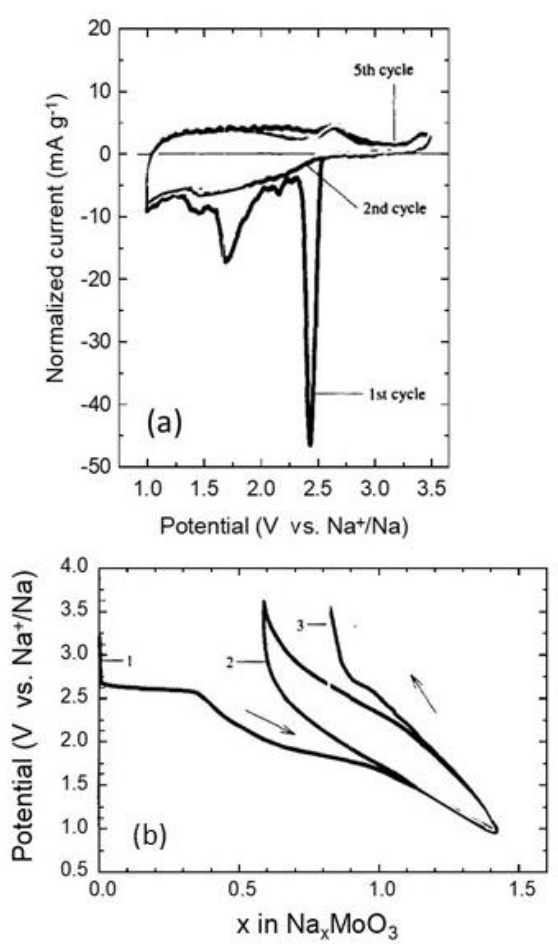
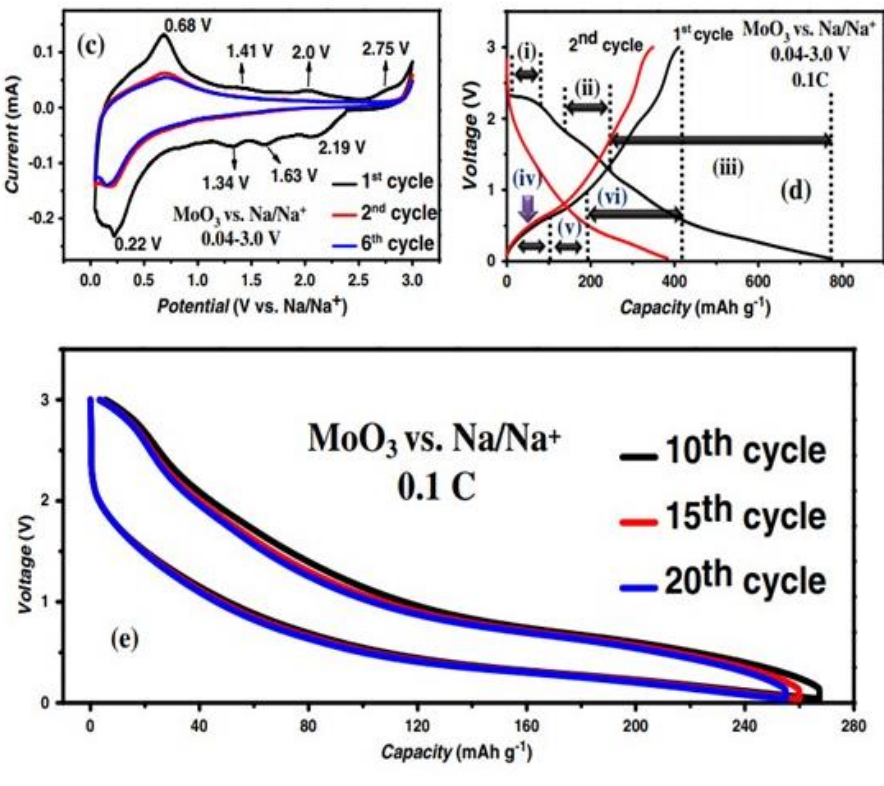

Fig. 18. Electrochemical patterns of the sodium intercalation in commercial $\alpha-\mathrm{MoO}_{3}$ powders. (a) Cyclic voltammogram in $0.5 \mathrm{~mol} \mathrm{~L}^{-1} \mathrm{NaClO}_{4} / \mathrm{PC}$ at $20 \mu \mathrm{V} \mathrm{s}^{-1}$ sweep rate. (b) Galvanostatic discharge charge curves in $0.5 \mathrm{~mol} \mathrm{~L}^{-1} \mathrm{NaClO}_{4} / \mathrm{PC}$ at $0.15 \mathrm{~mA} \mathrm{~cm}^{-2}$ (first three cycles). Reproduced with permission from [202]. Copyright 1995 Elsevier. Electrochemical patterns of the sodium intercalation in $\alpha-\mathrm{MoO}_{3}$ powders prepared by precipitation of phosphomolybdic acid. (c) Cyclic voltammogram of $\mathrm{MoO}_{3}$ vs. $\mathrm{Na}^{+} / \mathrm{Na}$ in the window 0.04 $3.0 \mathrm{~V}$ recorded at $0.058 \mathrm{mV} \mathrm{s}^{-1}$. (d) First and second galvanostatic voltage profiles of $\mathrm{MoO}_{3}$ vs. $\mathrm{Na}^{+} / \mathrm{Na}$ at $0.1 \mathrm{C}\left(0.1117 \mathrm{~A} \mathrm{~g}^{-1}\right)$ in the window 0.04-3.0 V. (e) Voltage profiles showing hysteresis at selected cycles. Reproduced with permission from [233]. Copyright 2013 Elsevier.

Sreedhara et al. [287] fabricated a 3D $\mathrm{MoO}_{3}-\mathrm{rGO}$ composite from $\mathrm{MoO}_{3}$ nanosheets chemically tagged with optimum amounts of rGO. The $\mathrm{MoO}_{3^{-}}(10 \mathrm{wt} \%)-\mathrm{rGO}$ composite exhibits remarkable electrochemical stability (first discharge capacity of $1061 \mathrm{mAh} \mathrm{g}^{-1}$ at $\mathrm{C} / 20$ rate; ICE of 88\%; capacity retention of $665 \mathrm{mAh} \mathrm{g}^{-1}$ after 100 cycles), cyclability and high rate capability over a wide range of operating currents (0.05-1C). At $1 \mathrm{C}$, the $\mathrm{MoO}_{3}-(10 \mathrm{wt} \%)$-rGO dislays a capacity of $330 \mathrm{mAh} \mathrm{g}^{-1}$. Jiang et al. [288] demonstrated a surface phosphorylation strategy to mitigate the degradation of $3 \mathrm{D}^{\mathrm{MoO}} 3$ array electrodes, which allows to sustain a capacity of $265 \mathrm{mAh} \mathrm{g}^{-1}$, or $\sim 90 \%$ of the initial value, at a rate of $2 \mathrm{~A} \mathrm{~g}^{-1}$ over 1500 cycles. Kinetic analysis unveils a capacitance-dominated $\mathrm{Na}^{+}$storage behavior, owing to the enhanced electron mobility imparted by oxygen vacancies that are simultaneously introduced by 
phosphorylation. Liu et al. [289] prepared a nanocomposite of $\mathrm{MoO}_{3}$ nanobelts coated with polypyrrole (PPy) as anode material and investigated the electrochemical performance of the full cell formed by PPy@ $\mathrm{MoO}_{3}$ as anode and $\mathrm{Na}_{0.35} \mathrm{MnO}_{2}$ as cathode in 0.5 mol L ${ }^{-1} \mathrm{Na}_{2} \mathrm{SO}_{4}$ aqueous electrolyte, which delivers an energy density of $20 \mathrm{Wh} \mathrm{kg}^{-1}$ at $80 \mathrm{Wkg}^{-1}$ and even maintain $18 \mathrm{Wh} \mathrm{kg}^{-1}$ at $2.6 \mathrm{kWkg}^{-1}$.

Yang et al. reported the synthesis of $\mathrm{MoO}_{3}$ nanoplates $\left(\mathrm{MoO}_{3} \mathrm{NPs}\right)$ from Mo-based metalorganic frameworks via a facile heating treatment [235]. When used as an anode in SIB, the material showed a discharge capacity of $154 \mathrm{mAh} \mathrm{g}^{-1}$ at $50 \mathrm{~mA} \mathrm{~g}^{-1}$ after 1200 cycles. Even at $500 \mathrm{~mA} \mathrm{~g}^{-1}$, it exhibits a specific capacity $217 \mathrm{mAh} \mathrm{g}^{-1}$ after 500 cycles. It is believed that the nanoplate morphology prevents the pulverization caused by volume expansion in SIBs. Li et al. [290] reported that $\mathrm{MoO}_{3-x}$ grown on flexible carbon cloth, with a well-controlled oxygen vacancy, exhibits a specific capacity of $\sim 150 \mathrm{mAh} \mathrm{g}^{-1}$ after 200 cycles at $0.1 \mathrm{~A} \mathrm{~g}^{-1}$ current rate in the voltage range 4.0-1.0 V vs. $\mathrm{Na}^{+} / \mathrm{Na}$, and long-life performance of $79 \mathrm{mAh} \mathrm{g}^{-1}$ after 2000 cycles at $1 \mathrm{~A} \mathrm{~g} \mathrm{~g}^{-1}$. The oxygen vacancy in $\mathrm{MoO}_{3-\delta}$ is responsible for the two-plateau voltage profile, in contrast to the sloping feature observed in $\alpha-\mathrm{MoO}_{3}$. Xu et al. [291] demonstrated the beneficial effect of oxygen vacancies $(\mathrm{OVs})$ in $\mathrm{MoO}_{3-\delta}$ nanosheet anode for SIBs. A series of measurements show that the OVs increase the electric conductivity and Na-ion diffusion coefficient, and that the ultrathin $\mathrm{Al}_{2} \mathrm{O}_{3}$ coating promotes the effective reduction of cyclinginduced solid-electrolyte interphase. The $\mathrm{Al}_{2} \mathrm{O}_{3}$ coated $\mathrm{MoO}_{3-\delta}$ nanosheets exhibited high reversible capacity and great rate capability with the capacities of $283.9\left(50 \mathrm{~mA} \mathrm{~g}^{-1}\right)$ and 179.3 $\mathrm{mAh} \mathrm{g}{ }^{-1}\left(1 \mathrm{~A} \mathrm{~g}^{-1}\right)$ after 100 cycles. Rod-like $\alpha-\mathrm{MoO}_{3}$ is successfully designed by alternating voltage induced electrochemical synthesis (AVIES) approach with subsequent control of the morphology and texture of $\mathrm{MoO}_{3}$ by applying various calcination temperature of $300-600{ }^{\circ} \mathrm{C}$ [292]. When utilized for SIBs, it presents the high charge capacities of $305 \mathrm{mAh} \mathrm{g}^{-1}$ at $1 \mathrm{C}$ rate and $143 \mathrm{mAh} \mathrm{g}^{-1}$ at $10 \mathrm{C}$. Even after 3000 cycles at $10 \mathrm{C}$, a significant capacity of $108 \mathrm{mAh} \mathrm{g}^{-1}$ is still delivered. Zhu et al. [293] fabricated an amorphous $\mathrm{MoS}_{2} / \mathrm{MoO}_{3} /$ nitrogen-doped carbon composite using a reaction that partially sulfurizes organic-inorganic hybrid material $\mathrm{Mo}_{3} \mathrm{O}_{10}$ $\left(\mathrm{C}_{2} \mathrm{H}_{10} \mathrm{~N}_{2}\right.$ ) (named as $\mathrm{MoO}_{y} /$ ethylenediamine) nanowire precursors at low temperature of 300 ${ }^{\circ} \mathrm{C}$. Tested in sodium cell, the composite retains $539 \mathrm{mAh} \mathrm{g}^{-1}$ after 200 cycles at $300 \mathrm{~mA} \mathrm{~g}^{-1}$ and maintains $340 \mathrm{~mA} \mathrm{~h} \mathrm{~g}^{-1}$ at $1000 \mathrm{~mA} \mathrm{~g}^{-1}$ after 220 cycles. The $\alpha-\mathrm{MoO}_{3}$ nanosheets vertically grown on activated carbon fiber cloth exhibit a discharge capacity of $2.5 \mathrm{mAh} \mathrm{cm}^{-2}(1621 \mathrm{mAh}$ $\mathrm{g}^{-1}$ ) at $0.1 \mathrm{~mA} \mathrm{~cm}^{-2}$ and capacity retention of $90 \%$ after 200 cycles at $0.2 \mathrm{~mA} \mathrm{~cm}^{-2}$ [294]. Zhang et al. [259] prepared $\mathrm{MoO}_{3} /$ reduced graphene oxide $\left(\mathrm{MoO}_{3} / \mathrm{rGO}\right)$ composites via one-step hydrothermal method, and evaluated as anode materials for SIBs. The $\mathrm{MoO}_{3} / \mathrm{rGO}$ composite 
with 6 wt.\% rGO delivers the highest reversible capacity of $\sim 208 \mathrm{mAh} \mathrm{g}^{-1}$ at $50 \mathrm{~mA} \mathrm{~g}^{-1}$ after 50 cycles. Table 7 summarizes the electrochemical performance of $\mathrm{MoO}_{3}$ composites as anode materials for SIBs prepared by various methods.

Table 7. Electrochemical performance of $\mathrm{MoO}_{3}$ composites as anode materials for SIBs prepared by various methods. Relevant cycle number is given in brackets.

\begin{tabular}{llccc}
\hline Material & Synthesis & $\begin{array}{c}\text { Specific } \\
\text { capacity } \\
\left(\mathrm{mAh} \mathrm{g}^{-1}\right)\end{array}$ & $\begin{array}{c}\text { Current rate } \\
\left(\mathrm{mA} \mathrm{g}^{-1}\right)\end{array}$ & Ref. \\
\hline$\alpha-\mathrm{MoO}_{3}$ & Precipitation & 117 & $223(500)$ & {$[233]$} \\
$\mathrm{MoO}_{3}-\mathrm{rGO}$ & Sonication+hydrothermal & 330 & $1000(100)$ & {$[287]$} \\
$\mathrm{MoO}_{3} \mathrm{NPs}$ & Heat treatment & 154 & $50(1200)$ & {$[235]$} \\
$\mathrm{MoO}_{3}$ arrays & Surface phosphorylation & 265 & $2000(1500)$ & {$[288]$} \\
$\mathrm{MoO}_{3-x}$ & Grown on carbon cloth & 79 & $1000(2000)$ & {$[290]$} \\
$\mathrm{Al}_{2} \mathrm{O}_{3} / \mathrm{MoO}_{3-x}$ & Coating & 179 & $1000(100)$ & {$[291]$} \\
$\mathrm{Rod}_{-}-\mathrm{kike} \alpha-\mathrm{MoO}_{3}$ & Electrochemical & 108 & $10 \mathrm{C}(3000)$ & {$[292]$} \\
$\mathrm{MoS}_{2} / \mathrm{MoO}_{3} / \mathrm{N}_{-}$doped $\mathrm{C}$ & Organo-metallic & 538 & $300(200)$ & {$[293]$} \\
$\mathrm{MoO}_{3} \mathrm{NSs} / \mathrm{C}$ fibers & Hydrothermal & 1458 & $65(200)$ & {$[294]$} \\
$\mathrm{MoO}_{3} / \mathrm{rGO}$ & Hydrothermal & 208 & $50(50)$ & {$[259]$} \\
$\mathrm{MoO}_{3} / \mathrm{rGO}$ & Spray-drying & 1115 & $500(100)$ & {$[223]$} \\
$\mathrm{MoO}_{3} / \mathrm{rGO}$ & Spray-drying & 1000 & $0.5 \mathrm{C}(100)$ & {$[295]$} \\
$\mathrm{MoO}_{2} / \mathrm{MoSe}$ & Solvothermal+annealing & 540 & $500(200)$ & {$[296]$} \\
\hline
\end{tabular}

\subsection{Monoclinic $\beta-\mathrm{MoO}_{3}$}

$\mathrm{MoO}_{3}$ in its $\beta$-modification presents a great interest in many applications such as catalysts [297,298], gas sensors [299] and batteries [300]. It was revealed that $\beta-\mathrm{MoO}_{3}$ exhibits better response than that of $\alpha-\mathrm{MoO}_{3}$ in some catalysis reactions due to the high acidity of Lewis acid sites on the surface of $\beta-\mathrm{MoO}_{3}$ [301]. Therefore, a metastable $\beta-\mathrm{MoO}_{3}$ which has been reported to have high catalytic property in methanol oxidation to formaldehyde [302] due to the overall symmetry of this phase.

\subsubsection{Structure}

Since 1986, the $\beta$-phase $\mathrm{MoO}_{3}$ with distorted $3 \mathrm{D} \mathrm{ReO}$-related structure similar to $\mathrm{WO}_{3}$ is known from the work of McCarron [46,303,304]. This novel metastable phase with monoclinic symmetry results from the thermal treatment of spray-dried powders of aqueous molybdic acid solutions [46]. The $\beta-\mathrm{MoO}_{3}$ phase ( $P 2_{1} / \mathrm{c}$ S.G., $a=7.118 \AA, b=5.366 \AA, c=5.568 \AA, \beta=$ 91.99 ${ }^{\circ}$, and JCPDS: 00-047-1081) has a crystal structure similar to $\mathrm{ReO}_{3}$ (cubic, $P m \overline{3} m$ ), which possesses a three-dimensional network of $\mathrm{ReO}_{6}$ octahedra sharing the six corners. Its structure 
is markedly different from the crystal structure of $\alpha-\mathrm{MoO}_{3}$, in which the $\mathrm{MoO}_{6}$ octahedral units share corner oxygen atoms in the direction of the $c$-direction, and edge sharing occurs in the direction of the $c$-axis (inset Fig. 19a). The absence of van der Waal forces is due to adjacent $\mathrm{MoO}_{6}$ octahedra sharing corners, which form a 3D monoclinic network. As shown in (Fig. 19a) the XRD pattern of $\beta-\mathrm{MoO}_{3}$ is characterized with two dominant peaks at $2 \theta=22.9^{\circ}$ and $24.9^{\circ}$ corresponding to the (001) and (200) planes, respectively. Fig. 19b shows the Raman spectrum of $\beta-\mathrm{MoO}_{3}$, which differs than the $\alpha-\mathrm{MoO}_{3}$ spectral features. The peaks at 775, 840 and 904 $\mathrm{cm}^{-1}$ are the Raman profiles corresponding to the Mo-O stretching modes of $\beta-\mathrm{MoO}_{3}$. The absence of peak in the high-frequency range $\left(v>904 \mathrm{~cm}^{-1}\right)$ indicates that no oxygen atoms are singly coordinated [305].

Phuc et al. [306] reported the existence of a new metastable $\beta-\mathrm{MoO}_{3}$ green phase synthesized from $\mathrm{MoO}_{2} \mathrm{Cl}_{2}$ solution derived from $\mathrm{H}_{2} \mathrm{MoO}_{4}$ powder and concentrated $\mathrm{HCl}$ solution. This new phase crystallizes in a triclinic structure similar to that of $\mathrm{WO}_{3}$ and is stable up to $435^{\circ} \mathrm{C}$. The XRD pattern exhibits three main reflection at $22.9^{\circ}, 24.0^{\circ}$, and $24.9^{\circ}$, which are indexed as (002), (020) and (200) of the triclinic symmetry ( $P \overline{1}$ space group) [307]. The Raman spectrum of the $\beta-\mathrm{MoO}_{3}$ green phase displays Mo-O-Mo vibration modes located at 767,842 and $898 \mathrm{~cm}^{-1}$ along with a weak peak at $708 \mathrm{~cm}^{-1}$, which does not exist in the spectrum of the $\beta-\mathrm{MoO}_{3}$ yellow phase. The $\beta$ '- $\mathrm{MoO}_{3}$ phase was prepared by heating the $\mathrm{D}_{0.99} \mathrm{MoO}_{3}$ intercalate in oxygen at $200{ }^{\circ} \mathrm{C}$, driving off $\mathrm{D}_{2} \mathrm{O}$. The structure of $\beta$ ' $-\mathrm{MoO}_{3}$ was determined from neutron powder diffraction as monoclinic ( $P 2_{1} / n$ S.G., $a=7.4245(1) \AA, b=7.4783(1) \AA$, $\left.c=7.6897(1) \AA, \beta=90.090(2)^{\circ}\right)$ is isostructural with the room temperature monoclinic modification of $\mathrm{WO}_{3}[47]$. 

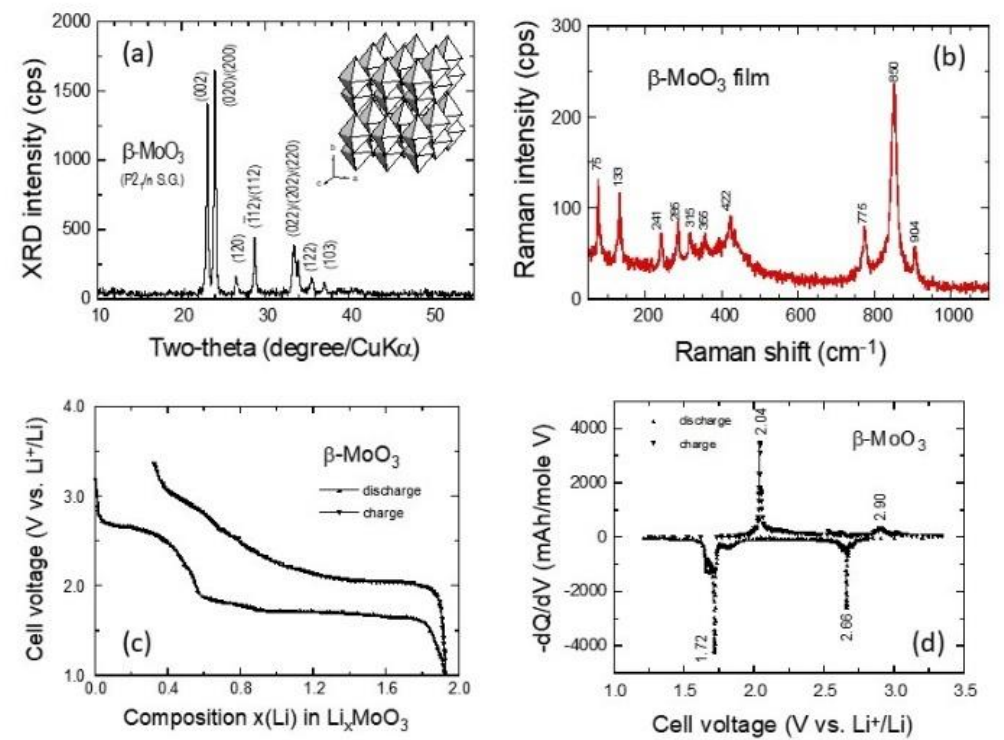

Fig. 19. (a) XRD pattern of the $\beta-\mathrm{MoO}_{3}$ yellow phase ( $P 2_{1} / c$ space group). (b) Raman spectrum recorded with the excitation line at $\lambda=532 \mathrm{~nm}$. (c) GCD profile carried out at $\mathrm{C} / 10$ rate. (d) Differential capacity plot (-d $Q / \mathrm{d} V)$ vs. $V$.

\subsubsection{Synthesis}

The synthesis of the metastable $\beta-\mathrm{MoO}_{3}$ phase is limited due to the difficulty in finding suitable molybdenum source such as ammonium molybdate, molybdic acid, polyoxomolybdate. The first successful preparation of $\beta-\mathrm{MoO}_{3}$ was reported by McCarron [46] who employed a soft-chemical route. The synthesis consists of the dehydration of blue molybdic acid $\left(\mathrm{Mo}_{36} \mathrm{O}_{112}\left(\mathrm{H}_{2} \mathrm{O}\right)_{16}\right)_{8}$ solution, which is obtained via cation exchange of $\mathrm{Na}_{2} \mathrm{MoO}_{4}$ solution ( $1 \mathrm{~mol} \mathrm{~L}^{-1}$ of $\mathrm{Na}_{2} \mathrm{MoO}_{4}$ only gives $0.1 \mathrm{~mol} \mathrm{~L}^{-1}$ of blue molybdic acid solution). Mizushima et al. [301] reported that this method consumes a lot of water and also has very low yield, i.e., the Mo content in the final solution was only 3.3\% of the initial value. In 2011, Mizushima et al. synthesized the $\beta-\mathrm{MoO}_{3}$ phase (yellow powders) by a soft chemical transformation of $\alpha-\mathrm{MoO}_{3}$ via the addition of $\mathrm{HNO}_{3}$ to an aqueous solution of $\alpha-\mathrm{MoO}_{3}$, followed by drying and calcination [308]. Yao et al. synthesized $\beta-\mathrm{MoO}_{3}$ from sodium molybdate solution [299] but $\alpha-\mathrm{MoO}_{3}$ was detected in the final product. $\beta-\mathrm{MoO}_{3}$ crystal has a yellow color [46,306,309-311]. Moreover, $\beta-\mathrm{MoO}_{3}$ can reportedly be obtained by a novel method of freeze drying the same molybdic acid solution [312]. These methods yield a mixture of $\alpha-\mathrm{MoO}_{3}$ and $\beta-\mathrm{MoO}_{3}$. Juárez Ramírez and Martínez-de-la-Cruz [310] produced pure $\beta-\mathrm{MoO}_{3}$ free from the $\alpha$ phase through vacuum drying. This method, however, requires a very long drying time. In 2005, Mizushima et al. [311] reported a new preparation method for pure 
$\beta-\mathrm{MoO}_{3}$ using a generalized rotary evaporator. The simple evaporation of a cation-exchanged molybdic acid solution forms pure $\alpha-\mathrm{MoO}_{3}$ crystallites (bright yellow powder) after calcination at $573 \mathrm{~K}$, whereas the addition of a small amount of nitric acid to the solution resulted in selective formation of the $\beta$-phase. The preparation of $\beta-\mathrm{MoO}_{3}$ thin films has reported by several workers. Porous high surface area thin films of nanosheet-shaped (50-100 nm thick) monoclinic $\beta-\mathrm{MoO}_{3}$ were deposited onto platinized Si substrates using patch antenna-based atmospheric microplasma processing [313]. $\beta-\mathrm{MoO}_{3}$ thin films were prepared by reactive rf sputtering deposition at low substrate temperature of $200{ }^{\circ} \mathrm{C}$ under a $65 \% \mathrm{Ar}+35 \% \mathrm{O}_{2}$ gas mixture at the pressure of $0.13 \mathrm{~Pa}$ [314]. Nearly a pure $\beta$-phase was formed (i.e., well-resolved XRD reflections at ca. $2 \theta=23.0,25.0,47.5$ and $51.8^{\circ}$ corresponding to the (011), (200), (022) and (400) of the $P 2_{1} / c$ structure, respectively), which exhibits a preferred $a$-axis orientation when the annealing temperature is in the range of $300-350{ }^{\circ} \mathrm{C} . \mathrm{MoO}_{3}$ films were electrodeposited on fluorine-doped tin oxide (FTO) glass substrates from sodium-molybdate $\left(\mathrm{Na}_{2} \mathrm{MoO}_{4}\right)$ solutions. The monoclinic $\beta$-phase was obtained by manipulating the cyclic voltammetry conditions [299]. Characterization of the $\mathrm{MoO}_{3}$ films grown by molecular beam epitaxy on c-plane sapphire substrates was conducted by Koike et al. [315]. XRD and Raman measurements revealed that amorphous, (100) $\beta$-phase, and (010) $\alpha$-phase $\mathrm{MoO}_{3}$ films were preferentially grown at 150,200 , and $350{ }^{\circ} \mathrm{C}$, respectively. Their optical bandgap energies were estimated to be $\sim 3.5 \mathrm{eV}$ for the amorphous, $\sim 3.7 \mathrm{eV}$ for the $\beta$-phase, and $\sim 4.1 \mathrm{eV}$ for the $\alpha$-phase films. The $\beta$-phase films were completely transformed into stable $\alpha$-phase films at $600{ }^{\circ} \mathrm{C}$.

A transformation from the $\beta$ to $\alpha$ phase took place spontaneously at the temperature ranging from 387 to $450{ }^{\circ} \mathrm{C}$, according to several reports [304,316-318]. Topotactic transition of metastable $\beta-\mathrm{MoO}_{3}$ to orthorhombic $\alpha-\mathrm{MoO}_{3}$ has been reported as a result of thermal treatments at temperature $350{ }^{\circ} \mathrm{C}$ and above. The presence of the $\beta$-phase of $\mathrm{MoO}_{3}$ at low temperature $\sim 250{ }^{\circ} \mathrm{C}$ is supported by Kuzmin [316], Julien [317] and McEvoy [318], who have shown that sintering in air of hydrated, amorphous molybdenum oxide at relatively low temperatures produces a morphological change from an amorphous phase to a metastable, monoclinic $\beta-\mathrm{MoO}_{3}$. Raman microprobe spectroscopy experiments have revealed that two phases of $\mathrm{MoO}_{3}$ coexist. Some regions exhibit characteristic Raman shifts of 997, 821, and $668 \mathrm{~cm}^{-1}$ that are unique to $\alpha-\mathrm{MoO}_{3}$ while other regions exhibit Raman stretches at 850 and $776 \mathrm{~cm}^{-1}$ that are specific to $\beta-\mathrm{MoO}_{3}[319]$. 


\subsubsection{Li intercalation}

Pristine $\beta-\mathrm{MoO}_{3}$ exhibits an electrical conductivity below $10^{-7} \mathrm{~S} \mathrm{~cm}^{-1}$ [320], which implies to build an electrode using of carbon additive. In 2003, Juárez Ramírez and Martínez-de-laCruz demonstrated the ability of $\beta-\mathrm{MoO}_{3}$ obtained through soft chemistry methods to accommodate electrochemically $\mathrm{Li}^{+}$ions [300,310]. Electrochemical experiments were carried out in Swagelok-type cells using $\mathrm{Li}$ foil as negative electrode and a $1 \mathrm{~mol} \mathrm{~L}^{-1} \mathrm{LiPF}_{6}$ in ethylene carbonate (EC)/dimethyl carbonate (DMC) as electrolyte. The cathode electrode was made of $\beta-\mathrm{MoO}_{3}$ powders, carbon black and ethylene-propylene-dieneterpolymer (EPDT) in a 90:9:1 ratio. Lithium insertion in $\beta-\mathrm{MoO}_{3}$ proceeds at least in a two-step reduction process. The maximum amount of lithium inserted leads to a specific capacity of $370 \mathrm{mAh} \mathrm{g}^{-1}$ (gravimetric energy density of $666 \mathrm{Wh} \mathrm{kg}^{-1}$ ). However, a total loss of $25 \%$ occurs after the first chargedischarge cycle due to structural transformations with variable $\mathrm{Li}_{\mathrm{x}} \mathrm{MoO}_{3}$ composition. For several discharge/charge cycles, the $\mathrm{Li} / / \beta-\mathrm{MoO}_{3}$ cell is able to maintain $280 \mathrm{mAh} \mathrm{g}^{-1}$ at $400 \mu \mathrm{A}$ $\mathrm{cm}^{-2}$ current density. Porous $\beta-\mathrm{MoO}_{3}$ nanosheets (50-100 nm thick) produced by atmospheric microplasma were applied to LIBs [313]. The insertion/de-insertion of $\mathrm{Li}^{+}$ions was performed in $1 \mathrm{~mol} \mathrm{~L}^{-1} \mathrm{LiN}\left(\mathrm{SO}_{2} \mathrm{CF}_{3}\right)_{2}$ in $\mathrm{EC}: \mathrm{DEC}(1 / 1, \mathrm{v} / \mathrm{v})$ electrolyte. The cyclic voltammogram displays cathodic peaks at 2.2 and $1.6 \mathrm{~V}$ and the anodic peaks at 1.7 and $2.1 \mathrm{~V}$. At galvanostatic current of $10 \mu \mathrm{A} \mathrm{g}^{-1}$, the discharge process proceeds through several steps and two-phase regions are observed at 1.7 and $2.7 \mathrm{~V}$, respectively. The charge capacity is $370 \mathrm{mAh} \mathrm{g}^{-1}$ and corresponds to a mole fraction of $2 \mathrm{Li}$ atoms per Mo atom. McEvoy et al. [321] investigated the $\mathrm{Li}$-ion insertion energetics and kinetics of $\beta-\mathrm{MoO}_{3}$ films prepared by electrodeposition from acidic peroxo-polymolybdate solutions. Films deposited on ITO-coated glass substrates and sintered in the temperature range $250-350{ }^{\circ} \mathrm{C}$ display an intermixed $\alpha-\beta-\mathrm{MoO}_{3}$ structure. In $\mathrm{LiClO}_{4} /$ propylene carbonate solution, the electrochemical response for films sintered at $T \geq 250$ ${ }^{\circ} \mathrm{C}$ exhibits three sets of distinguishable redox peaks. This response is assigned to the faradaic electron transfer and to a large capacitive charge during $\mathrm{Li}^{+}$insertion. The smaller anodic peak area after the first cycle suggests that the insertion/deinsertion process is only $60 \%$ reversible. It is more likely due to some fraction of $\mathrm{Li}^{+}$becoming trapped in the film due to the irreversible formation of a molybdenum bronze (i.e., $\mathrm{Li}_{x+2} \mathrm{Mo}_{1-\mathrm{x}}^{\mathrm{VI}} \mathrm{Mo}_{\mathrm{x}-\mathrm{z}}^{\mathrm{V}} \mathrm{Mo}_{\mathrm{z}}^{\mathrm{IV}} \mathrm{O}_{3-y-z}$ ). Figure $19 \mathrm{c}$ shows the typical first discharge charge curve of a $\beta-\mathrm{MoO}_{3}$ film prepared by pulsed-laser deposition on silicon wafer at $T_{\mathrm{s}}=250{ }^{\circ} \mathrm{C}$. The $\mathrm{OCV}$ of the $\mathrm{Li} / / \beta-\mathrm{MoO}_{3}$ cell is $3.20 \mathrm{~V}$ vs. $\mathrm{Li}^{+} / \mathrm{Li}$. In the potential range 3.2-1.0 V, the transfer of $1.92 \mathrm{e}^{-/ M o}$ occurs during the discharge at $\mathrm{C} / 10$ rate (36 $\mathrm{mA} \mathrm{g}^{-1}$ ) yielding a specific capacity of $357 \mathrm{mAh} \mathrm{g}^{-1}$. The first charge occurs with a coulombic efficiency of $83 \%$. The two distinct sets of redox reaction are determined by the plot 
of the differential capacity (-d $Q / \mathrm{d} V$ ) vs. $V$ at $2.66 / 1.72 \mathrm{~V}$ and $2.90 / 2.04 \mathrm{~V}$ for the anodic and cathodic peaks, respectively (Fig. 19d).

\subsection{Hexagonal h-MoO 3}

Hexagonal molybdenum trioxide $\left(\mathrm{h}-\mathrm{MoO}_{3}\right)$ is known for one century when, in 1906, Rosenheim described the preparation of a molybdic acid hydrate by precipitation of an aqueous solution of ammonium paramolybdate, $\left(\mathrm{NH}_{4}\right)_{6}\left[\mathrm{Mo}_{7} \mathrm{O}_{24}\right]_{3} 4 \mathrm{H}_{2} \mathrm{O}$, acidified with $\mathrm{HNO}_{3}$ [322]. In 1969, the Roseheim's process was used by Peters for the XRD analysis of the isolated precipitates [323]. In 1980s, several workers revised the structure of hexagonal molybdates [324,325]. Caiger et al. [325] reported that the "hexagonal $\mathrm{MoO}_{3}$ " series corresponds to the partially dehydrated and de-ammoniated ammonium decamolybdate $\mathrm{NH}_{4} \mathrm{Mo}_{5} \mathrm{O}_{15} \mathrm{OH} \cdot 2 \mathrm{H}_{2} \mathrm{O}$. $\mathrm{Mc}$ Carron et al. investigated the crystal structure of $\mathrm{h}-\mathrm{MoO}_{3}$ with incorporation of sodium and proton in the tunnels [324]. Functional modifications and diversified applications of h- $\mathrm{MoO}_{3}$ can be found in Refs. [325-331]

\subsubsection{Structure}

The framework of hexagonal h- $\mathrm{MoO}_{3}$ is constructed from zigzag chains of $\mathrm{MoO}_{6}$ octahedra linked to each other by corner sharing along the $c$ direction giving large one-dimensional tunnels (Fig. 20a). The h- $\mathrm{MoO}_{3}$ phase can generally be formulated as $\left(A_{2} \mathrm{O}\right)_{\mathrm{x}} \cdot \mathrm{MoO}_{3} \cdot\left(\mathrm{H}_{2} \mathrm{O}\right)_{\mathrm{y}}$, where $A$ is an alkali-metal ion or ammonium ion, and the exact values of $x$ and $y$ depend on the details of the preparation and subsequent treatment [101,332-334]. The salient structural feature for crystalline $\mathrm{h}-\mathrm{MoO}_{3}$ is the presence of tunnel ( $\sim 3 \AA$ in diameter) running along the $c$ axis, in which cations or water molecules can be sitting. Each tunnel is enclosed by $12 \mathrm{MoO}_{6}$ octahedra linked by sharing corners along the $a$ and $b$ directions and by edges along the $c$ direction (Fig. 20a). The tunnel structure in $\mathrm{h}-\mathrm{MoO}_{3}$ exhibits better intrinsic properties than $\alpha-\mathrm{MoO}_{3}$, such as high sensitivity, coloration efficiency, and faster response. The sample prepared via the precipitation of molybdenum oxide from an ammonium paramolybdate solution, by the addition of nitric acid has a "sea-urchin" shape composed of h- $\mathrm{MoO}_{3}$ nanorods (SEM images in Fig. 20b) [335]. Figure 20c depicts the XRD pattern of crystalline h-MoO 3 . The diffraction peaks appeared at $2 \theta=9.62^{\circ}, 16.72^{\circ}, 19.34^{\circ}, 25.68^{\circ}, 29.26^{\circ}, 33.86^{\circ}$ and $35.32^{\circ}$ can be attributed to the planes of (100) (110) (200) (210) (300) (220) and (310), respectively of the hexagonal structure (space group $P 6_{3} / m$ ) with lattice parameters $a=10.53 \AA$ and $c=14.97 \AA$ (JCPDS card No. 21-0569) [13,27,28,332,335]. However, using Rietveld refinements, XRD reflections were successfully indexed with $a=10.55 \AA$ and $c=3.72 \AA$ [48]. A structural transformation from 
hexagonal to stable orthorhombic $\alpha-\mathrm{MoO}_{3}$ phase was observed at $350{ }^{\circ} \mathrm{C}$ [107]. The publication by Lunk et al. [334] aimed to dispel the confusion concerning the identity of the hexagonal molybdenum trioxide (HEMO) phases variously described in the literature. The reported HEMO composition are characterized by virtually identical XRD patterns with unit cell parameters $\mathrm{a} \approx 10.60 \AA$ and $\mathrm{c} \approx 3.72 \AA$. As occurred in the case of $\mathrm{MnO}_{2}$ hollandite, the presence of large cations into the tunnel can stabilize the h- $\mathrm{MoO}_{3}$ structure [337]. However, the growth of crystalline h- $\mathrm{MoO}_{3}$ without large cations incorporated into the tunnels can be obtained from two methods: one is the hot liquid-phase process [335], and the other is the liquid-phase process followed by autoclaving and vacuum heat-treatment [27,332]. The crystallinity and phase purity of as-synthesized nanorods were evidenced by micro-Raman spectrum (Figure 20d), which exhibits sharp high-frequency peaks at $980,915,902$ and $888 \mathrm{~cm}^{-1}$ assigned to the symmetrical and asymmetrical stretching modes of $\mathrm{Mo}=\mathrm{O}$ double bond. The peak at $818 \mathrm{~cm}^{-1}$ is assigned to the stretching mode of $\mathrm{Mo}_{2}-\mathrm{O}$ and the band at $694 \mathrm{~cm}^{-1}$ is the scissoring vibration of the OMo-O bonds. Raman peaks at 395, 412 and $495 \mathrm{~cm}^{-1}$ are attributed to the bending modes of OMo-O bonds, while the peaks at 247 and $220 \mathrm{~cm}^{-1}$ are assigned to the twisting vibration of OMo-O bonds [48,338,339]. Raman peaks in the low-frequency $\left(174\right.$ and $\left.145 \mathrm{~cm}^{-1}\right)$ belong to the external lattice modes.

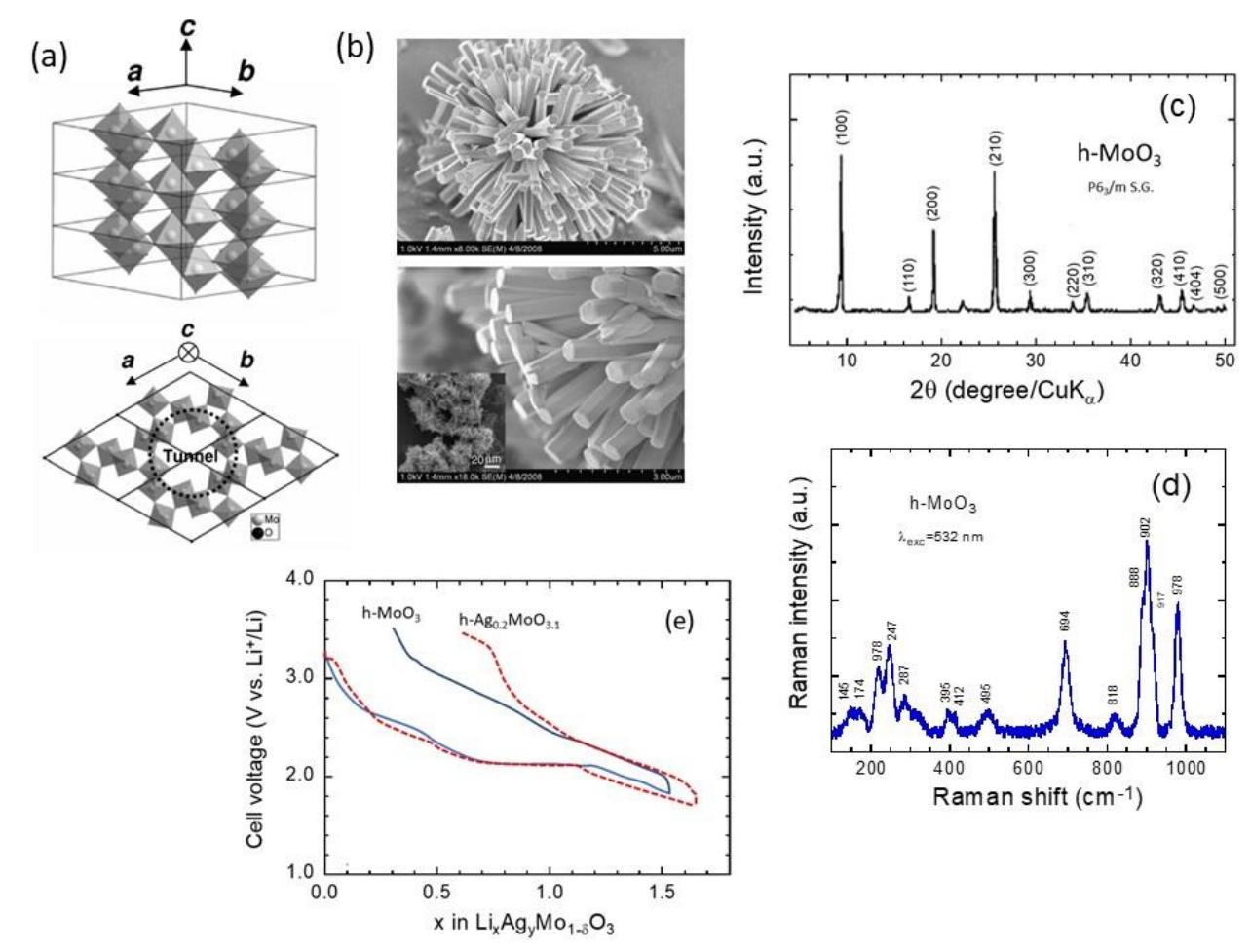

Fig. 20. (a) Crystallographic structure of $h-\mathrm{MoO}_{3}$. The unit cell is shown by a thin black line. (b) SEM images of h-MoO 3 nanorods: projected view (top) and side view (bottom). Reproduced with permission from [335]. Copyright 2009 Elsevier. (c) XRD pattern of h-MoO 3 with 
reflection indexed with $P 6_{3} / m$ S.G (JCPDS card No. 21-0569). (d) Raman spectrum of h-MoO recorded with the laser excitation $\lambda_{\mathrm{exc}}=532 \mathrm{~nm}$. (e) Galvanostatic discharge-charge profiles recorded at $50 \mu \mathrm{A} \mathrm{cm}{ }^{-2}$ current density for h- $\mathrm{MoO}_{3}$ electrode with empty tunnels and h$\mathrm{Ag}_{0.2} \mathrm{MoO}_{3.1}$ electrode. Reproduced with permission from [340]. Copyright 1995 Elsevier.

\subsubsection{Synthesis}

The metastable hexagonal form of $h-\mathrm{MoO}_{3}$ has been successfully prepared starting from the ammonium molybdate, using a "chimie douce" reaction [107,332,341-345]. In the precipitation method, a mixture of ammonium heptamolybdate tetrahydrate $\left(\mathrm{NH}_{4}\right)_{6} \mathrm{Mo}_{7} \mathrm{O}_{24} \cdot 4 \mathrm{H}_{2} \mathrm{O}$ and concentrated nitric acid $\left(37 \% \mathrm{HNO}_{3}\right)$ heated to a temperature in the range $55-85{ }^{\circ} \mathrm{C}$ was used $[13,107,346]$. Hydrothermal technique has been widely used for the synthesis of h- $\mathrm{MoO}_{3}[332,333,347]$. Zheng et al. [332] prepared h- $\mathrm{MoO}_{3}$ nanobelts by a simple hydrothermal route from peroxomolybdate solution with the presence of sodium nitrate as a mineralizer. It was demonstrated that the high openness degree in the tunnel structure of $\mathrm{h}-\mathrm{MoO}_{3}$ provides larger spatial locations for cation insertion/extraction and diffusion. Song et al. prepared the high purity h- $\mathrm{MoO}_{3}$ phase via chemical precipitation, hydrothermal treatment and calcination. In the procedure of precipitation, the concentrated $\mathrm{HCl}$ played a key role for the formation of the metastable h- $\mathrm{MoO}_{3}$ [13]. Atuchin et al. [28] prepared h- $\mathrm{MoO}_{3}$ nanocrystals in the form of well-faceted straight hexagonal rods with an aspect ratio of $l / d \simeq 60$. Han et al. [348] demonstrated that rod-shaped $\mathrm{h}-\mathrm{MoO}_{3}$ were obtained by hydrothermal method using a low concentration of nitric acid (0.1-1.0 mol L-1 $\left.\mathrm{HNO}_{3}\right)$, while higher concentration leads the nanostructured $\alpha-\mathrm{MoO}_{3}$ phase. Hexagonal and truncated hexagonal shaped $\mathrm{MoO}_{3}$ nanoplates $\left(\mathrm{MoO}_{3} \mathrm{HNP}\right)$ were synthesized through a simple vapor-deposition method in Ar atmosphere under ambient pressure without the assistant of any catalysts. The nanoplates have a large area surface. The Raman spectrum shows a significant size effect on the vibrational property of $\mathrm{MoO}_{3} \mathrm{HNP}$ [344]. Hexagonal $\mathrm{MoO}_{3}$ nanoparticles were synthesized by hydrothermal method ( $T=90{ }^{\circ} \mathrm{C}$ for $12 \mathrm{~h}$ ) from a solution of $0.2 \mathrm{~mol} \mathrm{~L}^{-1}$ ammonium molybdate in $10 \mathrm{ml}$ of distilled water added with $5 \mathrm{ml}$ of concentrate $\mathrm{HNO}_{3}$. When heated to $T>150{ }^{\circ} \mathrm{C}, \mathrm{h}-\mathrm{MoO}_{3}$ transforms to the layered $\alpha-\mathrm{MoO}_{3}$ phase $[107,326]$. Using chemical precipitation, the h- $\mathrm{MoO}_{3}$ phase with unique rod-like morphology was synthesized by Song et al. [13]. Guan et al. [349] obtained a nanodisk of hexagonal $\mathrm{h}-\mathrm{MoO}_{3}$ by heat treatment of rhodamine $\mathrm{B} /$ molybdic acid aggregates (RBMA). Dhage et al. [29] fabricated $h-\mathrm{MoO}_{3}$ nanorods via the probe sonication route using ammonium molybdate, urea and sodium dodecyl sulphate at $70{ }^{\circ} \mathrm{C}$. Irmawati and Shafizah [344] produced pure h- $\mathrm{MoO}_{3}$ nanocrystals through the acid washing method, which consists in 
the reduction of the basic aqueous solution of ammonium heptamolybdate tetrahydrate and ammonium carbonate from $\mathrm{pH}$ of 8.85 to $1.95-2.10$ by addition of $5 \mathrm{~mol} \mathrm{~L}^{-1} \mathrm{HNO}_{3}$ (lattice parameters $a=10.55 \AA$ and $c=14.89 \AA$ ). Pan and coworkers [48] prepared nano- and microrods h- $\mathrm{MoO}_{3}$ using modified liquid-phase processes with concentrated $\mathrm{HNO}_{3}$ and $\mathrm{H}_{2} \mathrm{SO}_{4}$ and determine the hexagonal structural patterns as $a \approx 10.57 \AA$ and $c \approx 3.72 \AA$. The fabricated rods have a BET total surface area of $\sim 3 \mathrm{~m}^{2} \mathrm{~g}^{-1}$, with crystallite size ranging from 33 to $46 \mathrm{~nm}$. Zheng et al. [332] synthesized $\mathrm{h}-\mathrm{MoO}_{3}$ nanobelts by a simple hydrothermal route from peroxomolybdate solution with the presence of sodium nitrate as a mineralizer.

\subsubsection{Li intercalation}

Due to the many empty sites in the tunnel structure, i.e., hexagonal tunnel and trigonal cavity (Fig. 20e), the h-MoO 3 electrode exhibits a high capacity on $\mathrm{Li}^{+}$battery application [324,325,332,340,350-351]. In the early work by Gao et al. [340], the lithium intercalation/deintercalation reaction was studied on h- $\mathrm{MoO}_{3}$ with empty tunnels and $\mathrm{Ag}$ containing tunnels. In the discharge curves carried out at $30 \mu \mathrm{A} \mathrm{cm}^{-2}$ in the potential range 1.7$3.5 \mathrm{~V}$ vs. $\mathrm{Li}^{+} / \mathrm{Li}$ (Fig. 20e), the voltage plateau at $x=0.7$ indicates a two-phase region with lattice parameters $a=10.559(5) \AA$ and $c=3.725(3) \AA$ (i.e., $0.97 \%$ volume change). For the hexagonal $\mathrm{Ag}_{0.2} \mathrm{MoO}_{3.1}$ electrode, the ICE was reduced to $\sim 60 \%$. Electrochemical tests, carried out at current density of $0.1 \mathrm{~mA} \mathrm{~cm}{ }^{-2}$ in the voltage range $1.2-4.0 \mathrm{~V} \mathrm{vs.} \mathrm{Li}^{+} / \mathrm{Li}$, show excellent performances with an initial reversible discharge specific capacity of $402 \mathrm{mAh} \mathrm{g}^{-1}$, i.e., insertion of 2.2 Li/Mo. Xu et al. reported a first discharge voltage plateau at $\sim 1.8 \mathrm{~V}$ for hydrothermally synthesized h- $\mathrm{MoO}_{3}$ [352]. Tang et al. [353] fabricated h- $\mathrm{MoO}_{3} /$ graphene composites using a facile hydrothermal method via a template effect of GO on catalyzing the phase transition from $\alpha-\mathrm{MoO}_{3}$ to $\mathrm{h}-\mathrm{MoO}_{3}$. The galvanostatic charge/discharge tests of this composite as anode of $\mathrm{Li}$ cell exhibit a first reversible capacity of 987 and $739 \mathrm{mAh} \mathrm{g}^{-1}$ after 30 cycles under the current

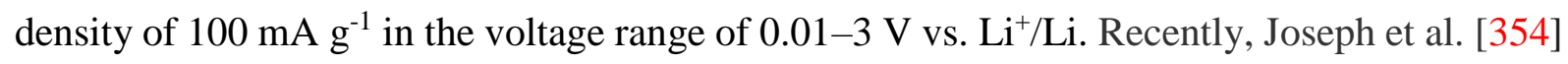
fabricated $\mathrm{MoO}_{3}$ microrods with hexagonal structure as an Al-ion intercalation host material and show its use as an electrode for an aqueous Al-ion battery. $\mathrm{h}-\mathrm{MoO}_{3}$ microrods yield a discharge capacity of $\sim 300 \mathrm{mAh} \mathrm{g}^{-1}$ for 150 cycles at a current density of $3 \mathrm{~A} \mathrm{~g}^{-1}$ and $90 \%$ capacity retention after 400 cycles. Xiao et al. [355] used a solution-based method to synthesized 2D h- $\mathrm{MoO}_{3}$ nanosheets $\mathrm{Mo}$ was dissolved in $\mathrm{H}_{2} \mathrm{O}_{2}$ to produce the molecular peroxomolybdate precursor solution mixed with $\mathrm{NaCl}$ microcrystals as lattice-matched templates. 2D h- $\mathrm{MoO}_{3}$ was tested in a $1 \mathrm{~mol} \mathrm{~L}^{-1} \mathrm{LiClO}_{4}$ solution with a 1:1 mixture of ethylene carbonate and dimethyl carbonate. Intriguingly, a gravimetric capacity of $996 \mathrm{C} \mathrm{g}^{-1}$ (277 mAh 
$\mathrm{g}^{-1}, 1.49 \mathrm{Li} / \mathrm{Mo}$ ) at $2 \mathrm{mV} \mathrm{s}^{-1}$ was much larger than that previously reported for mesoporous $\alpha$ $\mathrm{MoO}_{3}$ in $1 \mathrm{~mol} \mathrm{~L}^{-1} \mathrm{LiClO}_{4}$ with propylene carbonate.

The coloration properties from facile $\mathrm{Li}^{+}$ion insertion/extraction in electrochromic devices was demonstrated by several workers. Zheng et al. [332] showed that the performances concerning photochromism on two types of $\mathrm{MoO}_{3}$ nanobelt suspensions show that the photochemical efficiency of $\mathrm{h}-\mathrm{MoO}_{3}$ is more excellent than that of $\alpha-\mathrm{MoO}_{3}$. Electrochromic performance of the h- $\mathrm{MoO}_{3}$ nanobelts coated film was tested in a three-electrode cell cycled between -1.0 and $-2.0 \mathrm{~V}$ vs. SCE with $1 \mathrm{~mol} \mathrm{~L}^{-1} \mathrm{LiClO}_{4}$ in propylene carbonate as electrolyte and graphite plate as the counter electrode. Two strong and wide transmittance peaks at $\sim 620$ and $590 \mathrm{~nm}$ imply that the $\mathrm{MoO}_{3}$ nanobelt film can display from green-blue to dark blue color at different voltages. Huang et al. [211] reported the synthesis of $\mathrm{h}-\mathrm{MoO}_{3}$ nanorods (average length of 20-50 mm and a width of 1-10 mm) using a hydrothermal treatment at $180{ }^{\circ} \mathrm{C}$ for 24 $\mathrm{h}$ of a solution of $\left(\mathrm{NH}_{4}\right)_{6} \mathrm{Mo}_{7} \mathrm{O}_{24} \cdot 4 \mathrm{H}_{2} \mathrm{O}$ adjusted at $\mathrm{pH} 1$ by addition of $8 \mathrm{~mol} \mathrm{~L}^{-1} \mathrm{HNO}_{3}$. Electrochemical properties of h- $\mathrm{MoO}_{3}$ (Fig. 21) were examined as anode for LIB over 100 cycles at $0.1 \mathrm{C}$ rate. The discharge capacity of $780 \mathrm{mAh} \mathrm{g}^{-1}$ (2nd cycle) rapidly drops to 132 $\mathrm{mAh} \mathrm{g}^{-1}$ after 100 cycles, merely $14 \%$ of the 2 nd cycle. The structure of $\mathrm{h}-\mathrm{MoO}_{3}$ leads to poor capacity stability. After 20 cycles, the hexagonal framework transforms to agglomerated bulk structure with slow $\mathrm{Li}^{+} / \mathrm{e}^{-}$transfer kinetic and finally nanorods are pulverized after 100 cycles (Fig. 21d). Table 8 lists the electrochemical performance of some h- $\mathrm{MoO}_{3}$ anode materials for LIBs. Electrochemical properties of $\mathrm{h}-\mathrm{MoO}_{3}$ have been also investigated by Song et al. [350]. The first reversible discharge specific capacity can reach $402 \mathrm{mAh} \mathrm{g}^{-1}$ (2.2 Li/Mo uptake) at $0.1 \mathrm{~mA} \mathrm{~cm}{ }^{-2}$ current density in the voltage range $1.2-4.0 \mathrm{~V} \mathrm{vs.} \mathrm{Li}^{+} / \mathrm{Li}$. 

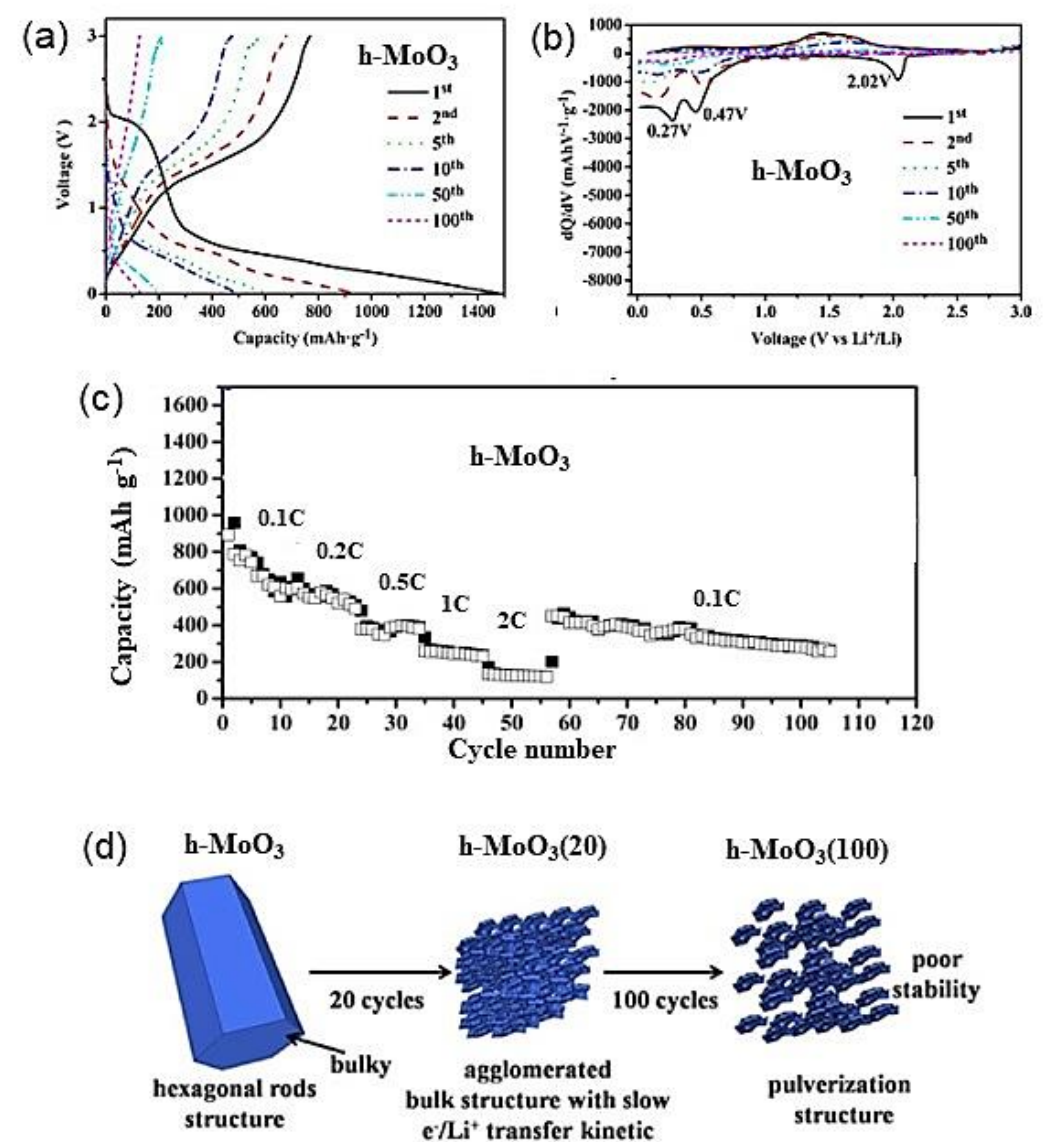

Fig. 21. (a) Galvanostatic charge-discharge curves in different cycles carried out at $0.1 \mathrm{C}$ rate of h-MoO . (b) Differential capacity vs; voltage curves. (c) Rate capability of h- $\mathrm{MoO}_{3}$ at rates between 0.1 and 2C. (d) Schematic illustration of the structural changes upon cycling.

Reproduced with permission from [211]. Copyright 2016 Elsevier.

Table 8. Electrochemical performance of $\mathrm{h}-\mathrm{MoO}_{3}$ anode materials for LIBs.

\begin{tabular}{llccc}
\hline Material & Synthesis & $\begin{array}{c}\text { Specific } \\
\text { capacity } \\
\left(\mathrm{mAh} \mathrm{g}^{-1}\right)\end{array}$ & $\begin{array}{c}\text { Current rate } \\
\left(\mathrm{mA} \mathrm{g}^{-1}\right)\end{array}$ & Ref. \\
\hline $\mathrm{h}-\mathrm{MoO}_{3} \mathrm{NRs}$ & Hydrothermal & 132 & $0.1 \mathrm{C}(100)$ & {$[211]$} \\
$\mathrm{h}-\mathrm{MoO}_{3} /$ graphene & Hydrothermal & 739 & $100(30)$ & {$[353]$} \\
$\mathrm{h}-\mathrm{MoO}_{3} \mathrm{NRs}$ & Solvothermal & 780 & $0.1 \mathrm{C}(150)$ & {$[356]$} \\
\hline
\end{tabular}

\subsection{Monoclinic $\mathrm{MoO}_{3}$-II phase}

The metastable $\mathrm{MoO}_{3}$-II $\left(\varepsilon-\mathrm{MoO}_{3}\right)$ phase was highlighted by Mc Carron and Calabrese [357] from the combination of high pressure and high temperature (60 kbar and $\left.700{ }^{\circ} \mathrm{C}\right)$, using a tetrahedral anvil apparatus at elevated temperature. Using a soft-chemical synthesis of the high-pressure phase of molybdenum trioxide, $\mathrm{MoO}_{3}$-II, has been described by Baker et al. [49]. A topotactic dehydration of either the white molybdenum trioxide monohydrate $\mathrm{MoO}_{3} \cdot \mathrm{H}_{2} \mathrm{O}$, or 
the hemihydrate $\mathrm{MoO}_{3} \cdot 1 / 2 \mathrm{H}_{2} \mathrm{O}$ provides a convenient synthetic route to the high-pressure phase. The structural filiations between the various molybdenum trioxide and trioxide hydrate phases are delineated, and simple mechanistic models for the transformations have been proposed, which involves a change in the stacking sequence of the Mo-O layers. $\mathrm{MoO}_{3}-\mathrm{II}$ is the highpressure modification of $\alpha-\mathrm{MoO}_{3}$. Like the $\alpha-\mathrm{MoO}_{3}$ layered structure, the individual $\mathrm{MoO}_{3 / 3} \mathrm{O}_{2 / 2} \mathrm{O}_{1 / 1}$ layers of $\mathrm{MoO}_{3}-\mathrm{II}$ and $\alpha-\mathrm{MoO}_{3}$ are virtually identical. The stacking sequence of the layers of $\mathrm{MoO}_{3}$-II ( $A A A$ stacking) differs from that of $\alpha-\mathrm{MoO}_{3}(A B A$ stacking), which is equated with an improved packing efficiency for the layers of $\mathrm{MoO}_{3}-\mathrm{II}$ versus those of $\alpha-\mathrm{MoO}_{3}$ (Fig. 22). Its structure is monoclinic, $P 2_{1} / m$ S.G., with unit cell parameters $a=3.954(1) \AA$, $b=$ 3.687(2) $\AA, c=7.095(4) \AA$ and $\beta=103.75(4)^{\circ}\left(4.75 \mathrm{~g} \mathrm{~cm}^{-3}\right)$. In contrast, Åsbrink et al. [358] reported the lattice parameters of $\alpha-\mathrm{MoO}_{3}$ as a function of pressure up to $7.4 \mathrm{GPa}$ at ambient temperature, but did not find any high-pressure phase transition. Liu et al. [44] demonstrated that the $\mathrm{MoO}_{3}-\mathrm{II}$ phase can be achieved at $12 \mathrm{GPa}$ and room temperature. The lattice parameters refined within the $P 2_{1} / m$ space group for the new phase were $a=3.860$ (3) $\AA, b=3.711(6) \AA, c$ $=6.329(4) \AA, \beta=104.811^{\circ}$, and unit cell volume $V=87.66(5) \AA^{3}(Z=2)$. The metastable $\mathrm{MoO}_{3}-$ II phase is relatively more stable than $\mathrm{h}-\mathrm{MoO}_{3}$ but can convert rapidly to stable orthorhombic phase $\alpha-\mathrm{MoO}_{3}$ at temperatures above $200{ }^{\circ} \mathrm{C}$ [8,357]. Another high-pressure phase, the monoclinic $\mathrm{MoO}_{3}$-III phase ( $P 2_{1} / c$ S.G.), has been observed at pressure of $25 \mathrm{GPa}$ at room temperature. The lattice parameters refined within the $P 2_{1} / c$ space group for the $\mathrm{MoO}_{3}$-III phase were $a=5.749(2) \AA, b=4.804(6) \AA, c=6.095(3) \AA, \beta=116.73(5)^{\circ}$, and unit cell volume $V=150.36(5) \AA^{3}(Z=4)$. The Raman spectrum of $\mathrm{MoO}_{3}$-III did not display the peak associated with the unique molybdyl bond ( $v \mathrm{Mo}=\mathrm{O}$ stetch) confirming this phase is not a layered structure. The stretching modes at 786, 834 and $893 \mathrm{~cm}^{-1}$ reveal the Mo-O bonds in the corner-sharing $\mathrm{MoO}_{6}$ octahedra. The $\mathrm{MoO}_{3}$-III phase is likely a distortion of the $\mathrm{ReO}_{3}$-type structure [44].

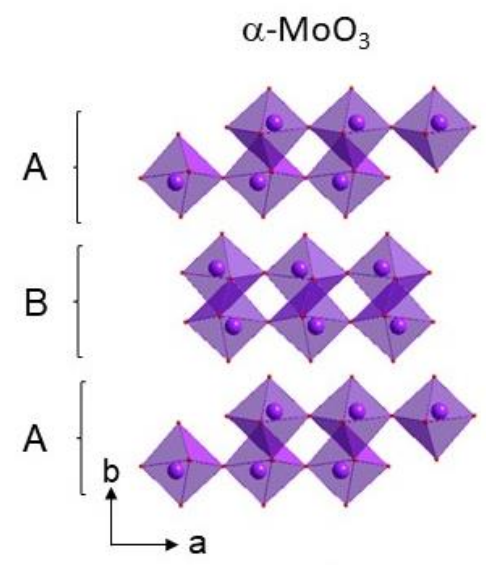

(a)

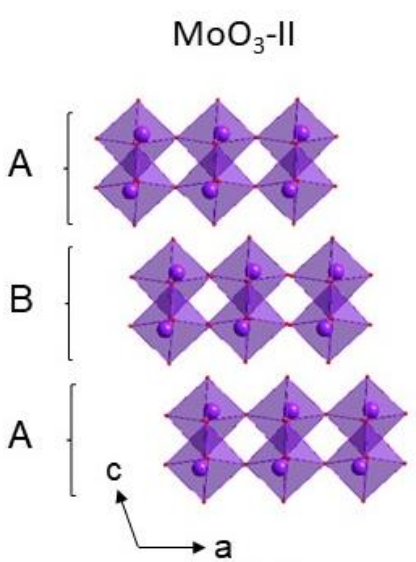

(b)

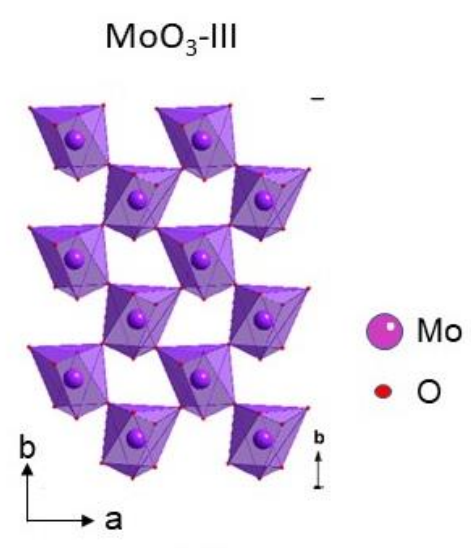

(c) 
Fig. 22. Crystallographic structures of molybdenum trioxides. (a) Orthorhombic $\alpha-\mathrm{MoO}_{3}$ structure with $A B A$ stacking. (b) Monoclinic $P 2_{1} / m \mathrm{MoO}_{3}$-II structure with $A A A$ stacking. Mo atoms of the $B$ layer within $\mathrm{MoO}_{6}$ a mirror plane compared with $\alpha-\mathrm{MoO}_{3}$. (c) Monoclinic $P 2_{1} / c$ structure of the high-pressure phase $\mathrm{MoO}_{3}$-III. Purple circles represent the Mo atoms and red circles the O atoms. Reproduced with permission from [44]. Copyright 2009

\subsection{Bronzes of Molybdenum}

In 1895, the first molybdenum bronze was synthesized by Stavenhagen and Engels [359]. The sodium molybdenum bronze $\mathrm{Na}_{6} \mathrm{Mo}_{7} \mathrm{O}_{24}\left(3 \mathrm{NaO} \cdot 7 \mathrm{MoO}_{3}\right)$ was produced by electrolytic reduction of fused sodium molybdate. Under water, the bronze appears as indigo blue, shiny metal needles that lost some of their metallic sheen when drying and turned a dark blue color. In 1970, Réau et al. [69] investigated the monoclinic $\mathrm{Li}_{x} \mathrm{MoO}_{3}$ phases, which refer to violetblue bronzes prepared in a range of stoichiometry with $0.31 \leq x \leq 0.39$. The main interest of molybdenum bronzes was motivated by their transport anomalies (charge-density wave instabilities). In the 1980s, molybdenum bronzes were studied as low-dimensional metallic conductors, with the generic formula $A_{\mathrm{x}} \mathrm{Mo}_{\mathrm{y}} \mathrm{O}_{\mathrm{z}}$ where $A$ is hydrogen or alkali metal. They are distinguished by their color: red bronzes $\left(\mathrm{Li}_{0.33} \mathrm{MoO}_{3}, \mathrm{~K}_{0.33} \mathrm{MoO}_{3}\right)$, blue bronzes $\left(\mathrm{K}_{0.3} \mathrm{MoO}_{3}\right)$, and purple bronzes $\left(\mathrm{Li}_{0.9} \mathrm{Mo}_{6} \mathrm{O}_{17}, \mathrm{Na}_{0.9} \mathrm{Mo}_{6} \mathrm{O}_{17}\right)$ [360-363]. In 1984, McCarroll and Greenblatt reported the synthesis of several single crystals of $\mathrm{Li}_{x} \mathrm{MoO}_{3}$ bronze with different compositions: violet-red $\mathrm{Li}_{0.9} \mathrm{Mo}_{6} \mathrm{O}_{17}$, violet-blue $\mathrm{Li}_{0.32} \mathrm{MoO}_{3}$ and blue $\mathrm{Li}_{0.04} \mathrm{MoO}_{3}$ [364]. A lithium-ion battery was fabricated with a lithium molybdenum bronze as anode [365]. The molybdenum bronze $\mathrm{Li}_{\mathrm{x}} \mathrm{MoO}_{3} \cdot \varepsilon \mathrm{H}_{2} \mathrm{O}$ with $0.20 \leq x \leq 0.30$ and $\varepsilon \leq 0.1$ was prepared in a preferred embodiment, using a method that prevent the co-intercalation of proton. For instance, $\mathrm{Li}_{\mathrm{x}} \mathrm{MoO}_{3} \cdot \mathrm{EH}_{2} \mathrm{O}$ is formed from $\mathrm{MoO}_{3}$ suspended in aqueous solution in argon atmosphere, by simultaneous addition of sodium dithionite and hydrated lithium molybdate. In the voltage range 3.5-0.005 V vs. Li, the composite electrode exhibits a capacity retention of $72 \%$ after 20 cycles.

\section{Hydrated Mo-O phases}

\subsection{Structure}

A rich family of crystalline molybdenum(VI) oxide hydrates (MOHs), $\mathrm{MoO}_{3} \cdot n \mathrm{H}_{2} \mathrm{O}$, are known for $1 \leq n \leq 2$, which include the monoclinic dihydrate, $\mathrm{MoO}_{3} \cdot 2 \mathrm{H}_{2} \mathrm{O}$, two monohydrates, the yellow monoclinic $\mathrm{MoO}_{3} \cdot \mathrm{H}_{2} \mathrm{O}$, and the white triclinic $\mathrm{MoO}_{3} \cdot \mathrm{H}_{2} \mathrm{O}$, a white hemihydrate, $\mathrm{MoO}_{3} \cdot 1 / 2 \mathrm{H}_{2} \mathrm{O}$, and a white orthorhombic $\mathrm{MoO}_{3} \cdot 1 / 3 \mathrm{H}_{2} \mathrm{O}$ (Table 9). The $\mathrm{MoO}_{3} \cdot 2 / 3 \mathrm{H}_{2} \mathrm{O}$ hydrate has been also reported [366]. The structure of $\mathrm{MoO}_{3} \cdot 2 \mathrm{H}_{2} \mathrm{O}$ is made of layers of $\mathrm{MoO}_{5}\left(\mathrm{OH}_{2}\right)$ 
octahedra exchanging their oxygens in the equatorial plane and stacking along the $b$-direction [367]. Yellow monohydrate $\left(\beta-\mathrm{MoO}_{3} \cdot \mathrm{H}_{2} \mathrm{O}\right)$ displays a structure with equatorial sharing oxygens and axial $\mathrm{Mo}-\mathrm{OH}_{2}$ and $\mathrm{Mo}=\mathrm{O}$ bonds [368]. White monohydrate $\left(\alpha-\mathrm{MoO}_{3} \cdot \mathrm{H}_{2} \mathrm{O}\right)$ has a triclinic structure (space group $P \overline{1}$, JCPDS card No. 16-1449) closely related to that $\alpha-\mathrm{MoO}_{3}$ and crystallizes in well-shaped needles. Its structure is formed by edge-sharing octahedra parallel to the $b$-direction and includes $\mathrm{Mo}^{-} \mathrm{OH}_{2}, \mathrm{Mo}=\mathrm{O}$ and $\mathrm{Mo}-\mathrm{O}_{3}$ bonds [369]. The $\mathrm{MoO}_{3} \cdot 1 / 2 \mathrm{H}_{2} \mathrm{O}$ structure is built of layers parallel to the b-direction formed of edge-sharing distorted $\mathrm{MoO}_{6}$ octahedra and $\mathrm{MoO}_{5}\left(\mathrm{OH}_{2}\right)$ octahedra [370]. $\mathrm{MoO}_{3} \cdot 1 / 3 \mathrm{H}_{2} \mathrm{O}$ presents slightly distorted $\mathrm{MoO}_{6}$ octahedra leading to a base-centered orthorhombic structure [41,309,371].

Table 9. Crystallographic parameters of the various molybdenum oxide hydrates.

\begin{tabular}{lcccc}
\hline \multirow{2}{*}{ Compound } & Space group & \multicolumn{3}{c}{ Cell parameters $(\AA)$} \\
\cline { 3 - 5 } & & $a / \alpha$ & $b / \beta$ & $c / \gamma$ \\
\hline $\mathrm{MoO}_{3} \cdot \mathrm{H}_{2} \mathrm{O}$ & $P 2_{1} / c$ & 7.55 & $10.69 / 91.0^{\circ}$ & 7.28 \\
$\alpha-\mathrm{MoO}_{3} \cdot \mathrm{H}_{2} \mathrm{O}$ & $P 1$ & 7.388 & $3.70 / 113.6^{\circ}$ & $6.673 / 91.6^{\circ}$ \\
$\mathrm{MoO}_{3} \cdot 2 \mathrm{H}_{2} \mathrm{O}$ & $P 2 / n$ & 10.476 & $13.822 / 91.6^{\circ}$ & 10.606 \\
$\mathrm{MoO}_{3} \cdot 1 / 3 \mathrm{H}_{2} \mathrm{O}$ & $P b n m$ & 7.697 & 12.647 & 7.338 \\
$\mathrm{MoO}_{3} \cdot 1 / 2 \mathrm{H}_{2} \mathrm{O}$ & $P 2 / m$ & 9.658 & $3.71 / 102.4^{\circ}$ & 7.087 \\
$\mathrm{~h}-\mathrm{MoO}_{3} \cdot 1 / 2 \mathrm{H}_{2} \mathrm{O}$ & $P 6_{3} / m$ & 10.584 & - & 3.728 \\
\hline
\end{tabular}

During the dehydration process of molybdic acid, several hydrated phases are formed. Yellow monoclinic mono-hydrate $\mathrm{MoO}_{3} \cdot \mathrm{H}_{2} \mathrm{O}$ is formed by the topotactic loss of the intralayer water molecule on the dehydration of $\mathrm{MoO}_{3} \cdot \mathrm{H}_{2} \mathrm{O}$ [368]. The white monoclinic hemi-hydrate $(n=1 / 2)$ was prepared by precipitation from nitric acid solution [368], and by ion exchange method from sodium molybdate [366]. White orthorhombic $\mathrm{MoO}_{3} \cdot 1 / 3 \mathrm{H}_{2} \mathrm{O}$ was grown by hydrothermal treatment at $110{ }^{\circ} \mathrm{C}$ of aqueous solution of molybdic acid [309]. By dehydration of molybdic acid, the monoclinic $\beta-\mathrm{MoO}_{3}$ with $\mathrm{ReO}_{3}$-type structure is formed which transforms to the orthorhombic $\alpha-\mathrm{MoO}_{3}$ phase above $400{ }^{\circ} \mathrm{C}[70,154]$.

The different steps are observed as endothermic peaks in TGA curves indicating multistep dehydration and structural rearrangements of the $\mathrm{MOH}$ framework (Fig. 4). Above $325{ }^{\circ} \mathrm{C}$, $\beta-\mathrm{MoO}_{3}$ and $\alpha-\mathrm{MoO}_{3}$ phases are formed. A broad exothermic peak at $480{ }^{\circ} \mathrm{C}$ originates from the irreversible phase transformation from monoclinic to orthorhombic structure. The phase transformation is associated with loss of oxygen observed particularly for the samples heat 
treated above $750^{\circ} \mathrm{C}$ leading sub-oxide such as $\mathrm{MoO}_{2.8}\left(\mathrm{Mo}_{5} \mathrm{O}_{14}\right)$ [121]. The DSC curve of $\mathrm{MoO}_{3} \cdot \mathrm{H}_{2} \mathrm{O}$ shows three broad endothermic peaks at 198,246 , and $325^{\circ} \mathrm{C}$ on heating in argon atmosphere at the rate $2{ }^{\circ} \mathrm{C} \mathrm{min}^{-1}$, which is correlated with the weight losses. At the first stage $33 \%$ of the water molecules was removed forming the product $\mathrm{MoO}_{3} \cdot 1 / 3 \mathrm{H}_{2} \mathrm{O}$.

Günter [368] reported that the dehydration process is a topotactic-like reaction with a slight expansion in both axial direction and an increase in symmetry; in molybdenum trioxide, the coordination octahedra partly share edges instead of corners only, which explains the change in the lattice constants and in symmetry. The low-temperature phase $\beta-\mathrm{MoO}_{3}$ (bright yellow colour) is formed around $450{ }^{\circ} \mathrm{C}$, while the layered $\alpha-\mathrm{MoO}_{3}$ phase (white transparent) is formed at $750{ }^{\circ} \mathrm{C}$. Some samples with black colour are formed at $750{ }^{\circ} \mathrm{C}$, indicating an oxygen-deficient $\mathrm{MoO}_{3-\delta}$ structure. The dehydration mechanism of Mo mono hydrate (molybdic acid) can be summarized by the relation

$$
\begin{gathered}
\mathrm{MoO}_{3} \cdot \mathrm{H}_{2} \mathrm{O} \rightarrow \mathrm{MoO}_{3} \cdot 2 / 3 \mathrm{H}_{2} \mathrm{O}+1 / 3 \mathrm{H}_{2} \mathrm{O} \uparrow \rightarrow \mathrm{MoO}_{3} \cdot 1 / 3 \mathrm{H}_{2} \mathrm{O}+1 / 3 \mathrm{H}_{2} \mathrm{O} \uparrow \\
\rightarrow \beta-\mathrm{MoO}_{3}+1 / 3 \mathrm{H}_{2} \mathrm{O} \uparrow \rightarrow \alpha-\mathrm{MoO}_{3} \rightarrow \mathrm{MoO}_{3-\delta},
\end{gathered}
$$

Vibrational spectra of $\mathrm{MoO}_{3} \cdot \mathrm{H}_{2} \mathrm{O}$ and dehydrated products obtained after heat treatment were studied by Raman spectroscopy, which appears to be a sensitive technique to distinguish unambiguously inter-lamellar $\mathrm{MoO}_{6}$ octahedra from octahedra sharing two common edges. The Raman spectrum of the product heated above $470{ }^{\circ} \mathrm{C}$ exhibits superposition the spectral features of $\beta-\mathrm{MoO}_{3}$ and $\alpha-\mathrm{MoO}_{3}$ crystal. Moreover, FTIR spectra of dehydrated $\mathrm{MoO}_{3} \cdot n \mathrm{H}_{2} \mathrm{O}(n<1)$ shown in Fig. 4c are also more complex than that of crystalline $\mathrm{MoO}_{3}$, but spectral features can be discussed in terms of internal and external modes as usual for oxide lattices. The highest frequency bands are due to the symmetric stretching mode of the shortest $\mathrm{Mo}=\mathrm{O}$ bond (the socalled molybdyl-mode), whereas the next highest bands are assigned to the stretch of intermediate bridging Mo-O bonds (longer Mo-O distances). The bending modes due to O-Mo$\mathrm{O}$ bonds are located in the medium frequency range [77], while the external modes appear below $300 \mathrm{~cm}^{-1}$. FTIR results (Fig. 4c) clearly show the change in the local structure of the MOs for annealing treatment $T>250{ }^{\circ} \mathrm{C}$ of starting $\mathrm{MoO}_{3} \cdot \mathrm{H}_{2} \mathrm{O}$ in good agreement with XRD patterns (Fig. 4b). Here, the modifications of the crystallinity can be deduced using the shape and frequency of the four groups of peaks. At intermediate heat treatment we observe the bands attributed to the mixed phase during the transformation from $\beta-\mathrm{MoO}_{3}$ to $\alpha-\mathrm{MoO}_{3}$ [309].

Camacho-López et al. [372] reported that the $\mathrm{MoO}_{3} \cdot 1.4 \mathrm{H}_{2} \mathrm{O}$ glassy phase transforms to the amorphous $\mathrm{MoO}_{3} \cdot 0.7 \mathrm{H}_{2} \mathrm{O}$ phase prior to its crystallization, while the sample heated at $500{ }^{\circ} \mathrm{C}$ crystallizes into the orthorhombic $\alpha-\mathrm{MoO}_{3}$ with micro-crystallites having an average size of 6.8 
$\mu \mathrm{m}$. The local structure of products obtained by dehydration was investigated by Raman spectroscopy as shown in Fig. 23 with the correspond SEM images of the as-prepared samples. In the Mo-O stretching mode region $\left(100-600 \mathrm{~cm}^{-1}\right)$ the broad bands are due to the highly disordered $\mathrm{MoO}_{5}\left(\mathrm{H}_{2} \mathrm{O}\right)$ octahedral units in the amorphous hydrated sample $\left(\mathrm{a}-\mathrm{MoO}_{3} \cdot 1.4 \mathrm{H}_{2} \mathrm{O}\right)$. These bands are centered on those of the Raman spectrum of the polycrystalline $\mathrm{MoO}_{3} \cdot 1 \mathrm{H}_{2} \mathrm{O}$ phase, so the patterns of $\mathrm{MoO}_{3} \cdot 1.4 \mathrm{H}_{2} \mathrm{O}$ are the features envelop of $\mathrm{MoO}_{3} \cdot 1 \mathrm{H}_{2} \mathrm{O}$. The sample a- $\mathrm{MoO}_{3} \cdot 1.4 \mathrm{H}_{2} \mathrm{O}$ heated at $120{ }^{\circ} \mathrm{C}$ for $1 \mathrm{~h}$ transforms to $\mathrm{MoO}_{3} \cdot 0.7 \mathrm{H}_{2} \mathrm{O}$. The overall decrease of the Raman signal is due to the enhancement of the electrical conductivity (decrease of the penetration depth of the light) of the partially dehydrated sample [319]. The Raman spectrum exhibits the spectral features at 705,850 and $948 \mathrm{~cm}^{-1}$ of the $\mathrm{MoO}_{3} \cdot 1.4 \mathrm{H}_{2} \mathrm{O}$ with additional vibrations at 665 and $983 \mathrm{~cm}^{-1}$ assigned to the Mo-O3 stretch $\left(B_{2 g}, B_{3 g}\right.$ mode) and $\mathrm{M}=\mathrm{O}$ stretch ( $A_{g}$ mode) of the $\mathrm{MoO}_{3} \cdot 0.7 \mathrm{H}_{2} \mathrm{O}$ phase, respectively. These structural changes are related to water removal, which induces shorter $\mathrm{Mo}=\mathrm{O}$ bonds and the less octahedral distortion. For wellcrystallized $\alpha-\mathrm{MoO}_{3}$, the peak at $983 \mathrm{~cm}^{-1}$ shows a red shift to $995 \mathrm{~cm}^{-1}$ and becomes a narrow line due to its non-polar character. It is worth noting that the line shape of the stretching modes is a function of the particle size growing with the annealing temperature of the glassy phase. Thus, the phonon confinement is observed in the case of $\mathrm{MoO}_{3}$ crystallization, i.e., the Raman peaks broadened and little asymmetry is observed at $819 \mathrm{~cm}^{-1}$. When $\mathrm{MoO}_{3}$ nano-particles formed were large in diameter $(L \geq 40 \mathrm{~nm})$ no significant downshift can be observed. The frequency of the stretch of terminal Mo=O shows a step at ca. $T_{\mathrm{a}}=120^{\circ} \mathrm{C}$.
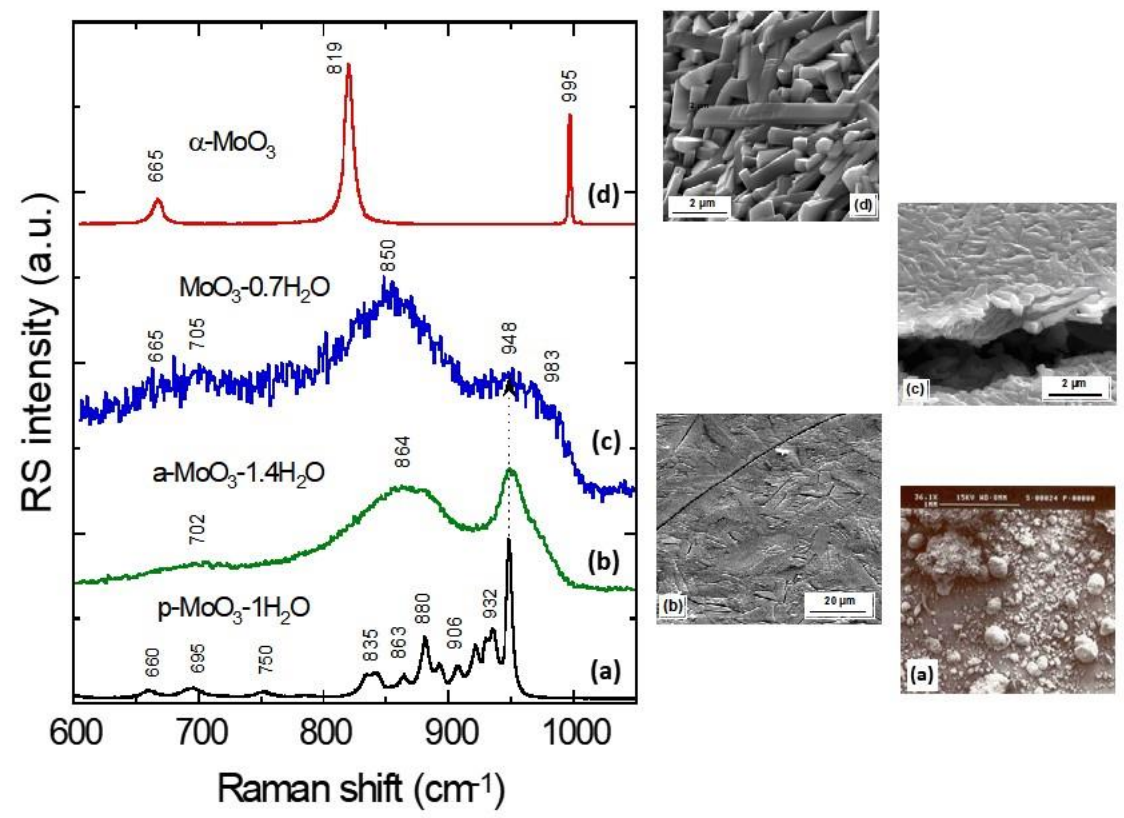

Fig. 23. Raman spectra for four different molybdenum trioxide phases: the $\mathrm{MoO}_{3} \cdot 1 \mathrm{H}_{2} \mathrm{O}$ polycrystalline powders, the $\mathrm{MoO}_{3} \cdot 1.4 \mathrm{H}_{2} \mathrm{O}$ hydrated phase, the partially $\mathrm{MoO}_{3} \cdot 0.7 \mathrm{H}_{2} \mathrm{O}$ 
dehydrated phase, and the orthorhombic $\alpha-\mathrm{MoO}_{3}$ phase with their corresponding SEM images.

Haro-Poniatowski et al. [102] have reported the preparation of hydrated $\mathrm{MoO}_{3}$ by acidification of sodium molybdate $\left(\mathrm{Na}_{2} \mathrm{MoO}_{4}\right)$ solution and have also revealed the dependence of the morphology and color of the resulting product on the drying procedure. Using Raman scattering techniques, they demonstrated the evolution of the sample from a low temperature glass phase to a high temperature glass phase then crystallization under laser radiation. The thermally induced structural transformations in hydrated $\mathrm{MoO}_{3}$ samples prepared by acidification of $\mathrm{Na}_{2} \mathrm{MoO}_{4}$ solution have been investigated dynamically by combined analytic techniques such as thermo-Raman spectroscopy, thermogravimetry, differential thermal calorimetry and X-ray diffraction [103]. Results reveal that the structural evolution proceeds through an amorphous phase after dehydration processes, formation of sub-microcrystals, the possible $\mathrm{MoO}_{3}$-II phase and the $\alpha-\mathrm{MoO}_{3}$ phase. The structural evolution under a flow of nitrogen gas indicated that the sample formed after dehydration could be oxygen deficient $\mathrm{MoO}_{3-\delta}$. Du et al. [373] prepared the $\mathrm{MoO}_{3} \cdot 0.55 \mathrm{H}_{2} \mathrm{O}$ phase by sonication of ammonium molybdate solution added to a mixture of 3-mercaptopropyltrimethoxysilane (MPTS) with anhydrous toluene. The light-blue sample obtained after vacuum drying at $70{ }^{\circ} \mathrm{C}$ for $6 \mathrm{~h}$ has a hexagonal structure with lattice parameters $\alpha=10.581 \AA, c=3.720 \AA$ (JCPDS card No. 761003). $\mathrm{MoO}_{3} \cdot 0.55 \mathrm{H}_{2} \mathrm{O}$ was converted into $\alpha-\mathrm{MoO}_{3}$ till the temperature reached $400{ }^{\circ} \mathrm{C}$.

\subsection{Electrical conductivity}

Figure 24 shows the temperature dependence of the electrical conductivity, $\sigma_{\mathrm{dc}}$, of MOHs heat-treated at various temperatures in the range $140-458{ }^{\circ} \mathrm{C}$. It is well known that transitionmetal oxides can be non-stoichiometric. $\mathrm{MoO}_{3}$ is such a material. $\mathrm{Mo}^{5+}$ ions can be produced as a consequence of the formation of oxygen vacancies. The conduction process has been described as a carrier hopping mechanism between localized states [18]. Small polarons are formed around these ions, due to the highly polar structure of this oxide. A thermally activated electronic hopping between lower and higher valence states is responsible for the electric transport. Also, it has been pointed out that the number of vacancies in $\mathrm{MoO}_{3}$ films is indicated by the colour of the film [177]. The electrical conductivity curves shown in Fig. 24 are typical of a hopping mechanism. The activation energies of the high-temperature regime are in the range $0.5-0.7 \mathrm{eV}$. The increase in $\sigma_{\mathrm{dc}}$ suggests a decrease of the $\mathrm{O} / \mathrm{Mo}$ ratio due to the oxygen 
loss in annealed materials. The highly treated samples $\left(T_{\mathrm{a}}=458{ }^{\circ} \mathrm{C}\right)$ have the highest electrical conductivity values.

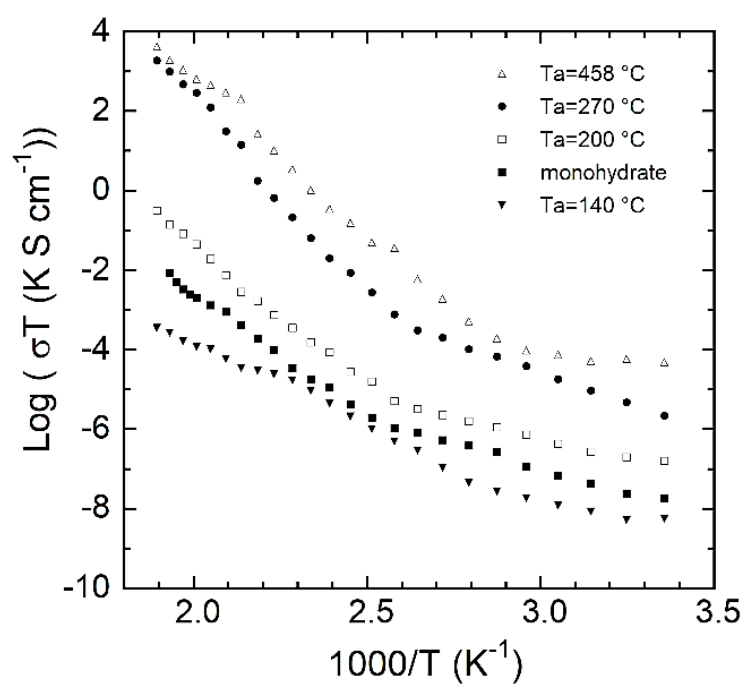

Fig. 24. Arrhenius plots of the electrical conductivity of molybdenum monohydrate $\mathrm{MoO}_{3} \cdot 1 \mathrm{H}_{2} \mathrm{O}$ and products heat-treated at various temperatures in the range $140-458{ }^{\circ} \mathrm{C}$.

\subsection{Intercalation in $\mathrm{MoO}_{3} \cdot n \mathrm{H}_{2} \mathrm{O}$}

Molybdate-based layered hybrids derived by intercalating organic guest species into the interlayer spaces of $\mathrm{MoO}_{6}$ layers have also been a hot research topic, and the as-obtained organic-inorganic hybrids can be used as the precursors to prepare $\mathrm{MoO}_{3}$ nanostructures [167,374-376]. Afsharpour et al. [374] synthesized molybdenum oxide nanohybrids using yellow molybdic acid and amino-carboxylates as the starting materials in an ethanol-water (1:3) mixed solution, and $\alpha-\mathrm{MoO}_{3}$ nanostructures with high surface areas were obtained by calcining the as-obtained nanohybrids at $600{ }^{\circ} \mathrm{C}$. Niederberger et al. [167] prepared molybdenum oxideamine hybrid composites by hydrothermally treating the ethanol-water mixed suspension of yellow $\mathrm{MoO}_{3} \cdot 2 \mathrm{H}_{2} \mathrm{O}$ and amines at $120{ }^{\circ} \mathrm{C}$, and the molybdenum oxide-amine hybrid composites were used as the precursor to synthesize a-MoO${ }_{3} \cdot \mathrm{H}_{2} \mathrm{O}$ nanofibers. Shukoor et al. [375] systematically investigated the intercalation behaviors of amines with various n-alkyl lengths into yellow molybdic acid $\left(\mathrm{MoO}_{3} \cdot 2 \mathrm{H}_{2} \mathrm{O}\right)$ in ethanol/water $(1 / 3, \mathrm{v} / \mathrm{v})$ solutions, and the as-obtained hybrids were transformed to $\mathrm{MoO}_{3}$ rods, scrolls and disks by $33 \% \mathrm{HNO}_{3}$ treatment. In these intercalation reactions, elevated temperatures are usually necessary. Chen et al. [374] investigated molybdate-based inorganic-organic hybrids, which are formed from the reaction of white molybdic acid $\left(\mathrm{MoO}_{3} \cdot \mathrm{H}_{2} \mathrm{O}\right)$ powders and n-octylamine at room temperature, for sensing applications. 
The suitability of MOHs as 3-volt electrode materials for non-aqueous lithium batteries has been assessed by several workers [121,319,366,377-379]. In early studies of electrochemical lithium insertion in MOHs Kumagai et al. [201,380,381]. Discharge profiles and kinetics are dependent on the amount of "structural water" into the host lattice. Compositional range was reported to be more than $2.5 \mathrm{Li} / \mathrm{Mo}$ reversibly inserted into crystalline $\mathrm{MoO}_{3} \cdot 2 \mathrm{H}_{2} \mathrm{O}$, which is higher than the $1.5 \mathrm{Li} / \mathrm{Mo}$ obtained for anhydrous $\alpha-\mathrm{MoO}_{3}$. Numerous hydrated forms of $\mathrm{MoO}_{3} \cdot \mathrm{y}\left(\mathrm{H}_{2} \mathrm{O}\right)(\mathrm{y}=0.3 \sim 0.6)$ were prepared using the Freedman's method by hydrothermal acidification of $\mathrm{Na}_{2} \mathrm{MoO}_{4}$ solution with $6 \mathrm{~mol} \mathrm{~L}-1 \mathrm{HCl}$. The orthorhombic structure was obtained at $\mathrm{HCl} / \mathrm{Na}_{2} \mathrm{MoO}_{4}$ ratio of $2.0 \sim 1.5$ and $150 \sim 180{ }^{\circ} \mathrm{C}$, while a hexagonal network was formed at lower ratio. The as-prepared $\mathrm{MoO}_{3} \cdot 0.58\left(\mathrm{H}_{2} \mathrm{O}\right)$ has crystallographic parameters $a=3.955 \AA, b=13.805 \AA, c=3.684 \AA$ and $V=201.1 \AA^{3}$. As shown in the XRD patterns (Fig. 25a), the (021) reflection intensity is sensitive with the annealing temperature. The initial discharge-charge curves in $1 \mathrm{~mol} \mathrm{~L}^{-1} \mathrm{LiClO}_{4}$ in propylene carbonate as electrolyte at $0.2 \mathrm{~mA} \mathrm{~cm}{ }^{-2}$ current density and cycling performance are shown in Figs 25b-c. The maximum first discharge capacity of $335 \mathrm{mAh} \mathrm{g}^{-1}$ is delivered by the $\mathrm{MoO}_{3} \cdot 0.58\left(\mathrm{H}_{2} \mathrm{O}\right)$ electrode heat-treated at $200{ }^{\circ} \mathrm{C}$. However, a rapid decrease in specific capacity is observed after few cycles (Fig. 25c) [382]. The same group of workers reported the suitability of $\mathrm{MoO}_{3} \cdot \mathrm{H}_{2} \mathrm{O}$ to deliver a discharge capacity of about $400 \mathrm{mAh} \mathrm{g}^{-1}$ with a voltage plateau around $2.5 \mathrm{~V}$ vs. $\mathrm{Li}^{+} / \mathrm{Li}$. The $\mathrm{MoO}_{3} \cdot \mathrm{H}_{2} \mathrm{O}$ crystal was found to be changed from a monoclinic to orthorhombic structure with lattice parameters of $a=5.285 \AA, b=10.824 \AA, c=5.237 \AA$ on discharge to $0.5 \mathrm{e}^{-} / \mathrm{Mo}$ [201]. Similar synthesis process was used to prepared yellow $\mathrm{MoO}_{3} \cdot 2 \mathrm{H}_{2} \mathrm{O}$ powders in $1 \mathrm{~mol} \mathrm{~L}^{-1} \mathrm{Na}_{2} \mathrm{MoO}_{4}$ aqueous solution with $3 \mathrm{~mol} \mathrm{~L}-1 \mathrm{HCl}$ at $100{ }^{\circ} \mathrm{C}$. Starting from an initial value of about $340 \mathrm{mAh} \mathrm{g}^{-1}$ obtained at a discharge exchange rate of $\mathrm{C} / 10$, the specific capacity continuously decreases with cycling. However, after the tenth cycle in the potential limits 3.8-2.0 V about $300 \mathrm{mAh} \mathrm{g}^{-1}$ are still available against only $240 \mathrm{mAh} \mathrm{g}^{-1}$ in the case of conventional $\mathrm{MoO}_{3}$ [383]. Komaba et al. [336] showed that the orthorhombic $x\left(\mathrm{Li}_{2} \mathrm{O}\right) \cdot \mathrm{MoO}_{3} \cdot y\left(\mathrm{H}_{2} \mathrm{O}\right)$ electrode which was hydrothermally formed from $\mathrm{Li}_{2} \mathrm{MoO}_{4}$ system underwent electrochemical lithium intercalation up to $\mathrm{Li} / \mathrm{Mo} \approx 1.6\left(>300 \mathrm{mAh}\left(\mathrm{g}_{\text {oxide }}\right)^{-1}\right)$ on electroreduction until $1.3 \mathrm{~V}$ vs. $\mathrm{Li}^{+} / \mathrm{Li}$. 

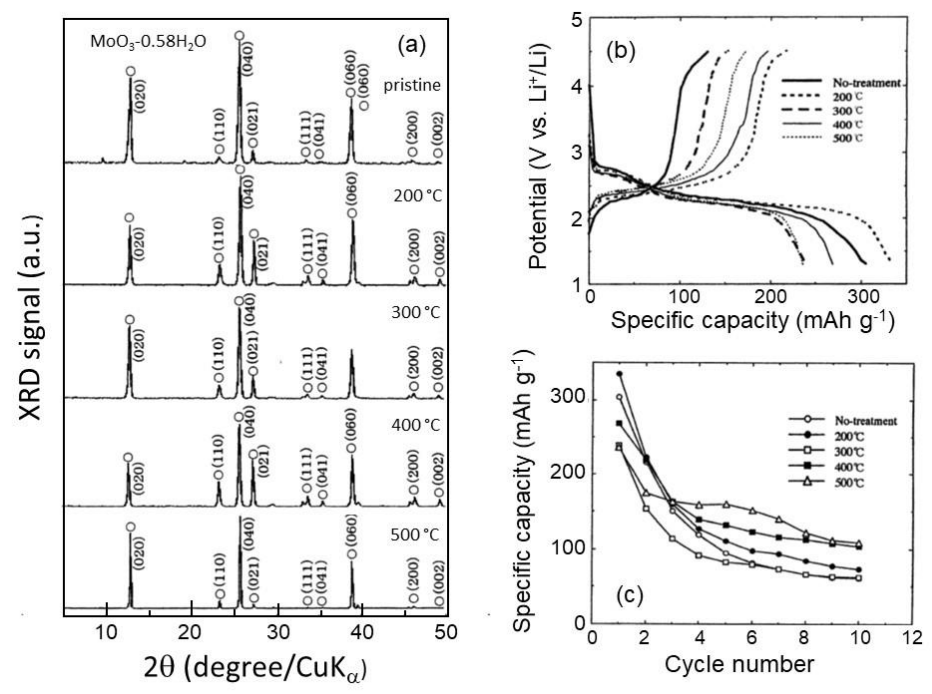

Fig. 25. (a) XRD patterns of orthorhombic $\mathrm{MoO}_{3} \cdot 0.58\left(\mathrm{H}_{2} \mathrm{O}\right)$ electrode prepared at $150{ }^{\circ} \mathrm{C}$ with $\mathrm{H}^{+} / \mathrm{Na}^{+}$ratio of 2.0 and its heat-treated products (o: orthorhombic phase). (b) Initial dischargecharge curves in $1 \mathrm{~mol} \mathrm{~L}^{-1} \mathrm{LiClO}_{4}$ in propylene carbonate as electrolyte at $0.2 \mathrm{~mA} \mathrm{~cm}^{-2}$ current density. (c) cycling performance. On line at https://books.google.fr/books?

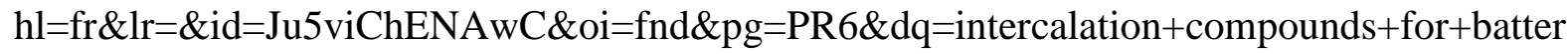
$\mathrm{y}+$ materials.

It was made clear as a general trend that the discharge capacity of MOHs increases with decreasing water content, but cycle life increases with increasing water content in the compositional range $0.33<n<1.0$. Julien et al. [121,366,377] reported the discharge curves performed on $\mathrm{MOHs}$ from open circuit potential down to $2.5 \mathrm{~V}$ vs. $\mathrm{Li}^{+} / \mathrm{Li}(-0.77 \mathrm{~V}$ vs. $\mathrm{Ag} / \mathrm{AgCl}$ ). This general trend has been also observed for $\mathrm{MoO}_{3}$ thin films prepared by electrodeposition from peroxo-polymolybdate solutions [318]. Amorphous oxide-hydrate of molybdenum $\mathrm{MoO}_{3} \cdot 2 \mathrm{H}_{2} \mathrm{O}$ was obtained during the synthesis of $\beta-\mathrm{MoO}_{3}$ by cation exchange of an aqueous solution of $\mathrm{Na}_{2} \mathrm{MoO}_{4} \cdot 2 \mathrm{H}_{2} \mathrm{O}$ passed through a cation exchange resin (Dowex 50WX8-200). As a product of this process, a solution with a pale green color and a pH of 2 was obtained. This solution was placed in a $50 \mathrm{ml}$ vessel that was connected to a vacuum pump for $36 \mathrm{~h}$. In this time, all water was removed slowly and a green powder was obtained as a residue [378]. Electrochemical lithium insertion in amorphous $\mathrm{MoO}_{3} \cdot 2 \mathrm{H}_{2} \mathrm{O}$ led to a specific capacity of the cell of $490 \mathrm{mAh} \mathrm{g}^{-1}$. This value exceeds notably the capacity developed by anhydrous $\beta$ $\mathrm{MoO}_{3}\left(370 \mathrm{mAh} \mathrm{g}^{-1}\right)$. Kumagai et al. [380] investigated $x\left(\left(\mathrm{NH}_{4}\right)_{2} \mathrm{O}\right) \cdot \mathrm{MoO}_{3} \cdot y\left(\mathrm{H}_{2} \mathrm{O}\right)$ (with $x=$ 0.075-0.042, $y=0.40-0.043$ ) as cathode materials in Li cells. At current densities of $0.5 \mathrm{~mA}$ $\mathrm{cm}^{-2}$ and an average discharge voltage of $2 \mathrm{~V}$, theoretical energy densities of ca. $600 \mathrm{Wh} \mathrm{kg}^{-1}$ 
have been predicted, which are considerably higher than in the case of completely dehydrated molybdenum oxides. However, the performance of $x\left(\left(\mathrm{NH}_{4}\right)_{2} \mathrm{O}\right) \cdot \mathrm{MoO}_{3} \cdot y\left(\mathrm{H}_{2} \mathrm{O}\right)$ decreases drastically with subsequent cycling. The differing discharge mechanisms for the latter compounds (heterogeneous reaction) and $\mathrm{MoO}_{3}$ (homogeneous reaction) has been discussed on the grounds of discharge characteristics, XRD data, and structural models. The maximum amount of lithium $(\sim 3.3 \mathrm{Li} / \mathrm{Mo})$ incorporated in amorphous $\mathrm{MoO}_{3} \cdot 2 \mathrm{H}_{2} \mathrm{O}$ leads to a specific capacity of $490 \mathrm{mAh} \mathrm{g}^{-1}$. The charge-discharge curve showed a good reversibility in the potential range from 3.2 to $1.1 \mathrm{~V} v s$. $\mathrm{Li}^{+} / \mathrm{Li}$, where the cell voltage decreased monotonously as a function of the degree of lithium inserted [378].

Monoclinic monohydrate, $\mathrm{MoO}_{3} \cdot 1 \mathrm{H}_{2} \mathrm{O}$, having only one coordinated water molecule, shows a discharge capacity of about $200 \mathrm{mAh} \mathrm{g}^{-1}$ of acid weight equivalent and a discharge potential around $2.5 \mathrm{~V}$ vs. $\mathrm{Li}^{+} / \mathrm{Li}$. This electrode material displays a good charge-discharge cyclic behaviour at a capacity below $1 \mathrm{Li} / \mathrm{Mo}$, while keeping the original layered lattice on cycling. Guzman et al. [366] studied a crystalline $\mathrm{MoO}_{3} \cdot 1 \mathrm{H}_{2} \mathrm{O}$ electrode prepared by sol-gel method, while Yebka et al. used commercial molybdebum-trioxide hydrate powders [319]. Figure 27 presents the electrochemical behavior of the crystalline $\mathrm{MoO}_{3} \cdot 1 \mathrm{H}_{2} \mathrm{O}$ investigated at the current rate of $\mathrm{C} / 10$ (cathode loading of $2.3 \mathrm{mg} \mathrm{cm}^{-2}$ ). In the potential voltage $1.5-3.0 \mathrm{~V}$ vs. $\mathrm{Li}^{+} / \mathrm{Li}$, the first discharge occurs a $\mathrm{Li}$ uptake identical to that of anhydrous $\mathrm{MoO}_{3}(1.5 \mathrm{Li} / \mathrm{Mo})$. The electroinsertion of $\mathrm{Li}$ ions occurs mainly in two steps in the potential range between 3.0 and $1.5 \mathrm{~V}$ (compositional range $0.0 \leq x \leq 1.5$ ): a first plateau at ca. $2.85 \mathrm{~V}$ in the range $0 \leq x \leq$ 0.25 and at wide plateau at ca. $2.35 \mathrm{~V}$ with a sloppy region in between, which corresponds to a single-phase insertion mechanism (Fig. 26a). The $\mathrm{MoO}_{3} \cdot 1 \mathrm{H}_{2} \mathrm{O}$ electrode delivers a first discharge capacity of $344 \mathrm{mAh} \mathrm{g}^{-1}$, which maintains at $\sim 200 \mathrm{mAh} \mathrm{g}^{-1}$ after 100 cycles (Fig. 26b). The discharge/charge curves have been modelled using the Armand's model with two adjacent domains including an ion-ion interaction term for each voltage region [3]. The electrochemical behaviour of anhydrous sample shows higher discharge capacity than that of hydrated $\mathrm{MoO}_{3}\left(262 \mathrm{mAh} \mathrm{g}{ }^{-1}\right) . \mathrm{MoO}_{3} \cdot 1 \mathrm{H}_{2} \mathrm{O}$ has only a coordinated water molecule in the structure. It is obvious that this open structure is favourable to the lithium insertion. The temperature dependence of the discharge-charge shows that $\mathrm{Li} / / \mathrm{MoO}_{3} \cdot 1 \mathrm{H}_{2} \mathrm{O}$ cells can operate efficiently at different temperatures in the range of $25-50{ }^{\circ} \mathrm{C}$. However, in the case of $\mathrm{Li} / / \mathrm{MoO}_{3} \cdot 1 \mathrm{H}_{2} \mathrm{O}$ operating at $50{ }^{\circ} \mathrm{C}$, the cell voltage range is about $5 \%$ less than for the material operating at $25{ }^{\circ} \mathrm{C}$. Amorphous $\mathrm{MoO}_{3} \cdot 1 \mathrm{H}_{2} \mathrm{O}$ electrode exhibits stepwise discharge behaviour, including two plateaus: the first step up to $0.3 \mathrm{e}^{-/ \mathrm{Mo}}$ and the second one up to $1.0 \mathrm{e}^{-} / \mathrm{Mo}$. A 
discharge capacity of $260 \mathrm{mAh} \mathrm{g}^{-1}$ is delivered in the potential range corresponding to $1.5 \mathrm{e}^{-/ \mathrm{Mo}}$ [366].
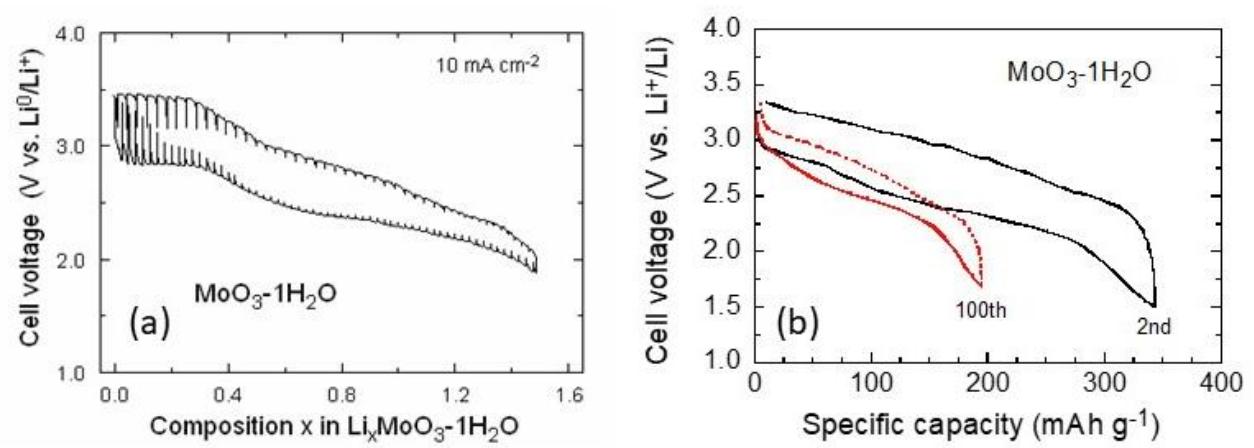

Fig. 26. (a) First galvanostatic discharge-charge curve of the $\mathrm{MoO}_{3} \bullet 1 \mathrm{H}_{2} \mathrm{O}$ positive electrode recorded at $\mathrm{C} / 10$ rate in the potential range 2.0-3.5 $\mathrm{V}$ vs. $\mathrm{Li}^{+} / \mathrm{Li}$. (b) Electrochemical patterns of $\mathrm{MoO}_{3} \bullet 1 \mathrm{H}_{2} \mathrm{O}$ at the $2^{\text {nd }}$ and $100^{\text {th }}$ cycle.

The electrochemical features of the crystalline $\mathrm{MoO}_{3} \cdot 1 / 2 \mathrm{H}_{2} \mathrm{O}$ electrode are rather similar with the appearance of three plateaus at. ca. 2.5, 1.75 and 1.5 V (Fig. 27a). This electrochemical behaviour is attributed to the large cavities available for Li ions, which prevent repulsive forces between inserted ions. The structure of $\mathrm{MoO}_{3} \cdot 1 / 2 \mathrm{H}_{2} \mathrm{O}$ may be described as an alteration of linear double rows of edge-sharing distorted $\mathrm{MoO}_{6}$ and $\mathrm{MoO}_{5}\left(\mathrm{H}_{2} \mathrm{O}\right)$ octahedral [309]. In the potential range 3.0-1.0 V, the $\mathrm{MoO}_{3}$ hemihydrate electrode delivers a first discharge capacity of $353 \mathrm{mAh}$ $\mathrm{g}^{-1}$ for a charge transfer of $\sim 1.5 \mathrm{e}^{-/ M o}$. The cyclability of $\mathrm{MoO}_{3} \cdot 1 / 2 \mathrm{H}_{2} \mathrm{O}$ (Fig. 27b) shows the electrode cycled 100 times at $\mathrm{C} / 10$ rate retains a capacity of $201 \mathrm{mAh} \mathrm{g}^{-1}$. Figure $27 \mathrm{c}$ presents the XRD patterns of $\mathrm{Li}_{\mathrm{x}} \mathrm{MoO}_{3} \cdot 1 / 2 \mathrm{H}_{2} \mathrm{O}$ as a function of the amount of $\mathrm{Li}$ electrochemically inserted. The monoclinic structure remains largely unchanged upon lithiation with the strongest (001) reflection line shifted toward lower angles (inset Fig. 27c). This result suggests that, on discharging, $\mathrm{Li}^{+}$ions are inserted between the layers leading to a small increase of the interlayer spacing, which can be explained by a model of rigid hydrated- $\mathrm{MoO}_{3}$ layers in their original state separated by intercalated Li cations. Figure 27d displays the FTIR absorption spectra of pristine and $\mathrm{Li}$ intercalated products. The FTIR spectra of $\mathrm{Li}_{0.15} \mathrm{MoO}_{3} \cdot 1 / 2 \mathrm{H}_{2} \mathrm{O}$ and $\mathrm{Li}_{0.15} \mathrm{MoO}_{3} \cdot 1 / 2 \mathrm{H}_{2} \mathrm{O}$ samples show new bands at 1780, 1200, 1148, 1117 and $1087 \mathrm{~cm}^{-1}$. The band at $1780 \mathrm{~cm}^{-1}$ is assigned to the stretching vibration $v_{\mathrm{C}=\mathrm{O}}$ of propylene carbonate molecules. Its position is shifted towards lower energies compared with pure propylene carbonate suggesting that solvent molecules are bonded at the surface of the oxide network. The bands situated in the region 1200-1080 $\mathrm{cm}^{-1}$ are attributed to the stretching mode of Li atoms inserted between layers vibrating against the nearest neighboring oxygen atoms [366]. 

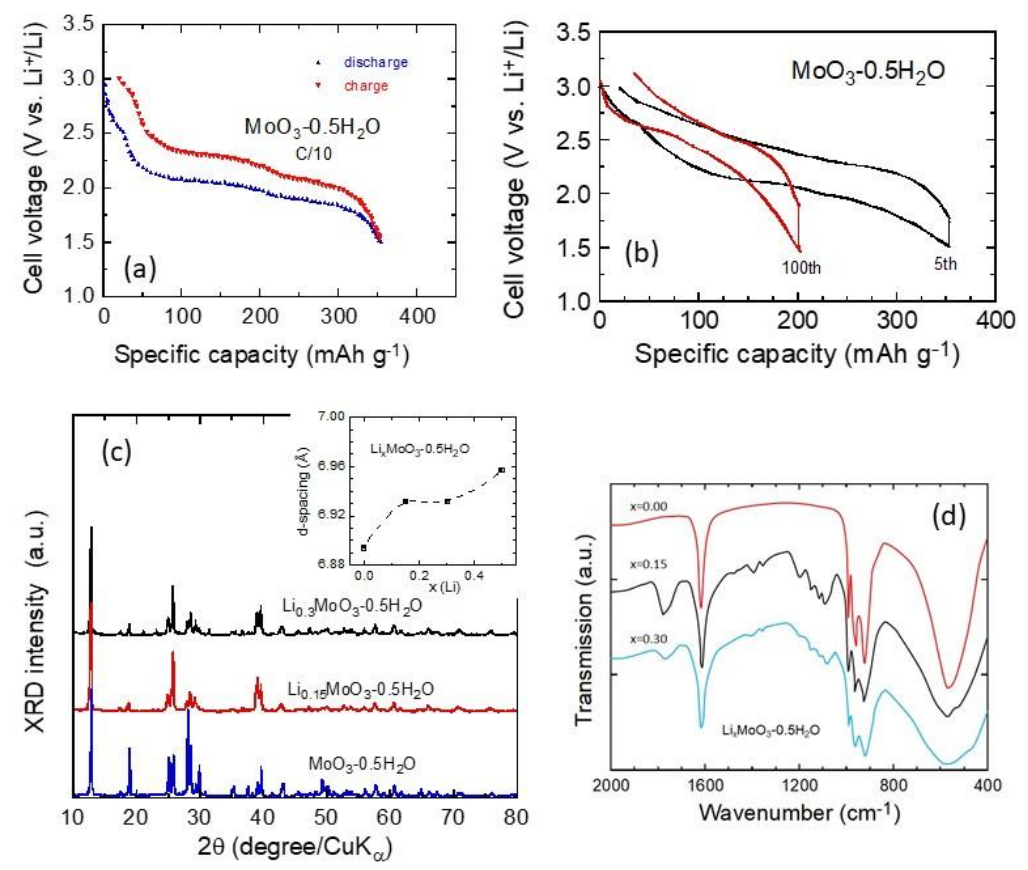

Fig. 27. (a) Typical discharge curves of amorphous $\mathrm{MoO}_{3} \cdot 1 / 2 \mathrm{H}_{2} \mathrm{O}$ powders cycled at $\mathrm{C} / 10$ rate in the potential window3.0-1.5 V vs. $\mathrm{Li}^{+} / \mathrm{Li}$. (b) Electrochemical patterns of $\mathrm{MoO}_{3} \cdot 1 / 2 \mathrm{H}_{2} \mathrm{O}$ at the $5^{\text {th }}$ and $100^{\text {th }}$ cycle. (c) XRD patterns of lithiated $\mathrm{MoO}_{3} \cdot 1 / 2 \mathrm{H}_{2} \mathrm{O}$ powders using electrochemical titration. The insert shows the variation of the d-spacing vs. $x(\mathrm{Li})\left(\right.$ reflection at $\left.2 \theta=12.8^{\circ}\right)$. (d) FTIR absorption spectra of pristine $\mathrm{MoO}_{3} \cdot 1 / 2 \mathrm{H}_{2} \mathrm{O}$ and electrochemically $\mathrm{Li}$ inserted $\mathrm{Li}_{x} \mathrm{MoO}_{3} \cdot 1 / 2 \mathrm{H}_{2} \mathrm{O}(x=0.15$ and 0.3$)$.

$\mathrm{MoO}_{3} \cdot 0.66 \mathrm{H}_{2} \mathrm{O}$ powders were prepared by heating molybdic acid $\left(\mathrm{MoO}_{3} \cdot \mathrm{H}_{2} \mathrm{O}\right)$ at $T_{\mathrm{a}}=216$ ${ }^{\circ} \mathrm{C}$ [121,317,319]. Figures 28a-b show the typical discharge-charge curves of $\mathrm{Li}_{\mathrm{x}} \mathrm{MoO}_{3} \cdot 2 / 3 \mathrm{H}_{2} \mathrm{O} / / \mathrm{Li}$ cells cycled at $\mathrm{C} / 10$ rate in the potential range 3.5-1.5 $\mathrm{V}$ vs. $\mathrm{Li}^{+} / \mathrm{Li}$, which exhibit electrochemical patterns as follows: (i) an initial OCV of $\sim 3.5 \mathrm{~V}$, (i) a Li uptake $1.5 \mathrm{Li}$ per Mo atom providing a discharge capacity of $260 \mathrm{mAh} \mathrm{g}^{-1}$, (iii) a large voltage plateau at ca. $2.2 \mathrm{~V}$, and (iv) the discharge capacity remains at $162 \mathrm{mAh} \mathrm{g}^{-1}$ after 100 cycles. Note the absence of the first discharge voltage plateau in the $0.0<x<0.25$ observed in discharge profiles of other $\mathrm{MOHs}$ and of anhydrous $\mathrm{MoO}_{3}$, which show the strong dependence of the water content on the $\mathrm{Li}$ insertion process in $\mathrm{MOH}$ frameworks. The S-shaped behaviour of the discharge-charge curves of the $\mathrm{MoO}_{3} \cdot 2 / 3 \mathrm{H}_{2} \mathrm{O}$ electrode suggests single-phase reaction $\mathrm{Li}_{\mathrm{X}} \mathrm{MoO}_{3} \cdot 2 / 3 \mathrm{H}_{2} \mathrm{O}$ in the range $0.0 \leq x \leq 1.5$. Structural changes in Li-intercalated were analysed using in situ XRD in $\mathrm{MoO}_{3} \cdot 2 / 3 \mathrm{H}_{2} \mathrm{O} / \mathrm{LiClO}_{4}-\mathrm{PC}$ electrolyte/Li cell (Fig. 28c) and Raman spectroscopy (Fig. 28d). The Raman spectrum of $\mathrm{MoO}_{3} \cdot 2 / 3 \mathrm{H}_{2} \mathrm{O}$ is in fair agreement with the spectrum of $\mathrm{MoO}_{3}$ [77]. Bands located at 120 and $150 \mathrm{~cm}^{-1}$ are assigned to vibrations of the $\left(\mathrm{O}_{2} \mathrm{Mo}_{2}\right)_{\mathrm{n}}$ chains while bands 
located at 335, 440 and $657 \mathrm{~cm}^{-1}$ are attributed to the vibration of the $\mathrm{O}-\mathrm{Mo}_{3}$. After lithium insertion, we observed features as follows. (i) The intensities of original Raman-active vibrations decrease drastically and the background increases. (ii) The background also increases as the frequency shift increases, probably owing to the modification of the electronic band structure upon intercalation. (iii) The low-frequency part of the spectrum remains almost unchanged, indicating that the layered structure of $\mathrm{MoO}_{3} \cdot 2 / 3 \mathrm{H}_{2} \mathrm{O}$ is maintained. (iv) New peaks appear at 562, 546, and $278 \mathrm{~cm}^{-1}$, which are assigned to a longitudinal and transverse intercalation mode [384], in which intercalant species vibrate strongly against the host lattice. Moreover, the reversible insertion behaviour has been also observed by Raman measurements. The original Raman spectrum has been recovered on discharge-charge cycling. Note that the change in colour with increasing Li content seems to start from the physical edges of the sample proceeding along the crystal imperfections (grain boundaries, micro cracks, planer defects, etc.) to a uniform coloration of the crystal [385]. Figure 28e shows the interplanar distance, $d_{\text {int }}$, deduced from the position of the (200) reflection peak as a function of the Li concentration within the $\mathrm{MoO}_{3} \cdot 2 / 3 \mathrm{H}_{2} \mathrm{O}$ framework. In situ XRD patterns were recorded during charge and discharge in the potential range 3.4-1.2 V. The shift toward lower $2 \theta$ position of the (200) line reveals that $\mathrm{Li}$ ions are inserted between layers upon discharge the cell, resulting in a significant increase in the interlayer spacing of about $6 \%$. Layer separation in spite of the reduced dimensions of $\mathrm{Li}$ ions $(0.69 \AA, C N=6)$ is constantly reported for layered compounds. Besenhard and Schollhorn demonstrated an interlayer separation of $1 \AA$ for $x=1$ for the parent oxide $\mathrm{Li}_{x} \mathrm{MoO}_{3}$ [61]. An expansion of $12 \%$ for $d_{\text {int }}$ in the basic structure of $\mathrm{Mo}_{18} \mathrm{O}_{52}$ has been observed by Pasquali et al [386]. The lattice expansion in $\mathrm{Li}_{x} \mathrm{MoO}_{3}$ does not increase continuously with the degree of intercalation, $x$, but shows a maximum in the vicinity of $x=0.1$. Similar situation has been observed for molybdenum bronzes $\mathrm{H}_{x} \mathrm{MoO}_{3}$ [387].
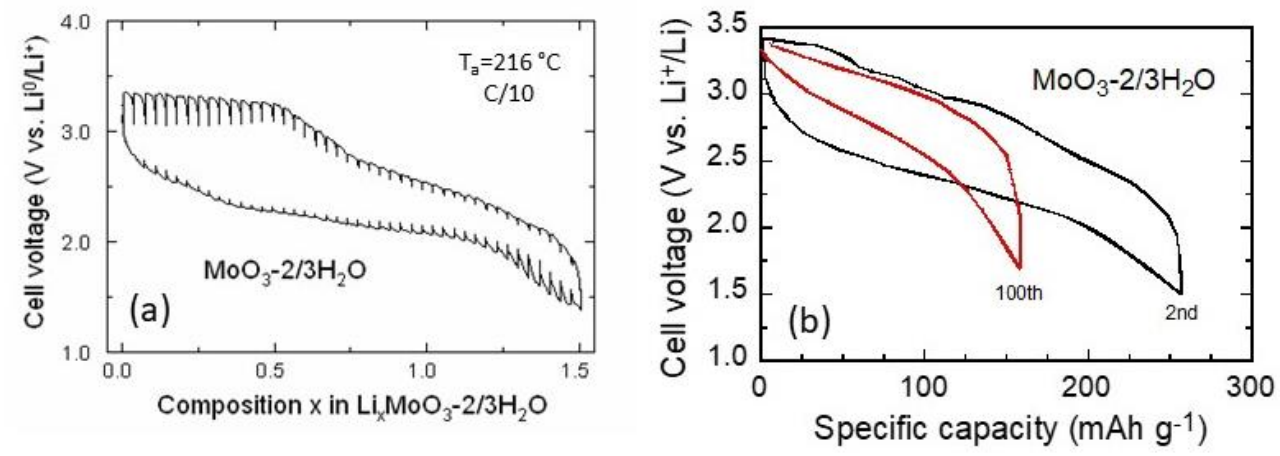

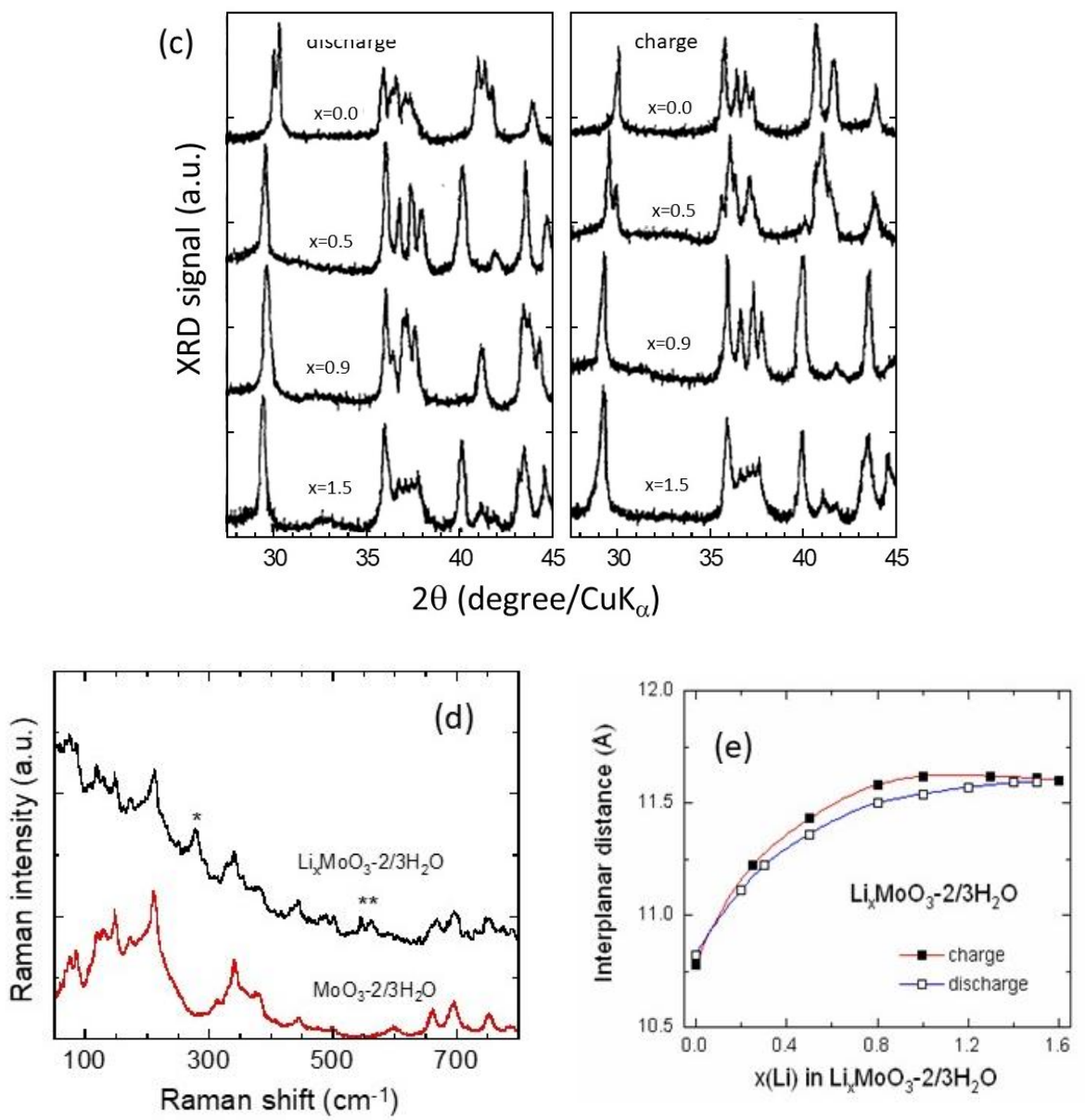

Fig. 28. (a) Galvanostatic discharge-charge curve of the $\mathrm{MoO}_{3} \cdot 2 / 3 \mathrm{H}_{2} \mathrm{O}$ positive electrode. Electrochemical measurements were performed at a rate of $\mathrm{C} / 5$. (b) Electrochemical patterns of $\mathrm{MoO}_{3} \cdot 2 / 3 \mathrm{H}_{2} \mathrm{O}$ at the $2^{\text {nd }}$ and $100^{\text {th }}$ cycle. (c) In situ XRD patterns of $\mathrm{Li}$-intercalated $\mathrm{MoO}_{3} \cdot{ }^{2} / 3 \mathrm{H}_{2} \mathrm{O}$ in $\mathrm{LiClO}_{4}-\mathrm{PC}$ electrolyte. (d) Raman spectra of molybdenum hydrate $\mathrm{Li}_{\mathrm{x}} \mathrm{MoO}_{3} \cdot 2 / 3 \mathrm{H}_{2} \mathrm{O}$ and its lithium intercalated product. New peaks marked by stars are the fingerprints of Li ions located in the interlayer space. (e) Variation of the interplanar distance deduced from the (200) Bragg peak with the $\mathrm{Li}$ concentration within the $\mathrm{MoO}_{3} \cdot 2 / 3 \mathrm{H}_{2} \mathrm{O}$ framework. In-situ XRD patterns were recorded during charge $(\mathbf{\square})$ and discharge $(\bullet)$ in the potential range 3.4-1.2 V.

Using a vacuum drying technique Ramirez et al. have prepared an amorphous hydrate molybdenum oxide a- $\mathrm{MoO}_{3} \cdot 2 \mathrm{H}_{2} \mathrm{O}$ [310]. Electrochemical lithium insertion in a- $\mathrm{MoO}_{3} \cdot 2 \mathrm{H}_{2} \mathrm{O}$ shows a maximum amount of $\mathrm{Li}$ incorporated of $\sim 3.3 \mathrm{Li} / \mathrm{Mo}$, which leads to a specific capacity of $490 \mathrm{mAh} \mathrm{g}^{-1}$ [378]. This value exceeds by more than $20 \%$ the specific capacity developed by its homolog crystalline form $\left(400 \mathrm{mAh} \mathrm{g}^{-1}\right)$. The charge-discharge curves show a good reversibility in the potential range from 3.2 to $1.1 \mathrm{~V} \mathrm{vs.} \mathrm{Li}^{+} / \mathrm{Li}$, where the cell voltage decreased monotonously as a function of the degree of lithium inserted. Yuan and Si prepared a triclinic 
$\alpha-\mathrm{MoO}_{3} \cdot \mathrm{H}_{2} \mathrm{O}$ sample by direct chemical reaction of Mo powders and $\mathrm{H}_{2} \mathrm{O}_{2}$ with the formation of precursor $\mathrm{MoO}_{2}(\mathrm{OH})(\mathrm{OOH})$. Partly dehydrated $\alpha-\mathrm{MoO}_{3} \cdot x \mathrm{H}_{2} \mathrm{O}$ with $x=0.936,0874$ and 0.752 were prepared by vacuum dehydration at 110,150 and $165^{\circ} \mathrm{C}$, respectively (Fig. 29) [379]. Figure 29c presents the first two galvanostatic discharge-charge curves for the triclinic $\alpha-\mathrm{MoO}_{3} \cdot \mathrm{H}_{2} \mathrm{O}$ and its dehydrated products (loading $\sim 2 \mathrm{mg}$ ) tested in 2016-type coin cell with $\mathrm{Li}$ metal anode cycled at $0.1 \mathrm{~A} \mathrm{~g}^{-1}$ current density in the potential range $3.0-0.001 \mathrm{~V} \mathrm{vs}^{+} / \mathrm{Li}$. These profiles show a broad plateau at $0.2 \mathrm{~V}$ ascribed to the conversion reaction involving the transformation of $\mathrm{Li}_{x} \mathrm{MoO}_{3} \cdot \mathrm{H}_{2} \mathrm{O}$ to $\mathrm{Mo}$ and $\mathrm{Li}_{2} \mathrm{O}$ matrix.

Recently, Yu et al. [388] demonstrated a water-incorporation strategy to expand the interlayer gap of $\alpha-\mathrm{MoO}_{3}$, in which water molecules take the place of the non-bridging oxygen of layered lattice. The incorporated $\mathrm{H}_{2} \mathrm{O}$ molecules expand the interlayer channel dimension, i.e., increase of the b-lattice parameter to $15.02 \AA$ compared to $\alpha-\mathrm{MoO}_{3}(13.85 \AA)$. The composition $\mathrm{MoO}_{2.92} \cdot 0.07 \mathrm{H}_{2} \mathrm{O}$ was determined by TGA. The modified $\alpha-\mathrm{MoO}_{3}$ electrode exhibits specific capacity of $963 \mathrm{C} \mathrm{g}^{-1}$ at $0.1 \mathrm{mV} \mathrm{s}^{-1}$, and boosted cycling stability, i.e., a capacity of $455 \mathrm{C} \mathrm{g}^{-1}$ is maintained after 600 cycles at $100 \mathrm{~mA} \mathrm{~g}^{-1}$. A fast-kinetics dual-ionintercalation energy storage device was assembled by combining the $\mathrm{Li}^{+}$intercalation $\alpha-\mathrm{MoO}_{3} \cdot \mathrm{nH}_{2} \mathrm{O}$ anode with an anion-intercalation graphite cathode in 2 mol L-1 $\mathrm{LiPF}_{6}$ electrolyte. Operating within a 1.0-3.5 V voltage window an energy density of $44 \mathrm{Wh} \mathrm{L}^{-1}$ was delivered (based on the whole device). The significant role of the incorporated $\mathrm{H}_{2} \mathrm{O}$ molecules in accelerating the diffusion of $\mathrm{Li}^{+}$within the $\mathrm{MoO}_{2.92} \cdot 0.07 \mathrm{H}_{2} \mathrm{O}$ lattice was studied by galvanostatic titration. The $D_{L i}^{*}$ values $2.4 \times 10^{-12}-3.5 \times 10^{-10} \mathrm{~cm}^{2} \mathrm{~s}^{-1}$ ) are substantially higher than those in $\alpha-\mathrm{MoO}_{3}\left(3.9 \times 10^{-13}-6.0 \times 10^{-11} \mathrm{~cm}^{2} \mathrm{~s}^{-1}\right)$.
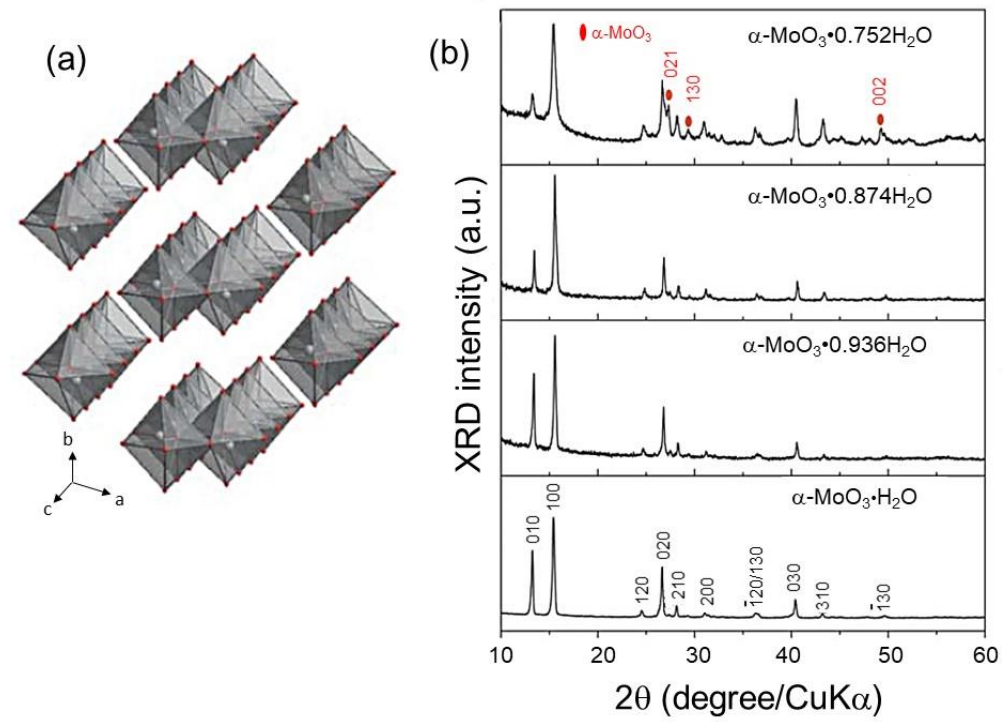

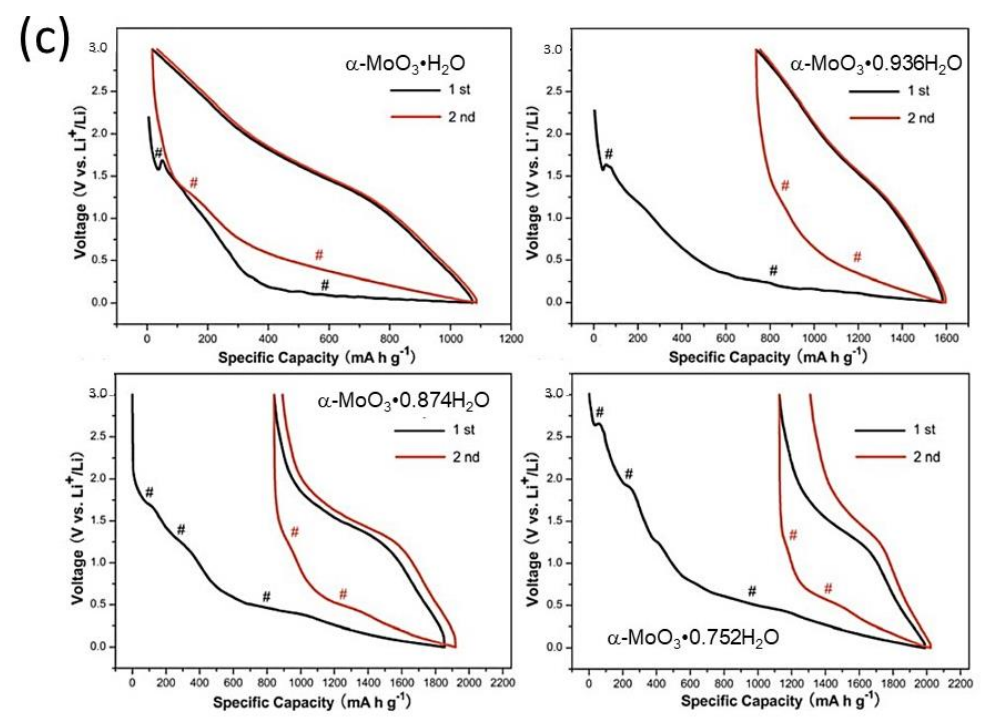

Fig. 29. (a) The crystal structure of the triclinic monohydrated molybdenum oxide $\alpha-\mathrm{MoO}_{3} \cdot 1 \mathrm{H}_{2} \mathrm{O}$. (b) XRD patterns of pristine $\alpha-\mathrm{MoO}_{3} \cdot 1 \mathrm{H}_{2} \mathrm{O}$ and its partially dehydrates $\alpha-\mathrm{MoO}_{3} \cdot 0.936 \mathrm{H}_{2} \mathrm{O}, \alpha-\mathrm{MoO}_{3} \cdot 0.874 \mathrm{H}_{2} \mathrm{O}$, and $\alpha-\mathrm{MoO}_{3} \cdot 0.752 \mathrm{H}_{2} \mathrm{O}$. (c) The first two dischargecharge profiles of $\alpha-\mathrm{MoO}_{3} \cdot x \mathrm{H}_{2} \mathrm{O}$ cycled at $0.1 \mathrm{~A} \mathrm{~g}^{-1}$ current density between 3.0 and $0.001 \mathrm{~V}$ vs. $\mathrm{Li}^{+} / \mathrm{Li}$. Reproduced with permission from [379]. Copyright 2013 The Royal Society of Chemistry.

\section{Oxygen deficient $\mathrm{MoO}_{3-\delta}$}

\section{1. $\mathrm{MoO}_{3-\delta}$ suboxides}

$\mathrm{MoO}_{3-\delta}$ suboxides with stoichiometric deviation $\delta<1$ belong to the class of materials that offer a tunability of their intrinsic electronic properties from wide bandgap semiconductor $\mathrm{MoO}_{3}$ to semi-metallic $\mathrm{MoO}_{2}$ [8]. Upon inducing oxygen defects, $\mathrm{Mo}^{6+}$ ions can be reduced to $\mathrm{Mo}^{5+}$ and finally $\mathrm{Mo}^{4+}$, the oxygen vacancies not only increase the interlayer spacing and the electrical conductivity of $\mathrm{MoO}_{3}$, but also enhance charge storage kinetics [389]. The varieties of oxidation states in oxygen-deficient $\mathrm{MoO}_{3-\delta}$ compounds make them highly attractive in the field of energy storage and conversion and they have found applications in LIBs [236,390], solid state thin-film microbatteries [72,173,], electrochemical supercapacitors [194,391], gas sensors [392], electrochromic devices [231], solar cells [393,394], anode interlayers for photovoltaic devices [395], smart windows [396], light-emitting diodes [397], etc. These devices take advantage of the changes in the degree of crystallinity, cationic environment, stoichiometry deviation, band gap energy and electronic conductivity, which can be controlled by the growth conditions. 


\subsubsection{Structure}

Regarding the electronic structure, the defective oxygen generates gap states, which change the optical appearance, i.e., the oxides exhibit color transitions from transparent to yellow and eventually grayish/blue. Thus, the molybdenum suboxides phases can be classified in three groups: (i) the nearly-stoichiometric $\mathrm{MoO}_{3-\delta}$ (with $\delta<0.03$ ), which retains the orthorhombic symmetry, is unintentionally an $n$-type semiconductor at ambient conditions, partly due to intrinsic point defects related to oxygen vacancies $\left(V_{\mathrm{O}}\right)$ and molybdenum interstitials $\left(\mathrm{Mo}_{i}\right)$ [34], (ii) the defective $\mathrm{MoO}_{3-\delta}$ (with $0.03<\delta<0.11$ ) and (iii) $\mathrm{Mo}_{\mathrm{n}} \mathrm{O}_{3 \mathrm{n}-1}$ suboxides (Magnéli phases, $n=4-9$ ), which collapse into $\mathrm{ReO}_{3}$-type structures with crystallographic shear planes due to the destabilization of the $\mathrm{MoO}_{3}$ structure by the loss of oxygen [35-40]. The schematic representation of the crystal structure of the layered $\alpha-\mathrm{MoO}_{3}$ phase and the vacancies of the three inequivalent oxygen positions $\mathrm{O} 1$ (apical), $\mathrm{O} 2$ (corner-sharing) and $\mathrm{O} 3$ (edge-sharing) are shown in Fig. 30 [398]. An O1 vacancy $\left(\mathrm{V}_{\mathrm{O}(1)}\right)$ leads to two localized electrons on the neighboring Mo that are thus in the $\mathrm{Mo}^{4+}\left(4 \mathrm{~d}^{2} 5 \mathrm{~s}^{0}\right)$ configuration; $\mathrm{O} 2$ and $\mathrm{O} 3$ vacancies create a bipolaron with electrons localized on two separate $\mathrm{Mo}^{5+}$ sites in the first and second coordination spheres for $\mathrm{V}_{\mathrm{O}(2)}$ and on the opposite side of the vacancy for $\mathrm{V}_{\mathrm{O}(3)}$ [399]. At higher vacancy concentration, the shear structure is energetically more favorable than the point defects [400]. Inzami et al. accurately explored the effect of oxygen nonstoichiometry on the electronic structure and properties of the oxygen-deficient $\mathrm{MoO}_{3-\delta}$ material using a van der Waals density functional calculation [398]. It is shown that: (i) the electronic structure of layered $\mathrm{MoO}_{3-\mathrm{d}}$ is highly sensitive to changes in oxygen stoichiometry as $\mathrm{Mo}^{6+}$ has an empty $4 \mathrm{~d}$ shell; (ii) the layered structure efficiently screens the structural perturbations caused by oxygen vacancies, and (iii) the oxygen deficiency gives rise to Mo $4 \mathrm{~d}$ gap states with energy levels dependent on the type of oxygen vacancy.

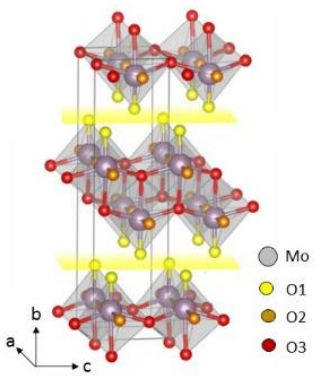

(a)

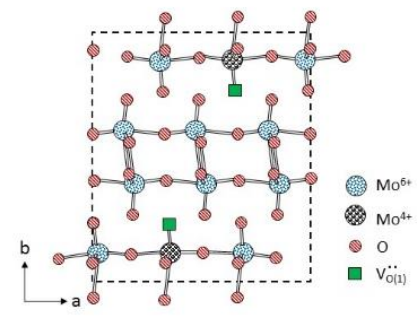

(b)

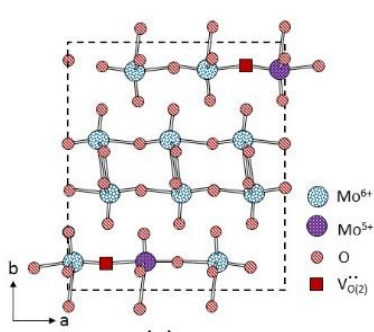

(c)

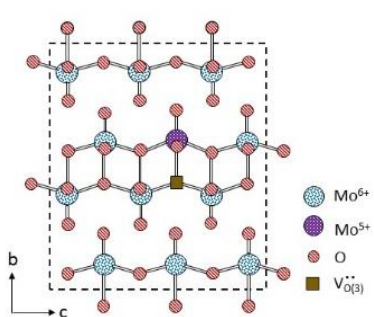

(d) 
Fig. 30. Crystal structure of the layered $\alpha-\mathrm{MoO}_{3}$ phase (a) and the vacancies of the three inequivalent oxygen positions O1 (apical) (b), O2 (corner-sharing) (c) and O3 (edge-sharing) (d). Adapted from [398]. Copyright 2016 American Chemical Society.

Figure 31 shows a schematic diagram of the electronic states of molybdenum oxides as a function of the oxygen vacancies. The electronic character varies from insulator $\left(\mathrm{MoO}_{3}\right)$ to semiconductor $\left(\mathrm{MoO}_{3-\delta}\right)$ and finally to metal-like $\left(\mathrm{Mog}_{9} \mathrm{O}_{26}\right)$, in agreement with conductivity measurements [399]. It is well established that increasing $\delta$ in $\mathrm{MoO}_{3-\delta}$ can lower the bandgap [401]. The electron distribution in pure $\mathrm{MoO}_{3}$ follows the ionic model $\left(\mathrm{Mo}^{6+}\right.$ and $\left.\mathrm{O}^{2-}\right)$ corresponding to the $\mathrm{Mo} 4 \mathrm{~d}^{0}$ configuration. For non-stoichiometric $\mathrm{MoO}_{3}$ oxides, extended Mo $4 d$ states, which then lie in the bandgap as gap states due to the occurrence of $\mathrm{Mo}^{5+}$ and $\mathrm{Mo}^{4+}$ ions, are filled by electrons donated from oxygen vacancies. The formation of oxygen deficiency (termed also as sub-stoichiometric) not only produces an increase of the electrical conductivity $\sigma_{\mathrm{e}}[402,403]$ owing to the additional gap states, but also increases the surface energy of the particles and promotes electrochemical reactions [397,399]. Magnetic susceptibility measurements showed that $\mathrm{MoO}_{3}, \mathrm{MoO}_{2}$ and $\mathrm{Mo}_{\mathrm{n}} \mathrm{O}_{3 \mathrm{n}-1}$ shear suboxides in between are all feebly paramagnetic.

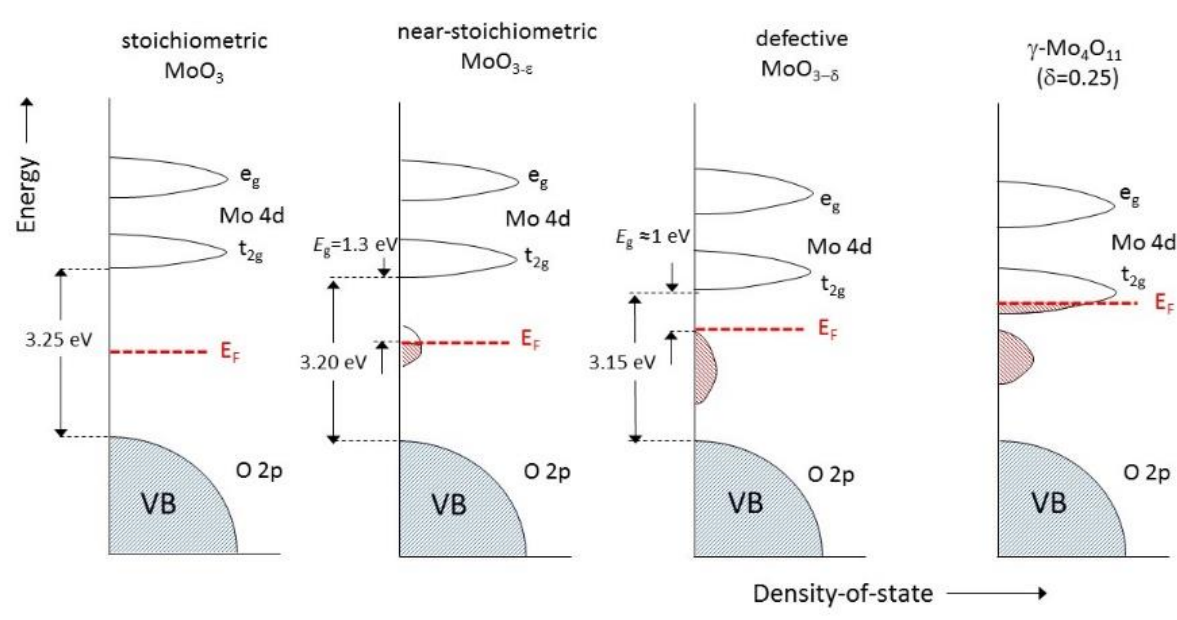

Fig. 31. Schematic diagram of the electronic states of molybdenum oxides as a function of the oxygen vacancies. The electronic character varies from insulator $\left(\mathrm{MoO}_{3}, \sigma_{\mathrm{e}}>10^{-9} \mathrm{~S} \mathrm{~cm}^{-1}\right)$ to semiconductor (defective $\mathrm{Mo}_{9} \mathrm{O}_{26}, \sigma_{\mathrm{e}} \approx 10^{-1} \mathrm{~S} \mathrm{~cm}^{-1}$ ) to metal-like $\left(\gamma-\mathrm{Mo}_{4} \mathrm{O}_{11}, \sigma_{\mathrm{e}} \approx 10^{2} \mathrm{~S} \mathrm{~cm}^{-1}\right.$ ). Copyright Lakshmi-Narayana et al. [72]. Open access article under the CC BY-NC-ND license.

\subsubsection{Determination of $\delta$}


X-ray photoelectron spectroscopy (XPS) is an appropriate tool to evaluate the stoichiometry of oxygen deficient $\mathrm{MoO}_{3-\delta}$ compounds. From the Mo $3 \mathrm{~d}$ core level spectra, the presence of Mo in low valence states, i.e., $\mathrm{Mo}^{5+}$ and $\mathrm{Mo}^{4+}$, can be evidenced by fitting the XPS $3 \mathrm{~d}_{5 / 2}$ and $3 \mathrm{~d}_{3 / 2}$ peaks at binding energies around 235 and $232 \mathrm{eV}$, respectively (Table 10) $[85,404]$.

Table 10. Standard binding energies of Mo $3 \mathrm{~d}$ levels for molybdenum at different oxidation states [405].

\begin{tabular}{lcc}
\hline Peak assignment & \multicolumn{2}{c}{ Binding energy $(\mathrm{eV})$} \\
\cline { 2 - 3 } & $3 \mathrm{~d}_{5 / 2}$ & $3 \mathrm{~d}_{3 / 2}$ \\
\hline $\mathrm{Mo}^{6+}$ & 232.5 & 235.7 \\
$\mathrm{Mo}^{5+}$ & 231.5 & 234.7 \\
$\mathrm{Mo}^{4+}$ & 230.1 & 233.3 \\
$\mathrm{Mo}^{3+}$ & 229.3 & 232.5 \\
$\mathrm{Mo}^{2+}$ & 228.4 & 232.6 \\
$\mathrm{Mo}^{0}$ & 227.7 & 230.9 \\
\hline
\end{tabular}

Based on the deconvolution of the Mo 3d core-level peaks by using equal-width Gaussian peaks $3 \mathrm{~d}_{5 / 2}$ and $3 \mathrm{~d}_{3 / 2}$ spin-orbit components, the ratio of $\mathrm{Mo}^{6+} / \mathrm{Mo}^{5+}$ in a sub-stoichiometric $\mathrm{MoO}_{3-\delta}$ oxide is calculated by the following equation [406]:

$$
k=\frac{M o^{6+}}{M o^{5+}}=\frac{R\left(M o^{6+} 3 d_{5 / 2}\right)+R\left(M o^{6+} 3 d_{3 / 2}\right)}{R\left(M o^{5+} 3 d_{5 / 2}\right)+R\left(M o^{5+} 3 d_{3 / 2}\right)},
$$

where $k$ is the ratio of the quantity of $\mathrm{Mo}^{6+} / \mathrm{Mo}^{5+}$ calculated from the ratio of the integrated peak area $(R)$, the valence state for molybdenum can be calculated by the relation [407]:

$$
\phi=\frac{6}{1+k^{-1}}+\frac{5}{1+k},
$$

and the stoichiometric deviation is given by:

$$
\delta=3-\frac{\phi}{2} .
$$

As an example, Figure 32a shows the XPS spectra of oxygen vacancies-rich $\alpha-\mathrm{MoO}_{3-\delta}$ nanobelts synthesized by hydrothermal process. Blue $\mathrm{MoO}_{3-\delta}$ nanobelts were obtained by calcining the $\mathrm{MoO}_{3}$ powder $\mathrm{NaH}_{2} \mathrm{PO}_{2} \cdot \mathrm{H}_{2} \mathrm{O}$ at $250{ }^{\circ} \mathrm{C}$ for $1 \mathrm{~h}$ in $\mathrm{N}_{2}$ atmosphere. A graphene nanomesh carbon nanotube/ $\mathrm{MoO}_{3-\delta}\left(\mathrm{GC} / \mathrm{MoO}_{3-\delta}\right)$ nanocomposite with more O-vacancy defects was also characterized [408]. For the pristine $\mathrm{MoO}_{3}$ nanobelts, the atomic ratio of $\mathrm{Mo}^{5+} / \mathrm{Mo}^{6+}$ is calculated to be 0.132 giving $\delta=0.02$, whereas is greatly increased to 0.308 for the $\mathrm{GC} / \mathrm{MoO}_{3}$ $\delta$ nanocomposite, indicating the partial reduction of $\mathrm{MoO}_{3}, \delta=0.12$. Consequently, the electrons occupied in $4 \mathrm{~d}$ band increase with $\delta$ improving the electrical conductivity to $0.83 \times 10^{-5} \mathrm{~S} \mathrm{~cm}^{-1}$ 
(two orders of magnitude higher than that of pristine pure $\mathrm{MoO}_{3}$ ). Diffuse reflectance spectra show that the bandgap is reduced largely from 3.25 to $2.95 \mathrm{eV}$ with the increase of O-vacancy concentration.
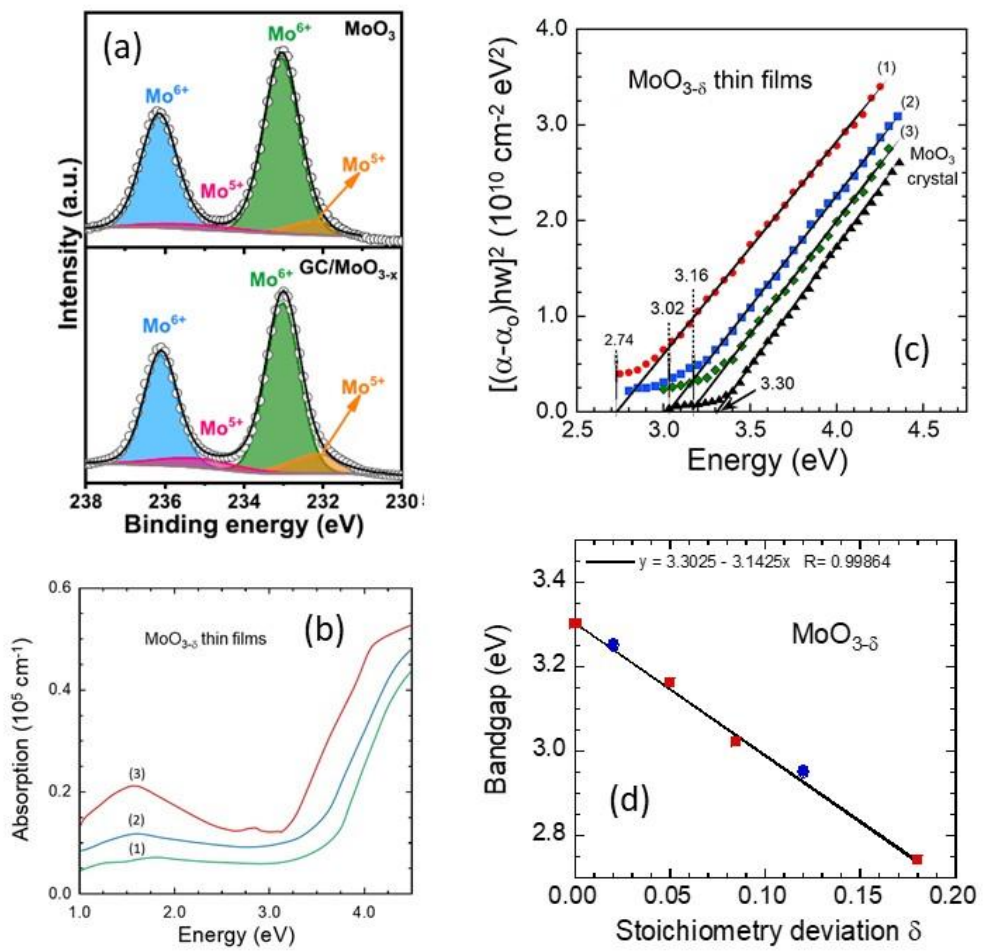

Fig. 32. (a) XPS core-level spectra of Mo $3 \mathrm{~d}$ for the oxygen vacancies-rich $\alpha-\mathrm{MoO}_{3-\delta}$ nanobelts. Reproduced with permission from [408]. Copyright 2019 Elsevier. (b) UV-Vis absorption spectra of flash-deposited $\alpha-\mathrm{MoO}_{3-\delta}$ thin films at different substrate temperatures: (1) $30^{\circ} \mathrm{C}$, (2) $120{ }^{\circ} \mathrm{C}$, and (3) $250{ }^{\circ} \mathrm{C}$. (c) Plot of $\left[\left(\alpha-\alpha_{0}\right) \hbar \omega\right]^{2}$ vs. photon energy for thin films and $\mathrm{MoO}_{3}$ crystal. The intercepts at $\alpha=0$ (full lines) give the bandgap energy. (d) variation of the bandgap with the stoichiometric deviation. Reproduced with permission from [153]. Copyright 1995 Elsevier.

Ultraviolet-visible spectroscopy can be also used to determine the stoichiometric deviation in $\mathrm{MoO}_{3-\delta}$ (Figs. 32b-c) [153]. The increase of O-vacancy concentration results in the enhanced absorbance from 300 to $1000 \mathrm{~nm}$. The fundamental absorption edge occurs at about $4 \mathrm{eV}$ with a high value of the absorption coefficient $3 \times 10^{4} \mathrm{~cm}^{-1}$. A broad absorption band in the red region, i.e., $1.5 \mathrm{eV}$, corresponds to the excitation of trapped electrons into the conduction band. As a result, various degrees of coloration occurred. It is worth noting that the coloration of the films is associated with the absorption edge shift. For example, films grown at room temperature are white and transparent, whereas films deposited at higher substrate temperatures 
$\left(T_{\mathrm{s}}>120^{\circ} \mathrm{C}\right)$ are deeply colored. The intrinsic absorption edge of the films was evaluated in terms of the direct transition. The optical absorption coefficient $\alpha$ is calculated by the expression:

$$
\alpha=\frac{1}{d} \ln \left\{\frac{(1-R)^{2}}{2 T}+\sqrt{\left[\frac{\left(1-R^{2}\right)}{2 T}\right]^{2}+R^{2}}\right\},
$$

where $d$ is the sample thickness, $T$ the transmittivity and $R$ the reflectivity determined from the optical transmission and reflection spectra, respectively (Fig. 32b). The theory of interband absorption near the threshold shows that $\alpha$ vary according the equation:

$$
\alpha h v=B\left(h v-E_{\mathrm{g}}\right)^{n},
$$

where $h$ is the Planck constant, $v$ the frequency, $B$ the probability parameter, $E_{\mathrm{g}}$ is the optical bandgap and $n$ an exponent, which characterizes the transition process ( $n=1 / 2$ for direct allowed transitions). Thus, the Tauc plot $\left[\left(\alpha-\alpha_{0}\right) \hbar \omega\right]^{2}$ vs. photon energy yields a linear behavior in the region of strong absorption near the absorption edge, as shown in Fig. 32c. Extrapolating the linear portion of this straight portion to $\alpha=0$ gives the optical bandgap. The optical bandgap of crystalline $\mathrm{MoO}_{3}$ is $E_{\mathrm{g}}=3.05 \mathrm{eV}$. As shown in Fig. 32d, the bandgap of $\mathrm{MoO}_{3-\delta}$ suboxides decreases linearly with the increase of the stoichiometric deviation in the range $0 \leq \delta \leq 0.15$.

\subsection{3. $\mathrm{Li}$ insertion in $\mathrm{MoO}_{3-\delta}$}

Generally, the oxygen deficient $\mathrm{MoO}_{3-\delta}$ oxides, as cathode or anode materials, exhibits several appealing characteristics for lithium-ion storage, including high specific capacity, good stability against cycling and fast charge transport kinetics [132]. The bulk structure of $\mathrm{MoO}_{3-\delta}$ under reductive and oxidative reaction conditions was investigated in situ with time-resolved X-ray absorption spectroscopy (XAS) [409]. The $\mathrm{MoO}_{3-\delta}$ suboxide phases (with $0<\delta<0.25$ ) exhibit Li-insertion capacity much higher than that of stoichiometric $\mathrm{MoO}_{3}$ phase, which justifies the efforts to fabricate them under the form of thin films. For the development of these technologies, oxygen vacancies are easily generated in the $\mathrm{MoO}_{3-\delta}$ materials prepared in a thin film architecture by optimizing the deposition conditions [410]. Jung et al. [236] investigated the electrochemical reactivity of ball-milled $\mathrm{MoO}_{3-\delta}$ as anode materials for lithium-ion batteries. High-energy ball-milling converts highly-crystalline $\mathrm{MoO}_{3}$ bulk powders into partially reduced low crystalline $\mathrm{MoO}_{3-\delta}$ materials with a reduced particle size. Oxygen deficiency gradually increases as the ball milling time increases. Bulk $\mathrm{MoO}_{3}$ powders were partially reduced to give nanostructured $\mathrm{MoO}_{2.929}, \mathrm{MoO}_{2.903}$, and $\mathrm{MoO}_{2.895}$ by ball-milling for 4,6 , and $8 \mathrm{~h}$, respectively. When tested in the $0.01-3 \mathrm{~V} v s . \mathrm{Li}^{+} / \mathrm{Li}$ range the first discharge 
capacity is beyond $1100 \mathrm{mAh} \mathrm{g}^{-1}$, which is indicative of a complete conversion reaction. The lithiation in $\mathrm{MoO}_{3-\delta}$ suboxides occurs with two steps: intercalation (>1.5 V) and conversion $(<0.5 \mathrm{~V})$, although their voltage profiles become smother than that of $\mathrm{MoO}_{3}$ bulk. Additionally, incomplete re-oxidation during subsequent charge results in the formation of $\mathrm{MoO}_{2}$ instead of $\mathrm{MoO}_{3}$, which in turn affects the reactivity in subsequent cycles. As compared to bulk $\mathrm{MoO}_{3}$, ball-milled $\mathrm{MoO}_{3-\delta}$ showed significantly enhanced cycle performance. The anode material ballmilled for $8 \mathrm{~h}$ has $64.4 \%$ discharge efficiency at the $35^{\text {th }}$ cycle against $27.6 \%$ for bulk at the $10^{\text {th }}$ cycle, which has been attributed to the nano-texture wherein nanometer-sized particles aggregate to form secondary ones. Jegal et al. [390] prepared a mixed-valence $\mathrm{MoO}_{3-\delta} / \mathrm{CNT}$ nanocomposite $(x<0.1)$ using a one-pot microwave-assisted hydrothermal reaction in which 5 $\mathrm{nm} \mathrm{MoO}_{3-\delta}$ nanoparticles are coated on the surfaces of CNT. The nanocomposite had a reversible discharge capacity of could deliver discharge capacities of 770, 700, and $570 \mathrm{mAh}$ $\mathrm{g}^{-1}$ at current densities of 450,900 , and $1800 \mathrm{~mA} \mathrm{~g}^{-1}$, respectively.

Highly dispersed ultra-small $\mathrm{MoO}_{\mathrm{y}}$ nanoparticles (1.5-3.5 $\mathrm{nm}$ ) anchored on N-doped 3D hierarchically porous carbon $\left(3 \mathrm{D}-\mathrm{MoO}_{\mathrm{y}} @ \mathrm{CN}\right)$ were prepared using an efficient in-situ chelating and hard-templating strategy. An optimized 3D-MoOy $@ \mathrm{CN}$ heat-treated at $700{ }^{\circ} \mathrm{C}$ delivers specific capacities of 742 and $431 \mathrm{mAh} \mathrm{g}^{-1}$ at current density of 100 and $1000 \mathrm{~mA} \mathrm{~g}^{-1}$ after 1000 cycles, respectively. This excellent performance is attributed to the unique hierarchical porous morphology (specific BET surface area of $109 \mathrm{~m}^{2} \mathrm{~g}^{-1}$ and pore volume of $0.30 \mathrm{~cm}^{3} \mathrm{~g}^{-1}$ ) structure with strong binding of the ultra-small $\mathrm{MoO}_{\mathrm{y}}$ nanoparticles onto N-doped carbon surface, which can avoid the agglomeration and alleviate the volume expansion of $\mathrm{MoO}_{\mathrm{y}}$ nanoparticles in the charge-discharge process [406]. $\mathrm{MoO}_{3-\delta}$ nanowires were synthesized in a hot-filament chemical vapor deposition reactor in which molybdenum filaments were resistively heated to $775^{\circ} \mathrm{C}$ in $10 \mathrm{sccm}$ of oxygen at a pressure of $\sim 150 \mathrm{~Pa}$ [134]. Structural characterization revealed the $\mathrm{Mo}_{17} \mathrm{O}_{47}$ phase. It has been shown that $\mathrm{Mo}_{17} \mathrm{O}_{47}$ nanowire arrays can retain a capacity of $630 \mathrm{mAh} \mathrm{g}^{-1}$ for up to 20 cycles at a current density of $50 \mathrm{~mA} \mathrm{~g}^{-1}$. Also, it has been reported that a $10-\mathrm{nm}$ silicon coated $\mathrm{MoO}_{3-\delta}$ hybrid architectures, deposited by microwave plasma CVD have shown a capacity retention of $780 \mathrm{mAh} \mathrm{g}^{-1}$. Sun et al. [411] designed vertically aligned oxygen-deficient $\alpha-\mathrm{MoO}_{3-\delta}$ nanoflake arrays as 3D cathode for advanced all-solid-state thin film lithium batteries (TFLIBs). The $\alpha-\mathrm{MoO}_{3-\delta}$ electrode were fabricated by magnetron sputtering of metal Mo target. The Li/LIPON/MoO $3-\delta$ 3D-TFLIB exhibits high specific capacity of $266 \mathrm{mAh} \mathrm{g}^{-1}$ at $50 \mathrm{~mA} \mathrm{~g} \mathrm{~g}^{-1}$ current density, good rate performance $\left(110 \mathrm{mAh} \mathrm{g}^{-1}\right.$ at $\left.1000 \mathrm{~mA} \mathrm{~g}^{-1}\right)$, and excellent cycle performance $(92.7 \%$ capacity retention after 1000 cycles). 
Sun et al. prepared $\mathrm{MoO}_{\mathrm{y}}$ nanobelts with different quantities of oxygen vacancies through a "sauna reaction" and tested their performance in LIBs [412]. The number of oxygen vacancies depends on the duration for the production of $\mathrm{H}_{2}$ by the reaction of the carbon cloth and water vapor to reduce $\mathrm{MoO}_{3}$. The as-obtained $\mathrm{MoO}_{y}$ nanobelts deliver a reversible capacity of 400 $\mathrm{mAh} \cdot \mathrm{g}^{-1}$ at $1 \mathrm{~A} \cdot \mathrm{g}^{-1}$ after 200 cycles without obvious capacity loss. Furthermore, $\mathrm{MoO}_{\mathrm{y}}$ exhibits an excellent rate capability (400 and $267 \mathrm{mAh} \cdot \mathrm{g}^{-1}$ at 100 and $200 \mathrm{~mA} \cdot \mathrm{g}^{-1}$ current rate, respectively. Wang et al. [225] investigated the $\mathrm{MoO}_{3}-\mathrm{MnO}_{2}$ intergrown nanoparticles (6-8 nm in size) composite prepared by one-step hydrothermal synthesis as anode for LIBs. The composite attains an initial specific capacity of $2034 \mathrm{mAh} \mathrm{g}^{-1}$ and stays $1446 \mathrm{mAh} \mathrm{g}^{-1}$ after 50 cycles at a rate of $0.5 \mathrm{C}$ in the voltage range of $0.01-2.0 \mathrm{~V}$. The synergistic effect of $\mathrm{MoO}_{3}$ and $\mathrm{MnO}_{2}$ during intergrowth is attributed to the incorporation of $\mathrm{Mn}^{4+}$ is incorporated into the $\mathrm{MoO}_{3}$ lattice to modify its crystal structure, i.e., creation of oxygen deficiency. Carbon nanotube-wired and oxygen-deficient $\mathrm{MoO}_{3-\delta}$ nanobelts $\left(\mathrm{MoO}_{3-\delta} / \mathrm{CNTs}\right)$ were constructed via hydrothermal synthesis with subsequent controlled reduction in $\mathrm{H}_{2} / \mathrm{Ar}$ gas mixture [268]. The $\mathrm{MoO}_{3} / \mathrm{CNTs}$ composite, evaluated as an anode in the $0.05-3.0 \mathrm{~V}$ potential window, is able to retain a specific capacity of $421 \mathrm{mAh} \mathrm{g}^{-1}$ after 100 cycles at $200 \mathrm{~mA} \mathrm{~g}^{-1}$, and delivers 293 and $202 \mathrm{mAh} \mathrm{g}^{-1}$ at current densities of 2 and $4 \mathrm{~A} \mathrm{~g}^{-1}$, respectively. Zhang et al. [413] prepared several oxygen deficient $\alpha-\mathrm{MoO}_{3-\delta}$ cathode materials using $\mathrm{H}_{2}$ plasma etching process. From XPS measurements, the composition is calculated to be $\mathrm{MoO}_{2.912}$ and $\mathrm{MoO}_{2.870}$ for $\mathrm{MoO}_{3}$ etched for 10 and $20 \mathrm{~min}$, respectively, which is confirmed by the appearance of the Raman peak at $1008 \mathrm{~cm}^{-1}$ as a result of oxygen vacancy. The $\mathrm{MoO}_{2.912}$ electrode shows the best performance delivering a first specific capacity of $224 \mathrm{mAh} \mathrm{g}^{-1}$ at $1 \mathrm{~A} \mathrm{~g}^{-1}$ rate, which declines slowly to 67 $\mathrm{mAh} \mathrm{g}^{-1}$ over 1000 cycles.

In a SIBs, the oxygen vacancies of $\mathrm{MoO}_{3-\delta}$ play also an important role. They can enhance the electric conductivity and Na-ion diffusion coefficient [291]. Li and coworkers revealed how oxygen vacancies of $\mathrm{MoO}_{\mathrm{y}}$ influenced the performance of the SIBs [290]. $\mathrm{MoO}_{2.97}$, which possesses only a few oxygen vacancies exhibits the best specific capacity $\left(176.6 \mathrm{mAh} \cdot \mathrm{g}^{-1}\right.$ at 50 $\mathrm{mA} \cdot \mathrm{g}^{-1}$ ) and a $\sim 8 \%$ capacity loss over 2000 cycles compared with the highest capacity at the $500^{\text {th }}$ cycle. The voltage profile of $\mathrm{MoO}_{2.5}$ displays a two-plateau behavior suggesting the stabilized function of oxygen vacancies during the charge/discharge cycling. Yi et al. reported that oxygen-deficient $\mathrm{MoO}_{3}$ demonstrates excellent performances in Li-S batteries. The cells with $\mathrm{MoO}_{3-\delta}$ cathode deliver a capacity of $690 \mathrm{mAh} \mathrm{g}^{-1}$ after 200 cycles at $0.2 \mathrm{C}$, demonstrating a significant improvement of the capacity retention. Furthermore, at the current rate of $1 \mathrm{C}$, $\mathrm{MoO}_{3-\delta}$ cell displays a high initial capacity of $775 \mathrm{mAh} \mathrm{g}^{-1}$ and an enhanced surplus capacity 
of $480 \mathrm{mAh} \mathrm{g}^{-1}$ after 600 cycles [414]. Wu et al. [226] adopted a carbon-free strategy for an advanced LIB anode material, which consists of a mixture of $\mathrm{MoO}_{3}$ and $\mathrm{MoO}_{2}$. $\mathrm{MoO}_{2}$ nanoparticles treated with a smaller fraction of $\mathrm{O}_{2}\left(0.2 \% \mathrm{O}_{2}\right.$ in $\left.\mathrm{N}_{2}\right)$ show mixed phases which can be attributed to $\mathrm{MoO}_{2}, \mathrm{MoO}_{3}$, as well as a small fraction of $\mathrm{Mo}_{4} \mathrm{O}_{11}$. A high specific capacity up to $930.6 \mathrm{mAh} \cdot \mathrm{g}^{-1}$, long cycle-life (>200 cycles) and high rate capability. $\mathrm{MoO}_{3-\delta}$ nanobelts with different concentrations of oxygen vacancies were synthesized by a one-step hydrothermal process using different concentrations of ethanol as the reductant [415]. With the increasing amount of ethyl alcohol in the hydrothermal reaction, the sample color gradually changes from white (pure $\left.\alpha-\mathrm{MoO}_{3}\right)$ to dark $\left(\mathrm{MoO}_{2}+\mathrm{Mo}_{4} \mathrm{O}_{11}\right) . \mathrm{Mo}^{5+}$ in $\mathrm{MoO}_{3-\delta}$ appears blue and $\mathrm{MoO}_{2}$ looks black. $\mathrm{MoO}_{3-\delta}$ nanobelts, tested as anode for LIBs in a voltage window of $0.01-3.0 \mathrm{~V} \mathrm{vs.} \mathrm{Li}^{+} / \mathrm{Li}$, can maintain a high specific capacity of $\sim 500 \mathrm{mAh} \mathrm{g}^{-1}$ at a high current density of $1 \mathrm{~A} \mathrm{~g}^{-1}$ and can retain a high specific capacity of $641 \mathrm{mAh} \mathrm{g}^{-1}$ after 50 cycles at $100 \mathrm{~mA} \mathrm{~g}^{-1}$ and $420 \mathrm{mAh}$ $\mathrm{g}^{-1}$ after 100 cycles at $500 \mathrm{~mA} \mathrm{~g}^{-1}$.

\section{2. $\mathrm{MoO}_{3-\delta}$ thin films}

$\mathrm{MoO}_{3-\delta}$ thin films have been easily prepared using a broad variety of physical vapor deposition (PVD) methods, including thermal evaporation [194,416,417], magnetron sputtering [418,419], dip-coating [394], pulsed layer deposition (PLD) [115,173,420,421]. However, few works report the spin-coating deposition of $\mathrm{MoO}_{3-\delta}$ via a low-temperature solution process [422]. $\alpha-\mathrm{MoO}_{3-\delta}$ thin films with low resistivity were fabricated on glass substrate via conducting a two-step annealing treatment on the thin film deposited by thermal evaporation method. A heat-treatment in air enables the formation of the $\alpha$-phase layered structure (resistivity of $10^{6}$ $\Omega \cdot \mathrm{cm}$ ), whereas an annealing in $\mathrm{N}_{2}$ gives rise to the lowest resistivity of $5.4 \Omega \cdot \mathrm{cm}$ without deteriorating crystal structure [417]. The increase in carrier concentration was assigned to the presence of ionized oxygen vacancy during the $\mathrm{N}_{2}$ annealing as illustrated by the following equation:

$$
\mathrm{O}_{O}^{x}+2 \mathrm{Mo}^{6+} \rightleftharpoons \mathrm{V}_{O}+2 \mathrm{Mo}^{5+}+\frac{1}{2} \mathrm{O}_{2}(g) .
$$

Like stoichiometric $\mathrm{MoO}_{3}$, sub-stoichiometric $\mathrm{MoO}_{3-\delta}$ thin films can be obtained by evaporation in a vacuum at relatively low temperature $\left(T<500{ }^{\circ} \mathrm{C}\right)$ or in reducing atmosphere. However, few works explore the effect of oxygen deficiency and electrical conduction enhancement on energy storage properties [423]. Parashar demonstrated that the deposition temperature plays a crucial role on the composition of $\mathrm{MoO}_{3-\delta}$ thin film deposited by magnetron sputtering in argon plasma. At working pressure of $0.5 \mathrm{~Pa}$ and RF power of $75 \mathrm{~W}$, the film 
deposited at $T_{\mathrm{s}}=250{ }^{\circ} \mathrm{C}$ is a mixture of $\alpha-\mathrm{MoO}_{3}$ and $\mathrm{Mo}_{4} \mathrm{O}_{11}$ phases, while a pure $\alpha-\mathrm{MoO}_{3}$ phase is grown at $T_{\mathrm{s}}=350{ }^{\circ} \mathrm{C}$ [418]. Sub-stoichiometric $\mathrm{MoO}_{3-\delta}$ thin films were deposited on $\mathrm{SiO}_{2}$ glass and stainless-steel substrate using conventional RF sputtering technique [144]. The films fabricated in an Ar gas atmosphere at a sputtering gas pressure of $4 \mathrm{~Pa}$, a radio-frequency power of $200 \mathrm{~W}$, a substrate temperature of $100{ }^{\circ} \mathrm{C}$ and a deposition rate of $1.16 \mu \mathrm{m} \mathrm{h}^{-1}$ exhibit the $\mathrm{Mog}_{9} \mathrm{O}_{26}$ structure (dark-blue color) with the crystallographic (010) plane oriented parallel to the substrate surface. The OCV of the $\mathrm{Mog}_{9} \mathrm{O}_{26}$ thin-film electrode ( $4.6 \mu \mathrm{m}$ thick) was $2.7 \mathrm{~V}$. The discharge capacities of the $1^{\text {st }}, 10^{\text {th }}$ and $21^{\text {st }}$ cycles were 398,318 and $289 \mu \mathrm{Ah} \mathrm{cm}^{-2}$, respectively, at a current density of $10 \mathrm{~mA} \mathrm{~cm}^{-2}$. Recently, He and coworkers [419] prepared sputtered $\mathrm{MoO}_{\mathrm{y}}$ thin films with different oxygen contents (fixed Ar flow rate of $10 \mathrm{sccm}$ and variable $\mathrm{O}_{2}$ flow rate from 0.4 to $1.5 \mathrm{sccm}$ corresponding to $3.8 \%-13 \%$ ). $\mathrm{MoO}_{2.95}, \mathrm{MoO}_{2.43}$, $\mathrm{MoO}_{2.7}$, and $\mathrm{MoO}_{1.45}$ thin films were obtained with $\mathrm{O}_{2}$ concentration of $13.0 \%, 8.6 \%, 6.5 \%$ and $3.8 \%$, respectively, showing that the decrease of the oxygen content pushes the Fermi level very close to the conduction band. Puppala et al. investigated the microstructure and morphology of PLD $\mathrm{MoO}_{3-\delta}$ thin films growth for catalytic applications using a femtosecond laser (f-PLD) and a nanosecond excimer-laser (n-PLD). Substantially textured films with a partially crystalline phase prior to annealing were obtained by the f-PDL laser, while the n-PLD-grown $\mathrm{MoO}_{3-\delta}$ films were predominantly amorphous with a smooth surface [186]. Sunu et al. claimed that asdeposited PLD films $\left(T_{\mathrm{s}}=400{ }^{\circ} \mathrm{C}, \Phi=4-5 \mathrm{~J} \mathrm{~cm}^{-2}\right.$, repetition rate of 15 to $20 \mathrm{~Hz}$, and $\mathrm{p}\left(\mathrm{O}_{2}\right)=$ $500 \mathrm{~Pa}$ ) are suboxide-like, i.e., mixture of $\eta-\mathrm{Mo}_{4} \mathrm{O}_{11}$ and $\chi-\mathrm{Mo}_{4} \mathrm{O}_{11}$, which transformed to $\mathrm{MoO}_{3}$ after annealing at $500{ }^{\circ} \mathrm{C}$ in air for $5 \mathrm{~h}$ [392].

Recently, the effects of operational conditions on structural, electronic and electrochemical properties on molybdenum suboxides $\left(\mathrm{MoO}_{3-\delta}\right)$ thin films were investigated [72]. Three classes of samples are obtained with different degrees of stoichiometric deviation without posttreatment: (i) amorphous $\mathrm{MoO}_{3-\delta}(\delta<0.05)$ (ii) nearly-stoichiometric samples $(\delta \approx 0)$ and (iii) suboxides $\mathrm{MoO}_{3-\delta}(\delta>0.05)$. The suboxide films $0.05 \leq \delta \leq 0.25$ deposited on $\mathrm{Au} / \mathrm{Ti} / \mathrm{SiO}_{2} /$ flexible-Si substrates with appropriate processing conditions show high electrochemical performance as an anode layer for lithium planar microbatteries. In the realm of simple synthesis, the $\mathrm{MoO}_{3-\delta}$ film deposited at $450{ }^{\circ} \mathrm{C}$ under oxygen pressure of $13 \mathrm{~Pa}$ is a mixture of $\alpha-\mathrm{MoO}_{3}$ and $\mathrm{Mo}_{8} \mathrm{O}_{23}$ phases (15:85). The electrochemical test of the $0.15 \mathrm{MoO}_{3}-$ $0.85 \mathrm{Mo}_{8} \mathrm{O}_{23}\left(\mathrm{MoO}_{2.894}\right)$ film shows a specific capacity of $484 \mu \mathrm{Ah} \mathrm{cm}^{-2} \mu \mathrm{m}^{-1}$ after 100 cycles of charge-discharge at a constant current of $0.5 \mathrm{~A} \mathrm{~cm}^{-2}$ in the potential range 3.0-0.05 $\mathrm{V}$. This capacity value corresponds to the insertion of $\sim 5.78 \mathrm{Li}^{+} / \mathrm{Mo}$, is close to the theoretical maximum (5.79 $\mathrm{Li}^{+} / \mathrm{Mo}$ ). Figure 33 presents the electrochemical performance of the $\mathrm{MoO}_{3-\delta}$ deposited at 
$450{ }^{\circ} \mathrm{C}$ under oxygen pressure of $13 \mathrm{~Pa}$ [72]. Amorphous $\mathrm{MoO}_{\mathrm{y}}$ thin films prepared by reactive magnetron sputtering deposition (total $\mathrm{Ar}+\mathrm{O}_{2}$ gas flow kept at $40 \mathrm{sccm}$ at $0.8 \mathrm{~Pa}$ using $20 \% \mathrm{O}_{2}$ ) consists of a mixture of amorphous $\mathrm{MoO}_{3}$ and $\mathrm{MoO}_{2}$ phases [424]. The a- $\mathrm{MoO}_{\mathrm{y}}$ thin films (1.1 $\mu \mathrm{m}$ thick) exhibit a high capacity of $338 \mu \mathrm{Ah} \cdot \mathrm{cm}^{-2}$ (about $845 \mathrm{mAh} \cdot \mathrm{g}^{-1}$ ) at a current density of $90 \mu \mathrm{A} \mathrm{cm}^{-2}$ even after 100 discharge/charge cycles, and have a rate capacity of $158 \mu \mathrm{Ah} \mathrm{cm}^{-2}$ at a high current density of $2000 \mu \mathrm{A} \mathrm{cm}^{-2}$.
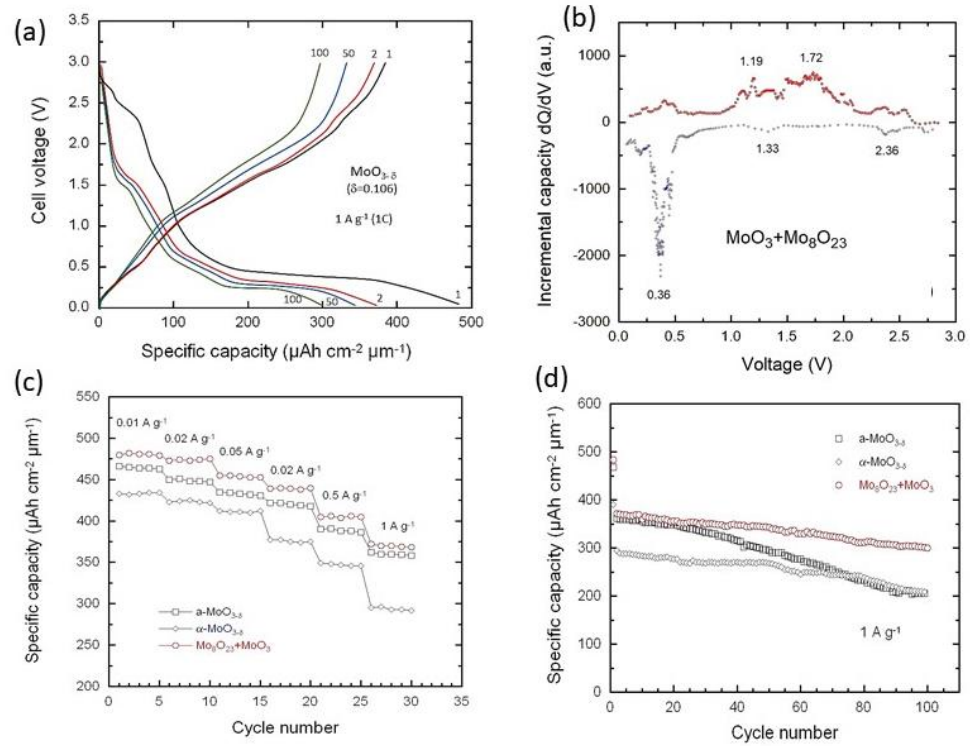

Fig. 33. Electrochemical tests of the $\mathrm{MoO}_{3}-\mathrm{Mo}_{8} \mathrm{O}_{23}$ (15:85) thin film in $\mathrm{Li}$ cells with $1 \mathrm{~mol} \mathrm{~L}$ $\mathrm{LiPF}_{6}$ dissolved in ethylene carbonate and dimethyl carbonate (EC:DMC; 1:1 w/w) as aprotic electrolyte. (a) Galvanostatic charge discharge profiles of a cell cycled at $1 \mathrm{~A} \mathrm{~g}^{-1}$ current density in the voltage range 3.0-0.05 V. (c) Differential capacity (-d $Q / \mathrm{d} V$ vs. $V$ ) of the first lithiationdelithiation cycle. (c) Rate capability. (d) Cyclability over 100 cycles at $1 \mathrm{~A} \mathrm{~g}^{-1}$ compared with amorphous $\mathrm{MoO}_{3-\delta}$ and $\alpha-\mathrm{MoO}_{3-\delta}$ film deposited at $300{ }^{\circ} \mathrm{C}$. Copyright Lakshmi-Narayana et al. [72]. Open access article under the CC BY-NC-ND license.

\section{Magnéli-type Mo oxides}

In the Mo-O binary system, there is the series $\mathrm{Mo}_{\mathrm{n}} \mathrm{O}_{3 \mathrm{n}-1}$, which crystallizes in the so-called Magnéli phases described in details by Kihlborg [37] (see crystallographic parameters in Table 11). They are oxygen deficient relative to $\mathrm{MoO}_{3}$. The removal of oxygen and accompanied partial reduction of $\mathrm{Mo}(\mathrm{VI})$ cations introduce crystallographic shear maintaining the layered framework. These oxides have been identified as derived from $\mathrm{MoO}_{3}$ by shear mechanism with networks of $\mathrm{MoO}_{6}$ octahedra. These units are connected in three dimensions with empty parallel tunnels involving the presence of potential sites for hosting $\mathrm{Li}^{+}$ions. The crystal structures of 
the $\mathrm{Mo}_{\mathrm{n}} \mathrm{O}_{3 \mathrm{n}-1}$ molybdenum oxides, with their respective single unit cells are shown in Fig. 34 . Since 1980s, quasi-2D layered $\mathrm{Mo}_{\mathrm{n}} \mathrm{O}_{3 \mathrm{n}-1}$ compounds with commensurate/incommensurate periodic lattice distortion (PLD) have attracted great attention due to their fascinating property of charge-density-wave (CDW) [425,426]. These intermediate molybdenum oxides are believed to be also catalytically active [427]. Furthermore, they exhibit a rich phase polymorphism and a variety of morphologies.

Table 11. Structural parameters of $\mathrm{Mo}_{\mathrm{n}} \mathrm{O}_{3 \mathrm{n}-1}$ molybdenum oxides.

\begin{tabular}{|c|c|c|c|c|c|}
\hline \multirow[t]{2}{*}{ Compound } & \multirow[t]{2}{*}{ Space group } & \multicolumn{3}{|c|}{ Cell parameters $(\AA)$} & \multirow[t]{2}{*}{ Ref. } \\
\hline & & $a / \alpha$ & $b / \beta$ & $c / \gamma$ & \\
\hline $\mathrm{Mo}_{17} \mathrm{O}_{47}$ & $\mathrm{Pba} 2$ & $21.61 / 90^{\circ}$ & $19.63 / 90^{\circ}$ & $3.951 / 90^{\circ}$ & [38] \\
\hline $\mathrm{Mo}_{9} \mathrm{O}_{26}$ & $P 2 / c$ & 14.45 & $4.00 / 96.0^{\circ}$ & 16.750 & [36] \\
\hline $\mathrm{Mo}_{8} \mathrm{O}_{23}$ & $P 2 / a$ & 16.88 & $4.052 / 106.19^{\circ}$ & 13.39 & [428] \\
\hline$\eta-\mathrm{Mo}_{4} \mathrm{O}_{11}$ & $P 2_{1} / a$ & $6.695 / 90^{\circ}$ & $5.440 / 94.31^{\circ}$ & $324.573 / 90^{\circ}$ & [429] \\
\hline$\gamma-\mathrm{Mo}_{4} \mathrm{O}_{11}$ & Pnam & $24.49 / 90^{\circ}$ & $6.752 / 90^{\circ}$ & $5.457 / 90^{\circ}$ & [430] \\
\hline $\mathrm{Mo}_{5} \mathrm{O}_{14}$ & $P 4 / n m m$ & 23.00 & - & 3.937 & [431] \\
\hline $\mathrm{Mo}_{18} \mathrm{O}_{52}$ & $P \overline{1}$ & $8.145 / 102.67$ & $11.89 / 67.82^{\circ}$ & $21.23 / 109.97^{\circ}$ & [35] \\
\hline
\end{tabular}

(a)

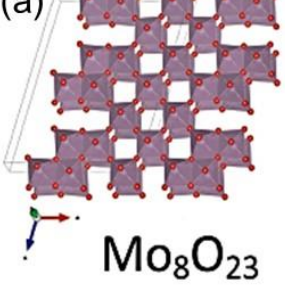

(d)

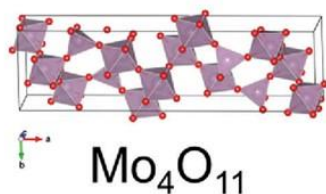

(f)

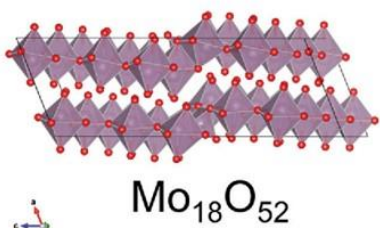

(b)

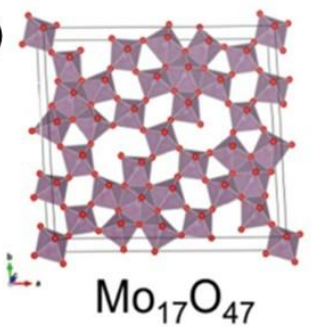

(c)

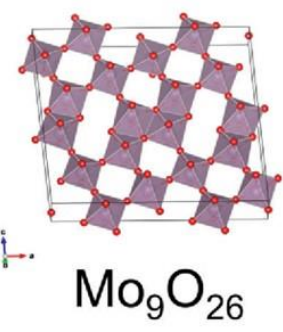

(e)

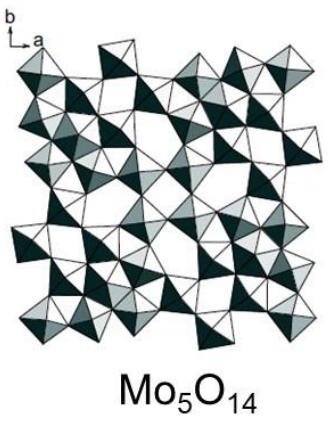

Fig. 34. Crystal structures of Magnéli $\mathrm{Mo}_{\mathrm{n}} \mathrm{O}_{3 \mathrm{n}-1}$ phases. Reproduced with permission from [400]. Copyright 2017 Royal Society of Chemistry.

In 1951, Glemser and Lutz [54] investigated the structure of several molybdenum blue oxides, the crystallized samples $\mathrm{Mo}_{8} \mathrm{O}_{23}$ and $\mathrm{Mo}_{9} \mathrm{O}_{26}$, amorphous blue oxide hydrates $\mathrm{MoO}_{2.75} \cdot n \mathrm{H}_{2} \mathrm{O}$ and $\mathrm{MoO}_{2.80} \cdot n \mathrm{H}_{2} \mathrm{O}$, and crystallized blue hydroxides $\mathrm{Mo}_{4} \mathrm{O}_{10}(\mathrm{OH})_{2}$ and $\mathrm{Mo}_{2} \mathrm{O}_{4}(\mathrm{OH})_{2}$, which are closely related to the starting material $\mathrm{MoO}_{3}$. The $\mathrm{Mo}_{\mathrm{n}} \mathrm{O}_{3 \mathrm{n}-1}$ phases 
include $\mathrm{Mo}_{4} \mathrm{O}_{11}$ [432,433], $\mathrm{Mo}_{5} \mathrm{O}_{14}$ [434], $\mathrm{Mo}_{6} \mathrm{O}_{17}, \mathrm{Mo}_{8} \mathrm{O}_{23}$ [36], $\mathrm{Mog}_{9} \mathrm{O}_{26}$ [40], $\mathrm{Mo}_{18} \mathrm{O}_{52}$ $[35,435]$ and $\mathrm{Mo}_{17} \mathrm{O}_{47}$, which are formed by a mixture of Mo oxidation states between +6 and +4. As experimental results, the topotactic reaction of lithium into the $\mathrm{MoO}_{\mathrm{y}}$ framework and reversibility have been demonstrated [66,67], and extent of lithiation depend on the stoichiometry of the $\mathrm{Mo}_{\mathrm{n}} \mathrm{O}_{3 \mathrm{n}-1}$ phases. Due to their tunneling structure with empty cavities, the $\mathrm{Mo}_{\mathrm{n}} \mathrm{O}_{3 \mathrm{n}-1}$ phases are performant cathode materials in non-aqueous lithium cells [61,436-439]. Christian and co-workers [440] shown that of the oxides $\mathrm{Mo}_{4} \mathrm{O}_{11}\left(\mathrm{MoO}_{2.75}\right), \mathrm{Mo}_{17} \mathrm{O}_{47}$ $\left(\mathrm{MoO}_{2.765}\right), \mathrm{Mo}_{8} \mathrm{O}_{23}\left(\mathrm{MoO}_{2.889}\right)$, and $\mathrm{Mog}_{9} \mathrm{O}_{26}\left(\mathrm{MoO}_{2.875}\right)$ the greatest reversible capacity (1.5 $\mathrm{Li} / \mathrm{Mo})$ after several deep discharge-charge cycles was exhibited by $\mathrm{Mo}_{17} \mathrm{O}_{47}$ in cells with $\mathrm{LiClO}_{4} /$ propylene carbonate electrolyte in the potential range 2.9-1.4 V (Table 12).

Table 12. Electrical and electrochemical characteristics of $\mathrm{Mo}_{\mathrm{n}} \mathrm{O}_{3 \mathrm{n}-1}$ oxides.

\begin{tabular}{lccc}
\hline Compound & $\rho(\Omega \mathrm{cm})$ & \multicolumn{2}{c}{ Li uptake $(\mathrm{Li} / \mathrm{Mo})$} \\
\cline { 3 - 4 } & & 1st cycle & 20th cycle \\
\hline $\mathrm{Mo}_{18} \mathrm{O}_{52}$ & 10 & 0.7 & 0.3 \\
$\mathrm{Mo}_{8} \mathrm{O}_{23}$ & 1 & 1.0 & 0.4 \\
$\mathrm{Mo}_{4} \mathrm{O}_{11}$ & 0.01 & 1.5 & 0.75 \\
$\mathrm{Mo}_{17} \mathrm{O}_{47}$ & 0.05 & 1.5 & 0.8 \\
$\mathrm{Mo}_{5} \mathrm{O}_{14}$ & 0.02 & 1.45 & - \\
\hline
\end{tabular}

\section{1. $\mathrm{Mo}_{4} \mathrm{O}_{11}\left(\mathrm{MoO}_{2.75}\right)$}

The $\mathrm{Mo}_{4} \mathrm{O}_{11}$ phase has two 2D modifications (metal-like), orthorhombic $\gamma-\mathrm{Mo}_{4} \mathrm{O}_{11}$ [441] and monoclinic $\eta-\mathrm{Mo}_{4} \mathrm{O}_{11}$ [442]; in the metallic $\eta-\mathrm{Mo}_{4} \mathrm{O}_{11}$ phase the layers with the $\mathrm{ReO}_{3}$-type are ordered parallel to each other, whereas in $\gamma-\mathrm{Mo}_{4} \mathrm{O}_{11}$ they are arranged like the mirror image of the former ones [443]. Cignini et al. [436] investigated the electrochemical behavior of the orthorhombic $\mathrm{Mo}_{4} \mathrm{O}_{11}$ phases in Li cells with different electrolytes. The higher specific capacity of $340 \mathrm{mAh} \mathrm{g}^{-1}$ was delivered in $\mathrm{LiClO}_{4} / \mathrm{PC}$. A Li//Mo $\mathrm{O}_{11}$ cell, discharged at $0.5 \mathrm{~mA} \mathrm{~cm}{ }^{-2}$, has given $610 \mathrm{Wh} \mathrm{kg}^{-1}$, based on the weight of $\mathrm{Li}$ and $\mathrm{Mo}_{4} \mathrm{O}_{11}$. When the discharge for $\mathrm{Mo}_{4} \mathrm{O}_{11}$ is stopped above $2 \mathrm{~V}$ corresponding to $x<0.7 \mathrm{e}^{-} / \mathrm{Mo}$ ), the lattice of this oxide is essentially retained, while at $1.5 \mathrm{~V}$, the $\mathrm{Mo}_{4} \mathrm{O}_{11}$ structure is greatly altered with the appearance of new phases.

\section{2. $\mathrm{Mo}_{5} \mathrm{O}_{14}\left(\mathrm{MoO}_{2.8}\right)$}

The crystal structure of $\mathrm{Mo}_{5} \mathrm{O}_{14}$ (denoted as $\theta$-Mo oxide) is tetragonal ( $P 4 / \mathrm{mbm}$ S.G.). The lattice consists of either distorted $\mathrm{MoO}_{6}$ octahedra and $\mathrm{MoO}_{7}$ pentagonal bi-pyramids which are coupled together by edge- and corner-sharing [431]. As shown in Fig. 34e, the pentagonal bipyramids are edge sharing with the neighbored octahedra perpendicular to the fivefold axis 
and tunnels are parallel to the $c$-axis. Few works reporting the lithiation of $\mathrm{Mo}_{5} \mathrm{O}_{14}$ are available in the literature $[121,436,410,444]$. Preliminary patterns of the fully lithiated $\mathrm{Mo}_{5} \mathrm{O}_{14}$ crystal suggest that the unit cell expands in the $b$-direction and contracts in both the $a$ - and $c$-directions upon insertion of lithium [440]. Among the $\mathrm{Mo}_{\mathrm{n}} \mathrm{O}_{3 \mathrm{n}-1}$ oxides, $\mathrm{Mo}_{4} \mathrm{O}_{11}, \mathrm{Mo}_{17} \mathrm{O}_{47}$, and $\mathrm{Mo}_{8} \mathrm{O}_{23}$, the compound $\mathrm{Mo}_{17} \mathrm{O}_{47}$ has the highest intercalation cyclability. Its average discharge voltage is $1.85 \mathrm{~V}$, and its reversible discharge capacity is $1.5 \mathrm{Li} / \mathrm{Mo}$. Its theoretical specific energy is $490 \mathrm{Wh} \mathrm{kg}^{-1}$. Cignini et al. reported a specific capacity of $310 \mathrm{~mA} \mathrm{~g}^{-1}$ for $\mathrm{Mo}_{5} \mathrm{O}_{14}$ as the positive electrode of a primary Li cell discharged at $0.5 \mathrm{~mA} \mathrm{~cm}^{-2}$ and $1.0 \mathrm{~V}$ cut-off. [436]. Nazri and Julien [121] showed that $\mathrm{MoO}_{2.8}$, an oxygen-deficient $\mathrm{Mo}_{5} \mathrm{O}_{14}$ prepared by dehydration and annealing treatment of molybdic acid powder $\left(\mathrm{MoO}_{3} \cdot 1 \mathrm{H}_{2} \mathrm{O}\right)$ at $750{ }^{\circ} \mathrm{C}$, exhibits a high electrical conductivity of $10^{-2} \mathrm{~S} \mathrm{~cm}^{-1}$. Such a material displays an excellent reversible capacity $\left(1.45 \mathrm{e}^{-}\right.$ /Mo) in cells with $1 \mathrm{~mol} \mathrm{~L}^{-1} \mathrm{LiClO}_{4}$ in propylene carbonate (PC) electrolyte in the potential range $3.3-1.3 \mathrm{~V}$ vs. $\mathrm{Li}^{+} / \mathrm{Li}$. The open-circuit voltage is $3.1 \mathrm{~V}$ vs. $\mathrm{Li} / \mathrm{Li}^{+}$. The first discharge displays a stepped behavior with a voltage plateau at ca. $2.2 \mathrm{~V}$ followed by a potential decline for $x>0.7 \mathrm{e}^{-} / \mathrm{Mo}$. This compound can be assigned to the $\mathrm{Mo}_{3}^{6+} \mathrm{Mo}_{2}^{5+}$ valence distribution. If reversible lithium incorporation produced all $\mathrm{Mo}^{4+}$, the expected lithium uptake would be 8/5(1.6) $\mathrm{e}^{-} / \mathrm{Mo}$; a value close to that measured by electrochemical titration. The gravimetric capacity of $326 \mathrm{mAh} \mathrm{g}^{-1}$ was much higher than the $280 \mathrm{mAh} \mathrm{g}^{-1}$ of anhydrous $\mathrm{MoO}_{3}$. Shembel et al. [445] reported the electrochemical performance of e- $\mathrm{Mo}_{4} \mathrm{O}_{11}$ synthesized from ammonium molybdate electrolyte in thin-layer binder-free electrodes. A first discharge capacity of 900 $\mathrm{mAh} \mathrm{g}{ }^{-1}$ is delivered at $30 \mathrm{~mA} \mathrm{~g}^{-1}$ current density. The reversible discharge capacity can exceed $225 \mathrm{mAh} \mathrm{g}^{-1}$ for more than 170 cycles.

Oxygen deficient $\mathrm{MoO}_{3-\delta}$ nanoparticles (200 nm thick) were prepared by a citrate sol-gel using ammonium heptamolybdate tetrahydrate as a source of Mo and heat treated with a small fraction of zirconia under reducing atmosphere [446]. The structural analyses reveal that the composite is a blend formed by layered $\alpha-\mathrm{MoO}_{3}$, orthorhombic oxygen deficient phases $\mathrm{MoO}_{3-\delta}$ with $\delta=0.25\left(\gamma-\mathrm{Mo}_{4} \mathrm{O}_{11}\right)$ and $\alpha-\mathrm{ZrMo}_{2} \mathrm{O}_{8}$. At $\mathrm{C} / 10$ rate, the composite delivered a stable reversible capacity of $135 \mathrm{mAh} \mathrm{g}^{-1}$ after the $50^{\text {th }}$ cycle. At a rate of $2 \mathrm{C}$ the reversible capacity is maintained at $118 \mathrm{mAh} \mathrm{g}^{-1}$. An amorphous $\mathrm{Mo}_{\mathrm{n}} \mathrm{O}_{3 \mathrm{n}-1} /$ carbon nanocomposite $(n \approx 5)$ was fabricated from a citrate-gel precursor heated at moderate temperature $\left(500{ }^{\circ} \mathrm{C}\right)$ in inert (argon) atmosphere. The as-prepared $\mathrm{Mo}_{5} \mathrm{O}_{14}$-type/C material is compared to $\alpha-\mathrm{MoO}_{3}$ synthesized from the same precursor in air. Thermal gravimetry and elemental analysis indicate the presence of $25.8 \pm 0.2 \%$ of carbon in the composite. The RS spectrum of $\mathrm{Mo}_{5} \mathrm{O}_{14} / \mathrm{C}$ demonstrates an oxygen deficiency in the molybdenum oxide and the presence of a partially graphitized carbon. 
Outstanding improvement in electrochemical performance is obtained for the $\mathrm{Mo}_{5} \mathrm{O}_{14}$ encapsulated by carbon $\left(325 \mathrm{mAh} \mathrm{g}^{-1}\right.$ at the $50^{\text {th }}$ cycle at $\left.70 \mathrm{~mA} \mathrm{~g}^{-1}\right)$ in comparison with the carbon-free $\mathrm{MoO}_{3}\left(95 \mathrm{mAh} \mathrm{g}^{-1}\right)$. The high performance of the $\mathrm{Mo}_{5} \mathrm{O}_{14} / \mathrm{C}$ composite is clearly revealed with a specific discharge capacity of $155 \mathrm{mAh} \mathrm{g}^{-1}$ at $10 \mathrm{C}$ rate $\left(7 \mathrm{~A} \mathrm{~g}^{-1}\right)$ [109]. $\mathrm{Mo}_{4} \mathrm{O}_{11}$ nanoparticles were decorated onto ultralight graphene sheets (HRG) self-assembled with sulfur homogeneously dispersed onto the surface were used as the cathode material for a lithium sulfur battery [447]. The $\mathrm{Mo}_{4} \mathrm{O}_{11}-\mathrm{HRG} / \mathrm{S}$ cathode deliver a specific capacity of $\sim 900 \mathrm{mAh} \mathrm{g}^{-1}$ at $0.1 \mathrm{C}$ rate after 80 cycles at cut-off of $1.5 \mathrm{~V}$. Tysyachny et al. [448] investigated the transport properties of the electrolytic oxide $\mathrm{Mo}_{4} \mathrm{O}_{11}$ as cathode material of lithium battery. The average values of $D_{L i}^{*}$ in $\mathrm{Mo}_{4} \mathrm{O}_{11}$ determined by cyclic voltammetry are in the range from 3.0 to $6.4 \times 10^{-12}$ $\mathrm{cm}^{2} \mathrm{~s}^{-1}$.

\section{3. $\mathrm{Mo}_{8} \mathrm{O}_{23}\left(\mathrm{MoO}_{2.875}\right)$}

$\mathrm{Mo}_{8} \mathrm{O}_{23}$ has a monoclinic crystal structure ( $P 2 / a$ S.G.), which derived from that of $\mathrm{ReO}_{3}$ by a shear mechanism, is formed by slabs, $8 \mathrm{MoO}_{6}$ octahedra thick, mutually connected by edge-sharing between octahedra. It is a 3D framework characterized by intersecting channels and of cavities (Fig. 34a). Besenhard and Schollhorn [61] reported that cathodes containing $\mathrm{Mo}_{8} \mathrm{O}_{23}$ can be galvanostatically reduced resulting in the first uptake of $\sim 1 \mathrm{e}^{-}$per Mo in 0.35 mol L-1 $\mathrm{LiAlCl}_{4} / \mathrm{DME}$ electrolyte, which reduced to $0.4 \mathrm{Li}$ after 20 cycles. Pistoia and coworkers examined the electrochemical properties of $\mathrm{Mo}_{8} \mathrm{O}_{23}$ as cathode in lithium cells. Fiordiponti et al. [439] reported that Li cells containing the monoclinic $\mathrm{Mo}_{8} \mathrm{O}_{23}$ cathode show a stepwise discharge curve with particularly noticeable knees for $0.2<x<0.3,0.6<x<0.7$, and $0.8<x<0.9$, which does not prevent a complete reversibility. For high values of Li content, more serious structure alterations start to take place to which the sharp fall of potential may be attributed. $\mathrm{Mo}_{8} \mathrm{O}_{23}$ exhibits at first a shrinkage of the unit cell until 0.2Li/Mo, which is attributed to the large empty cavities with at least 12 coordinating sites, followed by a lattice re-expansion. At $1.0 \mathrm{~mA} \mathrm{~cm}{ }^{-2}$ and $2.0 \mathrm{~V}$ cut-off, $85 \mathrm{mAh} \mathrm{g}^{-1}\left(0.89 \mathrm{e}^{-/ \mathrm{Mo}}\right)$ and $200 \mathrm{Wh} \mathrm{kg}^{-1}$ were obtained. $\mathrm{Mo}_{8} \mathrm{O}_{23}$ maintains good recharge efficiencies for over 15 cycles. The chemical diffusion coefficient $\mathrm{Li}$ ions in $\mathrm{Li}_{x} \mathrm{Mo}_{8} \mathrm{O}_{23}$ was measured in the range $0.0<x<0.8$. $D_{L i}^{*}$ reaches a maximum value of $5 \times 10^{-9} \mathrm{~cm}^{2} \mathrm{~s}^{-1}$ at $x$ near to 0.3 .

\section{4. $\mathrm{Mo}_{18} \mathrm{O}_{52}\left(\mathrm{MoO}_{2.889}\right)$}

$\mathrm{Mo}_{18} \mathrm{O}_{52}$ crystallized with the triclinic symmetry ( $P \overline{1}$ S.G.). Its network maintains the layered structure of $\mathrm{MoO}_{3}$ (Fig. 34f). Ressler et al. [449] investigated the bulk structural 
modification of Mo-O oxides by the reduction of $\mathrm{MoO}_{3}$ with propene and the oxidation of $\mathrm{MoO}_{2}$ with oxygen. The formation of a $\mathrm{Mo}_{18} \mathrm{O}_{52}$-type shear structure consists of generation of oxygen vacancies at the (100) or (001) facets by reaction with propene and a vacancy diffusion in the $\mathrm{MoO}_{3}$ bulk. Kaiser et al. [450] prepared $\mathrm{Mo}_{\mathrm{n}} \mathrm{O}_{3 \mathrm{n}-1}$ compounds by the solid-state reaction of powdered $\alpha-\mathrm{MoO}_{3}$ with Mo in the spark-plasma synthesis (SPS) process at temperatures up to $973 \mathrm{~K}: \mathrm{Mo}_{18} \mathrm{O}_{52}(x=2.889), \mathrm{Mo}_{17} \mathrm{O}_{47}(x=2.760)$, and $\gamma-\mathrm{Mo}_{4} \mathrm{O}_{11}(x=2.750)$, which show different thermoelectric properties. $\mathrm{Mo}_{18} \mathrm{O}_{52}$, which appears to be an intrinsic narrow-gap semiconductor (activation energy $\approx 0.3 \mathrm{eV}$ ), exceptionally low thermal conductivity over the full temperature range $\left(0.5-0.9 \mathrm{~W} \mathrm{~m}^{-1} \mathrm{~K}^{-1}\right)$, while $\gamma-\mathrm{Mo}_{4} \mathrm{O}_{11}$, and $\mathrm{Mo}_{17} \mathrm{O}_{47}$ show poor metallic conductivity. The highest power factor is achieved by $\mathrm{Mo}_{17} \mathrm{O}_{47}\left(30 \mathrm{~W} \mathrm{~m}^{-1} \mathrm{~K}^{-2}\right.$ for $440 \leq T \leq 610 \mathrm{~K})$. Preliminary electrochemical tests of $\mathrm{Mo}_{18} \mathrm{O}_{52}$ in $0.35 \mathrm{~mol} \mathrm{~L}^{-1} \mathrm{LaAlCl}_{4} / \mathrm{DME}$ were conducted at $0.3 \mathrm{~mA} \mathrm{~cm}{ }^{-2}$ current density. The galvanostatic reduction in the potential window from -0.1 to $-2.8 \mathrm{~V}$ vs. SCE yields $1.5 \mathrm{e}^{-}$per Mo [61]. Investigations of $\mathrm{Mo}_{18} \mathrm{O}_{52}$ by Pistoia et al. [438] show that this non-stoichiometric $\mathrm{Mo}_{18} \mathrm{O}_{52}$ oxide displays a high-rate capability as cathode for secondary Li cells. In a cell with $1 \mathrm{~mol} \mathrm{~L}^{-1} \mathrm{LiClO}_{4} / \mathrm{PC}$ electrolyte, it can intercalate reversibly up to $1.35 \mathrm{Li} / \mathrm{Mo}\left(250 \mathrm{mAh} \mathrm{g}^{-1}\right)$ at current density in the range 1.0 $\mathrm{mA} \mathrm{cm}{ }^{-2}$ and $1 \mathrm{~V}$ cut-off, forming ternary phases. In a cell with $2 \mathrm{~mol} \mathrm{~L}^{-1} \mathrm{LiAsF}_{6} /$ methyl formate electrolyte, it delivers $340 \mathrm{mAh} \mathrm{g}^{-1}$ (1.81 $\mathrm{e}^{-/ M o}$ charge transfer). $\mathrm{Li}^{+}$-ion diffusion is relatively fast in the $\mathrm{Mo}_{18} \mathrm{O}_{52}$ channels $\left(D_{L i}^{*}=10^{-9} \mathrm{~cm}^{2} \mathrm{~s}^{-1}\right)$ and gives rise to a structure, in which $\mathrm{Li}^{+}$is tetrahedrally coordinated by oxygen.

\section{5. $\mathrm{Mo}_{9} \mathrm{O}_{26}\left(\mathrm{MoO}_{2.889}\right)$}

$\mathrm{Mo}_{9} \mathrm{O}_{26}$ has the same composition than $\mathrm{Mo}_{18} \mathrm{O}_{52}$, but crystallizes with a monoclinic structure $\left(P 2 / c\right.$ S.G.), which derives from the metastable $\mathrm{ReO}_{3}$-type modification $\beta-\mathrm{MoO}_{3}$.

\section{6. $\mathrm{Mo}_{17} \mathrm{O}_{47}\left(\mathrm{MoO}_{2.765}\right)$}

Christian et al. [440] obtained their best results with $\mathrm{Mo}_{17} \mathrm{O}_{47}$. $\mathrm{Li} / / \mathrm{Mo}_{17} \mathrm{O}_{47}$ cells could be cycled over 35 times at current densities of $0.5 \mathrm{~mA} \mathrm{~cm}^{-2}$ and average discharge voltages of 1.85 $\mathrm{V}$. The $\mathrm{Mo}_{17} \mathrm{O}_{47}$ framework accommodates 1.5 electrons per Mo during the first cycle, which reduces to $0.8 \mathrm{e}^{-}$at the $20^{\text {th }}$ cycle. Among the $\mathrm{Mo}_{\mathrm{n}} \mathrm{O}_{3 \mathrm{n}-1}$ oxides, $\mathrm{Mo}_{17} \mathrm{O}_{47}$ has the highest intercalation cyclability. From these figures, the theoretical specific energy is $400 \mathrm{Wh} \mathrm{kg}^{-1}$. Meduri et al. [132] prepared $\mathrm{MoO}_{3-x}$ nanowire arrays with diameters of $\sim 90 \mathrm{~nm}$ in a hotfilament chemical vapor deposition reactor at $775^{\circ} \mathrm{C}$ in $10 \mathrm{sccm}$ of oxygen at a pressure of 146 $\mathrm{Pa}$. XRD and Raman characterization indicate an oxygen deficient $\mathrm{Mo}_{17} \mathrm{O}_{47}$ orthorhombic 
phase. The initial discharge capacity retention of $\sim 770 \mathrm{mAhg}^{-1}$ at a current density of $25 \mathrm{~mA}$ $\mathrm{g}^{-1}$ in the range $0.1-3.5 \mathrm{~V}$ corresponds to $4.1 \mathrm{Li}^{+}$ions per $\mathrm{MoO}_{3-x}$. A capacity of $\sim 630 \mathrm{mAh} \mathrm{g}^{-1}$ is retained for up to 20 cycles at a current density of $50 \mathrm{~mA} \mathrm{~g}^{-1}$. Hugues et al. [449] considered that, among Mo oxides with formulae between $\mathrm{MoO}_{2}$ and $\mathrm{MoO}_{3}, \mathrm{Mo}_{17} \mathrm{O}_{47}$ is the best cathode materials, which can supply current densities of $15 \mathrm{~mA} \mathrm{~cm}^{-2}$.

\section{Molybdenum Dioxide $\mathrm{MoO}_{2}$}

Molybdenum dioxide occurs as the mineral tugarinovite (molar mass $127.94 \mathrm{~g} \mathrm{~mol}^{-1}$, density $6.47 \mathrm{~g} \mathrm{~cm}^{-3}$, insoluble in water, melting point $1100^{\circ} \mathrm{C}$ ).

\subsection{Structure}

$\mathrm{MoO}_{2}$ crystallizes with the monoclinic structure with space group $P 2{ }_{1} / c\left(C_{2 h}^{5}\right)$, which can be viewed as a distorted rutile phase (Fig. 35a). This structure is composed of $\mathrm{MoO}_{6}$ octahedra joined by edge-sharing, which form a $(1 \times 1)$-tunnelling network (Fig. 35b). The lattice parameters of $\mathrm{MoO}_{2}$ are $a=5.6109 \AA, b=4.8562 \AA, c=5.6285 \AA$, and $\beta=120.95^{\circ}$ (JCPDS card No. 66-6787) $[452,453]$. The unit cell comprises four formula units. The metal atoms as well as the two inequivalent oxygen atoms occupy the general Wyckoff positions $(4 e)$. An interesting feature of $\mathrm{MoO}_{2}$ is that its metallic ground state (electrical resistivity $6.9 \times 10^{-4} \Omega$ cm) (Fig. 35c) [454]. The $d$ orbital can be separated into two sub-bands, i.e., $t_{2 \mathrm{~g}}$ and $e_{\mathrm{g}}$ bands by the crystal field. The $t_{2 \mathrm{~g}}$ band has a lower energy level and is partially filled by the two electrons, and the $e_{\mathrm{g}}$ band is empty and has a higher energy level located above the Fermi energy (Fig. 35d). This metallicity indeed differentiates $\mathrm{MoO}_{2}$ from insulating $\mathrm{MoO}_{3}$.
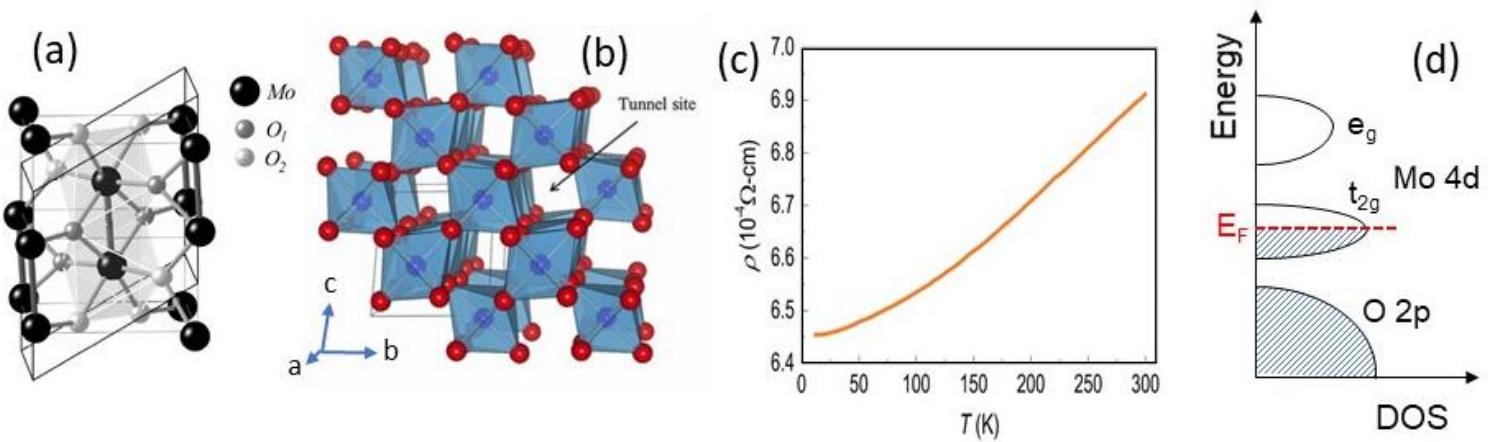

Fig. 35. (a) The distorted rutile structure of $\mathrm{MoO}_{2}$ (monoclinic, $\mathrm{P} 2{ }_{1} / \mathrm{c}$ S.G.). (b) View of the $(1 \times 1)$ tunnels in the rutile network. (c) Temperature-dependent resistivity. It shows a typical metallic behavior. The lowest resistivity is around $6.45 \times 10^{-4} \Omega \mathrm{cm}$. reproduced with permission from [454]. Copyright 2014 Royal society of Chemistry. (d) Schematic band 
diagram. The $d$ orbital can be separated into two sub-bands, i.e., $t_{2 \mathrm{~g}}$ and $e_{\mathrm{g}}$ bands by the crystal field. The $t_{2 \mathrm{~g}}$ band has a lower energy level and is partially filled by the two electrons, and the $e_{\mathrm{g}}$ band is empty and has a higher energy level located above the Fermi energy.

\subsection{Lithium insertion}

Importantly, $\mathrm{MoO}_{2}$ is considered to be one of the most studied anode systems for lithiumion batteries $[455,456]$. The lithium ions are inserted in the octahedral interstitial sites that are located in the tunnels between chains to form $\mathrm{Li}_{x} \mathrm{MoO}_{2}$ as reported 30 years ago $[457,458]$. $\mathrm{MoO}_{2}$ as Li-ion battery anode was systematically studied by Auborn and Barberio in 1987 for the first time [459] who demonstrated a relatively large capacity of 400-600 $\mathrm{mAh} \mathrm{g}^{-1}$.

The lithiation of $\mathrm{MoO}_{2}$ is a subject of debate since different mechanisms have been described, i.e., insertion reaction and conversion reaction delivering a theoretical gravimetric capacity of $838 \mathrm{mAh} \mathrm{g}^{-1}$ and a theoretical volumetric capacity of $1357 \mathrm{mAh} \mathrm{cc}^{-1}$ [460,461]. The first lithiation mechanism is an insertion-type reaction, which took place in the bulk and amorphous $\mathrm{MoO}_{2}$ electrodes with only one-electron reduction as described by the equation [457]:

$$
\mathrm{MoO}_{2}+x \mathrm{Li}^{+}+x \mathrm{e}^{-} \leftrightarrow \mathrm{Li}_{\mathrm{x}} \mathrm{MoO}_{2},
$$

with $0 \leq x \leq 0.98$. The second mechanism is a conversion reaction that gradually resolves $\mathrm{Li}_{\mathrm{x}} \mathrm{MoO}_{2}$ as described by the equation [462]:

$$
\mathrm{Li}_{x} \mathrm{MoO}_{2}+3.02 \mathrm{Li} \leftrightarrow 2 \mathrm{Li}_{2} \mathrm{O}+\mathrm{Mo}
$$

that evidences the formation of metallic $\mathrm{Mo}$ and $\mathrm{Li}_{2} \mathrm{O}$. In-situ XRD structural investigations of the lithium ions insertion into $\mathrm{MoO}_{2}$ have shown that the original monoclinic lattice $\left(P 2_{1} / c\right.$ S.G.) transforms to another monoclinic structure $\left(P 2{ }_{1} / c\right.$ S.G.) via an orthorhombic phase (Pnnm S.G.). Figure 36 presents the crystal structure of monoclinic $\mathrm{MoO}_{2}$, orthorhombic $\mathrm{Li}_{\mathrm{x}} \mathrm{MoO}_{2}$ and $\mathrm{Li}_{0.98} \mathrm{MoO}_{2}$. [463].
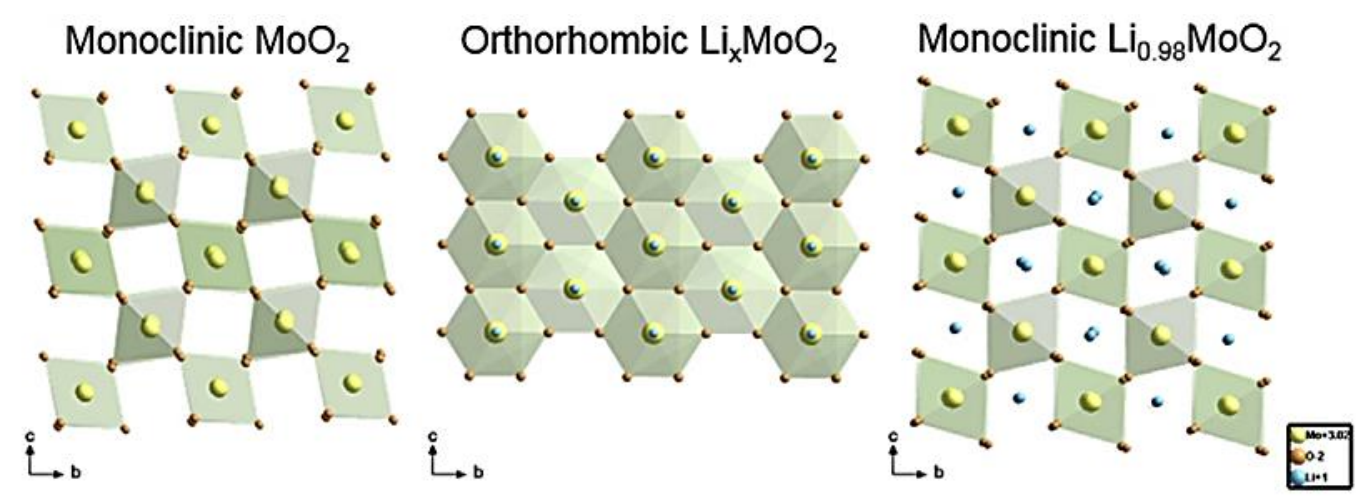

Fig. 36. The crystal structure of monoclinic $\mathrm{MoO}_{2}$, orthorhombic $\mathrm{Li}_{x} \mathrm{MoO}_{2}$ and $\mathrm{Li}_{0.98} \mathrm{MoO}_{2}$. reproduced with permission from [463]. Copyright 2016 Elsevier. 
The volume change associated with the $\mathrm{Li}$ insertion is only $11 \%$. Based on $\mathrm{Li}^{+}$insertion and extraction reaction, the phase transition $\mathrm{MoO}_{2}$ to $\mathrm{LiMoO}_{2}$ occurs in the potential range 2.5$1.0 \mathrm{~V}$ on discharge (reduction) and vice versa on charge (oxidation) [455,457,464]. In the first cycle, two pronounced reduction peaks were observed at 1.49 and $1.20 \mathrm{~V}$, which may arise from the phase transition from orthorhombic to the monoclinic phase due the Li insertion [465]. $\mathrm{Ku}$ et al. [466] demonstrated that structural defects in amorphous $\mathrm{MoO}_{2}$ electrodes can serve as a reversible $\mathrm{Li}^{+}$storage site for lithium secondary batteries. An unexpectedly high $\mathrm{Li}^{+}$storage capacity (up to four Li per $\mathrm{MoO}_{2}$ unit), which is larger by a factor of four than that for the crystalline counterpart. The conversion-type lithiation is discarded for this electrode from the absence of $\mathrm{Mo}$ metal and $\mathrm{Li}_{2} \mathrm{O}$ in the lithiated $\alpha-\mathrm{MoO}_{2}$ electrode with high specific capacity up to $810 \mathrm{mAh} \mathrm{g}^{-1}$. In comparison to $\mathrm{MoO}_{3}, \mathrm{MoO}_{2}$ has superior electronic conductivity, less charging potential, and higher volumetric capacity, which are highly important for application as an anode material in LIBs $[467,468]$. Figure 37 presents the typical electrochemical behavior of a $\mathrm{MoO}_{2}$ composite anode for LIB [468].
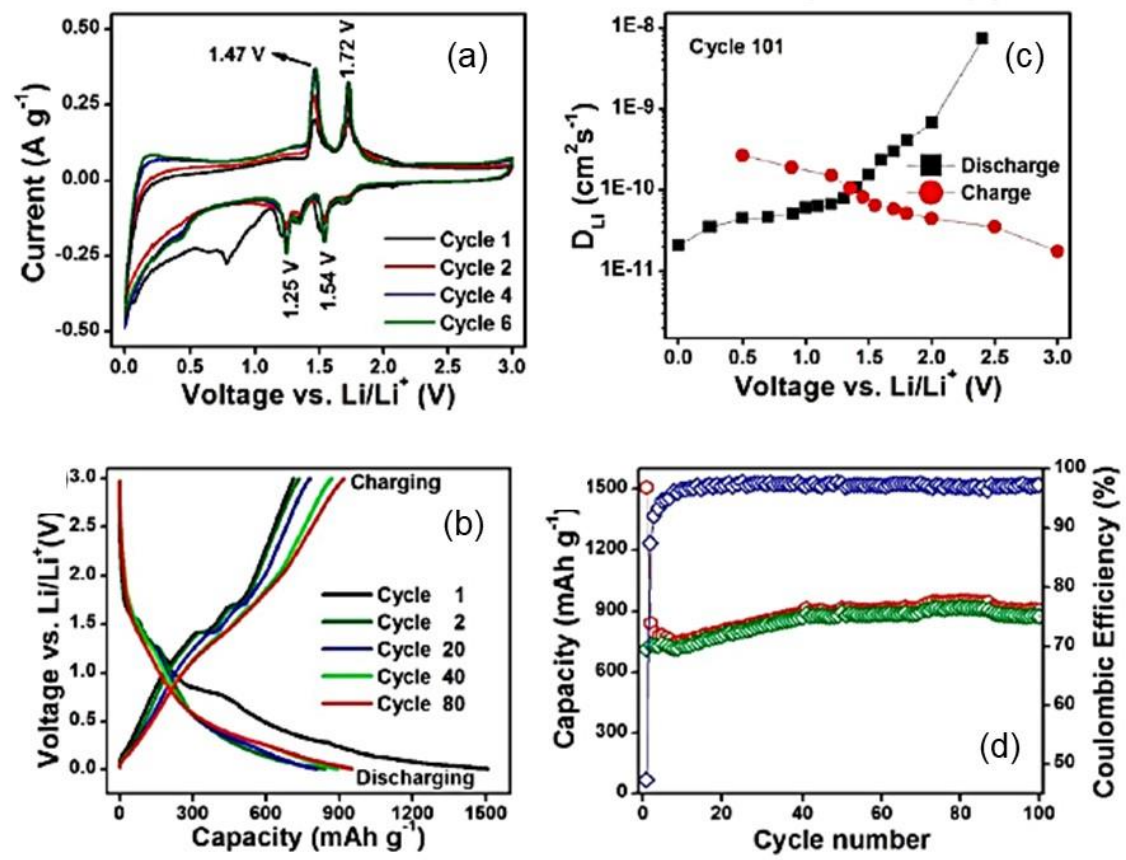

Fig. 37. Typical electrochemical properties of a $\mathrm{MoO}_{2}$ composite anode for LIB. (a) Cyclic voltammograms conducted at a sweep rate of $58 \mu \mathrm{V} \mathrm{s}^{-1}$ in the voltage range of $0.005-3.0 \mathrm{~V}$. $\mathrm{CV}$ curves contain strong redox couples centered at 1.25/1.47 and 1.54/1.72 V, which corresponds to $\mathrm{Li}$ intercalation and deintercalation into $\mathrm{MoO}_{2}$ according to Eq. 1. (b) Galvanostatic discharge-charge profiles of $\mathrm{Li}_{x} \mathrm{MoO}_{2}$ recorded at $100 \mathrm{~mA} \mathrm{~g}$-1 current rate. (c) Chemical diffusion coefficient of $\mathrm{Li}$ ion in $\mathrm{MoO}_{2}$ anode measured after 100 discharging/charging cycles. (d) Cyclability and coulombic efficiency over 100 cycles at 100 
$\mathrm{mA} \mathrm{g}^{-1}$ current rate. Reproduced with permission from [468]. Copyright 2016 American Chemical Society.

$\mathrm{MoO}_{2}$ has been synthesized using various techniques [469]: template method [455,470473], hydrothermal method [467,474-478], reduction of $\mathrm{MoO}_{3}$ [479-481], soft chemistry route [464,465,482], spray pyrolysis [483-485], carbothermal reaction [486], ion-exchange route [487], and so on. Traditionally, molybdenum dioxide is prepared by reducing $\mathrm{MoO}_{3}$ with hydrogen at high temperature and the product grows as micrometer size $[479,480]$. Manthiram et al. [488] and Liu et al. [489] reported the preparation of $\mathrm{MoO}_{2}$ powders by a reduction process in solution reaction routes, but their products showed a limited success because their lowdimensional nanosized powders. Liang et al. [477] prepared $\mathrm{MoO}_{2}$ nano-particles by a hydrothermal reaction route. The results show the resulting spherical, sheet-like and bar-shaped samples present a single phase $\mathrm{MoO}_{2}$ with monoclinic structure. $\mathrm{SnO}_{2} / \mathrm{MoO}_{3}$ nanowires were synthesized by a combination of hydrothermal (preparation of a white $\mathrm{MoO}_{3}$ precipitate from the yellowish solution of $\mathrm{MoO}_{2}$ powders dissolved in $\mathrm{H}_{2} \mathrm{O}_{2}$ ) and wet chemical (decoration of $\mathrm{MoO}_{3}$ nanowires by $\mathrm{SnO}_{2}$ nanoparticles by mixing $\mathrm{MoO}_{3}$ with $\mathrm{SnCl}_{2}$ with addition of $\mathrm{HCl}$ ) routes [228].

\section{3. $\mathrm{MoO}_{2}$ anode for LIBs}

The characteristic lithium-intercalation properties of spherical $\mathrm{MoO}_{2}$ powders imply there is a correlation between their nano-sized structure and an irreversible phase transition after the initial discharge process. $\mathrm{MoO}_{2}$ anode materials were made with various morphologies: nanobelts [490], nanorods [474,491], nanoporous powders [455,492], nanospheres [473,477] and nanosheets [493]. Rod type- $\mathrm{MoO}_{2}$ was synthesized by two steps: preparation of hexagonal $\mathrm{MoO}_{3}$ powders with rod shape followed by an ethanol-assisted reduction in $5 \% \mathrm{H}_{2} / \mathrm{Ar}$ atmosphere [335]. Zhang et al. [474] have prepared uniform $\mathrm{MoO}_{2}$ nanorods by a facile hydrothermal method, and the resultant samples were lithiated by subsequent treatment with $\mathrm{LiCl}$ solution. After lithiation, the $\mathrm{MoO}_{2}$ nanorods possessed a similar crystalline structure to the unlithiated sample. At a current density of $20 \mathrm{~mA} \mathrm{~g}^{-1}$, the lithiated specimen with better coulombic efficiency displayed a preferable cycling performance and exhibited excellent reversible charge-discharge capacity, while the unlithiated $\mathrm{MoO}_{2}$ exhibited more irreversible behavior. $\mathrm{MoO}_{2}$ nanosheets were synthesized for the first time by a solvothermal route using an ionic liquid [494]. When used as anode, the $\mathrm{MoO}_{2} / \mathrm{C}$ nanosheets exhibit a high reversible capacity of $620 \mathrm{mAh} \mathrm{g}^{-1}$ at $100 \mathrm{~mA} \mathrm{~g}^{-1}$ for 20 cycles. 
Since 2000, many works achieve improved electrochemical performance of $\mathrm{MoO}_{2}$ anode materials. Different architectures have been proposed including 2D [495,496] and 3D assemblies $[455,460,493,497]$. Spherical type- $\mathrm{MoO}_{2}$ was prepared by ultrasonic spray pyrolysis of aqueous ammonium molybdate and 5-20\% sucrose in 550-650 ${ }^{\circ} \mathrm{C}$ under $5 \% \mathrm{H}_{2} / \mathrm{Ar}$ atmosphere [484]. Shi et al. [455] prepared highly ordered mesoporous $\mathrm{MoO}_{2}$ by using phosphomobyldic acid as precursor and silica KIT-6 as hard template via nanocasting strategy. The mesoporous $\mathrm{MoO}_{2}$ electrode shows a first discharge capacity of $960 \mathrm{mAh} \mathrm{g}^{-1}\left(\mathrm{Li}_{4.6} \mathrm{MoO}_{2}\right)$ and a charge capacity of $630 \mathrm{mAh} \mathrm{g}^{-1}\left(\mathrm{Li}_{3} \mathrm{MoO}_{2}\right)$ in the potential range of 0.01-3.0 V. Sun et al. [498] fabricated $\mathrm{MoO}_{2}$ monolith using cotton cloth that is utilized as a binder-free alternative anode that exhibits a high reversible Li-storage capacity of $719 \mathrm{mAh} \mathrm{g}^{-1}$ at $200 \mathrm{~mA} \mathrm{~g}^{-1}$ after 30 cycles. Manthiram and Tsang [464] synthesized amorphous $\mathrm{MoO}_{2+\delta}(\delta=0.3)$ at ambient temperatures by a reduction of aqueous potassium molybdate solution with potassium borohydride. The amorphous sample exhibits excellent cyclability with a capacity of over 200 $\mathrm{mAh} \mathrm{g}^{-1}$ in the range 3 to $1 \mathrm{~V}$ in lithium cells with electrochemical behavior distinctly different from that of crystalline $\mathrm{MoO}_{2} \cdot \mathrm{MoO}_{2}$ nanoparticles $(\sim 100 \mathrm{~nm})$ were synthesized by reduction of $\mathrm{MoO}_{3}$ with ethanol vapor. This anode material exhibits good rate capability for the LIBs It displays an initial charge capacity of $318 \mathrm{mAh} \mathrm{g}^{-1}$, which maintains $100 \%$ after 20 cycles in the range of $0.01-3.00 \mathrm{~V}$ at a current density of $5 \mathrm{~mA} \mathrm{~cm}^{-2}$, and around $85 \%$ of the retrievable capacity is in the range of 1.0-2.0 $\mathrm{V}$ [467].

Tremella-like $\mathrm{MoO}_{2}$ consisting of nanosheets (NSs) were prepared using a $\mathrm{Fe}_{2} \mathrm{O}_{3}$-assisted hydrothermal reduction of $\mathrm{MoO}_{3}$ in ethylenediamine aqueous solution [493]. As an anode material for $\mathrm{LIB}, \mathrm{MoO}_{2} \mathrm{NSs}$ deliver a reversible capacity of $538 \mathrm{mAh} \mathrm{g}^{-1}$ with the coulombic efficiency of $70 \%$ at the current density of $0.5 \mathrm{~mA} \mathrm{~cm}^{-2}$ in the first cycle and sustains $\sim 300 \mathrm{mAh}$ $\mathrm{g}^{-1}$ at $5.0 \mathrm{~mA} \mathrm{~cm}{ }^{-2}$ after 22 cycles. Ultrafine $\mathrm{MoO}_{2}$ nanorods $(\sim 5 \mathrm{~nm}$ diameter $)$ were successfully synthesized by a nanocasting method using mesoporous silica SBA-15 as hard template. The ultrafine $\mathrm{MoO}_{2}$ nanorod electrode exhibits a first discharge capacity of $775 \mathrm{mAh}$ $\mathrm{g}^{-1}\left(\mathrm{Li}_{3.7} \mathrm{MoO}_{2}\right)$ at $\mathrm{C} / 20$ rate in the voltage range 3.0-0.01 $\mathrm{V}$. The capacity even reaches 830 mAh g ${ }^{-1}$ after 29 cycles [491]. $\mathrm{MoO}_{2}$ powder electrode was electrochemically activated [499] at high temperature. The lithiation behavior occurs by a one-electron reduction (by addition reaction) at room temperature. At elevated temperatures, this electrode is lithiated with fourelectron reduction by addition and continued conversion reaction. This phenomenon is named "thermoelectrochemical activation" because the extension from one- to four-electron reduction is achieved by a simple charge-discharge cycling made at elevated temperatures. This $\mathrm{MoO}_{2}$ electrode delivers a reversible specific capacity that is close to the theoretical four-electron 
capacity ( $838 \mathrm{mAh} \mathrm{g}^{-1}$ ) with an excellent cycle performance at room temperature. A templatefree solvothermal method has been developed to synthesize yolk-shell $\mathrm{MoO}_{2}$ microspheres [500]. They are composed of both a uniform porous shell of $80 \mathrm{~nm}$ in thickness and a porous core constructed from primary $\mathrm{MoO}_{2}$ nanocrystal clusters of $20 \mathrm{~nm}$ in size. Yolk-shell $\mathrm{MoO}_{2}$ microspheres can deliver a high specific capacity of $955 \mathrm{mAh} \mathrm{g}^{-1}$ in the first discharge at a current density of $50 \mathrm{~mA} \mathrm{~g}^{-1}$, and retain a reversible capacity of $847 \mathrm{~mA} \mathrm{~g}^{-1}$ after 50 cycles.

\section{4. $\mathrm{MoO}_{2}$ composites}

Several strategies have demonstrated the ability to mitigate the particle pulverization as a consequence of $\mathrm{Li}$ insertion and extraction and to improve the $\mathrm{MoO}_{2}$ electrochemical performance via the fabrication of nanocomposites including carbonaceous materials. By scaling down to the particle size, it results in shortening the transport paths for both ions and electrons, while the carbonaceous matrix maintains high conductivity, large surface area and chemical stability. The composites studied as lithium battery anodes include various carbon forms, such as carbon cloth [501], carbon coating [490,502-504], $\mathrm{MoO}_{2} / \mathrm{C}$ spheres [460], $\mathrm{MoO}_{2} /$ carbon hybrid nanowires [482], $\mathrm{MoO}_{2} / \mathrm{Mo}_{2} \mathrm{C}$ composite [461,487], $\mathrm{MoO}_{2} /$ ordered mesoporous carbon [471,505]. Nitride-coating [506] and $\mathrm{Mo}_{2} \mathrm{~N}$ nanolayer-coating [507] are also attractive synthetic approaches.

Uniform carbon-coated $\mathrm{MoO}_{2}$ nanospheres synthesized a one-pot hydrothermal method [502] exhibit significant improved electrochemical performance for high-rate lithium storage. Carbon-coated $\mathrm{MoO}_{2}$ lengthened a few micrometers produced by carbothermal reduction of $\mathrm{MoO}_{3}$ nanobelts were further ball-milled to reduce the particle size below $100 \mathrm{~nm} . \mathrm{C} / \mathrm{MoO}_{2}$ nanoparticles demonstrate a discharge capacity of $248 \mathrm{mAh}\left(\mathrm{g}_{\mathrm{MoO} 2}\right)^{-1}$ at $150 \mathrm{~mA} \mathrm{~g}^{-1}(0.5 \mathrm{C}$ rate $)$ with an average operation voltage of $1.3 \mathrm{~V}$. This anode material is also suitable for high rate charge and discharge, reaching $129 \mathrm{mAh} \mathrm{g}^{-1}$ for charge and $146 \mathrm{mAh} \mathrm{g}^{-1}$ for discharge even at 30C-rates $\left(9 \mathrm{~A} \mathrm{~g}^{-1}\right)$ [486]. Luo et al. [503] fabricated carbon-coated $\mathrm{MoO}_{2}$ nanofibers (with a uniform carbonaceous shell of $\sim 3 \mathrm{~nm}$ in thickness and a hierarchical core made of primary $\mathrm{MoO}_{2}$ nanocrystal clusters of $\sim 20 \mathrm{~nm}$ in size) through a controlled route based on single-nozzle electrospinning, air stabilization, and reduction/carbonization processes. These nanofibers exhibit a highly reversible capacity as high as $762.7 \mathrm{mAh} \mathrm{g}^{-1}$ over 100 cycles. Carbon coated $\mathrm{MoO}_{2}$ nanobelts were synthesized via a hydrothermal method followed by calcination under inert atmosphere, using $\alpha-\mathrm{MoO}_{3}$ nanobelts as the precursor and self-template, ethanol as the reducer and glucose as the carbon source [490]. Electrochemical tests of this anode material show a reversible capacity of $769 \mathrm{mAh} \mathrm{g}^{-1}$ at a current density of $100 \mathrm{~mA} \mathrm{~g}^{-1}$ in the first cycle, 
and retain $80.2 \%$ of the capacity after 30 cycles. Zhou et al. [462] have evaluated C-coated $\mathrm{MoO}_{2}$ nanocomposite, i.e., interconnected $\mathrm{MoO}_{2}$ nanocrystals with carbon nanocoating, prepared by one-pot hydrothermal route that show high specific capacities of $\sim 640 \mathrm{mAh} \mathrm{g}^{-1}$ at $200 \mathrm{~mA} \mathrm{~g}^{-1}$ and $\sim 575 \mathrm{mAh} \mathrm{g}^{-1}$ at $400 \mathrm{~mA} \mathrm{~g}^{-1}$. Chen et al. [470] designed a novel $\mathrm{MoO}_{2}-$ ordered mesoporous carbon $\left(\mathrm{MoO}_{2}-\mathrm{OMC}\right)$ hybrid through a two-step solvothermal chemical reaction route. Electrochemical tests reveal a first discharge capacity of $1642 \mathrm{mAh} \mathrm{g}^{-1}$ with an ICE of $63.6 \%$, and a reversible capacity as high as $1049 \mathrm{mAh} \mathrm{g}^{-1}$ even after 50 cycles at a current density of $100 \mathrm{~mA} \mathrm{~g}^{-1}$. The $\mathrm{MoO}_{2}-\mathrm{OMC}$ hybrid demonstrates an excellent high rate capability with capacity of $\sim 600 \mathrm{mAh} \mathrm{g}^{-1}$ even at a charge current density of $1600 \mathrm{~mA} \mathrm{~g}^{-1}$ after 50 cycles. A nano-sized $\mathrm{MoO}_{2} / \mathrm{C}$ composite was synthesized using a spray pyrolysis technique, and investigated as an anode material for Li-ion batteries. Spherical $\mathrm{MoO}_{2} / \mathrm{C}$ particles with the monoclinic phase ( $P 2_{1} / c$ S.G.) were obtained without any impurities, and with a primary particle size in the range 30-50 nm [483]. Liu et al. [475] synthesized $\mathrm{MoO}_{2} / \mathrm{C}$ composite nanospheres with cage-like structure by a simple hydrothermal reduction process using ammonium molybdate tetrahydrate $\left(\left(\mathrm{NH}_{4}\right)_{6} \mathrm{Mo}_{7} \mathrm{O}_{24} \cdot 4 \mathrm{H}_{2} \mathrm{O}\right)$ and ascorbic acid as a structure directing agent, reductive agent and carbon source. These porous structured electrodes can deliver a capacity of $692.5 \mathrm{mAh} \mathrm{g}^{-1}$ after 80 charge-discharge cycles at a current density of 200 $\mathrm{mA} \mathrm{g}^{-1}$ and can maintain excellent cycling stability (about $550 \mathrm{mAh} \mathrm{g}^{-1}$ after 475 cycles). Nanostructured monolithic hybrid mat made of $\mathrm{C} / \mathrm{MoO}_{2+\delta}$ nanofibers were fabricated through an electrospinning process by thermal treatment in $\mathrm{N}_{2}$. The free-standing anode $\mathrm{C} / \mathrm{MoO}_{2+\delta}$ composite exhibits a reversible capacity as high as $877 \mathrm{mAh} \mathrm{g}^{-1}$ after 250 cycles at a current density of $200 \mathrm{~mA} \mathrm{~g}^{-1}$. A capacity of $\sim 448 \mathrm{mAh} \mathrm{g}^{-1}$ could be maintained after 1000 cycles at $2000 \mathrm{~mA} \mathrm{~g}^{-1}$ rate [508]. Recently, Qing et al. [509] fabricated the composite $\mathrm{MoO}_{2} / \mathrm{VC}$ via a facile hydrothermal route, where vitamin $\mathrm{C}(\mathrm{VC})$ is a source of carbon. This composite LIB anode displays a discharge capacity of $\sim 300 \mathrm{mAh} \mathrm{g}^{-1}$ at $0.5 \mathrm{~A} \mathrm{~g}^{-1}$ after 120 cycles.

Several $\mathrm{MoO}_{2} / \mathrm{Mo}_{2} \mathrm{C}$ heterostructures have been fabricated as anode materials for LIBs [461,487,510]. $\mathrm{MoO}_{2} / \mathrm{Mo}_{2} \mathrm{C}$ heteronanotubes were fabricated by a one-step carbothermal reduction by using a mesoporous carbon CMK-3 acting as template and reactant [461]. $\mathrm{Mo}_{2} \mathrm{C}$ is an electrochemical inactive compound, which exhibits a high conduction of $\sim 10^{-2} \mathrm{~S} \mathrm{~cm}^{-1}$ and minimizes the charge transfer resistance of the composite. Cycled at 200 and $1000 \mathrm{~mA} \mathrm{~g}^{-1}$ for 140 cycles, the discharge capacities of the $\mathrm{MoO}_{2} / \mathrm{Mo}_{2} \mathrm{C}$ heteronanotubes remain to be 790 and $510 \mathrm{mAh} \mathrm{g}{ }^{-1}$, respectively. Ihsan et al. [510] synthesized $\mathrm{MoO}_{2} / \mathrm{Mo}_{2} \mathrm{C} / \mathrm{C}$ spheres through hydrothermal and calcination processes that demonstrates not only high cycling performance, but also good rate capability when they are used as anode materials for LIBs. After 100 cycles 
at $100 \mathrm{~mA} \mathrm{~g}^{-1}$, the discharge capacities of the $\mathrm{MoO}_{2} / \mathrm{Mo}_{2} \mathrm{C} / \mathrm{C}$ spheres as anode materials remain at $800 \mathrm{mAh} \mathrm{g}^{-1}$.

Zhang et al. [460] synthesized uniform hierarchical $\mathrm{MoO}_{2} / \mathrm{C}$ spheres through calcination of a $\mathrm{MoO}_{3} /$ resin precursor generated via a hydrothermal method in the presence of resorcinol, formaldehyde and $\left(\mathrm{NH}_{4}\right)_{6} \mathrm{Mo}_{7} \mathrm{O}_{24} \cdot 4 \mathrm{H}_{2} \mathrm{O}$. Used as an anode material, these spheres exhibit an initial capacity of $\sim 400 \mathrm{mAh} \mathrm{g}^{-1}$ at $0.5 \mathrm{~A} \mathrm{~g}^{-1}$ and high cycling performance after 400 cycles with capacities of $\sim 600$ and $\sim 500 \mathrm{mAh} \mathrm{g}^{-1}$ at 0.5 and $1.0 \mathrm{~A} \mathrm{~g}^{-1}$ rate, respectively. $\mathrm{MoO}_{2} /$ carbon nanowires were prepared by a method based on organic-inorganic hybrid nanocomposites with nanometer periodic structures [482]. The $\mathrm{MoO}_{2} / \mathrm{C}$ hybrid nanowires show good rate capability even at the high current density of $1000 \mathrm{~mA} \mathrm{~g}^{-1}$ as anode material for LIBs.

$\mathrm{MoO}_{2}$-loaded porous carbon hollow sphere composite materials were synthesized using $\mathrm{MoO}_{2}$ nanoparticles with an average size of $\sim 12 \mathrm{~nm}$ uniformly dispersed in the shells of the porous carbon hollow spheres (PCHS) [511]. The $\mathrm{MoO}_{2} / \mathrm{PCHS}$ composite containing $44.2 \%$ of $\mathrm{MoO}_{2}$ revealed a reversible capacity of $574 \mathrm{mAh} \mathrm{g}^{-1}$ at a current density of $50 \mathrm{~mA} \mathrm{~g}^{-1}$. After 80 cycles, this composite still retained a capacity of $640 \mathrm{mAh} \mathrm{g}^{-1}$ due to the presence of porous carbon, which prevents volume change or aggregation of the $\mathrm{MoO}_{2}$ nanoparticles during the $\mathrm{Li}$ ion insertion/extraction process. Zeng et al. [471] synthesized the nanocomposite of $\mathrm{MoO}_{2}$ ordered mesoporous carbon $\left(\mathrm{MoO}_{2}-\mathrm{OMC}\right)$ using a carbon thermal reduction route. This nanocomposite exhibits a large reversible capacity of $689 \mathrm{mAh} \mathrm{g}^{-1}$ after 50 cycles at a current density of $50 \mathrm{~mA} \mathrm{~g}^{-1}$. This nanocomposite offered a better accommodation of the strain and volume changes and a shorter path for $\mathrm{Li}$-ion and electron transport, leading to the improved capacity and enhanced rate capability of the anode material for LIBs.

Carbon-coated $\mathrm{MoO}_{2}$ nanobelts were fabricated via a hydrothermal route followed by calcination under inert atmosphere, using $\alpha-\mathrm{MoO}_{3}$ nanobelts as the precursor and self-template, ethanol as the reducer and glucose as the carbon source. The $\mathrm{C} / \mathrm{MnO}_{2} \mathrm{NBs}$ anode materials exhibit a reversible capacity of $769 \mathrm{mAh} \mathrm{g}^{-1}$ at a current density of $100 \mathrm{~mA} \mathrm{~g}^{-1}$ in the first cycle, and retain $80.2 \%$ of the capacity after 30 cycles [490]. Nanorods (250 nm in diameter), which consist of $\alpha-\mathrm{MoO}_{3}$ core and $\beta-\mathrm{MnO}_{2}$ shell (46 nm thick, tetragonal phase) were synthesized by a two-step hydrothermal process [214]. The $\alpha-\mathrm{MoO}_{3} @ \beta-\mathrm{MnO}_{2}$ nanorods show a reversible capacity of $1475 \mathrm{mAh} \mathrm{g}^{-1}$ at $0.1 \mathrm{C}$ rate and retains at $1127 \mathrm{mAh} \mathrm{g}^{-1}$ after 50 cycles. Even at high current rate of $6 \mathrm{C}$, the reversible capacity is $394 \mathrm{mAh} \mathrm{g}^{-1}$ and retains at $286 \mathrm{mAh} \mathrm{g}^{-1}$ after 50 cycles. A heterostructure, which consists of $\mathrm{MoO}_{2}$ nanoparticles anchored and embedded in the 1D N-doped carbon matrix were fabricated using the organic-inorganic $\mathrm{Mo}_{3} \mathrm{O}_{10}\left(\mathrm{C}_{6} \mathrm{H}_{8} \mathrm{~N}\right)_{2} \cdot 2 \mathrm{H}_{2} \mathrm{O}$ hybrid nanowires as a precursor and self-template. The nanowires were 
calcined at $650{ }^{\circ} \mathrm{C}$ for $5 \mathrm{~h}$ under an $\mathrm{Ar}$ flow $\left(50 \mathrm{~mL} \mathrm{~min}{ }^{-1}\right)$ to yield the $\mathrm{MoO}_{2} / \mathrm{N}-\mathrm{C}$ heteronanowires. Tested at a current density of $2 \mathrm{~A} \mathrm{~g}^{-1}$, the $\mathrm{MoO}_{2} / \mathrm{N}-\mathrm{C}$ composite delivers a reversible capacity of $700 \mathrm{mAh} \mathrm{g}^{-1}$ after 400 cycles, which still remains $570 \mathrm{mAh} \mathrm{g}^{-1}$ even after 1500 cycles [512]. Nanoporous 3D $\mathrm{MoO}_{2}$ single crystals were partially covered with a few atomic layers of $\mathrm{MoS}_{2}$ to form $\mathrm{MoS}_{2} / \mathrm{MoO}_{2}$ nanonetworks, which exhibit a reversible discharge specific capacity of $1233 \mathrm{mAh} \mathrm{g}^{-1}$ at a current density of $100 \mathrm{~mA} \mathrm{~g}^{-1}$. When discharged at 200 and $500 \mathrm{~mA} \mathrm{~g}^{-1}$, the capacities are 1158 and $826 \mathrm{mhA} \mathrm{g}^{-1}$ [513]. Wang et al. [514] prepared a mesoporous $\mathrm{MoO}_{2} @ \mathrm{C}$ nanocomposite using oleic acid to reduce the $\mathrm{MoO}_{3}$ precursor and to simultaneously coat the resultant $1 \mathrm{D} \mathrm{MoO}_{2}$ nanorods with carbon layers (BET surface area of $45.7 \mathrm{~m}^{2} \mathrm{~g}^{-1}$, and pore size of $3.8 \mathrm{~nm}$ ). The $\mathrm{MoO}_{2} @ \mathrm{C}$ electrode exhibits a high capacity of 1034 $\mathrm{mAh} \mathrm{g}^{-1}$ at $0.1 \mathrm{~A} \mathrm{~g}^{-1}$, and a capacity of $155 \mathrm{mAh} \mathrm{g}^{-1}$ at a super-high current rate of $22 \mathrm{~A} \mathrm{~g}^{-1}$. When, the $\mathrm{Li} / \mathrm{MoO}_{2} @ \mathrm{C}$ half cells cycled at 0.5 and $10 \mathrm{~A} \mathrm{~g}^{-1}$ retain 861 and $312 \mathrm{mAh} \mathrm{g}^{-1}$ capacity after 140 and 268 cycles, respectively. Recently, Zhang et al. [515] reported the design and fabrication of a composite, which consists of encapsulated $\mathrm{MoO}_{2}$ nanocrystals into flexible carbon nanofibers, using a needle-free electrospinning method combined with the subsequent carbonization process. The $\mathrm{MoO}_{2} / \mathrm{C}$ nanofiber membrane as self-supporting anode exhibits a discharge capacity of $450 \mathrm{mAh} \mathrm{g}^{-1}$ after 500 cycles at $2000 \mathrm{~mA} \mathrm{~g}^{-1}$. Table 13 summarizes the electrochemical performance of various $\mathrm{MoO}_{2}$ composites as anode materials for LIBs.

Table 13. Electrochemical performance of various $\mathrm{MoO}_{2}$ composites as anode materials for Li-ion batteries. The relevant cycle number is displayed in brackets.

\begin{tabular}{|c|c|c|c|c|}
\hline Material & Synthesis & $\begin{array}{c}\text { Reversible } \\
\text { capacity } \\
\left(\mathrm{mAh} \mathrm{g}^{-1}\right)\end{array}$ & $\begin{array}{l}\text { Current rate } \\
\left(\mathrm{mA} \mathrm{g}^{-1}\right)\end{array}$ & Ref. \\
\hline Nano $\mathrm{MoO}_{2}$ & Rheology & 402 & $100(40)$ & [516] \\
\hline $\mathrm{MoO}_{2} / \mathrm{Mo}_{2} \mathrm{~N}$ & Reduction of $\mathrm{MoO}_{3}$ & 815 & $100(150)$ & [517] \\
\hline $\mathrm{MoO}_{2} /$ graphene & Chemical vapor deposition & 986 & $50(150)$ & {$[518]$} \\
\hline $\mathrm{MoO}_{2} / \mathrm{C}$ & Ion exchange & 574 & $100(100)$ & [519] \\
\hline $\mathrm{MoO}_{2} / \mathrm{C}$ & Carbothermal reduction & 500 & $100(50)$ & {$[471]$} \\
\hline $\mathrm{MoO}_{2} / \mathrm{C}$ hollow spheres & Solvothermal & 580 & $200(200)$ & {$[520]$} \\
\hline Mesoporous $\mathrm{MoO}_{2}$ & Template casting & 750 & $42(30)$ & {$[455]$} \\
\hline Activated $\mathrm{MoO}_{2}$ & Electrochemical activation & 850 & $100(30)$ & [521] \\
\hline $\mathrm{MoO}_{2} \mathrm{HCSMSs}$ & Hydrolysis & 420 & $50(30)$ & {$[522]$} \\
\hline W-doped $\mathrm{MoO}_{2}$ & Nanocasting & 670 & $75(20)$ & [492] \\
\hline $\mathrm{C} / \mathrm{WO}_{\mathrm{x}} / \mathrm{MoO}_{2}$ & Hydrothermal & 670 & $90(50)$ & [523] \\
\hline $\mathrm{MoO}_{2} / \mathrm{C} \mathrm{NWs}$ & Solvothermal & 500 & $200(20)$ & [482] \\
\hline $\mathrm{C} / \mathrm{MoO}_{2} \mathrm{NSs}$ & Hydrothermal+annealing & 675 & $838(30)$ & {$[502]$} \\
\hline $\mathrm{MoS}_{2} / \mathrm{MoO}_{2}$ & Sulfur assisted & 654 & $500(80)$ & {$[513]$} \\
\hline $\mathrm{C} / \mathrm{MoO}_{2} \mathrm{NBs}$ & Hydrothermal+annealing & 617 & $100(30)$ & {$[490]$} \\
\hline $\mathrm{MoO}_{2}$ monolith & Morphosynthesis & 719 & $200(20)$ & [498] \\
\hline
\end{tabular}




\begin{tabular}{llccc}
\hline$\alpha-\mathrm{MoO}_{3} @ \beta-\mathrm{MnO}_{2}$ & Two-step hydrothermal & 286 & $6 \mathrm{C}(50)$ & {$[214]$} \\
$\mathrm{MoO}_{2} / \mathrm{N}$-doped C NWs & Calcination & 700 & $2000(400)$ & {$[512]$} \\
$\mathrm{C}-\mathrm{coated}_{\mathrm{MoO}_{2}}$ & Hydrothermal & 312 & $10000(268)$ & {$[514]$} \\
$\mathrm{MoO}_{2} /$ flexible C & Electrospinning & 450 & $2000(500)$ & {$[515]$} \\
\hline
\end{tabular}

\section{5. $\mathrm{MoO}_{2}$ /graphene composites}

To overcome the sluggish lithiation/delithiation kinetics of micron-scale particles, several graphite-based nanocomposites have been created such as graphite oxide [524], and graphene (GR) [465,525,526], graphene oxide (GO) [465,527-529], and reduced graphene oxide (rGO) [530-534]. Using a microwave-assisted hydrothermal process and subsequent thermal annealing, Palanisamy et al. [535] prepared 3D porous self-assembled $\mathrm{MoO}_{2}$ /graphene microspheres. Such hybrid is built from interconnected $\mathrm{MoO}_{2}$ nanoparticles $(3-5 \mathrm{~nm})$ in the graphene matrix. The $\mathrm{MoO}_{2}$ /graphene composite anode delivers a high reversible capacity of $\sim 1300 \mathrm{mAh} \mathrm{g}^{-1}$ after 80 cycles at C/10 rate and excellent rate capability (913 and $390 \mathrm{mAh} \mathrm{g}^{-1}$ at $2 \mathrm{C}$ and 5C rates, respectively). Sun et al. [465] have investigated self-assembled hierarchical $\mathrm{MoO}_{2} /$ graphene nanoarchitectures fabricated on a large scale through a facile solution-phase process and subsequent reduction of the Mo-precursor/graphene composite. The as-formed $\mathrm{MoO}_{2} /$ graphene nanohybrid (containing $11.2 \mathrm{wt}$ \% graphene) as an anode material for LIBs exhibits not only a highly reversible capacity but also an excellent cycling performance as well as good rate capability, a specific capacity of $597 \mathrm{mAh} \mathrm{g}^{-1}$ is delivered after 70 cycles at current density of $1000 \mathrm{~mA} \mathrm{~g}^{-1}$. Tang et al. [528] reported the electrochemical performance of $\mathrm{MoO}_{2}$ /graphene nanocomposite synthesized via a two-step of hydrothermal-calcination method. When used as anode material for LIBs, the $\mathrm{MoO}_{2}$ /graphene composite shows a first discharge capacity of $674 \mathrm{mAh} \mathrm{g}^{-1}$ with a reversible capacity of $430 \mathrm{mAh} \mathrm{g}^{-1}$. Significantly, the composite can also deliver a reversible capacity of as high as1009 $\mathrm{mAh} \mathrm{g}^{-1}$ after 60 charge/discharge cycles. Chen et al. [481] reported the electrochemical properties of hierarchical nanocomposites including $\mathrm{MoO}_{2}$ nanocrystal-functionalized graphene synthesized by in-situ reduction process. The discharge capacity is still up to $997 \mathrm{mAh} \mathrm{g}^{-1}$ after 50 cycles and $370 \mathrm{mAh} \mathrm{g}^{-1}$ after 200 cycles at $10 \mathrm{C}$ rate.

Nanostructured $\mathrm{MoO}_{2} / \mathrm{GO}$ composites, which consists of a mixture of $\mathrm{MoO}_{2}$ nanorods and nanoparticles uniformly distributed at the surface of GO sheets, were synthesized by a simple solvothermal method of a GO suspension with $\left(\mathrm{NH}_{4}\right)_{6} \mathrm{Mo}_{7} \mathrm{O}_{24}$ and $\mathrm{HNO}_{3}$ in ethanol at $160{ }^{\circ} \mathrm{C}$ for $16 \mathrm{~h}$ [524]. The $\mathrm{MoO}_{2} / \mathrm{GO}$ with $10 \mathrm{wt} . \% \mathrm{GO}$ tested in lithium half-cell delivered an initial capacity of $800 \mathrm{mAh} \mathrm{g}^{-1}$ at current density of $0.8 \mathrm{~A} \mathrm{~g}^{-1}$ corresponding to Li uptake of 3.43 moles and a reversible capacity of $720 \mathrm{mAh} \mathrm{g}^{-1}$ at a current density of $100 \mathrm{~mA} \mathrm{~g}^{-1}$ and $560 \mathrm{mAh} \mathrm{g}^{-1}$ at 
a high current density of $800 \mathrm{~mA} \mathrm{~g}^{-1}$ after 30 cycles. The improved reversible capacity, rate capacity, and cycling performance of the composites are attributed to synergistic reaction between $\mathrm{MoO}_{2}$ and $\mathrm{GO}$. $\mathrm{MoO}_{2} / \mathrm{rGO}$ composites fabricated by hydrothermal route followed by

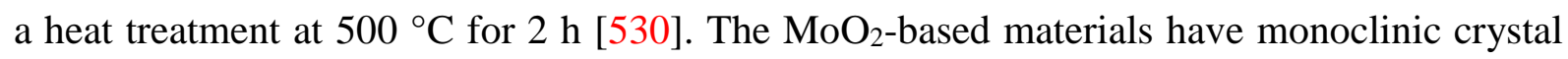
structure, and worm like shape with average dimensions of 100-200 nm width and 0.5-1 $\mu \mathrm{m}$ length. There are two steps of $\mathrm{Li}$ ion intercalation/de-intercalation for the $\mathrm{MoO}_{2} / \mathrm{rGO}$ anode at the potential ranging from 1.0 to $3.5 \mathrm{~V}$ vs. $\mathrm{Li}^{+} / \mathrm{Li}$, locating at $1.60 / 1.75$ and $1.25 / 1.40 \mathrm{~V}$, respectively with a first discharge capacity of $221 \mathrm{mAh} \mathrm{g}^{-1}$ and $R_{\mathrm{SEI}}$ and $R_{\mathrm{CT}}$ resistances of 2-4 $\Omega$ and below $5 \Omega$, respectively. Petnikota et al. [468] studied the insertion of Li and conversion mechanism of $\mathrm{MoO}_{2}$ (below $0.8 \mathrm{~V}$ ) in exfoliated graphene oxide/ $\mathrm{MoO}_{2}$ composites as anode materials. Graphene oxide was used as a reducing agent of $\mathrm{MoO}_{3}$ (molar ratio of 4:1) and as a source for exfoliated graphene oxide (EGO) to fabricate $\mathrm{EGO} / \mathrm{MoO}_{2}$ composites with 46 wt.\% graphene. The small particle size of $\sim 33 \mathrm{~nm}$ indicates that agglomeration of $\mathrm{MoO}_{2}$ has been controlled with the increased amount of EGO. The initial capacity of $713 \mathrm{mAh} \mathrm{g}^{-1}$ increased slightly to $878 \mathrm{mAh} \mathrm{g}^{-1}$ after 100 cycles at $100 \mathrm{~mA} \mathrm{~g}^{-1}$ current rate in the voltage window 0.005 3.0 V. Kinetics investigated by cyclic voltammetry revealed high values of the diffusion coefficients of $\mathrm{Li}$ ions in the range $6 \times 10^{-10}-1 \times 10^{-11} \mathrm{~cm}^{2} \mathrm{~s}^{-1}$ during $\mathrm{Li}_{\mathrm{x}} \mathrm{MoO}_{2}$ lithiation $(0<x$ <4). Hu et al. [478] prepared $\mathrm{MoO}_{2} / \mathrm{GO}$ composites via hydrothermal route at $200{ }^{\circ} \mathrm{C}$ for $24 \mathrm{~h}$ using Mo powder and exfoliated GO produced by sonication. $\mathrm{MoO}_{2}$ nanoparticles $(5-15 \mathrm{~nm}$ in size) were homogeneously dispersed on GO. When tested as an anode material for lithium, the $\mathrm{MoO}_{2} / \mathrm{GO}$ composite displayed an initial specific capacity of 780 and $500 \mathrm{mAh} \mathrm{g}^{-1}$ at 0.1 and $0.5 \mathrm{~A} \mathrm{~g}^{-1}$, respectively. The beneficial contribution of exfoliated GO was evidenced by EIS measurements, as the charge transfer resistance of $44 \mathrm{~W}$ for $\mathrm{MoO}_{2} / \mathrm{GO}$ was much lower than $300 \mathrm{~W}$ for pure $\mathrm{MoO}_{2}$ nanoparticles, due to more conductive pathway for Li-ion transportation. Huang and coworkers [536] fabricated a composite of $\mathrm{MoO}_{2}$ nanoparticles ( $\left.100 \mathrm{~nm}\right)$ anchored on GO for sodium-ion battery anodes. This $\mathrm{MoO}_{2} / \mathrm{GO}$ hybrid (15 wt.\% GO) yielded a discharge capacity of $483 \mathrm{mAh} \mathrm{g}^{-1}\left(\sim 2318 \mathrm{mAh} \mathrm{cm}^{-3}\right)$ at the current density of $100 \mathrm{~mA} \mathrm{~g}^{-1}$ and a capacity fading of $0.019 \%$ per cycle over the first 1000 cycles. Tang et al. reported the electrochemical properties of $\mathrm{rGO}$-wrapped $\mathrm{MoO}_{2}$ porous nanobelts $\left(\mathrm{rGO} / \mathrm{MoO}_{2} \mathrm{NBs}\right)$ synthesized using a

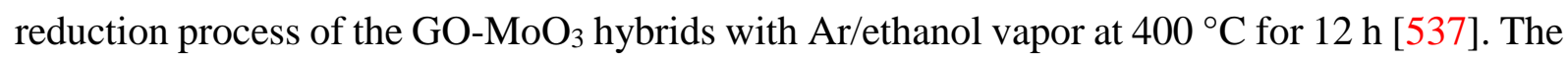
full-scale multi-electron conversion reaction in $\mathrm{rGO} / \mathrm{MoO}_{2} \mathrm{NBs}$ (with $8 \mathrm{wt}$.\% rGO) led to a high reversible capacity of $974 \mathrm{mAh} \mathrm{g}^{-1}$ at the current density of $60 \mathrm{~mA} \mathrm{~g}^{-1}$ after $6^{\text {th }}$ cycle and, after initial activation, a specific capacity of $420 \mathrm{mAh} \mathrm{g}^{-1}$ was retained at the end of 1900 cycles at $5 \mathrm{~A} \mathrm{~g}^{-1}$ rate. Zhu et al. [216] demonstrated that $\mathrm{rGO} / \mathrm{MoO}_{2}$ nanobelt composite (with 19.4 
wt.\% rGO) synthesized by a simple thermal reduction of $\mathrm{MoO}_{3}$ and $\mathrm{GO}$ at $550{ }^{\circ} \mathrm{C}$ for $2 \mathrm{~h}$ in a $10 \% \mathrm{H}_{2} / \mathrm{Ar}$ atmosphere had a BET specific surface area and pore volume of $17.68 \mathrm{~m}^{2} \mathrm{~g}^{-1}$ and $0.09 \mathrm{~cm}^{3} \mathrm{~g}^{-1}$, respectively. This self-assembled hybrid shows attractive electrochemical performance as LIB anodes with specific discharge capacity reaching $584 \mathrm{mAh} \mathrm{g}^{-1}$ after 100 cycles at $1 \mathrm{~A} \mathrm{~g}^{-1}$.

In 2017, Ju and coworkers [538] designed a TiO $/$ rGO/ $\mathrm{MoO}_{2} @$ Mo composite electrode for ESC. This architectural nanostructure with 3D walnut-shape synthesized by one-step hydrothermal method was composed of amorphous $\mathrm{TiO}_{2}$ decorating the $\mathrm{rGO} / \mathrm{MoO}_{2}$ surface grown on Mo foam. It exhibited a specific capacitance of $1636 \mathrm{~F} \mathrm{~g}^{-1}$ at $1.25 \mathrm{~A} \mathrm{~g}^{-1}$ with only $3.5 \%$ capacitance loss after 5000 cycles. Tightly anchored $\mathrm{MoO}_{2}$ nanoparticles $(10-20 \mathrm{~nm}$ in size) deposited on the basal plane of rGO were fabricated using a green supercritical methanol $(\mathrm{scMeOH})$ route. When tested as an anode in lithium cells, the composite with $37 \mathrm{wt} \% \mathrm{MoO}_{2}$ loading (BET surface area of $14.3 \mathrm{~m}^{2} \mathrm{~g}^{-1}, 15 \%$ porosity) delivered a reversible capacity of 793 $\mathrm{mAh} \mathrm{g}^{-1}$ at $50 \mathrm{~mA} \mathrm{~g}^{-1}$ current rate [531]. Graphene oxide flexibly supported $\mathrm{MoO}_{2}$ porous hybrids were constructed by decomposition of $\left(\mathrm{NH}_{4}\right)_{2} \mathrm{MoO}_{4} / \mathrm{GO}$ preforms with the percentage of GO at 4.3, 15.2, and $20.8 \mathrm{wt} . \%$. The lithium storage performance was investigated at the current density of $0.1 \mathrm{~A} \mathrm{~g}^{-1}$ using various $\mathrm{MoO}_{2} / \mathrm{GO}$ architectures showing specific capacities of 901,1127 , and $967 \mathrm{mAh} \mathrm{g}^{-1}$ after 100 cycles for micrometer $\mathrm{MoO}_{2} / \mathrm{GO}, \mathrm{MoO}_{2} / \mathrm{GO}$ nanohoneycomb, and layered $\mathrm{MoO}_{2} / \mathrm{GO}$, respectively. The $\mathrm{MoO}_{2} / \mathrm{GO}$ nanohoneycomb delivered the capacity of $461 \mathrm{mAh} \mathrm{g}^{-1}$ at $5 \mathrm{~A} \mathrm{~g}^{-1}$ current rate with CE of 99.3\% [539]. Wang et al. [540] synthesized 2D layered mesoporous- $\mathrm{MoO}_{2} / \mathrm{rGO}$ composites $\left(\mathrm{m}-\mathrm{MoO}_{2} / \mathrm{rGO}\right)$ through a novel strategy using silica KIT-6/rGO as a template and ammonium molybdate as a precursor via a nanocasting method with subsequent heat treatment heated up to $600{ }^{\circ} \mathrm{C}$ for $6 \mathrm{~h}$ at a rate of $2{ }^{\circ} \mathrm{C} \mathrm{min}^{-1}$ in a mixed gas flow of $\mathrm{H}_{2} / \mathrm{Ar}$ (10:90). Analyses of the morphology validated the ordered mesoporous structure with a BET specific surface area of $86 \mathrm{~m}^{2} \mathrm{~g}^{-1}$, a pore size of 3-4 $\mathrm{nm}$ in a large domain and a pore volume of $0.19 \mathrm{~cm}^{3} \mathrm{~g}^{-1}$. The $\mathrm{m}-\mathrm{MoO}_{2} / \mathrm{rGO}(1: 1)$ electrode delivered an initial discharge capacity of $1160 \mathrm{mAh} \mathrm{g}^{-1}$ at current density of $0.1 \mathrm{~A} \mathrm{~g}^{-1}$ with a capacity loss of $31.9 \%$ during the first cycle and a reversible capacity is $801 \mathrm{mAh} \mathrm{g}^{-1}$ after 50 cycles.

In 2018, Chen et al. [541] investigated a hierarchical $\mathrm{MoO}_{2} @ \mathrm{rGO}(\sim 10 \mathrm{~nm} \mathrm{MoO} 2$ particle size and $21.1 \mathrm{wt} . \% \mathrm{rGO}$ ) composite prepared by hydrothermal route at $200{ }^{\circ} \mathrm{C}$ for 2 days, which exhibited outstanding electrochemical performance with a reversible capacity of $708 \mathrm{mAh} \mathrm{g}^{-1}$ at a current density of $0.5 \mathrm{~A} \mathrm{~g}^{-1}$ after 50 cycles. A capacity of $473 \mathrm{mAh} \mathrm{g}^{-1}$ was maintained when cycled at $2 \mathrm{~A} \mathrm{~g}^{-1}$ current rate. Li et al. [542] utilized Mo particles as both the reductant 
for $\mathrm{GO}$ and as the Mo source to prepare $\mathrm{MoO}_{2} / \mathrm{rGO}$ hybrid anodes. The $\mathrm{MoO}_{2} / \mathrm{rGO}$ composite with Mo:GO of 3:1 was used as an efficient cathode catalyst for the oxygen reduction reaction (ORR). Recently, Liu et al. [532] reported the direct growth of $\mathrm{MoO}_{2} / \mathrm{rGO}$ hollow sphere composites through hydrothermal technique. This advanced anode materials tested in potassium-ion batteries delivered a reversible specific capacity of $219 \mathrm{mAh} \mathrm{g}^{-1}$ after 200 cycles at $50 \mathrm{~mA} \mathrm{~g}^{-1}$ current rate. When cycled at $0.5 \mathrm{~A} \mathrm{~g}^{-1}$, a high charge specific capacity of 104 $\mathrm{mAh} \mathrm{g}^{-1}$ was achieved after 500 cycles. Li et al. [543] prepared the $\mathrm{MoO}_{2} / \mathrm{Mo}-\mathrm{GO}$ hybrids using a freeze-drying technique, which exhibited a high ICE of 97\%. A capacity of $550 \mathrm{mAh} \mathrm{g}^{-1} \mathrm{ws}$ delivered by the $\mathrm{MoO}_{2} / \mathrm{Mo}-\mathrm{GO}$ anode materials after 150 cycles at $0.1 \mathrm{~A} \mathrm{~g}^{-1}$ rate. Devina et al. [544] used the same technique to prepare $\mathrm{MoO}_{2} / \mathrm{rGO}$ composite attached with $\mathrm{Mo}_{2} \mathrm{C}$ during carbothermal hydrogen reduction. The $\mathrm{MoO}_{2} / \mathrm{Mo}_{2} \mathrm{C} / \mathrm{rGO}$ product displayed an increased ICE (77\%), long-term cyclability $\left(500 \mathrm{mAh} \mathrm{g}^{-1}\right.$ at $50 \mathrm{~mA} \mathrm{~g}^{-1}$ after 150 cycles), and high-rate performance (200 $\mathrm{mAh} \mathrm{g}^{-1}$ at $1 \mathrm{~A} \mathrm{~g}^{-1}$ ) compared with those of the $\mathrm{MoO}_{2} / \mathrm{rGO}$ composite (53\%; $280 \mathrm{mAh} \mathrm{g}^{-1}$ at $50 \mathrm{~mA} \mathrm{~g}^{-1}$ after 150 cycles; $120 \mathrm{mAh} \mathrm{g}^{-1}$ at $1 \mathrm{~A} \mathrm{~g}^{-1}$ ).

Recently, the fabrication of submicrometer-sized $\mathrm{MoO}_{2} @ \mathrm{MoS}_{2} / \mathrm{rGO}$ composite with a hierarchical core-shell structure was suggested by Zheng et al. [545]. The three-step synthesis includes: (i) the preparation of the $\mathrm{MoO}_{2} @ \mathrm{MoS}_{2}$ precursor using a solid-state reaction (i.e., $\mathrm{MoO}_{3}$ and sulfur heated at $600{ }^{\circ} \mathrm{C}$ for $1 \mathrm{~h}$ in a gas stream of $\mathrm{Ar} / \mathrm{H}_{2}$ (90:10)), (ii) a hydrothermal process at $180{ }^{\circ} \mathrm{C}$ for $4 \mathrm{~h}$ using a GO suspension, and (iii) a final heat treatment at $400{ }^{\circ} \mathrm{C}$ for 2 $\mathrm{h}$ in $\mathrm{Ar} / \mathrm{H}_{2}$ flowing gas. The electrochemical tests of the $\mathrm{MoO}_{2} @ \mathrm{MoS}_{2} / \mathrm{rGO}$ anode showed an initial reversible capacity of $833 \mathrm{mAh} \mathrm{g}^{-1}$ with ICE of $80.6 \%$ and improved cycling stability (733 $\mathrm{mAh} \mathrm{g}^{-1}$ after 80 cycles at $0.2 \mathrm{~mA} \mathrm{~g}^{-1}$ ). The good rate capability with a capacity of 645 $\mathrm{mAh} \mathrm{g}^{-1}$ at $4 \mathrm{~A} \mathrm{~g}^{-1}$ was also evidenced. An assembled $\mathrm{MoO}_{2} @ \mathrm{MoS}_{2} / \mathrm{rGO} \mathrm{LiCoO}_{2}$ full cell maintained a reversible capacity of $694 \mathrm{mAh} \mathrm{g}^{-1}$ (based on the mass of $\mathrm{MoO}_{2} @ \mathrm{MoS}_{2} / \mathrm{rGO}$ ) at $0.2 \mathrm{~mA} \mathrm{~g}^{-1}$ after 40 cycles. Electrochemical performance of $\mathrm{MoO}_{2} / \mathrm{rGO}$ composite anodes for LIBs from the recent literature are summarized in Table 14.

Table 14. Electrochemical performance of $\mathrm{MoO}_{2} / \mathrm{GO}$ composites as anode materials for LIBs. The relevant cycle number is displayed in brackets.

\begin{tabular}{llccc}
\hline Material & a) & Synthesis ${ }^{\mathrm{a})}$ & $\begin{array}{c}\text { Reversible } \\
\text { capacity } \\
\left(\mathrm{mAh} \mathrm{g}^{-1}\right)\end{array}$ & $\begin{array}{c}\text { Current } \\
\text { rate } \\
\left(\mathrm{mA} \mathrm{g}^{-1}\right)\end{array}$ \\
\hline $\mathrm{MoO}_{2} / \mathrm{GR}$ & layer-by-layer assembly & 676 & $48(100)$ & {$[546]$} \\
$\mathrm{MoO}_{2} / \mathrm{GR}$ & sonication in water $(11.2)$ & 597 & $1000(70)$ & {$[465]$} \\
$\mathrm{MoO}_{2} / \mathrm{rGO}$ & hydrothermal @ $200{ }^{\circ} \mathrm{C} / 24 \mathrm{~h}$ & 503 & $100(30)$ & {$[478]$} \\
$\mathrm{MoO}_{2} / \mathrm{rGO}$ & hydrothermal @ $400^{\circ} \mathrm{C} / 3 \mathrm{~h}(10.4)$ & 1009 & $100(60)$ & {$[528]$} \\
\hline
\end{tabular}




\begin{tabular}{llccc}
\hline $\mathrm{MoO}_{2} / \mathrm{rGO}$ & solid state reaction $(22.0)$ & 640 & $200(50)$ & {$[526]$} \\
$\mathrm{MoO}_{2} / \mathrm{GO}$ & thermal reduction $@ 550{ }^{\circ} \mathrm{C} / 2 \mathrm{~h}(51.7)$ & 752 & $100(100)$ & {$[547]$} \\
$\mathrm{MoO}_{2} / \mathrm{Gr}$ & hydrothermal $@ 180{ }^{\circ} \mathrm{C} / 26 \mathrm{~h}(33.2)$ & 769 & $540(83)$ & {$[525]$} \\
$\mathrm{MoO}_{2} / \mathrm{N}-\mathrm{rGO}$ & hydrothermal $@ 180{ }^{\circ} \mathrm{C} / 24 \mathrm{~h}$ & 400 & $1000(5)$ & {$[548]$} \\
$\mathrm{MoO}_{2} / \mathrm{exfol}-\mathrm{rGO}$ & solid-state graphenothermal $(46.0)$ & 878 & $100(100)$ & {$[468]$} \\
$\mathrm{MoO}_{2} \mathrm{NSs} / \mathrm{rGO}$ & in situ reduction of $\mathrm{MoO}$ & 1003 & $100(100)$ & {$[549]$} \\
$\mathrm{MoO}_{2} / \mathrm{GO}$ & solvothermal $@ 160^{\circ} \mathrm{C} / 16 \mathrm{~h}(10.0)$ & 500 & $800(30)$ & {$[524]$} \\
$\mathrm{MoO}_{2} / \mathrm{rGO}$ & solid-state reaction $@ 500{ }^{\circ} \mathrm{C}(15.0)$ & 276 & $100(1000)$ & {$[536]$} \\
$\mathrm{MoO}_{2} / \mathrm{rGO}$ & hydrothermal $@ 200{ }^{\circ} \mathrm{C} / 2$ days $(21.1)$ & 708 & $500(50)$ & {$[541]$} \\
$\mathrm{MoO}_{2} / \mathrm{rGO}$ & thermal reduction $@ 550{ }^{\circ} \mathrm{C}(19.4)$ & 584 & $1000(100)$ & {$[542]$} \\
$\mathrm{MoO}_{2} / \mathrm{rGO} / \mathrm{NBs}$ & surfactant-free self-assembly & 420 & $5000(1900)$ & {$[216]$} \\
$\mathrm{MoO}_{2} \mathrm{NBs} / \mathrm{rGO}$ & supercritical methanol route & 793 & $50(50)$ & {$[531]$} \\
$\mathrm{MoO}_{2} / \mathrm{Mo}-\mathrm{GO}$ & freeze-drying $(5.0)$ & 550 & $100(150)$ & {$[543]$} \\
$\mathrm{MoO}_{2} / \mathrm{rGO}$ & solid state reaction $@ 500{ }^{\circ} \mathrm{C}(15.2)$ & 1127 & $100(150)$ & {$[539]$} \\
$\mathrm{MoO}_{2} \mathrm{NBs} / \mathrm{rGO}$ & freeze-drying $(8.0)$ & 420 & $5000(1900)$ & {$[537]$} \\
$\mathrm{m}_{-} \mathrm{MoO}_{2} / \mathrm{rGO}$ & nanocasting $(50)$ & 801 & $100(100)$ & {$[540]$} \\
$\mathrm{MoO}_{2} @ \mathrm{MoS} / \mathrm{rGO}$ & hydrothermal $@ 180{ }^{\circ} \mathrm{C} / 4 \mathrm{~h}$ & 733 & $200(80)$ & {$[545]$} \\
$\mathrm{MoO}_{2} \mathrm{NPs} / \mathrm{graphene}$ & hydrothermal @ $180{ }^{\circ} \mathrm{C} / 12 \mathrm{~h}$ & 765 & $60(40)$ & {$[550]$} \\
\hline
\end{tabular}

a) graphene content in wt.\%.

6.6. Lithium molybdate $\mathrm{LiMoO}_{2}$

Molybdenum also forms several stable phases with lithium including $\mathrm{LiMoO}_{2}$ [551], $\mathrm{Li}_{2} \mathrm{MoO}_{3}$ [552], $\mathrm{Li}_{4} \mathrm{Mo}_{3} \mathrm{O}_{8}$ [553] and non-stoichiometric compounds such as $\mathrm{Li}_{0.74} \mathrm{MoO}_{2}$ [551]. There were few reports on the structure, physico-chemical properties and electrochemistry of $\mathrm{LiMoO}_{2}[554,555]$. However, its structure has been the subject of debate. Several groups have claimed that $\mathrm{LiMoO}_{2}$ crystallizes with the rock-salt-like structure isomorphs to the layered $\alpha-\mathrm{NaFeO}_{2}$ [551,554,556,557]. These groups did not consider the accepted theoretical predictions for 3D-systems according to which the structure would distort, while Hibble et al. [558] have determined that $\mathrm{LiMoO}_{2}$ adopts the monoclinic $C 2 / m$ space group by refinement of by neutron scattering data. The structure is best described with $a=10.543(6) \AA, b=2.8626(5)$ $\AA, c=10.899(6) \AA$, and $\beta=153.29^{\circ}$. The schematic representation is given in Fig. 38a. BenKamel et al. [555] synthesized $\mathrm{LiMoO}_{2}$ by a carbothermal method using citric acid as a chelating agent with a subsequent thermal treatment at $800{ }^{\circ} \mathrm{C}$ for $72 \mathrm{~h}$ in air. Analysis of the crystal structure by Rietveld refinements shows that lithium molybdate crystallizes in the monoclinic system $\left(R_{\mathrm{Bragg}}=1.24 \%\right)$ instead of the rhombohedral structure $\left(R_{\mathrm{Bragg}}=8.53 \%\right)$. This result is confirmed by the Raman spectroscopy experiment, which displays twelve bands instead of two for the rhombohedral $(R \overline{3} m)$ structure. Figure $38 \mathrm{~b}$ represents the chargedischarge profile of the $\mathrm{Li} / / \mathrm{LiMoO}_{2}$ cell cycled in the potential range $2-4 \mathrm{~V}$ at current density of $\mathrm{C} / 24$. Almost $0.9 \mathrm{Li}$ can be extracted when the cell is charged at $4.0 \mathrm{~V} \mathrm{vs}$. $\mathrm{Li}^{+} / \mathrm{Li}$. A good reversibility at the first cycle with the capacity retention of $168 \mathrm{mAh} \mathrm{g}^{-1}$, which can be 
compared with the theoretical value $198 \mathrm{mAh} \mathrm{g}^{-1}$. Measurements reveal the presence of multiple phase transitions during the lithium extraction process: the S-shaped potential corresponds to the extraction of $0.5 \mathrm{Li}$ in $\mathrm{Li}_{\mathrm{x}} \mathrm{MoO}_{2}$, the formation of an ordered composition close to $x=0.5$ and a plateau at $3.6 \mathrm{~V}$ attributed to the existence of a two-phase system, i.e., $\mathrm{Li}_{0.1} \mathrm{MoO}_{2}$ and $\mathrm{Li}_{0.5} \mathrm{MoO}_{2}$. The differential capacity curve (inset Fig. 38b) displays a sharp peak at ca. $3.6 \mathrm{~V}$ corresponding to the voltage plateau observed in the charge-discharge curves and

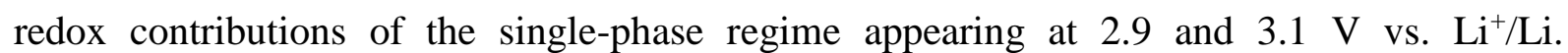
Measurements of $\mathrm{Li}$ ion kinetics reveal that diffusion coefficients for the $\mathrm{LiMoO}_{2}$ electrode are in the range of $10^{-12}-10^{-10} \mathrm{~cm}^{2} \mathrm{~s}^{-1}$ (Fig. 38c). The rate capability of $\mathrm{LiMoO}_{2}$ compared with that of $\mathrm{LiNi}_{0.8} \mathrm{Co}_{0.2} \mathrm{O}_{2}$ is shown in Fig. 38d.

(a)
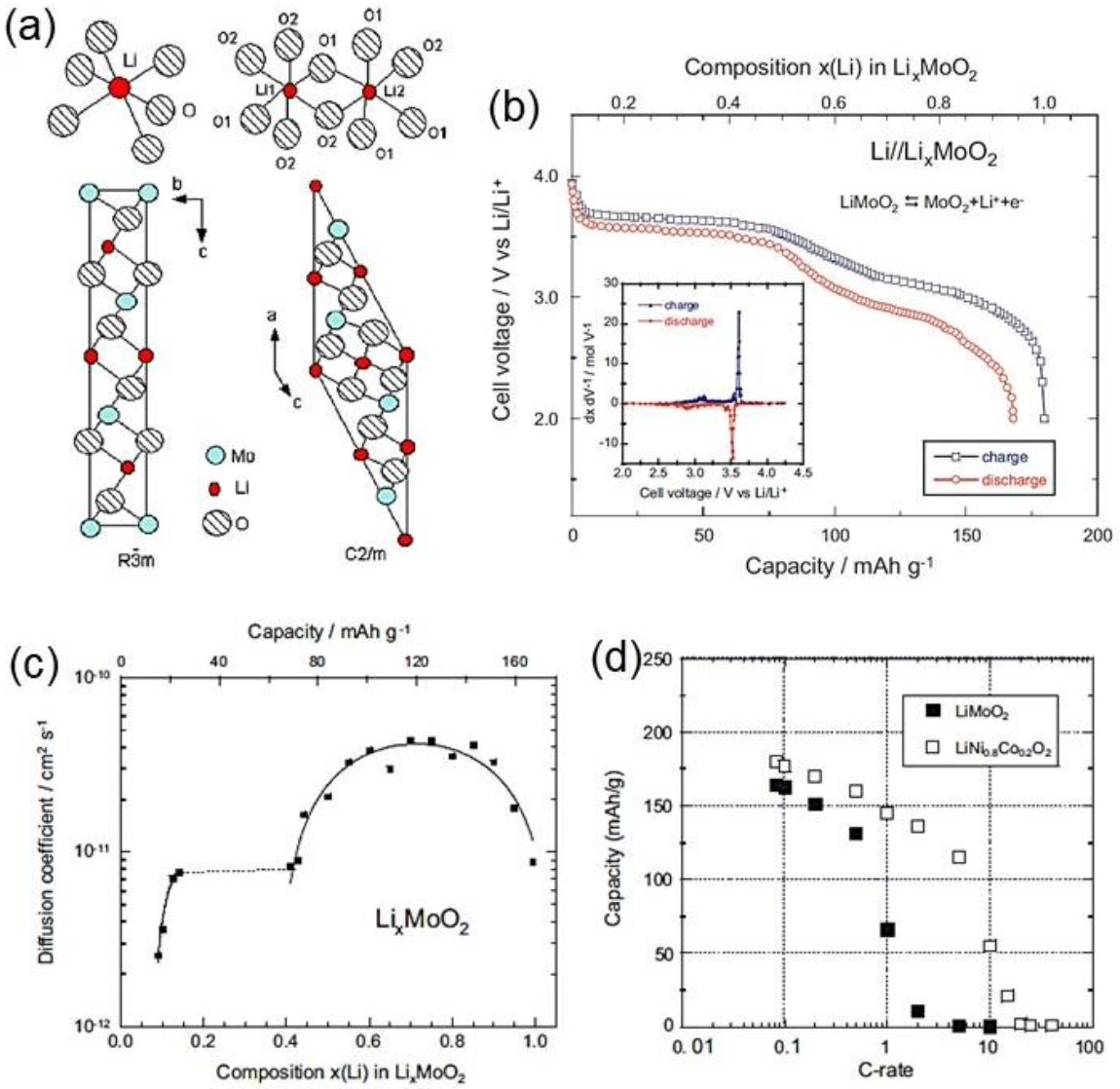

Fig. 38. (a) Schematic representation of the rhombohedral $(R \overline{3} m)$ and monoclinic $(C 2 / m)$ structures of $\mathrm{LiMoO}_{2}$. (b) Charge-discharge profile of the $\mathrm{Li} / / \mathrm{LiMoO}_{2}$ cell cycled in the potential range $2-4 \mathrm{~V}$ at $\mathrm{C} / 24$ rate. The electrode was $\mathrm{LiMoO}_{2}$ powders synthesized at $600{ }^{\circ} \mathrm{C}$ for $72 \mathrm{~h}\left(C 2 / m\right.$ S.G.) and the electrolyte was $1 \mathrm{~mol} \mathrm{~L}^{-1} \mathrm{LiPF}_{6}$ in $1: 1 \mathrm{EC} / \mathrm{DMC}$. The insert shows the differential capacity $\mathrm{d} Q / \mathrm{d} V$ vs. cell voltage obtained at the second cycle. (c) Evolution of the chemical diffusion coefficient of $\mathrm{Li}^{+}$ions in the $\mathrm{Li}_{x} \mathrm{MoO}_{2}$ cathode material as a function of the composition $x$. (d) Rate capability of the $\mathrm{LiMoO}_{2}$ electrode recorded at the $5^{\text {th }}$ cycle. Data 
obtained for the layered $\mathrm{LiNi}_{0.8} \mathrm{Co}_{0.2} \mathrm{O}_{2}$ cathode are shown for comparison. Reproduced with permission from [555]. Copyright 2012 Elsevier.

\subsection{Lithium molybdate $\mathrm{Li}_{2} \mathrm{MoO}_{3}$}

Because of high lithium storage capacity, high first coulombic efficiency, low cost and $\mathrm{Mo}(\mathrm{IV}) / \mathrm{Mo}(\mathrm{VI})$ redox couple, $\mathrm{Li}_{2} \mathrm{MoO}_{3}$, can serve as anodes [559] as well as cathodes for LIBs [560,561]. $\mathrm{Li}_{2} \mathrm{MoO}_{3}$ has a theoretical $\mathrm{Li}^{+}$extraction/insertion capacity of $339 \mathrm{mAh} \mathrm{g}^{-1}$ simply by a single $\mathrm{Mo}^{4+} / \mathrm{Mo}^{6+}$ redox reaction. $\mathrm{Li}_{2} \mathrm{MoO}_{3}$ synthesized through ball milling and thermal reduction presents a first discharge capacity of about $835 \mathrm{mAh} \mathrm{g}^{-1}$ with an ICE of $97.6 \%$ at a current density of $100 \mathrm{~mA} \mathrm{~g}^{-1}$; a discharge capacity of $902 \mathrm{mAh} \mathrm{g}^{-1}$ is preserved after 150 cycles [559]. Phase-pure $\mathrm{Li}_{2} \mathrm{MoO}_{3}$ powders were prepared by reducing commercial $\mathrm{Li}_{2} \mathrm{MoO}_{4}$ at $650{ }^{\circ} \mathrm{C}$ for $24 \mathrm{~h}$ in flowing $\mathrm{H}_{2} / \mathrm{Ar}(10: 90 \mathrm{v} / \mathrm{v})$ [562]. A fresh electrode delivers $\sim 80 \mathrm{mAh} \mathrm{g}^{-1}$ after 20 cycles at $10 \mathrm{~mA} \mathrm{~g}^{-1}$ with ICE of $98.9 \%$, whereas the capacity of aged $\mathrm{Li}_{2} \mathrm{MoO}_{3}$ (obtained after 120 days in relative humidity <10\%) decreases drastically (75\% capacity loss at the $2^{\text {nd }}$ cycle). Kumakura et al. [563] prepared a $\mathrm{Li}_{2} \mathrm{MoO}_{3} / \mathrm{C}$ composite with the simple addition of acetylene black. As a cathode material tested in the range 1.5-4.3 V, it delivers a first specific capacity of $230 \mathrm{mAh} \mathrm{g}^{-1}$. The polycrystalline $\mathrm{Li}_{2} \mathrm{MoO}_{3}$ synthesized via simple liquid chemical reaction, followed by thermal reduction in $\mathrm{H}_{2} / \mathrm{Ar}(5: 95 \mathrm{v} / \mathrm{v})$ atmosphere exhibits a first discharge capacity of $836 \mathrm{mAh} \mathrm{g}^{-1}(\mathrm{ICE}==94.5 \%)$ at a current density of $100 \mathrm{~mA} \mathrm{~g}^{-1}$ over a voltage window of $0.01-3.0 \mathrm{~V}$. After 200 cycles at $300 \mathrm{~mA} \mathrm{~g}^{-1}$, a discharge capacity of 654 $\mathrm{mAh} \mathrm{g}^{-1}$ is preserved and the composite still keeps a discharge capacity of $489 \mathrm{mAh} \mathrm{g}^{-1}$ at 1600 $\mathrm{mA} \mathrm{g}^{-1}$ current rate [564]. Recently, Mao et al. [565] investigated the electrochemical performance of layered $\mathrm{Li}_{2} \mathrm{MoO}_{3}$ microspheres prepared from $\mathrm{MoO}_{2}$ microsphere as a selftemplate. Due to their enhanced mesoporous structure, $\mathrm{Li}_{2} \mathrm{MoO}_{3}$ microspheres deliver specific capacities of 247 and $76 \mathrm{mAh} \mathrm{g}^{-1}$ at current densities of 34 and $1000 \mathrm{~mA} \mathrm{~g}^{-1}$, respectively. Table 15 list the electrochemical performance of some $\mathrm{Li}_{2} \mathrm{MoO}_{3}$ used as cathode and anode of LIBs.

Table 15. Electrochemical performance of $\mathrm{Li}_{2} \mathrm{MoO}_{3}$ cathode/anode materials for LIBs.

Relevant cycle number is given in brackets.

\begin{tabular}{llccc}
\hline Material & Synthesis & $\begin{array}{c}\text { Specific } \\
\text { capacity } \\
\left(\mathrm{mAh} \mathrm{g}^{-1}\right)\end{array}$ & $\begin{array}{c}\text { Current rate } \\
\left(\mathrm{mA} \mathrm{g} \mathrm{g}^{-1}\right)\end{array}$ & Ref. \\
\hline Cathode & Solid phase & 140 & $5(50)$ & {$[566]$} \\
$\mathrm{Li}_{2} \mathrm{Mo}_{0.9} \mathrm{Co}_{0.1} \mathrm{O}_{3}$ & Ball milling & 180 & $20(50)$ & {$[567]$} \\
$\mathrm{C}_{2} \mathrm{Li}_{2} \mathrm{MoO}_{3}$ & Solid state reaction & 150 & $16(35)$ & {$[563]$} \\
$\mathrm{C} / \mathrm{Li}_{2} \mathrm{MoO}_{3}$ & & & & \\
\hline
\end{tabular}




\begin{tabular}{llccc}
\hline $\mathrm{Li}_{2} \mathrm{MoO}_{3}$ bulk & Reduction reaction & 80 & $10(20)$ & {$[562]$} \\
\hline $\begin{array}{l}\text { Anode } \\
\mathrm{Li}_{2} \mathrm{MoO}_{3}\end{array}$ & Liquid chemical reaction & 654 & $300(200)$ & {$[564]$} \\
\hline
\end{tabular}

\subsection{Other lithium molybdates}

Monoclinic $\mathrm{Li}_{1.33} \mathrm{Mo}_{2} \mathrm{O}_{4}$ was prepared by low temperature ion exchange of lithium for sodium in $\mathrm{Na}_{x} \mathrm{Mo}_{2} \mathrm{O}_{4}$ [568]. The study of the $\mathrm{Li} / / \mathrm{Li}_{0}{ }_{3} \mathrm{Mo}_{2} \mathrm{O}_{4}$ electrochemical cells shows that the electrode material can reversibly accommodate up to $1.7 \mathrm{Li}$ per $\mathrm{Mo}_{2} \mathrm{O}_{4}$ unit formula at an average of $3.0 \mathrm{~V}$ resulting in a theoretical energy density of $530 \mathrm{Wh} \mathrm{kg}^{-1}$ for the $\mathrm{Li}_{2} \mathrm{Mo}_{2} \mathrm{O}_{4}$ cathode material. Structural studies indicate that $\mathrm{Li}_{x} \mathrm{Mo}_{2} \mathrm{O}_{4}$ is a multiphase intercalation system over the range of composition $0.3<x<2.0 . \quad \mathrm{Li}_{2} \mathrm{MoO}_{4}$ nanoparticles (hexagonal phenacite-like structure) have investigated as anode materials for LIBs [569,570]. Liu and coworkers [570] synthesized $1 \mathrm{D} \mathrm{Li}_{2} \mathrm{MoO}_{4}$ nanostructures (nanorods and nanotubes) via a sol-gel method adding $\mathrm{Li}_{2} \mathrm{CO}_{3}$ and $\mathrm{MoO}_{3}$ powders into distilled water with citric acid as an assistant agent and carbon source. The materials display initial discharge/charge capacities of $688 / 319 \mathrm{mAh} \mathrm{g}^{-1}$ (carbonfree powders), 750/420 $\mathrm{mAh} \mathrm{g}^{-1}$ (carbon-free nanorods), 850/476 $\mathrm{mAh} \mathrm{g}^{-1}$ (carbon-free nanotubes), 1016/648 $\mathrm{mAh} \mathrm{g}^{-1}$ (carbon-coated nanotubes). After 50 cycles at $90 \mathrm{~mA} \mathrm{~g}^{-1}$ current rate, the carbon-coated $\mathrm{Li}_{2} \mathrm{MoO}_{4}$ nanotubes deliver a specific capacity of $550 \mathrm{mAh} \mathrm{g}{ }^{-1}$. Crystallographic parameters of lithium molybdates are listed in Table 16.

Table 16. Crystallographic parameters of lithiated Mo oxides.

\begin{tabular}{lcccc}
\hline Compound & Structure & \multicolumn{3}{c}{ Cell parameters $(\AA)$} \\
\cline { 3 - 5 } & & $a / \alpha$ & $b / \beta$ & $c / \gamma$ \\
\hline $\mathrm{Li}_{1.3} \mathrm{Mo}_{2} \mathrm{O}_{4}$ & monoclinic & 10.666 & $2.885 / 99.5$ & 4.953 \\
$\beta-\mathrm{Li}_{2} \mathrm{MoO}_{3}$ & monoclinic & 4.990 & $8.642 / 99.5^{\circ}$ & 10.092 \\
\hline
\end{tabular}

\section{9. $\mathrm{MoO}_{2}$ anodes for SIBs}

The application of $\mathrm{MoO}_{2}$ as anode material for SIBs has made rapid progress, and the energy density has been improved greatly [571,572]. Several approaches have been conducted to improve the electrochemical performance of $\mathrm{MoO}_{2}$ anodes (i.e., capacity retention, long life cycling) including core-shell composite [573,574], carbon-based hybrid [536,575-577], and element doping [578]. Bao et al. [575] fabricated nanosized $\mathrm{MoO}_{2}$ on 3D porous carbon using a simple hydrothermal method with subsequent calcination. The porous $\mathrm{MoO}_{2} / \mathrm{C}$ composite 
(with surface area of $171.6 \mathrm{~m}^{2} \mathrm{~g}^{-1}$ ) exhibits the specific charge capacity of $\sim 463 \mathrm{mAh} \mathrm{g}^{-1}$ in the first cycle at $0.1 \mathrm{~A} \mathrm{~g} \mathrm{~g}^{-1}$. A reversible capacity of $\sim 367 \mathrm{mAh} \mathrm{g}^{-1}$ can be maintained after 200 cycles. Jiang et al. [577] prepared a $\mathrm{MoO}_{2} / \mathrm{C}$ nanocomposite using a simple hydrothermal method. This composite delivers a charge capacity of $557 \mathrm{mAh} \mathrm{g}^{-1}$ at $0.1 \mathrm{C}$ in the first cycle and has a good cycling stability for Na storage. Cui et al. [579] synthesized $\mathrm{MoO}_{2} @ \mathrm{C}$ nanoflowers through a grinding method followed by an annealing process. The $\mathrm{MoO}_{2} @ \mathrm{C}$ hybrid was tested at $0.1 \mathrm{~A} \mathrm{~g} \mathrm{~g}^{-1}$ and showed a reversible charge capacity of $172 \mathrm{mAh} \mathrm{g}^{-1}$. In the long-term cycling test $\left(1 \mathrm{~A} \mathrm{~g}^{-1}, 1000\right.$ cycles $)$, a reversible charge capacity of $166 \mathrm{mAh} \mathrm{g}^{-1}$ remained. He et al. [580] reported a $\mathrm{MoO}_{2}-\mathrm{C}$ composite with $\mathrm{MoO}_{2}$ nanosheets embedded in carbon matrix. The charge capacity vs. $\mathrm{Na}^{+} / \mathrm{Na}$ after 100 cycles is $\sim 367 \mathrm{mAh} \mathrm{g}^{-1}$. Zhao et al. [581] synthesized a $\mathrm{MoO}_{2}$ nanoparticles anchored graphene oxide, and the material exhibited a reversible charge capacity of $345 \mathrm{mAh} \mathrm{g}^{-1}$ after 100 cycles at $0.1 \mathrm{~A} \mathrm{~g}^{-1}$. $\mathrm{MoO}_{2}$ combined carbon dots (CDs) with nanoparticle stacking structure were fabricated via a facile hydrothermal route [509]. The $\mathrm{MoO}_{2} / \mathrm{CDs}$ granules (50 nm in size) exhibit a discharge capacity of $236 \mathrm{mAh} \mathrm{g}^{-1}$ at $0.5 \mathrm{~A} \mathrm{~g}^{-1}$ after 300 cycles in $1 \mathrm{~mol} \mathrm{~L}^{-1} \mathrm{NaClO}_{4}$ in ethylene carbonate (EC) and dimethyl carbonate (DMC) $\left(1: 1\right.$ in volume) as SIB electrolyte. $\mathrm{MoO}_{2}$ nanoparticles $(\approx 100 \mathrm{~nm})$ anchored on graphene oxide $\left(\mathrm{MoO}_{2} / \mathrm{GO}\right)$ were fabricated as SIB for anodes. The discharge gravimetric capacity of the $\mathrm{MoO}_{2} / \mathrm{GO}$ hybrid is stabilized at $345 \mathrm{mAh} \mathrm{g}^{-1}$ (volumetric capacity $\approx 1656 \mathrm{mAh} \mathrm{cm}^{-3}$ ) at the current density of $100 \mathrm{~mA} \mathrm{~g}^{-1}$ after 100 cycles. After 1000 cycles, the capacity loss is only $19 \%$ and the electrode is still able to deliver $276 \mathrm{mAh} \mathrm{g}^{-1}$ [536]. Valdez et al. [582] prepared $\mathrm{MoO}_{2} / \mathrm{C}$ composite fiber anodes using precursors solutions with different concentrations of $\mathrm{MoO}_{2} / \mathrm{PAN}$, which were force-spun into microfibrous mats and subsequently stabilized in air at $280^{\circ} \mathrm{C}$ and calcined at $700^{\circ} \mathrm{C}$ under $\mathrm{Ar}$ atmosphere. The $\mathrm{MoO}_{2} / \mathrm{C}$ composite exhibits a discharge capacity of 300-400 mAhg ${ }^{-1}$ after 100 cycles at $100 \mathrm{mAg}^{-1}$. Recently, Zhang et al. proposed the used of 2 wt.\% vinylene carbonate (VC) additive to improve the cyclic stability of $\mathrm{MoO}_{2}$ microspheres anode for SIBs. After 1000 cycles at $300 \mathrm{~mA} \mathrm{~g}^{-1}$ current rate, the $\mathrm{MoO}_{2}$ electrode exhibits a capacity retention of $96.5 \%\left(\sim 110 \mathrm{mAh} \mathrm{g}^{-1}\right)$ [583].

\section{Concluding remarks}

This review article shed light on the promising design strategies of molybdenum oxides for high kinetic energy storage. The technology of the molybdenum oxides used in energy storage devices from the 1980s to the recent progress was discussed. Due to their low molecular weight and their favourable electrochemical and solid-state properties, $\mathrm{MoO}_{\mathrm{y}}$ compounds appeared attractive as cathode and anode materials in electrochemical energy storage systems. Three 
major classes of Mo oxides, which exhibit various structural properties, have be distinguished: (i) anhydrous $\mathrm{Mo}$ oxides $\left(\mathrm{MoO}_{3}, \mathrm{Mo}_{\mathrm{n}} \mathrm{O}_{3 \mathrm{n}-1}, \mathrm{MoO}_{2}\right)$, (ii) molybdenum-oxide hydrates $\left(\mathrm{MoO}_{3} \cdot n \mathrm{H}_{2} \mathrm{O}\right)$, and (iii) nanostructured $\mathrm{MoO}_{\mathrm{y}}$. A comparison between the electrochemical features of the molybdenum-oxide hydrates with different degrees of dehydration and their anhydrous products shows that oxide-hydrates materials have a good cyclability with a discharge capacity of $160 \mathrm{mAh} \mathrm{g}^{-1}$ at the $100^{\text {th }}$ cycle. This value was greater than that of anhydrous $\mathrm{MoO}_{3}$. In a series of $\mathrm{MoO}_{3} \cdot n \mathrm{H}_{2} \mathrm{O}$ including sol-gel compounds, the main factor affecting the performance is expected to be the water content, which influencing the electrical conductivity and structural properties. Thermodynamics and kinetics of lithium-ion insertion are functions of the structural arrangement of the $\mathrm{MoO}_{6}$ octahedra in the host lattice. Diffusion coefficients can be modelled using either a simple model for site occupancy or an ideal lattice gas model. A raw $\mathrm{MoO}_{3}$ powder prepared by heat-treatment of molybdic acid in proper conditions exhibits the highest conductivity and displays the best electrochemical features for Li-ion insertion. Despite the attractive energy and power densities of the molybdenum oxides, these cathode materials belong to the class of 3-volt systems. The new development of nanostructured oxygen deficient $\mathrm{MoO}_{\mathrm{y}}$, and $\mathrm{MoO}_{\mathrm{y}}$-based composites as well, are promising electrodes materials for electrochemical energy storage devices due to their enhanced electronic conductivity, particularly supercapacitors and microbatteries, because they can instantaneously provide a high energy density with long cycle life.

Existing LIBs utilise graphite as anode with moderate theoretical capacity ( $\left.372 \mathrm{mAh} \mathrm{g}^{-1}\right)$ and limited fast-charging capabilities. Hence, the attractive electrochemical performances of the $\mathrm{MoO}_{3}$ and $\mathrm{MoO}_{2}$ composite networks benefit from the synergistic effects of the unique nanoarchitectures and the integrity of these anode materials. Monodispersed $\mathrm{MoO}_{\mathrm{y}}$ nanocrystals encapsulated in carbon matrix not only provide interfacial storage but also improve the transport kinetics of electrons and lithium ions. Extensive efforts have been made to overcome the defect of capacity degradation in $\mathrm{MoO}_{2}$ anode, and the preparation of $\mathrm{MoO}_{2} /$ carbon composite materials has proven to be an effective way. The mesoporous nature of the $\mathrm{MoO}_{2} / \mathrm{C}$ nanocomposite and the thin-layer carbon coating are believed to contribute to the enhanced electrochemical performance, which not only feature the efficient four-electron conversion reaction for $\mathrm{Li}^{+}$storage, but also effectively tolerate volume expansion during the cycling. In this review, we have also seen that with many distinctive properties, stoichiometric $\mathrm{MoO}_{3}$ and $\mathrm{MoO}_{2}$ can sustain high-rate capability as high-power battery electrodes to power electric vehicles. It is worthy to note that $\mathrm{MoO}_{3}$ is a material used in various devices such as gas sensors, catalysts, recording materials, electrochromic devices, and so on. 


\section{References}

[1] W. Su, H.R. Eichi, W. Zeng, M.-Y. Chow, A survey on the electrification of transportation in a smart grid environment, IEEE Trans. Ind. Inform. 8 (2012) 1-10.

[2] K. Zaghib, A. Mauger, C.M. Julien, Rechargeable lithium batteries for energy storage in smart grids, in: Rechargeable lithium batteries: from fundamentals to applications, A.A. Franco (Ed.), Woodhead Publ. Ltd, Cambridge (2015) chapter 12, pp. 319-351.

[3] M. Armand, Intercalation electrodes, in: Materials for Advanced Batteries, D.W. Murphy, J. Broadhead, B.C.H. Steele (Eds.), Plenum Press, New York (1980) pp 145-161.

[4] M. Lazzari, B. Scrosati, A cyclable lithium organic electrolyte cell based on two intercalation electrodes, J. Electrochem. Soc. 127 (1980) 773-774.

[5] H. Zhang, C. Li, G.G. Eshetu, S. Laruelle, S. Grugeon, K. Zaghib, C.M. Julien, A. Mauger, D. Guyomard, T. Rojo, N. Gisbert-Trejo, S. Passerini, X. Huang, Z. Zhou, P. Johansson, M. Forsyth, From solid solution electrodes and the rocking-chair concept to today's batteries, Angew. Chem. Int. Ed. 132 (2020) 542-546.

[6] A. Mauger, C.M. Julien, Critical review on lithium-ion batteries: are they safe? Sustainable? Ionics 23 (2017) 1933-1947.

[7] G.E. Blomgren, The development and future of lithium ion batteries, J. Electrochem. Soc. 164 (2017) A5019-A5025.

[8] I.A. de Castro, R.S. Datta, J.Z. Ou, A. Castellanos-Gomez, S. Sriram, T. Daeneke, K. Kalantar-zadeh, Molybdenum oxides-from fundamentals to functionality, Adv. Mater. 29 (2017) 1701619.

[9] G.A. Nazri, C. Julien, Far-infrared and Raman spectroscopy of molybdenum oxide single crystal, General Motors Publications, GMR Laboratories, Warren, MI, GMR-7403 (1991).

[10] J. Desmond, S. McCormack, P. McNamara, P. Lawlor, Rearview mirror assembly, European Patent 0,615,882A2 (Assessed on 18 March 1994).

[11] T. Tsumura, M. Inagaki, Lithium insertion/extraction reaction on crystalline $\mathrm{MoO}_{3}$, Solid State Ion. 104 (1997) 183-189.

[12] W. Li, F. Cheng, Z. Tao, J. Chen, Vapor-transportation preparation and reversible lithium intercalation/deintercalation of $\alpha-\mathrm{MoO}_{3}$ microrods, J. Phys. Chem. B 110 (2006) 119124.

[13] J. Song, X. Ni, L. Gao, H. Zheng, Synthesis of metastable h-MoO3 by simple chemical precipitation, Mater. Chem. Phys. 102 (2007) 245-248. 
[14] T. Brezesinski, J. Wang, S.H. Tolbert, B. Dunn, Ordered mesoporous $\alpha-\mathrm{MoO}_{3}$ with isooriented nanocrystalline walls for thin-film pseudocapacitors, Nat. Mater. 9 (2010) 146151.

[15] B. Tian, G. Williams, D. Ban, H. Aziz, Transparent organic light-emitting devices using a $\mathrm{MoO}_{3} / \mathrm{Ag} / \mathrm{MoO}_{3}$ cathode, J. Appl. Phys. 110 (2011) 104507.

[16] D. Mutschall, K. Holzner, E. Obermeier, Sputtered molybdenum oxide thin films for $\mathrm{NH}_{3}$ detection, Sens. Actuators B 36 (1996) 320-324.

[17] A.K. Prasad, D.J. Kubinski, P.I. Gouma, Comparison of sol-gel and ion beam deposited $\mathrm{MoO}_{3}$ thin film gas sensors for selective ammonia detection, Sens. Actuators B 93 (2003) $25-30$.

[18] D. Kwak, M. Wang, K.J. Koski, L. Zhang, H. Sokol, R. Maric, Y. Lei, Molybdenum trioxide $\left(\alpha-\mathrm{MoO}_{3}\right)$ nanoribbons for ultrasensitive ammonia $\left(\mathrm{NH}_{3}\right)$ gas detection: integrated experimental and density functional theory simulation studies, ACS Appl. Mater. Interfaces 11 (2019) 10697-10706.

[19] A.M. Taurino, A. Forleo, L. Francioso, P. Siciliano, M. Stalder, R. Nesper, Synthesis, electrical characterization, and gas sensing properties of molybdenum oxide nanorods, Appl. Phys. Lett. 88 (15) (2006) 152111.

[20] S.-Y. Lin, C.-M. Wang, K.-S. Kao, Y.-C. Chen, C.-C. Liu, Electrochromic properties of $\mathrm{MoO}_{3}$ thin films derived by a sol-gel process, J. Sol-Gel Sci. Technol. 53 (2010) 51-58.

[21] D.G. Kim, S.H. Kim, Y.D. Kim, Electrochromic property of $\mathrm{MoO}_{3}$ thin films deposited by chemical vapor transport synthesis, Jpn J. Appl. Phys. 50 (2011) 102601.

[22] R. Sivakumar, K. Shanthakumari, A. Thayumanavan, M. Jayachandran, C. Sanjeeviraja, Molybdenum oxide $\left(\mathrm{MoO}_{3}\right)$ thin film based electrochromic cell characterization in $0.1 \mathrm{M}$ $\mathrm{LiClO}_{4}$ PC electrolyte, J. Surf. Eng. 25 (2009) 548-554.

[23] J. Wang, K.C. Rose, C.M. Lieber, Load-independent friction: $\mathrm{MoO}_{3}$ nanocrystal lubricants, J. Phys. Chem. B 103 (1999) 8405-8409.

[24] J. Zhou, N.-S. Xu, S.-Z. Deng, J. Chen, J.-C. She, Z.-L. Wang, Large-area nanowire arrays of molybdenum and molybdenum oxides: synthesis and field emission properties, Adv. Mater. 15 (2003) 1835-1840.

[25] L. Cattin, M. Morsli, F. Dahou, S.Y. Abe, A. Khelil, J.C. Bernède, Investigation of low resistance transparent $\mathrm{MoO}_{3} / \mathrm{Ag} / \mathrm{MoO}_{3}$ multilayer and application as anode in organic solar cells, Thin Solid Films 518 (2010) 4560-4563. 
[26] J. Yun, W. Jang, T. Lee, Y. Lee, A. Soon, Aligning the band structures of polymorphic molybdenum oxides and organic emitters in light-emitting diodes, Phys. Rev. Appl. 7 (2017) 024025.

[27] J. Song, X. Ni, D. Zhang, H. Zheng, Fabrication and photoluminescence properties of hexagonal $\mathrm{MoO}_{3}$ rods, Solid State Sci. 8 (2006) 1164-1167.

[28] V.V. Atuchin, T.A. Gavrilova, V.G. Kostrovsky, L.D. Pokrovsky, I.B. Troitskaia, Morphology and structure of hexagonal $\mathrm{MoO}_{3}$ nanorods, Inorg. Mater. 44 (2008) 622627.

[29] S.R. Dhage, M.S. Hassan, O.-B. Yang, Low temperature fabrication of hexagon shaped h- $\mathrm{MoO}_{3}$ nanorods and its phase transformation, Mater. Chem. Phys. 114 (2009) 511-514.

[30] R. Schlögl, A. Knop-Gericke, M. Hävecker, U. Wild, D. Frickel, T. Ressler, R.E. Jentoft, J. Wienold, G. Mestl, A. Blume, O. Timpe, Y. Uchida, In situ analysis of metal-oxide systems used for selective oxidation catalysis: how essential is chemical complexity, Topics Catal. 15 (2001) 219-228.

[31] X. Ma, J. Gong, X. Yang, S. Wang, A comparative study of supported $\mathrm{MoO}_{3}$ catalysts prepared by the new "slurry" impregnation method and by the conventional method: Their activity in transesterification of dimethyl oxalate and phenol, Appl. Catal. A 280 (2005) 215-223.

[32] J. Huang, X. Wang, S. Li, Y. Wang, $\mathrm{ZnO} / \mathrm{MoO}_{3}$ mixed oxide nanotube: a highly efficient and stable catalyst for degradation of dye by air under room conditions, Appl. Surf. Sci. 257 (2010) 116-121.

[33] E. Gallei, E. Schwab, Development of technical catalysts, Catal. Today. 51 (3-4) (1999) $535-546$.

[34] E.D. Hanson, L. Lajaunie, S. Hao, B.D. Myers, F. Shi, A.A. Murthy, C. Wolverton, R. Arenal, V.P. Dravid, Systematic study of oxygen vacancy tunable transport properties of few-layer $\mathrm{MoO}_{3-\mathrm{x}}$ enabled by vapor-based synthesis, Adv. Func. Mater. 27 (2017) 1605380.

[35] L. Kihlborg, The crystal structure of $\mathrm{Mo}_{18} \mathrm{O}_{52}$ and the existence of homologous series of structures based on $\mathrm{MoO}_{3}$, Ark. Kemi 21 (1963) 443-460.

[36] A. Magnéli, The crystal structures of $\mathrm{Mog}_{9} \mathrm{O}_{26}$ (beta'-molybdenum oxide) and $\mathrm{Mo}_{8} \mathrm{O}_{23}$ (beta-molybdenum oxide), Acta Chem. Scand. 2 (1948) 501-517.

[37] L. Kihlborg, Studies on molybdenum oxides, Acta Chem. Scand. 13 (1959) 954-962.

[38] L. Kihlborg, The crystal structure of $\mathrm{Mo}_{17} \mathrm{O}_{47}$, Acta Chem. Scand. 14 (1960) 1612-1622. 
[39] S. Åsbrink, L. Kihlborg, A study of the crystal symmetry and structure of orthorhombic $\mathrm{Mo}_{4} \mathrm{O}_{11}$ by least squares techniques, Acta Chem. Scand. 18 (1964) 1571-1573.

[40] M. Sato, O. Onoda, Y. Matsuda, Structural transitions in $\mathrm{Mon}_{\mathrm{n}} \mathrm{O}_{3 \mathrm{n}-1}(\mathrm{n}=9$ and 10), J. Phys. C Solid State Phys. 20 (1987) 4763-4771.

[41] L. Seguin, M. Figlarz, R. Cavagnat, J.-C. Lassègues, Infrared and Raman spectra of $\mathrm{MoO}_{3}$ molybdenum trioxides and $\mathrm{MoO}_{3}-x \mathrm{H}_{2} \mathrm{O}$ molybdenum trioxide hydrates, Spectrochim. Acta Part A Mol. Biomol. Spectrosc. 51 (1995) 1323-1344.].

[42] M.S. Whittingham, Chemistry of intercalation compounds: metal guests in chalcogenide hosts, Prog. Solid State Chem. 12 (1978) 41-99.

[43] T.A. Kerr, H. Wu, L.F. Nazar, Concurrent polymerization and insertion of aniline in molybdenum trioxide: Formation and properties of a $[\text { poly(aniline) }]_{0.24} \mathrm{MoO}_{3}$ nanocomposite, Chem. Mater. 8 (1996) 2005-2015.

[44] D. Liu, W.W. Lei, J. Hao, D.D. Liu, B.B. Liu, X. Wang, X.H. Chen, Q.L. Cui, G.T. Zou, J. Liu, S. Jiang, High-pressure Raman scattering and x-ray diffraction of phase transitions in $\mathrm{MoO}_{3}$, J. Appl. Phys. 105 (2009) 023513.

[45] L. Kihlborg, Least squares refinement of crystal structure of molybdenum trioxide, Ark. Kemi. 21 (1963) 357-364.

[46] E. M. McCarron III, $\beta-\mathrm{MoO}_{3}$ : a metastable analogue of $\mathrm{WO}_{3}$, J. Chem. Soc. Chem. Commun. (1986) 336-338.

[47] J.B. Parise, E.M. McCarron III, W. Sleight, A new modification of $\mathrm{ReO}_{3}$-type $\mathrm{MoO}_{3}$ and the deuterated intercalation compound from which it is derived: $\mathrm{D}_{0.99} \mathrm{MoO}_{3}$, Mater. Res. Bull. 22 (1987) 803-811.

[48] W. Pan, R. Tian, H. Jin, Y. Guo, L. Zhang, X. Wu, L. Zhang, Z. Han, G. Liu, J. Li, G. Rao, H. Wang, W.Chu, Structure, optical, and catalytic properties of novel hexagonal metastable h- $\mathrm{MoO}_{3}$ nano- and microrods synthesized with modified liquid-phase processes, Chem. Mater. 22 (2010) 6202-6208.

[49] B. Baker, T.P. Feist, E.M. McCarron III, Soft chemical synthesis of a high-pressure phase of molybdenum trioxide: $\mathrm{MoO}_{3}$-II, J. Solid State Chemistry 119 (1995) 199-202.

[50] H. Bräkken, Die kristallstrukturen der trioxide von chrom, molybdän und wolfram, Z. Krist. 78 (1931) 484-488.

[51] N. Wooster, The crystal structure of molybdenum trioxide, $\mathrm{MoO}_{3}$, Z. Krist. 80 (1931) 504-512.

[52] G. Andersson, A. Magneli, On the crystal structure of molybdenum trioxide trioxide, Acta Chem. Scand. 4 (1950) 793-797. 
[53] O. Glemser, G. Lutz, Über molybdänoxyde, Z. Anorg. Allgem. Chem. 263 (1950) 2-14.

[54] O. Glemser, G. Lutz, Z. Über molybdänblau, Anorg. Allgem. Chem. 264 (1951) 17-33

[55] O. Glemser, G. Lutz, G. Meyer, Über niedere molybdänhydroxyde, Z. Anorg. Allg. Chemie 285 (1956) 173.

[56] R. Schöllhorn, R. Kuhlmann, J.O. Besenhard, Topotactic redox reactions and ion exchange of layered $\mathrm{MoO}_{3}$ bronzes, Mater. Res. Bull. 11 (1976) 83-90.

[57] C. Morehouse, R. Glicksman, An investigation of the discharge characteristics of groups VI-VIII oxides in an alkaline electrolyte, J. Electrochem. Soc. 107 (1960) 361-365.

[58] L. Campanella, G. Pistoia, $\mathrm{MoO}_{3}$ : A new electrode material for nonaqueous secondary battery applications, J. Electrochem. Soc. 118 (1971) 1905-1908.

[59] L. Campanella, G. Pistoia, Polarographic behavior of $\mathrm{MoO}_{3}$ in butyrolactone solutions, J. Electrochem. Soc. 120 (1973) 383-384.

[60] J.P. Gabano, Y. Jumel, J. P. Gomis, Electrodes for secondary lithium batteries, 144th Electrochem. Soc. Meeting, Boston (1973) Abstr. 134.

[61] M.S. Whittingham, The role of ternary phases in cathode reactions, J. Electrochem. Soc. 123 (1976) 315-320.

[61] J.O. Besenhard, R. Schöllhorn, The discharge reaction mechanism of the $\mathrm{MoO}_{3}$ electrode in organic electrolytes, J. Power Sources 1 (1976) 267-276.

[62] M.S. Whittingham, M.B. Dines, n-butyllithium - An effective, general cathode screening agent, J. Electrochem. Soc. 124 (1977) 1387-1388.

[63] J.O. Besenhard, J. Heydecke, H.P. Fritz, Characteristics of molybdenum oxide and chromium oxide cathodes in primary and secondary organic electrolyte lithium batteries. Part II. Transport properties, Solid State Ion. 6 (1983) 215-224.

[64] J.O. Besenhard, J. Heydecke, E. Wudy, H.P. Fritz, W. Foag, Characteristics of molybdenum oxide and chromium oxide cathodes in primary and secondary organic electrolyte lithium batteries. Part II. Transport properties, Solid State Ion. 8 (1983) 61-71.

[65] F. Bonino, L.P. Bicelli, B. Rivolta, M. Lazzari, F. Festorazzi, Amorphous cathode materials in lithium-organic electrolyte cells: tungsten and molybdenum trioxides, Solid State Ion. 17 (1985) 21-28.

[66] F.W. Dampier, The cathodic behavior of $\mathrm{CuS}, \mathrm{MoO}_{3}$, and $\mathrm{MnO}_{2}$ in lithium cells, J. Electrochem. Soc. 121 (1974) 656-659.

[67] M. Gargalit, Discharge behavior of $\mathrm{Li} / \mathrm{MoO}_{3}$ cells, J. Electrochem. Soc. 121 (1974) $1460-1461$. 
[68] R. Schöllhorn, Reversible topotactic redox reactions of solids by electron/ion transfer, Angew. Chem. Int. Ed. 19 (1980) 983-1003.

[69] J.M. Réau, C. Fouassier, P. Hagenmuller, Sur quelques nouveaux bronzes oxygène de molybdène, J. Solid State Chem. 1 (1970) 326-331.

[70] C. Julien, G.A. Nazri, Transport properties of lithium-intercalated $\mathrm{MoO}_{3}$, Solid State Ion. 68 (1994) 111-116.

[71] Y. Guo, J. Robertson, Origin of the high work function and high conductivity of $\mathrm{MoO}_{3}$, Appl. Phys. Lett. 105 (2014) 222110.

[72] A. Lakshmi-Narayana, O.M. Hussain, C.V. Ramana, M. Camacho-Lopez, A. AbdelGhany, A. Hashem, A. Mauger, C.M. Julien, Molybdenum-suboxide thin films as anode layers in planar lithium microbatteries, Electrochem (Basel) 2 (2020) 160-186.

[73] H. Bräkken, Die kristallstrukturen der trioxide von chrom, molybdän und wolfram, Z. Krist. 78 (1931) 484-488.

[74] N. Wooster, The crystal structure of molybdenum trioxide, $\mathrm{MoO}_{3}$, Z. Krist. 80 (1931) 504-512.

[75] H. Sitepu, B.H. O’Connor, D.J. Li, Comparative evaluation of the March and generalized spherical harmonic preferred orientation models using X-ray diffraction data for molybdite and calcite powders, Appl. Crystallogr. 38 (2005) 158-167.

[76] M.A. Py, K. Maschke, Intra- and interlayer contributions to the lattice vibrations in $\mathrm{MoO}_{3}$, Phys. B+C 105 (1981) 370-374.

[77] G.A. Nazri, C. Julien, Far-infrared and Raman studies of orthorhombic $\mathrm{MoO}_{3}$ single crystal, Solid State Ion. 53-56 (1992) 376-382.

[78] M. Dieterle, G. Weinberg, G. Mestl, Raman spectroscopy of molybdenum oxides - Part I. Structural characterization of oxygen defects in $\mathrm{MoO}_{3-\mathrm{x}}$ by DR UV/VIS, Raman spectroscopy and X-ray diffraction, Phys. Chem. Chem. Phys. 4 (2002) 812-821.

[79] I.R. Beattie, N. Cheetham, M. Gardner, D.E. Rogers, Calculation of the vibrational frequencies of polyatomic molecules, including those of crystals, J. Chem. Soc. A (1971) 2240-2245.

[80] M.A. Py, P.E. Schmid, J.T. Vallin, Raman scattering and structural properties of $\mathrm{MoO}_{3}$, Nuovo Cim. B 11. 38 (1977) 271-279.

[81] G. Mestl, N.F.D. Verbruggen, E. Bosch, H. Knözinger, Mechanically activated $\mathrm{MoO}_{3} .5$. Redox behavior, Langmuir 12 (1996) 2961-2968.

[82] H. Sinaim, D.J. Ham, J.S. Lee, A. Phuruangrat, S. Thongtem, T. Thongtem, Freepolymer controlling morphology of $\alpha-\mathrm{MoO}_{3}$ nanobelts by a facile hydrothermal 
synthesis, their electrochemistry for hydrogen evolution reactions and optical properties, J. Alloys Compd. 516 (2012) 172-178.

[83] T. Siciliano, A. Tepore, E. Filippo, G. Micocci, M. Tepore, Characteristics of molybdenum trioxide nanobelts prepared by thermal evaporation technique, Mater. Chem. Phys. 114 (2009) 687-691.

[84] L.G. Pereira, L.E.B. Soledade, J.M. Ferreira, S.J.G. Lima, V.J. Fernandes Jr., A.S. Araújo, C.A. Paskocimas, E. Longo, M.R.C. Santos, A.G. Souza, I.M.G. Santos, Influence of doping on the preferential growth of $\alpha-\mathrm{MoO}_{3}$, J. Alloys Compd. 459 (2008) 377-385.

[85] S.S. Sunu, E. Prabhu, V. Jayaraman, K.I. Gnanasekar, T.K. Seshagiri, T. Gnanasekaran, Electrical conductivity and gas sensing properties of $\mathrm{MoO}_{3}$, Sens. Actuators B 101 (2004) 161-174.

[86] M.E. Kurtoglu, T. Longenbach, Y. Gogotsi, Synthesis of quasi-oriented $\alpha-\mathrm{MoO}_{3}$ nanobelts and nanoplatelets on $\mathrm{TiO}_{2}$ coated glass, J. Mater. Chem. 21 (2011) 7931-7936.

[87] S. Berthumeyrie, J.-C. Badot, J.-P. Pereira-Ramos, O. Dubrunfaut, S. Bach, P. Vermaut|, Influence of lithium insertion on the electronic transport in electroactive $\mathrm{MoO}_{3}$ nanobelts and classical powders: Morphological and particle size effects, J. Phys. Chem. C 114 (2010) 19803-19814.

[88] Q.P. Ding, H.B. Huang, J.H. Duan, J.F. Gong, S.G. Yang, X.N. Zhao, Y.W. Du, Molybdenum trioxide nanostructures prepared by thermal oxidization of molybdenum, J. Cryst. Growth 294 (2006) 304-308.

[89] L. Cai, P.M. Rao, X. Zheng, Morphology-controlled flame synthesis of single, branched, and flower-like $\alpha-\mathrm{MoO}_{3}$ nanobelt arrays, Nano Lett. 11 (2011) 872-877.], hot plate method [90] B. Yan, Z. Zheng, J. Zhang, H. Gong, Z. Shen, W. Huang, T. Yu, Orientation controllable growth of $\mathrm{MoO}_{3}$ nanoflakes: Micro-Raman, field emission, and birefringence properties, J. Phys. Chem. C 113 (2009) 20259-20263.

[91] A. Gopala Krishna, R.V.S.S.N. Ravikumar, T. Vijaya Kumar, S.D. Ephraim, B. Ranjith, M. Pranoy, S. Dola, Investigation and comparison of optical and Raman bands of mechanically synthesised $\mathrm{MoO}_{3}$ Nano powders, Mater. Today: Proc. 3 (2016) 54-63.

[92] T.M. McEvoy, K.J. Stevenson, Elucidation of the electrodeposition mechanism of molybdenum oxide from iso- and peroxo-polymolybdate solutions, J. Mater. Res. 19 (2004) 429-438. 
[93] W. Li, S. Zhao, B. Qi, Y. Du, X. Wang, M. Huo, Fast catalytic degradation of organic dye with air and $\mathrm{MoO}_{3}$ :Ce nanofibers under room condition, Appl. Catal. B 92 (2009) $333-340$.

[94] S. Li, C. Shao, Y. Liu, S. Tang, R. Mu, Nanofibers and nanoplatelets of $\mathrm{MoO}_{3}$ via an electrospinning technique, J. Phys. Chem. Solids 67 (2006) 1869-1872.

[95] A. Michailovski, J.-D. Grunwaldt, A. Baiker, R. Kiebach, W. Bensch, G.R. Patzke, Studying the solvothermal formation of $\mathrm{MoO}_{3}$ fibers by complementary in situ EXAFS/EDXRD techniques, Angew. Chemie Int. Ed. 44 (2005) 5643-5647.

[96] A. Bouzidi, N. Benradame, H. Tabet-Derraz, C. Mathieu, B. Khelifa, R. Desfeux, Effect of substrate temperature on the structural and optical properties of $\mathrm{MoO}_{3}$ thin films by spray pyrolysis technique. Mater. Sci. Eng. B 97 (2003) 5-8.

[97] H. Martinez, J. Torres, M.E. Rodriguez-Garcia, L.D. Lopez-Carreno, Gas sensing properties of nanostructured $\mathrm{MoO}_{3}$ thin films prepared by spray pyrolysis, Phys. B Cond. Matter 407 (2012) 3199-3202.

[98] A.A. Mane, A.V. Moholkar, Orthorhombic $\mathrm{MoO}_{3}$ nanobelts based $\mathrm{NO}_{2}$ gas sensor, Appl. Surf. Sci. 405 (2017) 427-440.

[99] A. Klisinska, A.S. Mamede, E.M. Gaigneaux, Effect of the nature of the precursor on the morphology of $\mathrm{MoO}_{3}$ thin films spin-coated on Si (100), Thin Solid Films 516 (2008) 2904-2912.

[100] L. Fang, Y. Shu, A. Wang, T. Zhang, Template-free synthesis of molybdenum oxidebased hierarchical microstructures at low temperatures, J. Cryst. Growth. 310 (2008) 4593-4600.

[101] H. Ren, S. Sun, J. Cui, X. Li, Synthesis, functional modifications, and diversified applications of molybdenum oxides micro-/nanocrystals: A review. Cryst. Growth Des. 18 (2018) 6326-6369.

[102] E. Haro-Poniatowski, C. Julien, B. Pecquenard, J. Livage, M.A. Camacho-López, Laser-induced structural transformations in $\mathrm{MoO}_{3}$ investigated by Raman spectroscopy, J. Mater. Res. 13 (1998) 1033-1037.

[103] R. Murugan, A. Ghule, C. Bhongale, H. Chang, Thermo-Raman investigations on structural transformations in hydrated $\mathrm{MoO}_{3}$, J. Mater. Chem. 10 (2000) 2157-2162.].

[104] S. Wang, Y. Zhang, X. Ma, W. Wang, X. Li, Z. Zhang, Y. Qian, Hydrothermal route to single crystalline $\alpha-\mathrm{MoO}_{3}$ nanobelts and hierarchical structures, Solid State Commun. 136 (2005) 283-287. 
[105] X.W. Lou, H.C. Zeng, Hydrothermal synthesis of $\alpha-\mathrm{MoO}_{3}$ nanorods via acidification of ammonium heptamolybdate tetrahydrate, Chem. Mater. 14 (2002) 4781-4789.

[106] C.V. Subba Reddy, E.H. Walker, C. Wen, S.-I. Mho, Hydrothermal synthesis of $\mathrm{MoO}_{3}$ nanobelts utilizing poly(ethylene glycol), J. Power Sources 183 (2008) 330-333.

[107] A. Chithambararaj, A.C. Bose, Hydrothermal synthesis of hexagonal and orthorhombic $\mathrm{MoO}_{3}$ nanoparticles, J. Alloys Compd. 509 (2011) 8105-8110.

[108] L. Zhou, L. Yang, P. Yuan, J. Zou, Y. Wu, C. Yu, $\alpha-\mathrm{MoO}_{3}$ Nanobelts: A high performance cathode material for lithium ion batteries, J. Phys. Chem. C 114 (2010) $21868-21872$.

[109] A.M. Hashem, A.E. Abdel-Ghany, R.S. El-Tawil, S. Indris, H. Ehrenberg, A. Mauger, C.M. Julien, Amorphous $\mathrm{Mo}_{5} \mathrm{O}_{14}$-type/carbon nanocomposite with enhanced electrochemical capability for lithium-ion batteries, Nanomaterials 10 (2020) 8.

[110] R.-Q. Song, A.-W. Xu, B. Deng, Y.-P. Fang, Novel multilamellar mesostructured molybdenum oxide nanofibers and nanobelts: Synthesis and characterization, J. Phys. Chem. B 109 (2005) 22758-22766.

[111] G.S. Zakharova, C. Täschner, V.L. Volkov, I. Hellmann, R. Klingeler, A. Leonhardt, B. Büchne, Solid State Sci. 9 (2007) 1028-1032.

[112] L. Cheng, M. Shao, X. Wang, H. Hu, Single-crystalline molybdenum trioxide nanoribbons: Photocatalytic, photoconductive, and electrochemical properties. Chem. Eur. J. 15 (2009) 2310-2316.

[113] K. Dewangan, N. Nikkan Sinha, P.K. Sharma, A.C. Pandey, N. Munichandraiah, N. S. Gajbhiye, Synthesis and characterization of single-crystalline $\alpha-\mathrm{MoO}_{3}$ nanofibers for enhanced Li-ion intercalation applications, CrystEngCom 13 (2011) 927-933.

[114] X.-L. Li, J.-F. Liu, Y.-D. Li, Low-temperature synthesis of large-scale single-crystal molybdenum trioxide $\left(\mathrm{MoO}_{3}\right)$ nanobelts, Appl. Phys. Lett. 81 (2002) 4832.

[115] Y. Shen, R. Huang, Y. Li, S. Yao, Synthesis and photochromic properties of 1,3diaminopropane-induced $\mathrm{MoO}_{3}$ powder, Appl. Surf. Sci. 258 (2011) 414- 418.

[116] X. Yang, H. Ding, D. Zhang, X. Yan, C. Lu, J. Qin, R. Zhang, H. Tang, H. Song, Hydrothermal synthesis of $\mathrm{MoO}_{3}$ nanobelt-graphene composites, Cryst. Res. Technol. 46 (2011) 1195-1201.

[117] I. Shakir, M. Shahid, H.W. Yang, D.J. Kang, Structural and electrochemical characterization of $\alpha-\mathrm{MoO}_{3}$ nanorod-based electrochemical energy storage devices, Electrochim. Acta 56 (2010) 376-380. 
[118] I. Shakir, M. Shahid, S. Cherevko, C.-H. Chung, D.J. Kang, Ultrahigh-energy and stable supercapacitors based on intertwined porous $\mathrm{MoO}_{3}-\mathrm{MWCNT}$ nanocomposites, Electrochim. Acta 58 (2011) 76- 80.

[119] L. Jiao, H. Yuan, Y. Si, Y. Wang, M. Zhao, Y. Wang, A novel method for synthesis of microstructure $\mathrm{MoO}_{3}$, Mater. Lett. 59 (2005) 3112-3114.

[120] T.H. Chiang, H.C. Yeh, The synthesis of $\alpha-\mathrm{MoO}_{3}$ by ethylene glycol. Materials (Basel) 6 (2013) 4509-4625.

[121] G.A. Nazri, C. Julien, Studies of lithium intercalation in heat-treated products obtained from molybdic acid, Ionics 2 (1996) 1-6.

[122] J. Ding, S.A. Abbas, C. Hanmandlu, L. Lin, C.S. Lai, P.C. Wang, L.J. Li, C.W. Chu, C.C. Chang, Facile synthesis of carbon/ $\mathrm{MoO}_{3}$ nanocomposites as stable battery anodes, J. Power Sources 348 (2017) 270-280.

[123] M. Xu, J. Tang, H. Wu, G.F. Zheng, Mesoporous carbon coated molybdenum oxide nanobelts for improved lithium ion storage, RSC Adv. 4 (2014) 29586-29590.

[124] X. Li, J.T. Xu, L. Mei, Z.J. Zhang, C.Y. Cui, H.K. Liu, J.M. Ma, S.X. Dou, Electrospinning of crystalline $\mathrm{MoO}_{3} @ \mathrm{C}$ nanofibers for high-rate lithium storage, J. Mater. Chem. A 3 (2015) 3257-3260.

[125] C.Q. Feng, H. Gao, C.F. Zhang, Z.P. Guo, H.K. Liu, Synthesis and electrochemical properties of $\mathrm{MoO}_{3} / \mathrm{C}$ nanocomposite, Electrochim. Acta 93 (2013) 101-106.

[126] Q. Xia, H.L. Zhao, Z.H. Du, J. Wang, T.H. Zhang, J. Wang, P.P. Lv, Synthesis and electrochemical properties of $\mathrm{MoO}_{3} / \mathrm{C}$ composite as anode material for lithium-ion batteries, J. Power Sources 226 (2013) 107-111.

[127] C.M. Julien, A. Mauger, A. Vijh, K. Zaghib, Lithium Batteries: Science and Technology; Springer: Heidelberg, Germany, 2016.

[128] S.-H. Lee, Y.-H. Kim, R. Deshpande, P.A. Parilla, E. Whitney, D.T. Gillaspie, K.M. Jones, A.H. Mahan, S. Zhang, A.C. Dillon, Reversible lithium-ion insertion in molybdenum oxide nanoparticles, Adv. Mater. 20 (2008) 3627-3632

[129] Z. Wang, S. Madhavi, X.W. Lou, Ultralong $\alpha-\mathrm{MoO}_{3}$ nanobelts: synthesis and effect of binder choice on their lithium storage properties, J. Phys. Chem. C 116 (2012) 1250812503.

[130] D. Yan, X. Luo, H. Zhang, G. Zhu, L. Chen, G. Chen, H. Xu, A. Yu, Single crystalline $\alpha-\mathrm{MnO}_{3}$ microbelts derived from a bio-templating method for superior lithium storage application, J. Alloys Compd. 688 (2016) 481-486. 
[131] L. Mai, F. Yang, Y. Zhao, X. Xu, L. Xu, B. Hu, Y. Luo, H. Liu, Molybdenum oxide nanowires: synthesis and properties, Mater. Today 14 (2011) 346-353.

[132] P. Meduri, E. Clark, J.H. Kim, E. Dayalan, G.U. Sumanasekera, M.K. Sunkara, MoO3-x nanowire arrays as stable and high capacity anodes for lithium ion batteries. Nano Lett. 12 (2012) 1784-1788.

[133] P. Allen, L. Cai, L. Zhou, C. Zhao, P.M. Rao, Rapid synthesis of thin and long $\mathrm{Mo}_{17} \mathrm{O}_{47}$ nanowire-arrays in an oxygen deficient flame, Sci. Rep. 5 (2016) 27832.

[134] X. He, K. Zhang, X. Zhao, P. Zhang, M. Chen, Z. Zheng, Z. Han, T. Zhu, Y. Tong, X. $\mathrm{Lu}$, Stabilized molybdenum trioxide nanowires as novel ultrahigh-capacity cathode for rechargeable zinc ion battery, Adv. Sci. 6 (2019) 1900151.

[135] A.M Hashem, H. Groult, A. Mauger, K. Zaghib, C.M. Julien, Electrochemical properties of nanofibers $\alpha-\mathrm{MoO}_{3}$ as cathode materials for Li batteries, J. Power Sources 219 (2012) 126-132.

[136] S. Hu, X. Wang, Single-walled $\mathrm{MoO}_{3}$ nanotubes, J. Am. Chem. Soc. 130 (2008) 81268127.

[137] S. Hu, X. Ling; T. Lan, X. Wang, Cluster-based self-assembly route toward $\mathrm{MoO}_{3}$ single-walled nanotubes, Chem. Eur. J. 16 (2010) 1889-1896.

[138] J.V. Silveira, J.A. Batista, G.D. Saraiva, J.M. Filho, A.G. Sousza Filho, S. Hu, X. Wang, Temperature dependent behavior of single walled $\mathrm{MoO}_{3}$ nanotubes: A Raman spectroscopy study. Vibrat. Spectr. 54 (2010) 179-183.

[139] G. Zhao, N. Zhang, K. Sun, Electrochemical preparation of porous $\mathrm{MoO}_{3}$ film with a high rate performance as anode for lithium ion batteries, J. Mater. Chem. A 1 (2012) 221-224.

[140] X. Yu, L. Wang, J. Liu, X. Sun, Porous $\mathrm{MoO}_{3}$ film as a high-performance anode material for lithium-ion batteries, ChemElectroChem 1 (2014) 1476-1479.

[141] P.M.S. Monk, R.J. Mortimer, D.R. Rosseinsky, Electrochromism and Electrochromic Devices, Cambridge Univ. Press, Cambridge, 2007.

[142] T. Abhijith, T. V. Arun Kumar, V. S. Reddy, Organic bistable memory devices based on $\mathrm{MoO}_{3}$ nanoparticle embedded $\mathrm{Alq}_{3}$ structures, Nanotechnology 28 (2017) 095203.

[143] C. Julien, O.M. Hussain, L. El-Farh, M. Balkanski, Electrochemical studies of lithium insertion in $\mathrm{MoO}_{3}$ films, Solid State Ion. 53-56 (1992) 400-404.

[144] H. Ohtsuka, Y. Sakurai, Characteristics of $\mathrm{Li} / \mathrm{MoO}_{3-x}$ thin film batteries, Solid State Ion. 144 (2001) 59-64. 
[145] C.V. Ramana, V.V. Atuchin, H. Groult, C.M. Julien, Electrochemical properties of sputter-deposited $\mathrm{MoO}_{3}$ films in lithium batteries, J. Vacuum Sci. Technol. A 30 (2012) $04 \mathrm{D} 105$.

[146] C.M. Julien, A. Mauger, Pulsed laser deposition films for microbatteries, Coatings (Basel) 9 (2019) 386.

[147] R. Martinez, J.R. Vargas, V. Santes, E. Gomez, Preparation of molybdenum oxide thin films by MOCVD. J Alloys Compd. 434-435 (2007) 701-703.

[148] N. Miyata, T. Suzuki, R. Ohyama, Physical properties of evaporated molybdenum oxide films, Thin Solid Films 281-282 (1996) 218-222.

[149] C.V. Ramana, V.V. Atuchin, V.G. Kesler, V.A. Kochubey, L.D. Pokrovsky, V. Shutthanandan, U. Becker, R.C. Ewing, Growth and surface characterization of sputterdeposited molybdenum oxide thin films. Appl. Surf. Sci. 253 (2007) 5368-5374.

[150] T. Maruyama, T. Kanagawa, Electrochromic properties of molybdenum trioxide thin films prepared by chemical vapor deposition, J. Electrochem. Soc. 142 (1995) 16441647.

[151] T. Ivanova, A. Szekeres, M. Gartner, D. Gogova, K.A. Gesheva, Spectroscopic characterization of CVD-molybdenum oxide films, Electrochim. Acta 46 (2001) 2215 2219.

[152] A. Guerfi, L.H. Dao, Electrochromic molybdenum oxide thin films prepared by electrodeposition, J. Electrochem. Soc. 136 (1989) 2435-2436.

[153] C. Julien, A. Khelfa, O.M. Hussain, G.A. Nazri, Synthesis and characterization of flashevaporated $\mathrm{MoO}_{3}$ thin films, J. Cryst. Growth 156 (1995) 235-244.

[154] C. Julien, B. Yebka, G.A. Nazri, Temperature dependence of the vibrational modes of $\mathrm{MoO}_{3}$, Mater. Sci. Eng. B 38 (1996) 65-71.

[155] M. Al-Kuhaili, S.A. Durrani, I.A. Bakhtiari, Pulsed laser deposition of molybdenum oxide thin films, Appl. Phys. A 98 (2009) 609-615.

[156] A. Pardo, J. Torres, Substrate and annealing temperature effects on the crystallographic and optical properties of $\mathrm{MoO}_{3}$ thin films prepared by laser assisted evaporation, Thin Solid Films 520 (2012) 1709-1717.

[157] C.V. Ramana, O.M. Hussain, C.M. Julien, Electronic properties and performance upon lithium intercalation of $\mathrm{MoO}_{3}$ thin films grown by PLD, ECS Trans. 1-15 (2006) 1-7.

[158] M. Yahaya, M.M. Salleh, I.A. Talib, Optical properties of $\mathrm{MoO}_{3}$ thin films for electrochromic windows, Solid state Ion. 113-115 (1998) 421-423. 
[159] R. Sivakumar, R. Gopalakrishnan, M. Jayachandran, C. Sanjeeviraja, Characterization on electron beam evaporated $\alpha-\mathrm{MoO}_{3}$ thin films by the influence of substrate temperature, Current Appl. Phys. 7 (2007) 51-59.

[160] C.-S. Hsu, C.-C. Chan, H.-T. Huang, C.-H. Peng, W.-C. Hsu, Electrochromic properties of nanocrystalline $\mathrm{MoO}_{3}$ thin films, Thin Solid Films 516 (2008) 4839-4844.

[161] M. Epifani, P. Imperatori, L. Mirenghi, M. Schioppa, P. Siciliano, Synthesis and characterization of $\mathrm{MoO}_{3}$ thin films and powders from a molybdenum chloromethoxide, Chem. Mater. 16 (2004) 5495-5501.

[162] A. Boukhachem, C. Bouzidi, R. Boughalmi, R. Ouerteni, M. Kahlaoui, B. Ouni, H. Elhouichet, M. Amlouk, Physical investigations on $\mathrm{MoO}_{3}$ sprayed thin film for selective sensitivity applications, Ceram. Int. 40 (2014) 13427-13435.

[163] R. Pandeeswari, B.G. Jeyaprakash, Nanostructured $\alpha-\mathrm{MoO}_{3}$ thin film as a highly selective TMA sensor, Biosens. Bioelectr. 53 (2014) 182-186.

[164] V. Nirupama, M. Chandra Sekhar, T.K. Subramanyam, S. Uthanna, Structural and electrical characterization of magnetron sputtered $\mathrm{MoO}_{3}$ thin films. J. Phys. Conf. Ser. 208 (2010) 012101.

[165] C.V. Ramana, V.V. Atuchin, L.D. Pokrovsky, U. Beker, C.M. Julien, Structure and chemical properties of molybdenum oxide thin films, J. Vac. Sci. Technol. A 25 (2007) $1166-1171$.

[166] J. Swiatowska-Mrowiecka, S. de Diesbach, V. Maurice, S. Zanna, L. Klein, E. Briand, I. Vickridge, P. Marcus, Li-ion intercalation in thermal oxide thin films of $\mathrm{MoO}_{3}$ as studied by XPS, RBS, and NRA, J. Phys. Chem. C 112 (2008) 11050-11058.

[167] M. Niederberger, F. Krumeich, H.-J. Muhr, M. Müller, R. Nesper, Synthesis and characterization of novel nanoscopic molybdenum oxide fibers, J. Mater. Chem. 11 (2001) 1941-1945.

[168] B.C. Satishkumar, A. Govindaraj, M. Nath, C.N.R. Rao, Synthesis of metal oxide nanorods using carbon nanotubes as templates, J. Mater. Chem. 10 (2000) 2115-2119.

[169] A. Abdellaoui, G. Lévêque, A. Donnadieu, A. Bath, B. Bouchikhi, Iteratively derived optical constants of $\mathrm{MoO}_{3}$ polycrystalline thin films prepared by CVD, Thin Solid Films 304 (1997) 39-44.

[170] E. Haro-Poniatowski, M. Jouanne, J.F. Morhange, C. Julien, R. Diamant, M.

Fernandez-Guasti, G.A. Fuentes, J.C. Alonso, Micro-Raman characterization of $\mathrm{WO}_{3}$ and $\mathrm{MoO}_{3}$ thin films obtained by pulsed laser irradiation, Appl. Surf. Sci. 127 (1998) 674678. 
[171] C.V. Ramana, O.M. Hussain, C.M. Julien, Effect of growth temperature on the optical properties of pulsed-laser deposited $\mathrm{MoO}_{3}$ thin films, Mater. Sci. Indian J. 1 (2005)1015.

[172] C.V. Ramana, O.M. Hussain, C.M. Julien, Electronic properties of $\mathrm{MoO}_{3}$ thin films grown by PLD and ARE techniques and their performance upon lithium intercalation, Extended Abstract of the 208th ECS Meeting, Los Angeles, CA, USA (16-21 October $2005=$ p. 885 .

[173] C.V. Ramana, C.M. Julien, Chemical and electrochemical properties of molybdenum oxide thin films prepared by reactive pulsed-laser assisted deposition, Chem. Phys. Lett. 428 (2006) 114-118.

[174] C. Julien, Thin film technology and microbatteries, in: Lithium Batteries - New Materials, Developments and Perspectives, G. Pistoia (Ed.), Elsevier Science B.V., Amsterdam, The Netherlands (1994), pp.167-237.

[175] C. Julien, Lithium microbatteries, in: Materials for Lithium-ion Batteries, C. Julien, Z. Stoynov (Eds.), Kluwer Acad. Publ., Dordecht, The Netherlands (2000), pp. 381-400.

[176] H. Ohtsuka, J. Yamaki, Electrical characteristics of $\mathrm{Li}_{2} \mathrm{O}-\mathrm{V}_{2} \mathrm{O}_{5}-\mathrm{SiO}_{2}$ thin films, Solid State Ion. 35 (1989) 201-206.

[177] C. Julien, G.A. Nazri, J.P. Guesdon, A. Goreinstein, A. Khelfa, O.M. Hussain, Influence of the growth conditions on electrochemical features of $\mathrm{MoO}_{3}$ film-cathodes in lithium microbatteries, Solid State Ion. 73 (1994) 319-326.

[178] C. Julien, A. Khelfa, J.-P. Guesdon, A. Gorenstein, Lithium intercalation in $\mathrm{MoO}_{3}$ : a comparison between crystalline and disordered phases, Appl. Phys. A 59 (1994) 173-178.

[179] C. Julien, L. El-Farh, M. Balkanski, O.M. Hussain, G.A. Nazri, The growth and electrochemical properties of metal-oxide thin films: lithium intercalation, Appl. Surf. Sci. 65-66 (1993) 325-330.

[180] B. Yebka, C. Julien, Lithium intercalation in sputtered $\mathrm{MoO}_{3}$ films, Ionics 3 (1997) 8388.

[181] F.F. Ferreira, T.G. Souza Cruz, M.C.A. Fantini, M.H. Tabacniks, S.C. de Castro, J. Morais, A. de Siervo, R. Landers, A. Gorenstein, Lithium insertion and electrochromism in polycrystalline molybdenum oxide films, Solid State Ion. 136-137 (2000) 357-363.

[182] W. West, J. Whitacre, $\mathrm{MoO}_{3}$ cathodes for high-temperature lithium thin-film cells, NASA Tech Briefs NPO-41099 (2007) 19. 
[183] W. Jiebing, X. Rui, W. Shimin, T. Wufeng, T. Hua, S. Jing, Preparation and characterization of molybdenum oxide thin films by sol-gel process, J. Sol-Gel Sci. Technol. 27 (3) (2003) 315-319.

[184] E. Comini, G. Faglia, G. Sberveglieri, C. Cantalini, M. Passacantando, S. Santucci, Y. Li, W. Wlodarski, W. Qu, Carbon monoxide response of molybdenum oxide thin films deposited by different techniques, Sens. Actuators B 68 (2000) 168-174.

[185] S. Moitzheim, B. Put, P. Vereecken, Advances in 3D thin-film Li-ion batteries, Adv. Mater. Interfaces 6 (2019) 1900805.

[186] H.K. Puppala, A.T. Pelton, R.A. Mayanovic, A comparative characterization study of molybdenum oxide thin films grown using femtosecond and nanosecond pulsed laser deposition, Mater. Res. Soc. Adv. 1 (2016) 2585-2590.

[187] M.A. Ashrafi, M. Ranjbar, H. Kalhori, H. Salamati, Pulsed laser deposition of Mo-V-O thin films for chromogenic applications, Thin Solid Films 621 (2017) 220-228.

[188] C.C. Chang, J.Y. Luo, T.K. Chen, K.W. Yeh, T.W. Huang, C.H. Hsu, W.H. Chao, C.T. Ke, P.C. Hsu, M.J. Wang, Pulsed laser deposition of $\left(\mathrm{MoO}_{3}\right)_{1-\mathrm{x}}\left(\mathrm{V}_{2} \mathrm{O}_{5}\right)_{\mathrm{x}}$ thin films: Preparation, characterization and gasochromic studies, Thin Solid Films 519 (2010) $1552-1557$.

[189] S.K. Deb, Physical properties of a transition metal oxide: optical and photoelectric properties of single crystal and thin film molybdenum trioxide, Proc. R. Soc. A 304 (1477) (1968) 211-231.

[190] Q. Qu, W.-B. Zhang, K. Huang, H.-M. Chen, Electronic structure, optical properties and band edges of layered $\mathrm{MoO}_{3}$ : A first-principles investigation, Comput. Mater. Sci. 130 (2017) 242-248.

[191] C. Julien, G.A. Nazri, Solid State Batteries, Materials Design and Optimization, Kluwer, Boston, 1994.

[192] T.M. McEvoy, K.J. Stevenson, Spatially resolved measurement of inhomogeneous electrocoloration/insertion in polycrystalline molybdenum oxide thin films via chronoabsorptometric imaging, J. Am. Chem. Soc. 125 (2003) 8438-8439.

[193] R. Liang, H. Cao, D. Qian, $\mathrm{MoO}_{3}$ nanowires as electrochemical pseudocapacitor materials, Chem. Commun. 47 (2011) 10305-10307.

[194] H.-S. Kim, J.B. Cook, H. Lin, J.S. Ko, S.H. Tolbert, V. Ozolins, B. Dunn, Oxygen vacancies enhance pseudocapacitive charge storage properties of $\mathrm{MoO}_{3-\mathrm{x}}$, Nat. Mater. 16 (2017) 454-462. 
[195] N.A. Chernova, M. Roppolo, A.C. Dillon, M.S. Whittingham, Layered vanadium and molybdenum oxides: batteries and electrochromics, J. Mater. Chem. 19 (2009) 25262552.

[196] A.M. Hashem, M.H. Askar, M. Winter, J.H. Albering, J.O. Besenhard, Two-phase reaction mechanism during chemical lithium insertion into $\alpha-\mathrm{MoO}_{3}$, Ionics 13 (2007) 3-8.

[197] L. Mai, B. Hu, W. Chen, Y. Qi, C. Lao, R. Yang, Y. Dai, Z.L. Wang, Lithiated $\mathrm{MoO}_{3}$ nanobelts with greatly improved performance for lithium batteries, Adv. Mater. 19 (2007) $3712-3716$.

[198] L. Mai, B. Hu, Y. Qi, Y. Dai, W. Chen, Improved cycling performance of directly lithiated $\mathrm{MoO}_{3}$ nanobelts, Int. J. Electrochem. Sci. 3 (2008) 216-222.

[199] C. Villevieille, A. Gorzkowska-Sobas, H. Fjellvag, P. Novak, Freeze-dryed $\mathrm{Li}_{\mathrm{x}} \mathrm{MoO}_{3}$ nanobelts used as cathode materials for lithium-ion batteries: A bulk and interface study, J. Power Sources 297 (2015) 276-282.

[200] P.G. Dickens, G.J. Reynolds, Transport and equilibrium properties of some oxide insertion compounds, Solid State Ion. 5 (1981) 331-334.

[201] N. Kumagai, N. Kumagai, K. Tanno, Electrochemical characteristics and structural changes of molybdenum trioxide hydrates as cathode materials for lithium batteries, J. Appl. Electrochem. 18 (1988) 857-862.

[202] M.E. Spahr, P. Novak, O. Haas, R. Nesper, Electrochemical insertion of lithium, sodium, and magnesium in molybdenum(VI) oxide, J. Power Sources 54 (1995) 346-351.

[203] J.W. Bullard III, R.L. Smith, Structural evolution of the $\mathrm{MoO}_{3}(010)$ surface during lithium intercalation, Solid State Ion. 2003, 160, 335-349.

[204] B. Yebka, G.A. Nazri, C.M. Julien, In-situ structural features of Li-intercalated molybdenum trioxide with layer- and fiber-like frameworks, Proc. Electrochem. Soc. 20 (2003) 491-496.

[205] F. Leroux, B.E. Loene, L.F. Nazar, Electrochemical lithium intercalation into a polyaniline/ $/ \mathrm{V}_{2} \mathrm{O}_{5}$ nanocomposite, J. Electrochem. Soc. 143 (1996) L181.

[206] Y. Iriyama, T. Abe, M. Inaba, Z. Ogumi, Transmission electron microscopy (TEM) analysis of two-phase reaction in electrochemical lithium insertion within $\alpha-\mathrm{MoO}_{3}$, Solid State Ion. 135 (2000) 95-100.

[207] S. Basu, W.L. Worrel,1 Chemical diffusion of lithium in $\mathrm{Li}_{\mathrm{x}} \mathrm{TaS}_{2}$ and $\mathrm{Li}_{\mathrm{x}} \mathrm{TiS}_{2}$ at $30{ }^{\circ} \mathrm{C}$. In: Vashishta P, Mindy JN, Shenoy GK (eds) Fast ion transport in solids. North-Holland, Amsterdam (1979) pp 149-152. 
[208] W. Xia, Q. Zhang, F. Xu, L. Sun, New insights into electrochemical lithiation/delithiation mechanism of $\alpha-\mathrm{MoO}_{3}$ nanobelt by in situ transmission electron microscopy, ACS Appl. Mater. Interfaces 8 (2016) 9170-9177.

[209] H. Guo, D. Goonetilleke, N. Sharma, W. Ren, Z. Su, A. Rawal, C. Zhao, Two-phase electrochemical proton transport and storage in $\alpha-\mathrm{MoO}_{3}$ for proton batteries, Cell Rep. Phys. Sci. 1 (2020) 100225.

[210] H. Zhang, W. Wu, Q. Liu, F. Yang, Xin Shi, X. Liu, M. Yu, X. Lu, Interlayer engineering of $\alpha-\mathrm{MoO}_{3}$ modulates selective hydronium intercalation in neutral aqueous electrolyte. Angew. Chem. Int. Ed. 59 (2020) 2-10.

[211] J. Huang, J. Yan, J. Li, L. Cao, Z. Xu, J. Wu, L. Zhou, Y. Luo, Assembled-sheets-like $\mathrm{MoO}_{3}$ anodes with excellent electrochemical performance in Li-ion battery, J. Alloys Compd. 688 (2016) 588-595.

[212] R. Nadimicherla, R. Zha, L. Wei, X. Guo, single crystalline flowerlike $\alpha-\mathrm{MnO}_{3}$ nanorods and their application as anode material for lithium-ion batteries, J. Alloys Compd. 687 (2016) 79-86.

[213] B. Mendoza-Sánchez, T. Brousse, C. Ramirez-Castro, V. Nicolosi, P.S. Grant, An investigation of nanostructured thin film $\alpha-\mathrm{MoO}_{3}$ based supercapacitor electrodes in an aqueous electrolyte, Electrochim. Acta 91 (2013) 253-260.

[214] Q. Wang, D.-A. Zhang, Q. Wang, J. Sun, L.-L. Xing, X.-Y. Xue, High electrochemical performances of $\alpha-\mathrm{MoO}_{3} @ \mathrm{MnO}_{2}$ core-shell nanorods as lithium-ion battery anodes, Electrochim. Acta 146 (2014) 411-418.

[215] Q. Xia, H. Zhao, Z. Du, Z. Zeng, C. Gao, Z. Zhang, X. Du, A. Kulka, K. Swierczek, Facile synthesis of $\mathrm{MoO}_{3} /$ carbon nanobelts as high-performance anode material for lithium ion batteries, Electrochim. Acta 180 (2015) 947-956.

[216] Y. Zhu, X. Xu, G. Chen, Y. Zhong, R. Cai, L. Li, Z. Shao, Surfactant-free self-assembly of reduced graphite oxide- $\mathrm{MoO}_{2}$ nanobelt composites used as electrode for lithium-ion batteries. Electrochim. Acta 211 (2016) 972-981.

[217] Z. Yu, H. Jiang, D. Gu, J. Li, L. Wang, L. She, A new way to prepare $\mathrm{MoO}_{3} / \mathrm{C}$ as anode of lithium ion battery for enhancing the electrochemical performance at room temperature, J. Electrochem. Sci. Technol. 7 (2016) 170-178.

[218] J. Qiu, Z. Yang, Y. Li, N-doped carbon encapsulated ultrathin $\mathrm{MoO}_{3}$ nanosheets as superior anodes with high capacity and excellent rate capability for Li-ion batteries. J. Mater. Chem. A 3 (2015) 24245-24253. 
[219] B. Mendoza-Sánchez, P.S. Grant, Charge storage properties of a $\alpha-\mathrm{MoO}_{3} /$ carboxylfunctionalized single-walled carbon nanotube composite electrode in a $\mathrm{Li}$ ion electrolyte, Electrochim. Acta 98 (2013) 294-302.

[220] I. Shakir, M. Sarfraz, Evaluation of electrochemical charge storage mechanism and structural changes in intertwined $\mathrm{MoO}_{3}-\mathrm{MWCNT}$ composites for supercapacitor applications Electrochim. Acta 147 (2014) 380-384.

[221] L.S. Aravinda, U. Bhat, B.R. Bhat, Binder-free $\mathrm{MoO}_{3} /$ multiwalled carbon nanotube thin film electrode for high energy density supercapacitors, Electrochim. Acta 112 (2013) 663-669.

[222] Y. Hao, X. Wang, Y. Zheng, J. Shen, J. Yuan, A. Wang, L. Niu, S. Huang, Uniform Pt nanoparticles incorporated into reduced graphene oxides with $\mathrm{MoO}_{3}$ as advanced anode catalysts for methanol electro-oxidation, Electrochim. Acta 198 (2016) 127-134.

[223] G.D. Park, J.H. Kim, Y.J. Choi, Y.C. Kang, Large-scale production of $\mathrm{MoO}_{3}$-reduced graphene oxide powders with superior lithium storage properties by spray-drying process, Electrochim. Acta 173 (2015) 581-587.

[224] W. Zeng, G. Zhang, S. Hou, T. Wang, H. Duan, Facile synthesis of graphene@ $\mathrm{NiO} / \mathrm{MoO}_{3}$ composite nanosheet arrays for high-performance supercapacitors, Electrochim. Acta 151 (2015) 510-516.

[225] S. Wang, Q. Li, W. Pu, Y. Wu, M. Yang, $\mathrm{MoO}_{3}-\mathrm{MnO}_{2}$ intergrown nanoparticles composite prepared by one-step hydrothermal synthesis as anode for lithium ion batteries, J. Alloys Compd. 663 (2016) 148-155.

[226] D. Wu, R. Shen, R. Yang, W. Ji, M. Jiang, W. Ding, L. Peng, Mixed molybdenum oxides with superior performances as an advanced anode material for lithium-ion batteries, Sci. Rep. 7 (2017) 44697.

[227] X.-J. Wang, R. Nesper, C. Villevieille, P. Novák, Ammonolyzed $\mathrm{MoO}_{3}$ nanobelts as novel cathode material of rechargeable Li-ion batteries, Adv. Energy Mater. 3 (2013) 606-614.

[228] I. Shakir, M. Shahid, M. Nadeem, D.J. Kang, Tin oxide coating on molybdenum oxide nanowires for high performance supercapacitor devices, Electrochim. Acta 72 (2012) 134-137.

[229] H. Zhang, X. Liu, R. Wang, R. Mi, S. Li, Y. Cui, Y. Deng, J. Mei, H. Liu, Coating of $\alpha-$ $\mathrm{MoO}_{3}$ on nitrogen-doped carbon nanotubes by electrodeposition as a high-performance cathode material for lithium-ion batteries, J. Power Sources 274 (2015) 1063-1069. 
[230] L.C. Yang, W.L. Guo, Y. Shi, Y.P. Wu, Graphite@ $\mathrm{MoO}_{3}$ composite as anode material for lithium ion battery in propylene carbonate-based electrolyte, J. Alloys Compd. 501 (2010) 218-220.

[231] A.C. Dillon, A.H. Mahan, R. Deshpande, P.A. Parilla, K.M. Jones, S.H. Lee, Metal oxide nano-particles for improved electrochromic and lithium-ion battery technologies, Thin Solid Films. 516 (2008) 794-797.

[232] M.F. Hussan, Z.P. Guo, Z. Chen, H.K. Liu, Carbon-coated $\mathrm{MoO}_{3}$ nanobelts as anode materials for lithium-ion batteries, J. Power Sources 195 (2010) 2372-2376.

[233] S. Hariharan, K. Saravanan, P. Balaya, $\alpha-\mathrm{MoO}_{3}$ : A high performance anode material for sodium-ion batteries, Electrochem. Commun. 31 (2013) 5-9.

[234] C. Wang, L. Wu, H. Wang, W. Zuo, Y. Li, J. Liu, Fabrication and shell optimization of synergistic $\mathrm{TiO}_{2}-\mathrm{MoO}_{3}$ core-shell nanowire array anode for high energy and high power lithium-ion batteries, Adv. Funct. Mater. 25 (2015) 3524-3533.

[235] C. Yang, Q. Xiang, X. Li, Y. Xu, X. Wang, X. Xie, C. Li, H. Wang, L. Wang, $\mathrm{MoO}_{3}$ nanoplates: a high-capacity and long-life anode material for sodium-ion batteries, $\mathrm{J}$. Mater. Sci. 55 (2020) 12053-12064.

[236] Y.S. Jung, S. Lee, D. Ahn, A.C. Dillon, S.-H. Lee, Electrochemical reactivity of ballmilled $\mathrm{MoO}_{3-y}$ as anode materials for lithium-ion batteries, J. Power Sources 188 (2009) 286-291.

[237] L.A. Riley, S.-H. Lee, L. Gedvilias, A.C. Dillon, Optimization of $\mathrm{MoO}_{3}$ nanoparticles as negative-electrode material in high-energy lithium ion batteries, J. Power Sources 195 (2010) 588-592.

[238] X.-Y. Xue, Z.-H. Chen, L.-L. Xing, S. Yuan, Y.-J. Chen, $\mathrm{SnO}_{2} / \alpha-\mathrm{MoO}_{3}$ core-shell nanobelts and their extraordinarily high reversible capacity as lithium-ion battery anodes, Chem. Commun. 47 (2011) 5205-5207.

[239] A.C. Dillon, L.A. Riley, Y.S. Jung, C. Ban, D. Molina, A.H. Mahan, A.S. Cavanagh, S.M. George, S.-H. Lee, HWCVD $\mathrm{MoO}_{3}$ nanoparticles and a-Si for next generation Liion anodes, Thin Solid Films 519 (2011) 4495-4497.

[240] W. Tang, L. Liu, S. Tian, L. Li, Y. Yue, Y. Wu, K. Zhu, Aqueous supercapacitors of high energy density based on $\mathrm{MoO}_{3}$ nanoplates as anode material, Chem. Commun. 47 (36) (2011) 10058-10060.

[241] M.J. Aragon, B. Leon, C. Perez-Vicente, J.L. Tirado, On the use of transition metal oxysalts as conversion electrodes in lithium-ion batteries, J. Power Sources 189 (2009) $823-827$. 
[242] M. Sasidharan, N. Gunawardhana, H. Noma, M. Yoshio, K. Nakashima, $\alpha-\mathrm{MoO}_{3}$ hollow nanospheres as an anode material for Li-ion batteries, Bull. Chem. Soc. Jpn 85 (2011) 642-646.

[243] P.M. Ette, P. Gurunathan, K. Ramesha, Self-assembled lamellar alpha-molybdenum trioxide as high performing anode material for lithium-ion batteries, J. Power Sources 278 (2015) 630-638.

[244] L.A. Riley, A.S. Cavanagh, S.M. George, Y.-S. Jung, Y. Yan, S.-H. Lee, A.C. Dillon, Conformal surface coatings to enable high volume expansion Li-ion anode materials, ChemPhysChem 11 (2010) 2124-2130.

[245] X. Zhao, M. Cao, C. Hu, Thermal oxidation synthesis hollow $\mathrm{MoO}_{3}$ microspheres and their applications in lithium storage and gas-sensing, Mater. Res. Bull. 48 (2013) 22892295 .

[246] A.P Varghese, B. Gangaja, S. Nair, D. Santhanagopalan, New Li-ion battery full-cells: $\mathrm{MoO}_{3}$ nanobelts as high energy density electrode, Mater. Res. Express 6 (2019) 075003.

[247] T.A. Kerr, F. Leroux, L.F. Nazar, Surfactant-mediated incorporation of poly( $p$ phenylene) into $\mathrm{MoO}_{3}$, Chem. Mater. 10 (1998) 2588-2591.

[248] Y. Sun, J. Wang, B. Zhao, R. Cai, R. Ran, Z. Shao, Binder-free $\alpha-\mathrm{MoO}_{3}$ nanobelt electrode for lithium-ion batteries utilizing van der Waals forces for film formation and connection with current collector. J. Mater. Chem. A 1 (2013) 4736-4746.

[249] Y.N. Ko, S.B. Park, K.Y. Jung, Y.C. Kang, One-pot facile synthesis of ant-cavestructured metal oxide-carbon microballs by continuous process for use as anode materials in Li-ion batteries, Nano Lett. 13 (2013) 5462-5466.

[250] Q.-D. Yang, H.-T. Xue, X.-Yang, Z. Guan, Y. Cheng, S.-W. Tsang, C.-S. Lee, Low temperature sonochemical synthesis of morphology variable $\mathrm{MoO}_{3}$ nanostructures for performance enhanced lithium ion battery applications, Electrochim. Acta 185 (2015) 8389.

[251] S.-H. Lee, R. Deshpande, D. Benhammou, P.A. Parilla, A.H. Mahan, A.C. Dillon, Metal oxide nanoparticles for advanced energy applications, Thin Solid Films 517 (2009) 3591-3595.

[252] T. Tao, A.M. Glushenkov, C. Zhang, H. Zhang, D. Zhou, Z. Guo, H.K. Liu, Q. Chen, $\mathrm{H}$. $\mathrm{Hu}, \mathrm{Y}$. Chen, $\mathrm{MoO}_{3}$ nanoparticles dispersed uniformly in carbon matrix: A high capacity composite anode for Li-ion batteries, J. Mater. Chem. 21 (2011) 9350-9355. 
[253] C.-L. Liu, Y. Wang, C. Zhang, X.-S. Li, W.-S. Dong, In situ synthesis of $\alpha-$ $\mathrm{MoO}_{3} /$ graphene composites as anode materials for lithium ion batteries, Mater. Chem. Phys. 143 (2014) 1111-1118.

[254] L. Noerochim, J.Z. Wang, D. Wexler, Z. Chao, H.K. Liu, Rapid synthesis of freestanding $\mathrm{MoO}_{3}$ /graphene films by the microwave hydrothermal method as cathode for bendable lithium batteries, J. Power Sources 228 (2013) 198-205.

[255] C.L. Liu, Y. Wang, C. Zhang, X.S. Li, W.S. Dong, In situ synthesis of $\alpha-$ $\mathrm{MoO}_{3} /$ graphene composites as anode materials for lithium ion battery, Mater. Chem. Phys. 143 (2014) 1111-1118.

[256] K. Zhou, W. Zhou, X. Liu, Y. Sang, S. Ji, W. Li, J. Lu, L. Li, W. Niu, H. Liu, S. Chen, Ultrathin $\mathrm{MoO}_{3}$ nanocrystals self-assembled on graphene nanosheets via oxygen bonding as supercapacitor electrodes of high capacitance and long cycle life, Nano Energy 12 (2015) 510-520.

[257] Y. Cui, Y. Zhao, H. Chen, K. Wei, S. Ni, Y. Cui, S. Shi, First-principles study of $\mathrm{MoO}_{3}$ /graphene composite as cathode material for high-performance lithium-ion batteries, Appl. Surf. Sci. 433 (2018) 1083-1093.

[258] X. Cao, B. Zheng, W. Shi, J. Yang, Z. Fan, Z. Luo, X. Rui, B. Chen, Q. Yan, H. Zhang, Reduced graphene oxide-wrapped $\mathrm{MoO}_{3}$ composites prepared by using metal-organic frameworks as precursor for all-solid-state flexible supercapacitors, Adv. Mater. 27 (2015) 4695-4701.

[259] X. Zhang, C. Fu, J. Li, C. Yao, T. Lu, L. Pan, $\mathrm{MoO}_{3} /$ reduced graphene oxide composites as anode material for sodium ion batteries, Ceram. Int. 43 (2017) 3769-3773.

[260] G. Krishnamurthy, G. Veeresha, A facile one pot synthesis of $\mathrm{MoO}_{3}$ on reduced graphene oxide (RGO) and electrochemical studies for energy applications, Mater. Res. Express 6 (2019) 094013.

[261] D. Stamatis, E.L. Dreizin, K. Higa, Thermal initiation of $\mathrm{Al}_{-} \mathrm{MoO}_{3}$ nanocomposite materials prepared by different methods, J. Propulsion Power. 27 (2011)1079-1087.

[262] H. Sinaim, A. Phuruangrat, S. Thongtem, T. Thongtem, Synthesis and characterization of heteronanostructured $\mathrm{Ag}$ nanoparticles/ $\mathrm{MoO}_{3}$ nanobelts composites, Mater. Chem. Phys. 132 (2012) 358-363.

[263] Y. Zhang, B. Lin, J. Wang, P. Han, T. Xu, Y. Sun, X. Zhang, H. Yang, Polyoxometalates@ metal-organic frameworks derived porous $\mathrm{MoO}_{3} @ \mathrm{CuO}$ as electrodes for symmetric all-solid-state supercapacitor, Electrochim. Acta 191 (2016) 795-804. 
[264] O. Sachuk, N. Kopachevska, L. Kuznetsova, V. Zazhigalov, V. Starchevskyy. Influence of ultrasonic treatment on the properties of $\mathrm{ZnO}-\mathrm{MoO}_{3}$ oxide system, Chem. Chem. Technol. 11 (2017) 152-157.

[265] A. Martinez-Garcia, A. Kumar Thapa, R. Dharmadasa, T.Q. Nguyen, J. Jasinski, T.L. Druffel, M.K Sunkara, High rate and durable, binder free anode based on silicon loaded $\mathrm{MoO}_{3}$ nanoplatelets, Sci. Rep. 5 (2015) 10530.

[266] Z. Yuan, L. Si, D. Wei, L. Hu, Y. Zhu, X. Li, Y. Qian, Vacuum topotactic conversion route to mesoporous orthorhombic $\mathrm{MoO}_{3}$ nanowire bundles with enhanced electrochemical performance. J. Phys. Chem. C 118 (2014) 5091-5101.

[267] P.-J. Lu, M. Lei, J. Liu, Graphene nanosheets encapsulated $\alpha-\mathrm{MoO}_{3}$ nanoribbons with ultrahigh lithium ion storage properties, CrystEngComm 16 (2014) 6745-6755.

[268] J. Ni, G. Wang, J. Yang, D. Gao, J. Chen, L. Gao, Y. Li, Carbon nanotube-wired and oxygen-deficient $\mathrm{MoO}_{3}$ nanobelts with enhanced lithium-storage capability, J. Power Sources 247 (2014) 90-94.

[269] C. Yang, H. Lu, C. Li, L. Wang, H. Wang, Spatially-confined electrochemical reactions of $\mathrm{MoO}_{3}$ nanobelts for reversible high capacity: critical roles of glucose, Chem. Eng. J. 337 (2018) 1-9.

[270] D. Cao, Y. Dai, S. Xie, H. Wang, C. Niu, Pyrolytic synthesis of $\mathrm{MoO}_{3}$ nanoplates within foam-like carbon nanoflakes for enhanced lithium ion storage. J. Colloid Interface Sci. 514 (2018) 686-693.

[271] F. Ma, A. Yuan, J. Xu, P. Hu, Porous $\alpha-\mathrm{MoO}_{3} / \mathrm{MWCNT}$ nanocomposite synthesized via a surfactant-assisted solvothermal route as a lithium-ion-battery high-capacity anode material with excellent rate capability and cyclability. ACS Appl. Mater. Interfaces 7 (2015) 15531-15541.

[272] H. Sun, D. Hanlon, D.A. Dinh, J.B. Boland, A.E. Del Rio Castillo, C. Di Giovanni, A. Ansaldo, V. Pellegrini, J.N. Coleman, F. Bonaccorso, Carbon nanotubes-bridged molybdenum trioxide nanosheets as high performance anode for lithium ion batteries, 2D Mater. 5 (2018) 015024.

[273] J. Wu, Q. Lai, C. Zhong, Hydrothermal synthesis $\mathrm{MoO}_{3} @ \mathrm{CoMoO}_{4}$ hybrid as an anode material for high performance lithium rechargeable batteries, Funct. Mater. Lett. 12 (2019) 1850104.

[274] C. Yang, X. Zhong, Y. Jiang, Y. Yu, Reduced graphene oxide wrapped hollow molybdenum trioxide nanorod for high performance lithium-ion batteries, Chinese Chem. Lett. 28 (2017) 2231-2234. 
[275] S.R Sahu, V.R. Rikka, P. Haridoss, A. Chatterjee, R. Gopalan, R. Prakash, A Novel $\alpha-$ $\mathrm{MoO}_{3} /$ single-walled carbon nanohorns composite as high-performance anode material for fast-charging lithium-ion battery, Adv. Energy Mater. 10 (2020) 2001627.

[276] Y. Feng, K. Wu, J. Ke, Z. Guo, X. Deng, C. Bai, Y. Sun, Q. Wang, B. Yang, H. Dong, D. Xiong, M. He, Synthesis of ternary $\mathrm{SnO}_{2}-\mathrm{MoO}_{3}-\mathrm{C}$ composite with nanosheet structure as high-capacity, high-rate and long-lifetime anode for lithium-ion batteries, Ceram. Int. (2020) doi.org/10.1016/j.ceramint.2020.12.057.

[277] S. Zhao, Z. Zha, X. Liu, H. Tian, Z. Wu, W. Li, L.-B. Sun, B. Liu, Z. Chen, Coresheath structured $\mathrm{MoO}_{3} @ \mathrm{MoS}_{2}$ composite for high-performance lithium-ion battery anodes, Energy Fuels 34 (2020) 11498-11507.

[278] Y. Teng, H. Liu, D. Liu, Y. Chen, A hierarchically nanostructured composite of $\mathrm{MoO}_{3}-$ $\mathrm{NiO}$ /graphene for high-performance lithium-ion batteries, J. Electrochem. En. Conv. Stor. 18 (2021) 031003.

[279] S.H. Oh, S.M. Park, D.W. Kang, Y.C. Kang, J.S. Cho, Fibrous network of highly integrated carbon nanotubes/ $\mathrm{MoO}_{3}$ composite bundles anchored with $\mathrm{MoO}_{3}$ nanoplates for superior lithium ion battery, J. Ind. Eng. Chem. 83 (2020) 438-448.

[280] Z. Zhang, X. Chen, G. Zhang, C. Feng, Synthesis of $\mathrm{MoO}_{3} / \mathrm{V}_{2} \mathrm{O}_{5} / \mathrm{C}$ composite as novel anode for Li-ion battery application, J. Nanosci. Nanotechnol. 20 (2020) 2911-2916.

[281] G. Wang, J. Ni, H. Wang, L. Gao, High-performance CNT-wired $\mathrm{MoO}_{3}$ nanobelts for Listorage application. J. Mater. Chem. A 1 (2013) 4112-4118.

[282] J.S. Cho, Large scale process for low crystalline $\mathrm{MoO}_{3}$-carbon composite microspheres prepared by one-step spray pyrolysis for anodes in lithium-ion batteries, Nanomaterials 9 (2019) 539.

[283] S.H. Choi, Y.C. Kang, Crumpled graphene-molybdenum oxide composite powders: Preparation and application in lithium-ion batteries. ChemSusChem 7 (2014) 523-528.

[284] A. Kumar Mondal, S. Chen, D. Su, H. Liu, G. Wang, Fabrication and enhanced electrochemical performances of $\mathrm{MoO}_{3}$ /graphene composite as anode material for lithium-ion batteries, Int. J. Smart Grid Clean Energy 3 (2014) 142-148.

[285] A. Wold, W. Kunnmann, R.J. Arnott, A. Ferretti, Preparation and properties of sodium and potassium molybdenum bronze crystals, Inorg. Chem. 3 (1964) 545-547.

[286] W. Xia, F. Xu, C. Zhu, H.L. Xin, Q. Xu, P. Sun, L. Sun, Probing microstructure and phase evolution of $\alpha-\mathrm{MoO}_{3}$ nanobelts for sodium-ion batteries by in situ transmission electron microscopy. Nano Energy 27 (2016) 447-456. 
[287] M.B. Sreedhara, A.L. Santhosha, A.J. Bhattacharyya, C.N.R. Rao, Composite of fewlayer $\mathrm{MoO}_{3}$ nanosheets with graphene as a high performance anode for sodium-ion batteries, J. Mater. Chem. A 4 (2016) 9466-9471.

[288] Y. Jiang, M. Sun, Ni J, L. Li, Ultrastable sodium storage in $\mathrm{MoO}_{3}$ nanotube arrays enabled by surface phosphorylation. ACS Appl. Mater. Interfaces 11 (2019) 3776137767.

[289] Y. Liu, B. Zhang, S. Xiao, L. Liu, Z. Wen, Y. Wu, A nanocomposite of $\mathrm{MoO}_{3}$ coated with PPy as an anode material for aqueous sodium rechargeable batteries with excellent electrochemical performance. Electrochim Acta 116 (2014) 512-517.

[290] Y. Li, D. Wang, Q. An, B. Ren, Y. Rong, Y. Yao, Flexible electrode for long-life rechargeable sodium-ion batteries: effect of oxygen vacancy in $\mathrm{MoO}_{3-x}$. J Mater Chem $\mathrm{A}$ 4 (2016) 5402-5405.

[291] Y. Xu, M. Zhou, X. Wang, C. Wang, L. Liang, F. Grote, M. Wu, Y. Mi, Y. Lei, Enhancement of sodium ion battery performance enabled by oxygen vacancies, Angew. Chem. Int. Ed. 54 (2015) 8768-8771.

[292] S. Li, H. Hou, Z. Huang, H. Liao, X. Qiu, X. Ji, Alternating voltage introduced [001]oriented $\alpha-\mathrm{MoO}_{3}$ microrods for high-performance sodium-ion batteries. Electrochim. Acta 245 (2017) 949-956.

[293] K. Zhu, X. Wang, J. Liu,S. Li, H. Wang, L. Yang, S. Liu, T. Xie, Novel amorphous $\mathrm{MoS}_{2} / \mathrm{MoO}_{3} /$ nitrogen-doped carbon composite with excellent electrochemical performance for lithium ion batteries and sodium ion batteries, ACS Sustainable Chem. Eng. 5 (2017) 8025-8034.

[294] K. Wu, J. Zhan, G. Xu, C. Zhang, D. Pan, M. Wu, MoO 3 nanosheet arrays as superior anode materials for Li- and Na-ion batteries. Nanoscale 10 (2018) 16040-16049.

[295] V. Gangaraju, D. Bhargavi, D. Rangappa, Synthesis and characterization of $\alpha$ $\mathrm{MoO}_{3} / \mathrm{RGO}$ composite as anode material for Li-ion batteries using spray drying combustion, Mater. Today Proc. 4 (2017) 12328-12332.

[296] W. Kang, Y. Wang, D. Cao, Z. Kang, D. Sun, In-situ transformation into $\mathrm{MoSe}_{2} / \mathrm{MoO}_{3}$ heterogeneous nanostructures with enhanced electrochemical performance as anode material for sodium ion battery, J. Alloys Compd. 743 (2018) 410-418.

[297] C.J. Machiels, W.H. Cheng, U. Chowdhry, W.E. Farneth, F. Hong, E.M. McCarron, A.W. Sleight, The effect of the structure of molybdenum oxides on the selective oxidation of methanol, Appl. Catal. 25 (1986) 249-256. 
[298] T.T. Phuong Pham, P.H. Duy Nguyen, T. Tai Vo, H.H. Phuc Nguyen, C. Loc Luu Facile method for synthesis of nanosized $\beta-\mathrm{MoO}_{3}$ and their catalytic behavior for selective oxidation of methanol to formaldehyde, Adv. Nat. Sci. Nanosci. Nanotechnol. 6 (2015) 045010.

[299] D. D. Yao, J.Z. Ou, K. Latham, S. Zhuiykov, A. P. O’Mullane, K. Kalantar-zadeh, Electrodeposited $\alpha$ - and $\beta$-phase $\mathrm{MoO}_{3}$ films and investigation of their gasochromic properties, Cryst. Growth Des. 12 (2012) 1865-1870.

[300] I. Juarez-Ramirez, A. Martinez-de-la-Cruz, Electrochemical lithium insertion in $\beta-\mathrm{MoO}_{3}$ : Novel $\mathrm{Li}_{x} \mathrm{MoO}_{3}$ bronzes, J. Solid State Electrochem. 7 (2003) 259-263.

[301] T. Mizushima, K. Fukushima, H. Ohkita, N. Kakuta, Synthesis of $\beta-\mathrm{MoO}_{3}$ through evaporation of $\mathrm{HNO}_{3}$-added molybdic acid solution and its catalytic performance in partial oxidation of methanol, Appl. Catal. A. 326 (2007) 106-112.

[302] T.M. Huong, N.H.H. Phuc, H. Ohkita, T. Mizushima, N. Kakuta, Selective preparation of $\beta-\mathrm{MoO}_{3}$ and silicomolybdic acid(SMA) on MCM-41 from molybdic acid precursor and their partial oxidation performances, Stud. Surf. Sci. Catal. 175 (2010) 695-698.

[303] P.F. Carcia, E.M. McCarron III, Synthesis and properties of thin film polymorphs of molybdenum trioxide, Thin Solid Films 155 (1987) 53-63.

[304] C.N.R. Rao, J. Gopalakrishnan, K. Vidyasagar, A.K. Ganguli, A. Ramanam, L. Ganapathi, Novel metal oxides prepared by ingenious synthetic routes, J. Mater. Res. 1 (1986) 280-294.

[305] D.E. Diaz-Droguett, R. El-Far, V.M. Fuenzalida, A.L. Cabrera, In situ-Raman studies on thermally induced structural changes of porous $\mathrm{MoO}_{3}$ prepared in vapor phase under $\mathrm{He}$ and $\mathrm{H}_{2}$, Mater. Chem. Phys. 134 (2012) 631-638.

[306] N.H.H. Phuc, H. Ohkita, T. Mizushima, N. Kakuta, Simple method to prepare new structure of metastable molybdenum (VI) oxide, Mater. Lett. 76 (2012) 173-176.

[307] R. Diehl, G. Brandt, E. Salje, The crystal structure of triclinic $\mathrm{WO}_{3}$, Acta Cryst. B 34 (1978) 1105-1111.

[308] T. Mizushima, Y. Moriya, N. H. Huy Phuc, H. Ohkita, N. Kakuta, Soft chemical transformation of $\alpha-\mathrm{MoO}_{3}$ to $\beta-\mathrm{MoO}_{3}$ as a catalyst for vapor-phase oxidation of methanol. Catal. Commun. 13 (2011) 10-13.

[309] F. Hard, B. Gérand, G. Nowogrocki, M. Figlarz, Structural filiation between a new hydrate $\mathrm{MoO}_{3} \cdot 13 \mathrm{H}_{2} \mathrm{O}$ and a new monoclinic form of $\mathrm{MoO}_{3}$ obtained by dehydration, Solid State Ion. 32-33 (1989) 84-90. 
[310] I. Juárez-Ramírez, A. Martínez-de la Cruz, Synthesis of $\beta-\mathrm{MoO}_{3}$ by vacuum drying and its structural and electrochemical characterisation, Mater. Lett. 57 (2003) 1034-1039.

[311] T. Mizushima, K. Fukushima, M.H. Tran, H. Ohkita, N. Kakuta, Synthesis of $\beta-\mathrm{MoO}_{3}$ by simple evaporation of molybdic acid solution containing nitric acid, Chem. Lett. 34 (2005) 986-987.

[312] J.B. Parise, E.M. McCarron III, R. Von Dreele, J.A. Goldstone, $\beta-\mathrm{MoO}_{3}$ produced from a novel freeze drying route, J. Solid State Chem. 93 (1991) 193-201.

[313] D. Mariotti, H. Lindström, A.C. Bose, K. Ostrikov, Monoclinic $\beta-\mathrm{MoO}_{3}$ nanosheets produced by atmospheric microplasma: application to lithium-ion batteries, Nanotechnology 19 (2008) 495302.

[314] W.C. Chang, X.D. Qi, J.C. Kuo, S.C. Lee, S.K. Ng, D. Chen, Post-deposition annealing control of phase and texture for the sputtered $\mathrm{MoO}_{3}$ films, CrystEngComm 13 (2011) $5125-5132$.

[315] K. Koike, R. Wada, S. Yagi, Y. Harada, S. Sasa, M. Yano, Characteristics of $\mathrm{MoO}_{3}$ films grown by molecular beam epitaxy, Jpn. J. Appl. Phys. 53 (2014) 05FJ02.

[316] A. Kuzmin, J. Purans, Dehydration of the molybdenum trioxide hydrates $\mathrm{MoO}_{3} \cdot n \mathrm{H}_{2} \mathrm{O}$ : in situ X-ray absorption spectroscopy study at the Mo K edge, J. Phys.: Condens. Matter 12 (2000) 1959-1970.

[317] G. A. Nazri, C. Julien, Heat-treatment studies of molybdenum oxide-monohydrate, Solid State Ion. 80 (1995) 271-275.

[318] McEvoy, T. M.; Stevenson, K. J.; Hupp, J. T.; Dang, X. Electrochemical preparation of molybdenum trioxide thin films: Effect of sintering on electrochromic and electroinsertion properties, Langmuir 19 (2003) 4316-4326.

[319] B. Yebka, C. Julien, G.A. Nazri, Electrochemical features of hydrated molybdenum oxides in lithium batteries, Mater. Res. Soc. Symp. Proc. 548 (1999) 229-237.

[320] K. Yamamoto, R. Shimizu, S. Shiraki, T. Hitosugi, Transparent conducting properties of Re-doped $\beta-\mathrm{MoO}_{3}$ films, APL Mater. 4 (2016) 096104.

[321] T.M. McEvoy, K.J. Stevenson, Spatially resolved imaging of inhomogeneous charge transfer behavior in polymorphous molybdenum oxide. II. Correlation of localized coloration/insertion properties using spectroelectrochemical microscopy, Langmuir 21 (2005) 3529-3538.

[322] A. Rosenheim, Die darstellung von molybdänsäuredihydrayt, Z. Anorg. Chem. 50 (1906) 320. 
[323] H. Peters, L. Till, K.H. Radeke, Fällungsprodukte beim ansäuern von molybdatlösungen, Z. Anorg. Allg. Chem. 365 (1969) 14-21.

[324] E.M. McCarron III, D.M. Thomas, J.C. Calabrese, Hexagonal molybdates: Crystal structure of $\left(\mathrm{Na} \cdot 2 \mathrm{H}_{2} \mathrm{O}\right) \mathrm{Mo5}_{533}\left[\mathrm{H}_{4.5}\right]_{0.67} \mathrm{O}_{18}$, Inorg. Chem. 26 (1987) 370-373.

[325] N.A. Caiger, S. Crouch-Baker, P.G. Dickens, G.S. James, Preparation and structure of hexagonal molybdenum trioxide, J. Solid State Chem. 67 (1987) 369-673.

[326] V. Kumar, P.S. Lee, Redox active polyaniline-h- $\mathrm{MoO}_{3}$ hollow nanorods for Improved pseudocapacitive performance. J Phys. Chem. C 119 (2015) 9041-9049.

[327] J.V. Silveira, J.V.B. Moura, C. Luz-Lima, P.T.C. Freire, A.G. Souza Filho, Laserinduced thermal effects in hexagonal $\mathrm{MoO}_{3}$ nanorods, Vibr. Spectrosc. 98 (2018) 145151.

[328] C. Zhu, Q. Xu, W. Liu, Y. Ren, $\mathrm{CO}_{2}$-assisted fabrication of novel heterostructures of h- $\mathrm{MoO}_{3} / 1 \mathrm{~T}-\mathrm{MoS}_{2}$ for enhanced photoelectrocatalytic performance, Appl. Surf. Sci. 425 (2017) 56-62.

[329] X. Wang, W. Cui, M. Chen, Q. Xu, Supercritical $\mathrm{CO}_{2}$-assisted phase transformation from orthorhombic to hexagonal $\mathrm{MoO}_{3}$, Mater. Lett. 201 (2017) 129-132.

[330] Y. Song, Y. Zhao, Z. Huang, J. Zhao, Aqueous synthesis of molybdenum trioxide (h$\mathrm{MoO}_{3}, \alpha-\mathrm{MoO}_{3} \cdot \mathrm{H}_{2} \mathrm{O}$ and $\mathrm{h}-/ \alpha-\mathrm{MoO}_{3}$ composites) and their photochromic properties study, J. Alloys Compd. 693 (2017) 1290-1296.

[331] V. Kumar, X. Wang, P.S. Lee, Formation of hexagonal-molybdenum trioxide (h- $\mathrm{MoO}_{3}$ ) nanostructures and their pseudocapacitive behavior, Nanoscale 7 (2015) 11777-11786.

[332] L. Zheng, Y. Xu, D. Jin, Y. Xie, Novel metastable hexagonal $\mathrm{MoO}_{3}$ nanobelts: Synthesis, photochromic, and electrochromic properties. Chem. Mater. 21 (2009) 56815690.

[333] A. Chithambararaj, N.R. Yogamalar, A.C. Bose, Hydrothermally synthesized h-MoO 3 and $\alpha-\mathrm{MoO}_{3}$ nanocrystals: New findings on crystal-structure-dependent charge transport. Cryst. Growth Des. 16 (2016) 1984-1995.

[334] H.J. Lunk, H. Hartl, M.A. Hartl, M.J. Fait, I.G. Shenderovich, M. Feist, T.A. Frisk, L.L. Daemen, D. Mauder, A.A. Gurinov, Hexagonal Molybdenum Trioxide — known for 100 years and still a fount of new discoveries. Inorg. Chem. 49 (2010) 9400-9408.

[335] C. V. Ramana, V. V. Atuchin, I. B. Troitskaia, S. A. Gromilov, V. G. Kostrovsky, Lowtemperature synthesis of morphology controlled metastable hexagonal molybdenum trioxide $\left(\mathrm{MoO}_{3}\right)$. Solid State Commun. 149 (2009) 6-9. 
[336] S. Komaba, N. Kumagai, R. Kumagai, N. Kumagai, H. Yashiro, Molybdenum oxides synthesized by hydrothermal treatment of $\mathrm{A}_{2} \mathrm{MoO}_{4}(\mathrm{~A}=\mathrm{Li}, \mathrm{Na}, \mathrm{K})$ and electrochemical lithium intercalation into the oxides, Solid State Ion. 152-153 (2002) 319-326.

[337] J.D. Guo, P. Zavalij, M.S. Whittingham, Metastable hexagonal molybdates:

Hydrothermal preparation, structure and reactivity, J. Solid State Chem. 117 (1995) 323332.

[338] M.K. Patil, S.H. Gaikwad, S.P. Mukherjee Phase- and morphology-controlled synthesis of tunable plasmonic $\mathrm{MoO}_{3-\mathrm{x}}$ nanomaterials for ultrasensitive surface-enhanced Raman spectroscopy detection, J. Phys. Chem. C 124 (2020) 21082-21093.

[339] C.C. Zhang, L. Zheng, Z.M. Zhang, R.C. Dai1, Z.P. Wang, J. W. Zhang, Z.J. Ding, Raman studies of hexagonal $\mathrm{MoO}_{3}$ at high pressure, Phys. Status Solidi B 248 (2011) $1119-1122$.

[340] J. Guo, P. Zavalij, M.S. Whittingham, Metastable hexagonal molybdates: hydrothermal preparation, structure, and reactivity, J. Solid State Chem. 117 (1995) 323-332.

[341] T.P. Feist, P.K. Davies, Soft chemical synthesis of new compounds with the hexagonal molybdenum oxide structure, Chem. Mater. 3 (1991) 1011-1012.

[342] Y. Muraoka, J.C. Grenier, S. Petit, M. Pouchard, Preparation of hexagonal $\mathrm{MoO}_{3}$ by "Chimie Douce" reaction with $\mathrm{NO}_{2}$, Solid State Sci. 1 (2-3) (1999) 133-148.

[343] X. Chen, W. Lei, D. Liu, J. Hao, Q. Cui, G. Zou, Synthesis and characterization of hexagonal and truncated hexagonal shaped $\mathrm{MoO}_{3}$ nanoplates, J. Phys. Chem. C. 113 (2009) 21582-21585.

[344] R. Irmawati, M. Shafizah, The production of high purity hexagonal $\mathrm{MoO}_{3}$ through the acid washing of as-prepared solids, Int. J. Basic Appl. Sci. 9 (2009) 241-244.

[345] O. Mougin, J.-L. Dubois, F. Mathieu, A. Rousset, Metastable hexagonal vanadium molybdate study, J. Solid State Chem. 152 (2000) 353-360.

[346] P. Jittiarprn, L. Sikong, K. Kooptarnond, W. Taweepreda, Effects of precipitation temperature on the photochromic properties of h-MoO3. Ceram Int. 40 (2014) 1348713495.

[347] Y. Liu, S. Yang, Y. Lu, N.V. Podval'naya, W. Chen, G.S. Zakharova, Hydrothermal synthesis of $\mathrm{h}-\mathrm{MoO}_{3}$ microrods and their gas sensing properties to ethanol, Appl. Surf. Sc. 359 (2015) 114-119.

[348] B. Han, K.-H. Lee, Y.-W. Lee, S.-J. Kim, H.-C. Park, B.-M. Hwang, D.-H. Kwak, K.W. Park, $\mathrm{MoO}_{3}$ nanostructured electrodes prepared via hydrothermal process for lithium ion batteries, Int. J. Electrochem. Sci. 10 (2015) 4232-4240. 
[349] Z. S. Guan, Y. Zhang, Q. Zhang, D. Xu Li, Controllable size, shape and morphology of molybdic acid self-aggregated with rhodamine B to construct functional material, J.

Colloid. Interface Sci. 302 (2006) 113-122.

[350] J. Song, X. Wang, X. Ni, H. Zheng, Z. Zhang, M. Ji, T. Shen, X. Wang, Preparation of hexagonal- $\mathrm{MoO}_{3}$ and electrochemical properties of lithium intercalation into the oxide, Mater. Res. Bull. 40 (2005) 1751-1756.

[351] K. Eda, K. Chin, N. Sotani, M.S. Whittingham, $\mathrm{K}_{2} \mathrm{Mo}_{4} \mathrm{O}_{13}$ phases prepared by hydrothermal synthesis. J. Solid State Chem. 177 (2004) 916-921.

[352] Y. Xu, L. Xie, Y. Zhang, X. Cao, Hydrothermal synthesis of hexagonal $\mathrm{MoO}_{3}$ and its reversible electrochemical behavior as a cathode for Li-ion batteries, Electron. Mater. Lett. 9 (2013) 693-696.

[353] Q. Tang, L. Wang, K. Zhu, Z. Shan, X. Qin, Synthesis and electrochemical properties of h- $\mathrm{MoO}_{3} /$ graphene composite, Mater. Lett. 100 (2013) 127-129.

[354] J. Joseph, A.P. O’Mullane, K. Ostrikov, Hexagonal molybdenum trioxide (h-MoO 3$)$ as an electrode material for rechargeable aqueous aluminum-ion batteries, ChemElectroChem 6 (2019) 6002-6008.

[355] X. Xiao, H. Song, S. Lin, Y. Zhou., X. Zhan., Z. Hu, Q. Zhang, J. Sun, B. Yang, T. Li, L. Jiao, J. Zhou, J. Tang, Y. Gogotsi, Scalable salt-templated synthesis of twodimensional transition metal oxides, Nat. Commun. 7 (2016) 11296.

[356] J. Zhou, N. Lin, L. Wang, K. Zhang, Y. Zhu, Y. Qian, Synthesis of hexagonal $\mathrm{MoO}_{3}$ nanorods and a study of their electrochemical performance as anode materials for lithium-ion batteries, J. Mater. Chem. A 3 (2015) 7463-7468.

[357] E. M. McCarron and J. C. Calabrese, The growth and single crystal structure of a high pressure phase of molybdenum trioxide: $\mathrm{MoO}_{3}$-II, J. Solid State Chem. 91 (1991) 121125.

[358] S. Åsbrink, L. Kihlborg, E. M. McCarron, High pressure single-crystal X-ray diffraction studies of $\mathrm{MoO}_{3}$. I. Lattice parameters up to 7.4 GPa, J. Appl. Crystallogr. 21 (1988) 960962.

[359] A. Stavenhagen, E. Engels, Ueber Molybdänbronzen, Ber. Deut. Chem. Gesell. 28 (1895) 2280-2281.

[360] M. Greenblatt, W.H. McCarroll, R. Neifeld, M. Croft, J.V. Waszczak, Quasi twodimensional electronic properties of the lithium molybdenum bronze, $\mathrm{Li}_{0.9} \mathrm{Mo}_{6} \mathrm{O}_{17}$, Solid State Commun. 51 (1984) 671-674. 
[361] P.P. Tsai, J.A. Potenza, M. Greenblatt, H.J. Schugar, "Crystal structure of $\mathrm{Li}_{0.33} \mathrm{MoO}_{3}$, a stoichiometric, triclinic, lithium molybdenum bronze, J. Solid State Chem. 64 (1986) 4756.

[362] M. Onoda, K. Toriumi, Y. Matsuda, M. Sato, Crystal structure of lithium molybdenum purple bronze $\mathrm{Li}_{0.9} \mathrm{Mo}_{6} \mathrm{O}_{17}$, J. Solid State Chem. 66 (1987) 163-170.

[363] M. Greenblatt, Molybdenum oxide bronzes with quasi-low-dimensional properties, Chem. Rev. 88 (1988) 31-53.

[364] W.H. McCarroll, M. Greenblatt, Preparation of lithium molybdenum oxide bronzes by a temperature gradient flux growth technique, J. Solid State Chem. 54 (1984) 282-290.

[365] F.F. Leroux, LF. Nazar, Lithium ion battery containing molybdenum bronze, Canadian Patent CA02,222,494 A1. Assessed on 26 May 1997.

[366] G. Guzman, B. Yebka, J. Livage, C. Julien, Lithium intercalation studies in hydrated molybdenum oxides, Solid State Ion. 86-88 (1996) 407-413.

[367] B. Krebs, The crystal structure of $\mathrm{MoO}_{3}, 2 \mathrm{H}_{2} \mathrm{O}$ : a metal aquoxide with both co-ordinated and hydrate water, Chem. Soc. D Chem. Commun. (1970) 50-51.

[368] J.R. Günter, Topotactic dehydration of molybdenum trioxide hydrates, J. Solid State Chem. 5 (1972) 354-359.

[369] H.R. Oswald, J.R. Günter, E. Dubler, Topotactic decomposition and crystal structure of white molybdenum trioxide-monohydrate: prediction of structure by topotaxy, J. Solid State Chem. 13 (1975) 330-338.

[370] R.L. Fellows, M.H. Lloyd, J.F. Knight, H.L. Yakel, X-ray diffraction and thermal analysis of molybdenum(VI) oxide hemihydrate: monoclinic $\mathrm{MoO}_{3} \cdot 1 / 2 \mathrm{H}_{2} \mathrm{O}$, Inorg. Chem. 22 (1983) 2468-2470.

[371] H. Luo, M. Wei, K. Wei, A new metastable phase of crystallized $\mathrm{MoO}_{3} \cdot 0.3 \mathrm{H}_{2} \mathrm{O}$ nanobelts, Mater. Chem. Phys. 113 (2009) 85-90.

[372] M.A. Camacho-López, E. Haro-Poniatowski, L. Lartundo-Rojas, J. Livage, C.M. Julien, Amorphous-crystalline transition studied in hydrated $\mathrm{MoO}_{3}$, Mater. Sci. Eng. B 135 (2006) 88-94.

[373] K. Du, W. Fu, R. Wei, H. Yang, J. Xu, L. Chang, Q. Yu, G. Zou, Ultrasonic-assisted synthesis of highly dispersed $\mathrm{MoO}_{3}$ nanospheres using 3mercaptopropyltrimethoxysilane, Ultrason. Sonochem. 15 (2008) 233-238.

[374] M. Afsharpour, A. Mahjoub and M. M. Amini, Synthesis of molybdenum oxide nanohybrids as efficient catalysts in oxidation of alcohols. J. Inorg. Organomet. Polym. Mater. 19 (2009) 298-305. 
[375] M.I. Shukoor, H.A. Therese, L. Gorgishvili, G. Glasser, U. Kolb, W. Tremel, From layered molybdic acid to lower-dimensional nanostructures by intercalation of amines under ambient conditions, Chem. Mater. 18 (2006) 2144-2151.

[376] D. Chen, M. Liu, L.Yin, T. Li, Z. Yang, X. Li, B. Fan, H. Wang, R. Zhang, Z. Li, H. $\mathrm{Xu}, \mathrm{H}$. Lu, D. Yang, J. Sune, L. Gao, Single-crystalline $\mathrm{MoO}_{3}$ nanoplates: topochemical synthesis and enhanced ethanol-sensing performance, J. Mater. Chem. 21 (2011) 93329342.

[377] B. Yebka, C. Julien, G.A. Nazri, Electrochemical behavior of hydrated molybdenum oxides in lithium batteries, Ionics 5 (1999) 236-243.

[378] A. Martinez-de la Cruz, I. Juárez Ramirez, Electrochemical lithium insertion into amorphous $\mathrm{MoO}_{3} \cdot 2 \mathrm{H}_{2} \mathrm{O}$, J. Power Sources 133 (2004) 268-271.

[379] Z. Yuan, L. Si, Reversible lithium-ion insertion in triclinic hydrated molybdenum oxide nanobelts. J. Mater. Chem. A, 2013, 1, 15247-15251.

[380] N. Kumagai, N. Kumagai, K. Tanno, Electrochemical and structural characteristics of molybdenic acid as a new cathode material for nonaqueous lithium batteries. Electrochim. Acta 32 (1987) 1521-1526.

[381] N. Kumagai, S. Komaba, M. Abe, H. Yashiro, Hydrothermal synthesis of molybdenum oxide and lithium intercalation, Electrochem. Soc. Proc. 99-24 (1999) 215-229.

[382] N. Kumagai, S. Komaba, M. Abe, H. Yashiro, Hydrothermal synthesis of mobydenum oxide and lithium intercalation, In: Intercalation Compounds for Battery Materials, G.A. Nazri, M. Thackeray, T. Ohzuku (Eds.), Electrochem. Soc. Proc. 99-24 (2000) 215-229. On line at https://books.google.fr/books?hl=fr\&lr=\&id=Ju5viChENAw $\mathrm{C} \& \mathrm{oi}=\mathrm{fnd} \& \mathrm{pg}=\mathrm{PR} 6 \& \mathrm{dq}=$ intercalation + compounds+for+battery+materials.

[383] J.P. Pereira-Ramos, N. Kumagai, N. Kumagai, Low temperature molybdenum oxide as host lattice for lithium intercalation, J. Power Sources 56 (1995) 87-90.

[384] T. Sekine, C. Julien, I. Samaras, M. Jouanne, M. Balkanski, Vibrational modifications on lithium intercalation in $\mathrm{MoS}_{2}$, Mater. Sci. Eng. B 3 (1989) 153-158.

[385] E. Hatzikraniotis, I. Samaras, K.M. Paraskevopoulos, C. Julien, Lithium intercalation studies on $\mathrm{MoO}_{3}$ single crystals, Ionics 2 (1996) 24-28.

[386] M. Pasquali, G. Pistoia, F. Rodante, Non-stoichiometric molybdenum oxides as cathodes for lithium cells. part v. thermodynamic, kinetic and structural aspects of the behaviour of $\mathrm{Mo}_{8} \mathrm{O}_{23}$ and $\mathrm{Mo}_{18} \mathrm{O}_{52}$, Solid State Ion. 6 (1982) 319-325.

[387] L.A. Bursill, Crystallographic shear in molybdenum trioxide, Proc. Math. Phys. Eng. Sci. 311 (1969) 267-290. 
[388] M. Yu, H. Shao, G. Wang, F. Yang, C. Liang, P. Rozier, C.-Z. Wang, X. Lu, P. Simon, $X$. Feng, Interlayer gap widened $\alpha$-phase molybdenum trioxide as high-rate anodes for dual-ion intercalation energy storage devices, Nat. Commun. 11 (2020) 1348.

[389] T. Li, M. Beidaghi, X. Xiao, L. Huang, Z. Hu, W. Sun, X. Chen, Y. Gogotsi, J. Zhou, Ethanol reduced molybdenum trioxide for Li-ion capacitors, Nano Energy, 26 (2016) 100-107.

[390] J.-P. Jegal, H.K. Kim, J.-S. Kim, K.-B. Kim, One-pot synthesis of mixed-valence $\mathrm{MoO}_{\mathrm{x}}$ on carbon nanotube as an anode material for lithium ion batteries, J. Electroceram. 31 (2013) 218-223.

[391] B. Saravanakumar, R. Shobana, G. Ravi, V. Ganesh, R. Yuvakkumar, Preparation and electrochemical characterization of $\mathrm{Mog}_{9} \mathrm{O}_{26}$ nanopowders for supercapacitors applications, Nano-Struct. Nano-Objects 19 (2019) 100340.

[392] S.S. Sunu, E. Prabhu, V. Jayaraman, K.I. Gnanasekar, T. Gnanasekaran, Gas sensing properties of PLD made $\mathrm{MoO}_{3}$ film, Sens. Actuators B 94 (2003) 189-196.

[393] H. Simchi, B.E. McCandless, T. Meng, J.H. Boyle, W.N. Shafarman, Characterization of reactively sputtered molybdenum oxide films for solar cell application, J. Appl. Phys. 114 (2013) 13503.

[394] J. Bullock, A. Cuevas, T. Allen, C. Battaglia, Molybdenum oxide $\mathrm{MoO}_{\mathrm{x}}$ : A versatile hole contact for silicon solar cells, Appl. Phys. Lett. 105 (2014) 232109.

[395] J.J. Jacieniak, J. Seifter, J. Jo, T. Mates, A.J. Heegeer, A solution-processed $\mathrm{MoO}_{\mathrm{x}}$ anode interlayer for use within organic photovoltaic devices, Adv. Funct. Mater. 22 (2012) 2594-2605

[396] K.A. Gesheva, T.M. Ivanova, G.K. Bodurov, APCVD transition metal oxidesFunctional layers in smart windows, J. Phys. Conf. Ser. 559 (2014) 012002.

[397] M. Vasilopoulou, L.C. Palilis, D.G. Georgiadou, S. Kennou, I. Kostis, D. Davazoglou, P. Argitis, Barrierless hole injection through sub-bandgap occupied states in organic light emitting diodes using substoichiometric $\mathrm{MoO}_{\mathrm{x}}$ anode interfacial layer, Appl. Phys. Lett. 110 (2012) 013311

[398] K. Inzani, T. Grande, F. Vullum-Bruer, S.M. Selbach, A van der Waals density functional study of $\mathrm{MoO}_{3}$ and its oxygen vacancies, J. Phys. Chem. C 120 (2016) 89598968.

[399] H.A. Tahini, X. Tan, S.N. Lou, J. Scott, R. Amal, Y.H. Ng, S.C. Smith, Mobile polaronic states in $\alpha-\mathrm{MoO}_{3}$ : An ab initio investigation of the role of oxygen vacancies and alkali ions, ACS Appl. Mater. Interfaces 8 (2016) 10911-10917. 
[400] K. Inzani, M. Nematollahi, F. Vullum-Bruer, T. Grande, T.W. Reenaasb, S.M. Selbach, Electronic properties of reduced molybdenum oxides, Phys. Chem. Chem. Phys. 19 (2017) 9232-9245.

[401] X.K. Hu, Y.T. Qian, Z.T. Song, J.R. Huang, R. Cao, J.Q. Xiao, Comparative study on $\mathrm{MoO}_{3}$ and $\mathrm{H}_{x} \mathrm{MoO}_{3}$ nanobelts: structure and electric transport, Chem. Mater. 20 (2008) $1527-1733$

[402] M. Mattinen, P.J. King, L. Khriachtchev, M.J. Heikkilä, B. Fleming, S. Rushworth, K. Mizohata, K. Meinander, J. Räisänen, M. Ritala, M. Leskelä, Atomic layer deposition of crystalline molybdenum oxide thin films and phase control by post-deposition annealing, Mater. Today Chem. 9 (2018) 17-27.

[403] D.O. Scanlon, G.W. Watson, D.J. Payne, G.R. Atkinson, R.G. Egdell, D.S.L. Law, Theoretical and experimental study of the electronic structures of $\mathrm{MoO}_{3}$ and $\mathrm{MoO}_{2}, \mathrm{~J}$. Phys. Chem. C 114 (2010) 4636-4645.

[404] T. Zhang, C.-Y. Lee, B. Gong, B. Hoex, Thermal stability analysis of $\mathrm{WO}_{\mathrm{x}}$ and $\mathrm{MoO}_{\mathrm{x}}$ as hole selective contacts for Si solar cells using in situ XPS, AIP Conf. Proc. 1999 (2018) 040027.

[405] C.D. Wagner, W.M. Riggs. L.E. Davis, J.F. Moulder, G.E. Muilenberg, Handbook of X-ray Photoelectron Spectroscopy, Physical Electronics Division, Perkin-Elmer, Eden Prairie, Minnesota, 1979.

[406] Z. Li, Ch. Wang, X. Chen, X. Wang, X. Li, Y. Yamauchi, X. Xu, J. Wang, C. Lin, D. Luo, X. Wang, X.S. Zhao, $\mathrm{MoO}_{\mathrm{x}}$ nanoparticles anchored on $\mathrm{N}$-doped porous carbon as Li-ion battery electrode, Chem. Eng. J. 381 (2020) 122588.

[407] R. Zeng, H. Liu, W. Shen, A facile and controllable electrochemically fabricated nonstoichiometric $\mathrm{MoO}_{\mathrm{x}}$ film for novel opto-electronic devices, J. Micromech. Microeng. 29 (2019) 065012.

[408] J. Yang, X. Xiao, P.Chen, Kai Zhua, Kui Chenga, K. Ye, G. Wang, D. Cao, J. Yan, Creating oxygen-vacancies in $\mathrm{MoO}_{3-\mathrm{x}}$ nanobelts toward high volumetric energy-density asymmetric supercapacitors with long lifespan, Nano Energy 58 (2019) 455-465.

[409] T. Ressler, O. Timpe, T. Neisius, J. Find, G. Mestl, M. Dieterle, R. Schlögl, Timeresolved XAS investigation of the reduction/oxidation of $\mathrm{MoO}_{3-\mathrm{x}}$, J. Catal. 191 (2000) $75-85$. 
[410] Y. Hou, J. Wang, C. Hou, Y. Fan, Y. Zhai, H. Li, F. Dang, S. Chou, Oxygen vacancies promoting the electrocatalytic performance of $\mathrm{CeO}_{2}$ nanorods as cathode materials for Li- $\mathrm{O}_{2}$ batteries, J. Mater. Chem. A 7 (2019) 6552-6561.

[411] S. Sun, Q. Xia, J. Liu, J. Xu, F. Zan, J. Yue, S. V. Savilov, V.V. Lunin, H. Xia, Selfstanding oxygen-deficient $\alpha-\mathrm{MoO}_{3-\mathrm{x}}$ nanoflake arrays as 3D cathode for advanced allsolid-state thin film lithium batteries, J. Materiomics 5 (2019) 229-236.

[412] Z.Z. Sun, C.H. Yang, G.Y. Liu, H.B. Lu, R. Zhang, L.J. Wang, H. Wang, Largely enhanced electrochemical performance in $\mathrm{MoO}_{3-\mathrm{x}}$ nanobelts formed by a "sauna reaction": importance of oxygen vacancies, Electrochim. Acta 239 (2017) 16-24.

[413] G. Zhang, T. Xiong, M. Yan, L. He, X. Liao, C. He, C. Yin, H. Zhang, L. Mai, $\alpha-$ $\mathrm{MoO}_{3-\mathrm{x}}$ by plasma etching with improved capacity and stabilized structure for lithium storage. Nano Energy 49 (2018) 555-563.

[414] Y. Yi, H. An, P. Zhang, X. Tian, P. Yang, P. Liu, T. Wang, L. Qu, M. Li, G. Yang, B. Yang, Oxygen deficiency driven conversion of polysulfide by electrocatalysis: $\mathrm{MoO}_{3-\mathrm{x}}$ nanobelts for an improved lithium-sulfur battery cathode, ChemNanoMat 5 (2019) 926 931.

[415] Q.-L. Wu, S.-X. Zhao, L. Yu, L.-Q. Yu, X.-X. Zheng, G. Wei, In situ synthesis and electrochemical performance of $\mathrm{MoO}_{3-\mathrm{x}}$ nanobelts as anode materials for lithium-ion batteries, Dalton Trans. 48 (2019) 12832-12838.

[416] U. Akin, H. Safal, Thickness dependence of dispersion parameters of the $\mathrm{MoO}_{\mathrm{x}}$ thin films prepared using the vacuum evaporation technique, J. Alloys Compd. 647 (2015) 146-151.

[417] L. Meng, A. Yamada, Low-resistance orthorhombic $\mathrm{MoO}_{3-\mathrm{x}}$ thin film derived by twostep annealing, Thin solid Films 665 (2018) 179-183.

[418] P.K. Parashar, V.K. Komarala, Sputter deposited sub-stochiometric $\mathrm{MoO}_{\mathrm{x}}$ thin film as hole-selective contact layer for silicon based heterojunction devices, Thin Solid Films 682 (2019) 76-81.

[419] F. He, X. Yin, J. Li, S. Lin, L. Wu, X. Hao, J. Zhang, L. Feng, Characterization of sputtered $\mathrm{MoO}_{\mathrm{x}}$ thin films with different oxygen content and their application as back contact in CdTe solar cells, Vacuum 176 (2020) 109337.

[420] M.A. Camacho-Lopez, L. Escobar-Alarcon, E. Haro-Poniatowski, Structural transformations in $\mathrm{MoO}_{\mathrm{x}}$ thin films grown by pulsed laser deposition, Appl. Phys. A 78 (2004) 59-65. 
[421] V. Bhosle, A. Tiwari, J. Narayan, Epitaxial growth and properties of $\mathrm{MoO}_{\mathrm{x}}(2<x<2.75)$ films, J. Appl. Phys. 97 (2005) 083539.

[422] X. Zhang, F. You, Q. Zheng, Z. Zhang, P. Cai, X. Xue, J. Xiong, J. Zhang, Solutionprocessed $\mathrm{MoO}_{\mathrm{x}}$ hole injection layer towards efficient organic light-emitting diode, Org. Electron. 39 (2016) 43-49.

[423] M. Kröger, S. Hamwi, J. Meyer, T. Riedl, W. Kowalsky, A. Kahn, Role of the deeplying electronic states of $\mathrm{MoO}_{3}$ in the enhancement of hole injection in organic thin films, Appl. Phys. Lett. 95 (2009) 95, 123301.

[424] W. Chen, H. Zhang, Y. Wang, Z. Ma, Z. Li, In-situ microstructural investigations by electron-beam irradiation induced crystallization of amorphous $\mathrm{MoO}_{\mathrm{x}}$ thin films with high performance for Li-ion storage, Electrochim. Acta 144 (2014) 369-375.

[425] H. Guyot, C. Schlenker, J.P. Pougetf, R. Ayroles, C. Roucau, Evidence for an incommensurate charge density wave instability in h- $\mathrm{Mo}_{4} \mathrm{O}_{11}$, J. Phys. C Solid State Phys. 18 (1985) 4427-4434.

[426] J.Z. Ke, M. Yang, H.K. Zuo, H.P. Zhu, C.B. Liu, R. Chen, C. Dong, W.X. Liu, M.Y. Shi, J.F. Wang, Single crystal growth and electrical transport properties of $\eta-\mathrm{Mo}_{4} \mathrm{O}_{11}, \mathrm{~J}$. Alloys Compd. 835 (2020) 155417.

[427] S. Barber, J. Booth, D.R. Pyke, R. Reid, R.J.D. Tilley, The influence of crystallographic shear planes on the behavior of molybdenum-tungsten oxide catalysts for the selective oxidation of propene, J. Catal. 77 (1982) 180-191.

[428] L. Kihlborg, Least squares refinement of the structure of $\mathrm{Mo}_{8} \mathrm{O}_{23}$, Ark. Kemi 21 (1963) 461-469.

[429] R. Knorr, U. Müller, $\eta-\mathrm{Mo}_{4} \mathrm{O}_{11}$ und $\mathrm{Mg}_{2} \mathrm{Mo}_{3} \mathrm{O}_{8}$ : eine neue synthese und verfeinerung ihrer kristallstrukturen, Z. Anorg. Allg. Chem. 621 (1995) 541-545.

[430] L. Kihlborg, Crystal structure studies on monoclinic and orthorhombic $\mathrm{Mo}_{4} \mathrm{O}_{11}$, Arkiv Kemi 21 (1963) 365-377.

[431] L. Kihlborg, Stabilization of the tunnel structure of $\mathrm{Mo}_{5} \mathrm{O}_{14}$ by partial atom substitution, Acta Chem. Scand. 23 (1969) 1834-1835.

[432] R. L. Smith and G. S. Rohrer, Scanning probe microscopy of cleaved molybdates: $\alpha$ $\mathrm{MoO}_{3}(010), \mathrm{Mo}_{18} \mathrm{O}_{52}(100), \mathrm{Mo}_{8} \mathrm{O}_{23}(010)$, and $\eta-\mathrm{Mo}_{4} \mathrm{O}_{11}(100)$, J. Solid State Chem. 124 (1996) 104-115.

[433] M. Dieterle, G. Mestl, Raman spectroscopy of molybdenum oxides. Part II. Resonance Raman spectroscopic characterization of the molybdenum oxides $\mathrm{Mo}_{4} \mathrm{O}_{11}$ and $\mathrm{MoO}_{2}$, Phys. Chem. Chem. Phys. 4 (2002) 822-826. 
[434] A. Magnéli, The crystal structure of $\mathrm{Mo}_{4} \mathrm{O}_{11}$ ( $\gamma$-molybdenum oxide), Acta Chem. Scand. 2 (1948) 861-871.

[435] L.A. Bursill, Electron microscope study of a homologous series of shear structures based on molybdenum trioxide, Acta Crystallogr. A 28 (1972) 187-191.

[436] P. Cignini, M. Icovi, S. Panero, G. Pistoia, C. Temperoni, Non-stoichiometric molybdenum oxides as cathodes for lithium cells. Part. I. Primary batteries, J. Electroanal. Chem. 102 (1979) 333-341.

[437] M. Icovi, S. Panero, A. D’Agate, G. Pistoia, C. Temperoni, Non-stoichiometric molybdenum oxides as cathodes for lithium cells. Part. II. Secondary batteries, J. Electroanal. Chem. 102 (1979) 343-349.

[438] G. Pistoia, C. Temperoni, P. Cignini, M. Icovi, S. Panero, Non-stoichiometric molybdenum oxides as cathodes for lithium cells. Part. III. Cells based on $\mathrm{Mo}_{18} \mathrm{O}_{52}, \mathrm{~J}$. Electroanal. Chem. 108 (1980) 169-180.

[439] P. Fiordiponti, G. Pistoia, C. Temperoni, M. Icovi, S. Panero, Non-stoichiometric molybdenum oxides as cathodes for lithium cells. Part. IV. Factors influencing the performance of $\mathrm{Li} / \mathrm{Mo}_{8} \mathrm{O}_{23}$ batteries, J. Electroanal. Chem. 108 (1980) 181-190.

[440] P.A. Christian, J.N. Carides, F.J. DiSalvo, J. V. Waszczak, Molybdenum oxide cathodes in secondary lithium cells, J. Electrochem. Soc. 127 (1980) 2315-2319.

[441] M. Ghedira, H. Vincent, M. Marezio, J. Marcus, G. Furcaudot, Structure crystalline du conducteur metallique bidimensionnel $\mathrm{Mo}_{4} \mathrm{O}_{11-\gamma}$, , J. Solid State Chem. 56 (1985) 66-73.

[442] H. Gruber, H. Haselmair, H.P. Fritzer, On magnetic properties of some molybdenum oxides, J. Solid State Chem. 47 (1983) 84-91.

[443] H.-K. Fun, P. Yang, M. Sasaki, M. Inoue, H. Kadomatsu, Rietveld refinement of the crystal structure of $\gamma-\mathrm{Mo}_{4} \mathrm{O}_{11}$, Powder Diffraction 14 (1999) 284-288.

[444] C. Julien, B. Yebka, Electrochemical features of lithium batteries based on molybdenum-oxide compounds, in: Materials for Lithium Batteries; C. Julien, Z. Stoynov (Eds.), Kluwer Acad. Publ., Dordecht, The Netherlands (2000) pp. 263-277.

[445] E. Shembel, R. Apostolova, V. Nagirny, I. Kirsanova, Ph. Grebenkin, P. Lytvyn, Electrolytic molybdenum oxides in lithium batteries, J. Solid State Electrochem. 9 (2005) 96-105.

[446] A.M. Hashem, S.M. Abbas, A.E. Abdel-Ghany, A.E. Eid, A.A. Abdel-Khalek, S. Indris, H. Ehrenberg, A. Mauger, C.M. Julien, Blend formed by oxygen deficient $\mathrm{MoO}_{3-\delta}$ oxides as lithium-insertion compounds, J. Alloys Compd. 686 (2016) 744-752. 
[447] L. Zhou, N. Ding, J. Yang, L. Yang, Y. Zong, Z. Liu, A. Yu, Sulfur encapsulated in $\mathrm{Mo}_{4} \mathrm{O}_{11}$-anchored ultralight graphene for high-energy lithium sulfur batteries, ACS Sustainable Chem. Eng. 4 (2016) 3679-3687.

[448] V.P. Tysyachny, E.M. Shembel, R.D. Apostolova, V.M. Nagirny, K.E. Kylyvnyk, N.I. Eskova, Studies of the lithium ion transport properties in electrolytic molybdenum oxides, Solid state Ion. 169 (2004) 125-137.

[449] T. Ressler, J. Wienold, R. E. Jentoft, T. Neisius, Bulk structural investigation of the reduction of $\mathrm{MoO}_{3}$ with propene and the oxidation of $\mathrm{MoO}_{2}$ with oxygen, J. Catal. 210 (2002) 67-83.

[450] F. Kaiser, M. Schmidt, Y. Grin, I. Veremchuk, Molybdenum oxides MoO $_{\mathrm{x}}$ : sparkplasma synthesis and thermoelectric properties at elevated temperature, Chem. Mater. 32 (2020) 2025-2035.

[451] M. Hugues, N.A. Hampson, S.A.G.R. Karunathilaka, A review of cells based on lithium negative electrodes (anodes), J. Power sources 12 (1984) 83-144.

[452] B.G. Brandt, A.C. Skapski, A refinement of the crystal structure of molybdedum dioxide, Acta Chem. Scand. 21 (1967) 661-672.

[453] D.B. Rogers, R.D. Shannon, A.W. Sleight, J.L. Gillson, Crystal chemistry of metal dioxides with rutile-related structures, Inorg. Chem. 8 (1969) 841-849.

[454] E.Y. Ahn, Y.-S. Seo, J.H. Cho, I. Lee, J. Hwang, H. Jeen, Epitaxial growth and metallicity of rutile $\mathrm{MoO}_{2}$ thin film, RSC Adv. 6 (2016) 60704-60708.

[455] Y. Shi, B. Guo, S.A. Corr, Q. Shi, Y.-S. Hu, K.R. Heier, L. Chen, R. Seshadri, G.D. Stucky, Ordered mesoporous metallic $\mathrm{MoO}_{2}$ materials with highly reversible lithium storage capacity, Nano Lett. 9 (2009) 4215-4220.

[456] U.K. Sen, A. Shaligram, S. Mitra, Intercalation anode material for lithium ion battery based on molybdenum dioxide, ACS Appl. Mater. Interfaces 6 (2014) 14311-14319.

[457] J.R. Dahn, W. McKinnon, Structure and electrochemistry of $\mathrm{Li}_{\mathrm{x}} \mathrm{MoO}_{2}$, Solid State Ion. 23 (1987) 1-7.

[458] D. Murphy, F. DiSalvo, J. Carides, J. Waszczak, Topochemical reactions of rutile related structures with lithium, Mater. Res. Bull. 13 (1978) 1395-1402.

[459] J.J. Auborn, Y.L. Barberio, Lithium intercalation cells without metallic lithium: $\mathrm{MoO}_{2} / \mathrm{LiCoO}_{2}$ and $\mathrm{WO}_{2} / \mathrm{LiCoO}_{2}$. J. Electrochem. Soc. 134 (1987) 638-640.

[460] H.-J. Zhang, T.-H. Wu, K.-X. Wang, X.Y. Wu, X.-T. Chen, Y.-M. Jiang, X. Wei, J.S. Chen, Uniform hierarchical $\mathrm{MoO}_{2} /$ carbon spheres with high cycling performance for lithium ion batteries, J. Mater. Chem. A 1 (2013) 12038-12043. 
[461] H.J. Zhang, K.X. Wang, X.Y. Wu, Y.M. Jiang, Y.B. Zhai, C. Wang, X. Wei, J.S. Chen, $\mathrm{MoO}_{2} / \mathrm{Mo}_{2} \mathrm{C}$ heteronanotubes function as high-performance Li-ion battery electrode, Adv. Funct. Mater. 24 (2014) 3399-3404.

[462] L. Zhou, H.B. Wu, Z. Wang, X.W. Lou, Interconnected $\mathrm{MoO}_{2}$ nanocrystals with carbon nanocoating as high-capacity anode materials for lithium-ion batteries, ACS Appl. Mater. Interfaces 3 (2011) 4853-4857.

[463] A. Kim, E. Park, H. Lee, H. Kim, Highly reversible insertion of lithium into $\mathrm{MoO}_{2}$ as an anode material for lithium ion battery, J. Alloys Compd. 681 (2016) 301-306.

[464] A. Manthiram, C. Tsang, Synthesis of amorphous $\mathrm{MoO}_{2+\delta}$ and is electrode performance in lithium batteries, J. Electrochem. Soc. 143 (1996) L143-L144.

[465] Y. Sun, X. Lu, W. Luo, Y. Huang, Self-assembled hierarchical $\mathrm{MoO}_{2} /$ graphene nanoarchitectures and their application as a high-performance anode material for lithiumion batteries, ACS Nano 5 (2011) 7100-7107.

[466] J.H. Ku, J.H. Ryu, S.H. Kim, O.H. Han, S.M. Oh, Reversible lithium storage with high mobility at structural defects in amorphous molybdenum dioxide electrode, Adv. Funct. Mater. 22 (2012) 3658-3664.

[467] L. C. Yang, Q. S. Gao, Y. Tang, Y.P. Wu, R. Holze, $\mathrm{MoO}_{2}$ Synthesized by reduction of $\mathrm{MoO}_{3}$ with ethanol vapor as an anode material with good rate capability for the lithium ion battery, J. Power Sources 179 (2008) 357-360.

[468] S. Petnikota, K.W. Teo, L. Chen, A. Sim, S.K. Marka, M.V. Reddy, V.V.S.S. Srikanth, S. Adam, B.V.R. Chowdari, Exfoliated graphene oxide/ $\mathrm{MoO}_{2}$ composites as anode materials in lithium-ion batteries: an insight into intercalation of $\mathrm{Li}$ and conversion mechanism of $\mathrm{MoO}_{2}$, ACS Appl. Mater. Interfaces 8 (2016) 10884-10896.

[469] C.A. Ellefson, O. Marin-Flores, S. Ha, M.G. Norton, Synthesis and applications of molybdenum (IV) oxide, L. Mater. Sci. 47 (2012) 2057-2071.

[470] A. Chen, C. Li, R. Tang, Y. Qi, $\mathrm{MoO}_{2}-$ ordered mesoporous carbon hybrids as anode materials with highly improved rate capability and reversible capacity for lithium-ion battery, Phys. Chem. Chem. Phys. 15 (2013) 13601-13610.

[471] L. Zeng, C. Zheng, C. Deng, X. Ding, M. Wei, $\mathrm{MoO}_{2}$-ordered mesoporous carbon nanocomposite as an anode material for lithium-ion batteries, ACS Appl. Mater. Interfaces 5 (2013) 2182-2187.

[472] H.-J. Zhang, J. Shu, K.-X. Wang, X.-T. Chen, Y.-M. Jiang, X. Wei, J.S. Chen, Lithiation mechanism of hierarchical porous $\mathrm{MoO}_{2}$ nanotubes fabricated through one-step carbothermal reduction, J. Mater. Chem. A 2 (2014) 80-86. 
[473] Y.G. Liang, S.J. Yang, Z.H. Yi, J.T. Sun, Y.H. Zhou, Preparation, characterization and lithium-intercalation performance of different morphological molybdenum dioxide, Mater Chem. Phys. 93 (2005) 395-398.

[474] X. Zhang, X. Zeng, M. Yang, Y. Qi, Lithiated $\mathrm{MoO}_{2}$ nanorods with greatly improved electrochemical performance for lithium ion batteries, Eur. J. Inorg. Chem. 2014 (2014) 352-356.

[475] B. Liu, X. Zhao, Y. Tian, D. Zhao, C. Hu, M. Cao, A simple reduction process to synthesize $\mathrm{MoO}_{2} / \mathrm{C}$ composites with cage-like structure for high-performance lithium-ion batteries, Phys. Chem. Chem. Phys. 15 (2013) 8831-8837.

[476] Y. Liu, H. Zhang, P. Ouyang, Z. Li, One-pot hydrothermal synthesized $\mathrm{MoO}_{2}$ with high reversible capacity for anode application in lithium ion battery, Electrochim. Acta 102 (2013) 429-435.

[477] Y.G. Liang, Z.H. Yi, S. Yang, L.Q. Zhou, J.T. Sun, Y.H. Zhou, Hydrothermal synthesis and lithium-intercalation properties of $\mathrm{MoO}_{2}$ nano-particles with different morphologies, Solid State Ion. 177 (2006) 501-505.

[478] S. Hu, F. Yin, E. Uchaker, W. Chen, M. Zhang, J. Zhou, Y. Qi, G. Cao, Facile and green preparation for the formation of $\mathrm{MoO}_{2}-\mathrm{GO}$ composites as anode material for lithium-ion batteries, J. Phys. Chem. C 118 (2014) 24890-24897.

[479] A. Andersson, S. Hansen, Ammoxidation of toluene over molybdenum oxides, Catal. Lett. 1 (1988) 377-383.

[480] J. Sloczynski, Kinetics and mechanism of molybdenum(VI) oxide reduction, J. Solid State Chem. 118 (1995) 84-92.

[481] Y. Chen, X. Di, C. Ma, C. Zhu, P. Gao, J. Li, C. Sun, Q. Ouyang, Graphene--MoO hierarchical nanoarchitectures: in situ reduction synthesis and high rate cycling performance as lithium-ion battery anodes, RSC Adv. 3 (2013) 17659-17663.

[482] Q. Gao, L. Yang, X. Lu, J. Mao, Y. Zhang, Y. Wu, Y. Tang, Synthesis, characterization and lithium-storage performance of $\mathrm{MoO}_{2} /$ carbon hybrid nanowires, J. Mater. Chem. 20 (2010) 2807-2812.

[483] W. Cho, J.H. Song, J.H. Kim, Y.J. Kim, Electrochemical characteristics of nano-sized $\mathrm{MoO}_{2} / \mathrm{C}$ composite anode materials for lithium-ion batteries, J. Appl. Electrochem. 42 (2012) 909-915.

[484] J.H. Song, H.J. Kang, K.J. Kim, Y.N. Jo, Y.J. Kim, Electrochemical characteristics of $\mathrm{MoO}_{2}$ anode materials with various morphologies for LIB applications, ECS Meeting Abstr. MA2009-02 (2009) 479. 
[485] H. Choi, S.P. Yoon, J.-J. Han, J. Kim, M.R. Othman, Continuous synthesis of molybdenum oxide microspheres by ultrasonic spray pyrolysis, J. Ind. Eng. Chem. 47 (2016) 254-259.

[486] D.-Y. Park, Y.-K. Sun, S.-T. Myung, Carbothermal synthesis of molybdenum(IV) oxide as a high rate anode for rechargeable lithium batteries, J. Power Sources 280 (2015) 1-4.

[487] Y. Zhu, S. Wang, Y. Zhong, R. Cai, L. Li, Z. Shao, Facile synthesis of a $\mathrm{MoO}_{2}-\mathrm{Mo}_{2} \mathrm{C}-$ $\mathrm{C}$ composite and its application as favorable anode material for lithium-ion batteries, $\mathrm{J}$. Power Sources 307 (2016) 552-560.

[488] A. Manthiram, A. Dananjay, Y.T. Zhu, New route to reduced transition-metal, Chem. Mater. 6 (1994) 1601-1602.

[489] Y. Liu, Y. Qian, M. Zhang, Z. Chen, C. Wang, Preparation of nano-sized amorphous molybdenum dioxide by use of $\gamma$-ray radiation method, Mater. Res. Bull. 31 (1996) 10291033.

[490] L. Yang, L. Liu, Y. Zhu, X. Wang, Y. Wu, Preparation of carbon coated $\mathrm{MoO}_{2}$ nanobelts and their high performance as anode materials for lithium ion batteries, $\mathrm{J}$. Mater. Chem. 22 (2012) 13148-13152.

[491] B.K. Guo, X.P. Fang, B. Li, Y.F. Shi, C.Y. Ouyang, Y.S. Hu, Z.X. Wang, G.D. Stucky, L.Q. Chen, Synthesis and lithium storage mechanism of ultrafine $\mathrm{MoO}_{2}$ nanorods, Chem. Mater. 24 (2012) 457-463.

[492] X.P. Fang, B.L. Guo, Y.F. Shi, B. Li, C.X. Hua, C.H. Yao, Y.C. Chang, Y.S. Hu, Z.X. Wang, G.D. Stucky, L.Q. Chen, Enhanced Li storage performance of ordered mesoporous $\mathrm{MoO}_{2}$ via tungsten doping, Nanoscale 4 (2012) 1541-1544.

[493] L.C. Yang, Q.S. Gao, Y.H. Zhang, Y. Tang, Y.P. Wu, Tremella-like molybdenum dioxide consisting of nanosheets as an anode material for lithium ion battery, Electrochem. Commun. 10 (2008) 118-122.

[494] H. Zhang, L. Zeng, X. Wu, L. Lian, M. Wei, Synthesis of $\mathrm{MoO}_{2}$ nanosheets by an ionic liquid route and its electrochemical properties, J. Alloys Compd. 580 (2013) 358-362.

[495] X. Zhao, H.-E. Wang, X. Chen, J. Cao, Y.Zhao, Z.G. Neale, W. Cai, J. Sui, G. Cao, Tubular $\mathrm{MoO}_{2}$ organized by $2 \mathrm{D}$ assemblies for fast and durable alkali-ion storage, Energy Stor. Mater. 11 (2018) 161-169.

[496] Q. Hao, G. Cui, Y. Zhao, Z. Bakenov, Flower-like $\mathrm{MoSe}_{2} / \mathrm{MoO}_{2}$ composite with high capacity and long-term stability for lithium-ion battery, Nanomaterials (Basel) 9 (2019) 1256. 
[497] X.L. Ji, S. Herle, Y.H. Rho, L.F. Nazar, Carbon/ $\mathrm{MoO}_{2}$ composite based on porous semi-graphitized nanorod assemblies from in situ reaction of tri-block polymer, Chem. Mater. 19 (2007) 374-383.

[498] Y. Sun, X. Hu, J.C. Yu, Q. Li, W. Luo, L. Yuan, W. Zhang, Y. Huang, Morphosynthesis of a hierarchical $\mathrm{MoO}_{2}$ nanoarchitecture as a binder-free anode for lithium-ion batteries, Energy Environ. Sci. 4 (2011) 2870-2877.

[499] J.H. Ku, Y.S. Jung, K.T. Lee, C.H. Kim, S.M. Oh, Thermoelectrochemically activated $\mathrm{MoO}_{2}$ powder electrode for lithium secondary batteries, J. Electrochem. Soc. 156 (2009) A688-A693.

[500] X. Zhang, X. Song, S. Gao, Y. Xu, X. Cheng, H. Zhao, L. Huo, Facile synthesis of yolkshell $\mathrm{MoO}_{2}$ microspheres with excellent electrochemical performance as a $\mathrm{Li}$-ion battery anode, J. Mater. Chem. A 1 (2013) 6858-6864.

[501] Y. Sun, X. Hu, W. Luo, Y. Huang, Ultrafine $\mathrm{MoO}_{2}$ nanoparticles embedded in a carbon matrix as a high-capacity and long-life anode for lithium-ion batteries, J. Mater. Chem. 22 (2012) 425-431.

[502] Z. Wang, J.S. Chen, T. Zhu, S. Madhavi, X.W. Lou, One-pot synthesis of uniform carbon-coated $\mathrm{MoO}_{2}$ nanospheres for high-rate reversible lithium storage, Chem. Commun. 46 (2010) 6906-6908.

[503] W. Luo, X. Hu, Y. Sun, Y. Huang, Electrospinning of carbon-coated $\mathrm{MoO}_{2}$ nanofibers with enhanced lithium-storage properties, Phys. Chem. Chem. Phys. 13 (2011) 16735-16740.

[504] L. Yang, L. Liu, Y. Zhu, X. Wang, Y. Wu, Preparation of carbon coated $\mathrm{MoO}_{2}$ nanobelts and their high performance as anode materials for lithium ion batteries, $\mathrm{J}$. Mater.

[505] Y. Zhou, I. Lee, C.W. Lee, H.S. Park, H. Son, S. Yoon, Ordered mesoporous carbon$\mathrm{MoO}_{2}$ nanocomposite as high performance anode material in lithium ion batteries, Bull. Korean Chem. Soc. 35 (2014) 257-260.

[506] S. Yoon, K.-N. Jung, C. S. Jin, K.-H. Shin, Synthesis of nitrided $\mathrm{MoO}_{2}$ and its application as anode materials for lithium-ion batteries, J. Alloys Compd. 536 (2012) $179-183$

[507] J. Liu, S. Tang, Y. Lu, G. Cai, S. Liang, W. Wang, X. Chen, Synthesis of $\mathrm{Mo}_{2} \mathrm{~N}$ nanolayer coated $\mathrm{MoO}_{2}$ hollow nanostructures as high-performance anode materials for lithium-ion batteries, Energy Environ. Sci. 6 (2013) 2691-2697. 
[508] X. Liu, H. Xu, Y. Huang, X. Hu, Direct planting of ultrafine $\mathrm{MoO}_{2+\delta}$ nanoparticles in carbon nanofibers by electrospinning: self-supported mats as binder-free and long-life anodes for lithium-ion batteries, Phys. Chem. Chem. Phys. 18 (2016) 19832-19837.

[509] M. Qing, Y. Meng, Y. Wang, X. Li, C. Zhou, Y. Liang, Z. Zhang, Q. Liu, Y. Guo, D. Xiao, Building nanoparticle-stacking $\mathrm{MoO}_{2}-\mathrm{CDs}$ via in-situ carbon dots reduction as high-performance anode material for lithium ion and sodium ion batteries, Electrochim. Acta 319 (2019) 740-752.

[510] M. Ihsan, H. Wang, S.R. Majid, J. Yang, S.J. Kennedy, Z. Guo, H.K. Liu, $\mathrm{MoO}_{2} / \mathrm{Mo}_{2} \mathrm{C} / \mathrm{C}$ spheres as anode materials for lithium ion batteries, Carbon 96 (2016) 1200-1207.

[511] H. Gao, C.-L. Liu, Y. Liu, Z.-H. Liu, W.-S. Dong, $\mathrm{MoO}_{2}$-loaded porous carbon hollow spheres as anode materials for lithium-ion batteries, Mater. Chem. Phys. 147 (2014) 218224.

[512] L.C. Yang, W. Sun, Z.W. Zhong, J.W. Liu, Q.S. Gao, R.Z. Hu, M. Zhu, Hierarchical $\mathrm{MoO}_{2} / \mathrm{N}$-doped carbon heteronanowires with high rate and improved long-term performance for lithium-ion batteries, J. Power Sources 306 (2016) 78-84.

[513] Z. Xu, H. Wang, Z. Li, A. Kohandehghan, J. Ding, J. Chen, K. Cui, D. Mitlin, Sulfur refines $\mathrm{MoO}_{2}$ distribution enabling improved lithium ion battery performance, J. Phys. Chem. C 118 (2014) 18387-18396.

[514] Y. Wang, Z. Huang, Y. Wang, A new approach to synthesize $\mathrm{MoO}_{2} @ \mathrm{C}$ for lithium ion batteries, J. Mater. Chem. A 3 (2015) 21314-21320.

[515] X. Zhang, M. Gao, W. Wang, B. Liu, X. Li, Encapsulating $\mathrm{MoO}_{2}$ nanocrystals into flexible carbon nanofibers via electrospinning for high-performance lithium storage, Polymers (Basel) 13 (2021) 22.

[516] Y. Liang, S. Yang, Z. Yi, X. Lei, J. Sun, Y. Zhou, Low temperature synthesis of a stable $\mathrm{MoO}_{2}$ as suitable anode materials for lithium batteries, Mater. Sci. Eng. B 121 (2005) 152-155.

[517] J. Liu, S. Tang, Y. Lu, G. Cai, S. Liang, W. Wang, X. Chen, Synthesis of $\mathrm{Mo}_{2} \mathrm{~N}$ nanolayer coated $\mathrm{MoO}_{2}$ hollow nanostructures as high-performance anode materials for lithium-ion batteries, Energy Environ. Sci. 6 (2013) 2691-2697.

[518] Z.X. Huang, Y. Wang, Y.G. Zhu, Y. Shi, J.I. Wong, H.Y. Yang, 3D graphene supported $\mathrm{MoO}_{2}$ for high performance binder-free lithium ion battery, Nanoscale 6 (2014) 98399845 . 
[519] Y. Che, X.Y. Zhu, J.J. Li, J. Sun, Y.Y. Liu, C. Jin, C.H. Dong, Simple synthesis of $\mathrm{MoO}_{2} /$ carbon aerogel anodes for high performance lithium ion batteries from seaweed biomass, RSC Adv. 6 (2016) 106230-106236.

[520] Y.W. Wang, L. Yu, X.W. Lou, Formation of triple-shelled molybdenum-polydopamine hollow spheres and their conversion into $\mathrm{MoO}_{2} /$ carbon composite hollow spheres for lithium-ion batteries, Angew. Chem. Int. Ed. 55 (2016) 14668-14672.

[521] J.H. Ku, Y.S. Jung, K.T. Lee, C.H. Kim, S.M. Oh, Thermoelectrochemically activated $\mathrm{MoO}_{2}$ powder electrode for lithium secondary batteries, J. Electrochem. Soc. 156 (2009) A688-A693.

[522] Y.Z. Lei, J.C. Hu, H.W. Liu, J.L. Li, Template-free synthesis of hollow core-shell $\mathrm{MoO}_{2}$ microspheres with high lithium-Ion storage capacity, Mater. Lett. 68 (2012) $82-85$.

[523] S. Yoon, A. Manthiram, Microwave-hydrothermal synthesis of $\mathrm{W}_{0.4} \mathrm{Mo}_{0.6} \mathrm{O}_{3}$ and carbon-decorated $\mathrm{WO}_{\mathrm{x}}-\mathrm{MoO}_{2}$ nanorod anodes for lithium ion batteries, J. Mater. Chem. 21 (2011) 4082-4085.

[524] Y. Xu, R. Yi, B. Yuan, X. Wu, M. Dunwell, Q. Lin, L.Fei, S. Deng, P. Andersen, D. Wang, H. Luo, High capacity $\mathrm{MoO}_{2} /$ graphite oxide composite anode for lithium-ion batteries, J. Phys. Chem. Lett. 3 (2012) 309-314.

[525] A. Bhaskar, M. Deepa, T.N. Rao, U.V. Varadaraju, Enhanced nanoscale conduction capability of a $\mathrm{MoO}_{2} /$ graphene composite for high performance anodes in lithium ion batteries, J. Power Sources 216 (2012) 169-178.

[526] K.H. Seng, G.D. Du, L. Li, Z.X. Chen, H.K. Liu, Z.P. Guo, Facile synthesis of graphene-molybdenum dioxide and its lithium storage properties, J. Mater. Chem. 22 (2012) 16072-16077.

[527] M. Faraji, A. Abedini, Fabrication of electrochemically interconnected $\mathrm{MoO}_{3} / \mathrm{GO} / \mathrm{MWCNTs} /$ graphite sheets for high performance all-solid-state symmetric supercapacitor, Int. J. Hydrogen Energy 44 (2019) 2741-2751.

[528] Q. Tang, Z. Shan, L. Wang, X. Qin, $\mathrm{MoO}_{2}$-graphene nanocomposite as anode material for lithium-ion batteries, Electrochim. Acta 79 (2012) 148-153.

[529] R. Giardi, S. Porro, T. Topuria, L. Thompson, C.F. Pirri, H.-C. Kim, One-pot synthesis of graphene-molybdenum oxide hybrids and their application to supercapacitor electrodes, Appl. Mater. Today 1 (2015) 27-32. 
[530] Y. Cui, Y. Pu, Y. Hao, W. Bao, Q. Zhuang, Synthesis and electronic/ionic transport properties of $\mathrm{MoO}_{2} / \mathrm{rGO}$ anode for lithium ion batteries, J. Chin. Chem. Soc. 61 (2014) 1089-1092.

[531] J. Hwang, D. Yoon, B. Kweon, W. Chang, J. Kim, A simple, one-pot synthesis of molybdenum oxide-reduced graphene oxide composites in supercritical methanol and their electrochemical performance, RSC Adv. 6 (2016) 108298-108309.

[532] C. Liu, S. Luo, H. Huang, Y. Zhai, Z. Wang, Direct growth of $\mathrm{MoO}_{2} /$ reduced graphene oxide hollow sphere composites as advanced anode materials for potassium-ion batteries, ChemSusChem 12 (2019) 873-880.

[533] P. Lu, D. Xue, $\mathrm{MoO}_{2} /$ reduced graphene oxide composite electrode with improved cycling performance and high capacitance for supercapacitors, J. Nanoeng. Nanomanuf. 3 (2013) 73-78.

[534] M. Serrapede, M. Fontana, A. Gigot, M. Armandi, G. Biasotto, E. Tresso, P. Rivolo, A Facile and green synthesis of a $\mathrm{MoO}_{2}$-reduced graphene oxide aerogel for energy storage devices, Materials (Basel) 13 (2020) 594.

[535] K. Palanisamy, Y. Kim, H. Kim, J.M. Kim, W.-S. Yoon, Self-assembled porous $\mathrm{MoO}_{2} /$ graphene microspheres towards high performance anodes for lithium ion batteries, J. Power Sources 275 (2015) 351-361.

[536] J. Huang, Z. Xu, L. Cao, Q. Zhang, H. Ouyang, J. Li, Tailoring $\mathrm{MoO}_{2}$ /graphene oxide nanostructures for stable, high-density sodium-ion battery anodes, Energy Technol. 3 (2015) 1108-1114.

[537] W. Tang, C.X. Peng, C.T. Nai, J. Su, Y.P. Liu, M.V. Reddy, M. Lin, K.P. Loh, Ultrahigh capacity due to multi-electron conversion reaction in reduced graphene oxidewrapped $\mathrm{MoO}_{2}$ porous nanobelts, Small 11 (2015) 2446-2453.

[538] P. Ju, Z. Zhu, X. Shao, S. Wang, C. Zhao, X. Qian, C. Zhao, 3D walnut-shaped $\mathrm{TiO}_{2} / \mathrm{RGO} / \mathrm{MoO}_{2} @ \mathrm{Mo}$ electrode exhibiting extraordinary supercapacitor performance, $\mathrm{J}$. Mater. Chem. A 5 (2017) 18777-18785.

[539] Z. Xu, K. Yao, H. Fu, X. Shen, X. Duan, L. Cao, J. Huang, H. Wang, Constructing $\mathrm{MoO}_{2}$ porous architectures using graphene oxide flexible supports for lithium io battery anodes, Global Challenges (2017) 1700050.

[540] S. Wang, B. Liu, G. Zhi, G. Xu, Q. Wang, J. Zhang, 2D layered mesoporous $\mathrm{MoO}_{2} / \mathrm{rGO}$ composites for high performance anode materials in lithium-ion batteries, Micropor. Mesopor. Mater. 246 (2017) 14-23. 
[541] X. Chen, R. Liu, L Zeng, X. Huang, Y. Fang, J. Liu, Y. Xu, Q. Chen, M. Wei, Q. Qian, Preparation of hierarchical $\mathrm{MoO}_{2} @ \mathrm{RGO}$ composite and its application for high rate performance lithium-ion batteries, Mater. Lett. 212 (2018) 198-201.

[542] F. Li, L. Li, W. Wang, J. Gao, A new facile approach to prepare reduced graphene oxide and $\mathrm{MoO}_{2} /$ reduced graphene oxide as electrode materials for oxygen reduction reactions, J. Colloid Interface Sci. 519 (2018) 194-202.

[543] M. Li, Y. Zhu, X. Ji, S. Cheng, Facile synthesis of $\mathrm{MoO}_{2} / \mathrm{Mo}-\mathrm{GO}$ with high initial columbic efficiency and enhanced lithiation ability, Mater. Lett. 254 (2019) 332-335.

[544] W. Devina, J. Hwang, J. Kim, Synthesis of $\mathrm{MoO}_{2} / \mathrm{Mo}_{2} \mathrm{C} / \mathrm{rGO}$ composite in supercritical fluid and its enhanced cycling stability in Li-ion batteries, Chem. Eng. J. 345 (2018) 1-12.

[545] R. Zheng, Z. Tang, H. Wang, D. Sun, Y. Tang, Z. Xie, The fabrication of hierarchical $\mathrm{MoO}_{2} @ \mathrm{MoS}_{2} / \mathrm{rGO}$ composite as high reversible anode material for lithium ion batteries, Electrochim. Acta 364 (2020) 136996.

[546] F. Xia, X. Hu, Y. Sun, W. Luo, Y. Huang, Layer-by-layer assembled $\mathrm{MoO}_{2}$-graphene thin film as a high-capacity and binder-free anode for lithium-ion batteries, Nanoscale 4 (2012) 47074711.

[547] L. Guo, Y. Wang, Standing carbon-coated molybdenum dioxide nanosheets on graphene: morphology evolution and lithium ion storage properties, J. Mater. Chem. A 3 (2015) 4706-4715.

[548] X. Wang, Y. Xiao, J. Wang, L. Sun, M. Cao, Facile fabrication of molybdenum dioxide/nitrogen-doped graphene hybrid as high performance anode material for lithiumion batteries, J. Power Sources 274 (2015) 142-148.

[549] Y. Feng, H. Liu, One-dimensional architecture with reduced graphene oxide supporting ultrathin $\mathrm{MoO}_{2}$ nanosheets as high performance anodes for lithium-ion batteries, Nanotechnology 30 (2019) 315602.

[550] Q. Yang, Q. Liang, J. Liu, S. Liang, S. Tang, P. Lu, Y. Lu, Ultrafine $\mathrm{MoO}_{2}$ nanoparticles grown on graphene sheets as anode materials for lithium-ion batteries, Mater. Lett. 127 (2014) 32-35.

[551] L.E. Aleandri, R.E. McCarley, Hexagonal lithium molybdate, $\mathrm{LiMoO}_{2}$ : a close-packed layered structure with infinite molybdenum-molybdenum-bonded sheets, Inorg. Chem. 27 (1988) 1041-1044.

[552] J. Gopalakrishnan, V. Bhat, Oxidative extraction and ion-exchange of lithium in $\mathrm{Li}_{2} \mathrm{MoO}_{3}$ : synthesis of $\mathrm{Li}_{2-\mathrm{x}} \mathrm{MoO}_{3}(0<\mathrm{x} \leq 2.0)$ and $\mathrm{H}_{2} \mathrm{MoO}_{3}$, Mater. Res. Bull. 22 (1987) 769-774. 
[553] S.J. Hibble, I.D. Fawcett, A.C. Hannon, Structure of two disordered molybdates $\mathrm{Li}_{2} \mathrm{Mo}^{\mathrm{IV}} \mathrm{O}_{3}$ and $\mathrm{Li}_{4} \mathrm{Mo}_{3}{ }^{\mathrm{IV}} \mathrm{O}_{8}$, from total neutron scattering, Acta Cryst. B 53(1997) 604612.

[554] J. Barker, M.Y. Saidi, J.L. Swoyer, Lithium insertion properties of the layered $\mathrm{LiMoO}_{2}$ $(\mathrm{R} \overline{3} \mathrm{~m})$ made by a novel carbothermal reduction method, Solid State Ion. 158 (2003) 261267.

[555] K. Ben-Kamel, N. Amdouni, H. Groult, A. Mauger, K. Zaghib, C.M. Julien, Structural and electrochemical properties of $\mathrm{LiMoO}_{2}$, J. Power Sources 202 (2012) 314-321.

[556] J. Barker, M.Y. Saidi, J.L. Swoyer, Synthesis and electrochemical insertion properties of the layered $\mathrm{Li}_{x} \mathrm{MoO}_{2}$ phases $(x=0.74,0.85$, and 1.00), Electrochem. Solid State Lett. 6 (2003) A252-A256.

[557] R.E. McCarley, K.H. Lii, P.A. Edwards, L.F. Brough, New extended clusters in ternary molybdenum oxides, J. Solid State Chem. 57 (1985) 17-24.

[558] S.J. Hibble, I.D. Fawcett, A.C. Hannon, The true structure and metal-metal-bonded framework of $\mathrm{LiMo}^{\mathrm{III}} \mathrm{O}_{2}$ determined from total neutron scattering, Inorg. Chem. 36 (1997) 1749-1753.

[559] H.Y. He, D. Li, M.Q. Li, Electrochemical performance and reaction mechanism of the $\mathrm{Li}_{2} \mathrm{MoO}_{3}$ anode synthesized by ball milling and thermal reduction for lithium-ion batteries, Electrochim. Acta 224 (2017) 1-8.

[560] J. Ma, Y.N. Zhou, Y.R. Gao, X.Q. Yu, Q.Y. Kong, L. Gu, Z.X. Wang, X.Q. Yang, L.Q. Chen, Feasibility of using $\mathrm{Li}_{2} \mathrm{MoO}_{3}$ in constructing Li-rich high energy density cathode materials, Chem. Mater. 26 (2014) 3256-3262.

[561] E.C. Self, L.F. Zou, M.J. Zhang, R. Opfer, R.E. Ruther, G.M. Veith, B.H. Song, C.M. Wang, F. Wang, A. Huq, J. Nanda, Synthesis and electrochemical and structural investigations of oxidatively stable $\mathrm{Li}_{2} \mathrm{MoO}_{3}$ and $x \mathrm{xi}_{2} \mathrm{MoO}_{3}(1-\mathrm{x}) \mathrm{LiMO}_{2}$ composite cathodes, Chem. Mater. 30 (2018) 5061-5068.

[562] J. Ma, R.Y. Gao, Z.X. Wang, L. Chen, Structural and electrochemical stability of Lirich layer structured $\mathrm{Li}_{2} \mathrm{MoO}_{3}$ in air, J. Power Sources 258 (2014) 314-320.

[563] S. Kumakura, Y. Shirao, K. Kubota, S. Komaba Preparation and electrochemical properties of $\mathrm{Li}_{2} \mathrm{MoO}_{3} / \mathrm{C}$ composites for rechargeable Li-ion batteries, Phys. Chem. Chem. Phys. 18 (2016) 28556-28563.

[564] D. Li, H.Y. He, X.M. Wu, M.Q. Li, Electrochemical behavior of submicron $\mathrm{Li}_{2} \mathrm{MoO}_{3}$ as anodes in lithium-ion batteries, J Alloys Compd. 682 (2016) 759-765. 
[565] G.-C. Mao, H.-T. Yu, C.-F. Guo, Y. Xie, T.-F. Yi, $\mathrm{Li}_{2} \mathrm{MoO}_{3}$ microspheres with excellent electrochemical performances as cathode material for lithium-ion battery, Ionics 26 (2020) 4401-4411.

[566] Z.Y. Yu, J.H. Hao, W.J. Li, H.X. Liu, Enhanced electrochemical performances of cobalt-doped $\mathrm{Li}_{2} \mathrm{MoO}_{3}$ cathode materials, Materials (Basel) 12 (2019) 843.

[567] Z.Y. Yu, T.L. Yu, W.J. Li, J.S. Hao, H.X. Liu, N. Sun, M.Y. Lu, J. Ma, Improved electrochemical performances of carbon-coated $\mathrm{Li}_{2} \mathrm{MoO}_{3}$ cathode materials for $\mathrm{Li}$-ion batteries, Int. J. Electrochem. Sci. 13 (2018) 4504-4511.

[568] J.M. Tarascon, $\mathrm{Li}_{x} \mathrm{Mo}_{2} \mathrm{O}_{4}$ : a new promising cathode material for secondary lithium cells, J. Electrochem. Soc. 134 (1987) 1345-1351.

[569] X. Liu, Y. Zhao, Nanotube $\mathrm{Li}_{2} \mathrm{MoO}_{4}$ : a novel and high-capacity material as a lithiumion battery anode, Nanoscale 6 (2014) 13660-13667.

[570] X. Liu, Y. Zhao, Y. Dong, Q. Fan, Q. Kuang, Z. Liang, X. Lin, W. Han, Q. Li, M. Wen, Synthesis of one-dimensional $\mathrm{Li}_{2} \mathrm{MoO}_{4}$ nanostructures and their electrochemical performance as anode materials for lithium-ion batteries, Electrochim. Acta 174 (2015) 315-326.

[571] S.W. Kim, D.H. Seo, X. Ma, G. Ceder, K. Kang, Electrode materials for rechargeable sodium-ion batteries: potential alternatives to current lithium ion batteries, Adv. Energy Mater. 2 (2012) 710-721.

[572] C. Delmas, Sodium and sodium-ion batteries: 50 Years of research, Adv. Energy Mater. 8 (2018) 1703137.

[573] Y.L. Bai, X.Y. Wu, Y.S. Liu, C. Ma, X. Wei, K.X. Wang, J.S. Chen, Dandelionclockinspired preparation of core-shell $\mathrm{TiO}_{2} @ \mathrm{MoS}_{2}$ composites for high performance sodium ion storage, J. Alloys Compd. 815 (2019) 152386.

[574] Z. Chen, T. Yang, H. Shi, T. Wang, M. Zhang, G. Cao, Single nozzle electrospinning synthesized $\mathrm{MoO}_{2} @ \mathrm{C}$ core shell nanofibers with high capacity and long-term stability for lithium-ion storage, Adv. Mater. Interfaces 4 (2017) 1600816.

[575] X. Xia, S. Deng, D. Xie, Y. Wang, S. Feng, J. Wu, J. Tu, Boosting sodium ion storage by anchoring $\mathrm{MoO}_{2}$ on vertical graphene arrays, J. Mater. Chem. A 6 (2018) 1554615552.

[576] S. Bao, S. Luo, S. Yan, Z. Wang, Q. Wang, J. Feng, Y. Wang, T. Yi, Nanosized $\mathrm{MoO}_{2}$ spheres interspersed three-dimensional porous carbon composite as advanced anode for reversible sodium/potassium ion storage, Electrochim. Acta 307 (2019) 293-301. 
[577] J. Jiang, W. Yang, H. Wang, Y. Zhao, J. Guo, J. Zhao, M. Beidaghi, L. Gao, Electrochemical performances of $\mathrm{MoO}_{2} / \mathrm{C}$ nanocomposite for sodium ion storage: an insight into rate dependent charge/discharge mechanism, Electrochim. Acta 240 (2017) 379-387.

[578] L. Li, Z. Chen, H. Zhang, Z. Zhu, M. Zhang, The double effects of sulfur-doping on $\mathrm{MoO}_{2} / \mathrm{C}$ nanofibers with high properties for Na-ion batteries, Appl. Surf. Sci. 455 (2018) 343-348.

[579] C. Cui, Q. Wei, L. Zhou, L. Mai, J. Ma, Facile synthesis of $\mathrm{MoO}_{2} @ \mathrm{C}$ nanoflowers as anode materials for sodium-ion batteries, Mater. Res. Bull. 94 (2017) 122-126.

[580] H. He, Y. Man, J. Yang, J. Xie, M. Xu, $\mathrm{MoO}_{2}$ nanosheets embedded in amorphous carbon matrix for sodium-ion batteries, Roy. Soc. Open. Sci. 4 (2017) 170892-170898.

[581] C. Zhao, C. Yu, M. Zhang, H. Huang, S. Li, X. Han, X. Sun, Ultrafine $\mathrm{MoO}_{2}$-carbon microstructures enable ultralong-life power-type sodium ion storage by enhanced pseudocapacitance, Adv. Energy Mater. 7 (2017) 1602880-1602887.

[582] A. Valdez, J. Villarreal, L. Zuniga, M. Alcoutlabi, $\mathrm{MoS}_{2}$ and $\mathrm{MoO}_{2}$ loaded carbon microfibers as anode materials for lithium-ion and sodium-ion batteries, ECS Trans. 85 (2018) 357-368.

[583] W. Zhang, L. Xing, J. Chen, H. Zhou, S. Liang, W. Huang, W. Li, Improving the cyclic stability of $\mathrm{MoO}_{2}$ anode for sodium ion batteries via film-forming electrolyte additive, $\mathrm{J}$. Alloys Compd. 822 (2020) 153530. 